\title{
Diabetes, a way of life : lifestyle changes, glucose tolerance and fatty acid metabolism
}

\author{
Citation for published version (APA):
}

Mensink, M. R. (2003). Diabetes, a way of life : lifestyle changes, glucose tolerance and fatty acid metabolism. [Doctoral Thesis, Maastricht University]. Universitaire Pers Maastricht. https://doi.org/10.26481/dis.20030926mm

Document status and date:

Published: 01/01/2003

DOI:

10.26481/dis.20030926mm

Document Version:

Publisher's PDF, also known as Version of record

\section{Please check the document version of this publication:}

- A submitted manuscript is the version of the article upon submission and before peer-review. There can be important differences between the submitted version and the official published version of record.

People interested in the research are advised to contact the author for the final version of the publication, or visit the DOI to the publisher's website.

- The final author version and the galley proof are versions of the publication after peer review.

- The final published version features the final layout of the paper including the volume, issue and page numbers.

Link to publication

\footnotetext{
General rights rights.

- You may freely distribute the URL identifying the publication in the public portal. please follow below link for the End User Agreement:

www.umlib.nl/taverne-license

Take down policy

If you believe that this document breaches copyright please contact us at:

repository@maastrichtuniversity.nl

providing details and we will investigate your claim.
}

Copyright and moral rights for the publications made accessible in the public portal are retained by the authors and/or other copyright owners and it is a condition of accessing publications that users recognise and abide by the legal requirements associated with these

- Users may download and print one copy of any publication from the public portal for the purpose of private study or research.

- You may not further distribute the material or use it for any profit-making activity or commercial gain

If the publication is distributed under the terms of Article $25 \mathrm{fa}$ of the Dutch Copyright Act, indicated by the "Taverne" license above, 


\section{Diabetes: A Way of Life}

Lifestyle-Changes, Glucose Tolerance

and

Fatty Acid Metabolism 

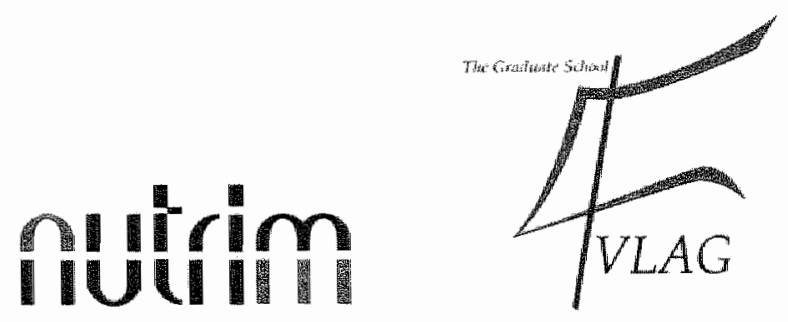

The study presented in this thesis was performed at the Nutrition and Toxicology Research Institute Mastricht (NUTRIM) which participates in the Graduate School VLAG (Food Technology, Agrobiotechnology, Nutrition and Health Sciences), accredited by the Royal Netherlands Academy of Arts and Sciences

Printed by: Datawyse, Universitaire Pers Maastricht

(C) Marco Mensink, 2003

ISBN $90-5278-389-6$ 


\section{Diabetes: A Way of Life}

Lifestyle-Changes, Glucose Tolerance

and

Fatty Acid Metabolism

\section{PROEFSCHIRIFT}

ter verkrijging van de graad van doctor aan de Universiteit Maastricht:

op gezag van de Rector Magnificus,

Prof. Dr. AC Nieuwenhuijzen Kruseman,

volgens het besluit van het College van Decanen,

in het openbaar te verdedigen.

op vrijdag 26 september 2003 om 14.00 uur

door

Marco Mensink

geboren te Zwolle op 28-09-1971

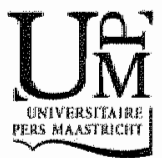




\section{Promotores:}

Prof. Dr. ir. WHM Saris

Prof. Dr. TWA de Bruin

\section{Co-promotores:}

Dr, ir. EE Blaak

Dr. ir. EJM Feskens (RIVM, Bilthoven)

\section{Beoordelingscommissie:}

Prof. Dr. H Kuipers (voorzitter)

Prof. Dr. R Heine (Vrije Universiteit, Amsterdam)

Dr. HA Keizer

Prof. Dr. PW de Leeuw

Prof. Dr. I Tuomilehto (National Public Health Institute, Helsinki, Finland)

The research described in this thesis was supported by grants of the Netherlands Organization for Scientific Research (ZonMW 940-35-034) and the Dutch Diabetes Research Foundation (DFN 98.901)

Financial support by the Netherlands Heart Foundation, the Dutch Diabetes Research Foundation and the Netherlands Association for the Study of Obesitas (NASO) for the publication of this thesis is gratefully acknowledged 


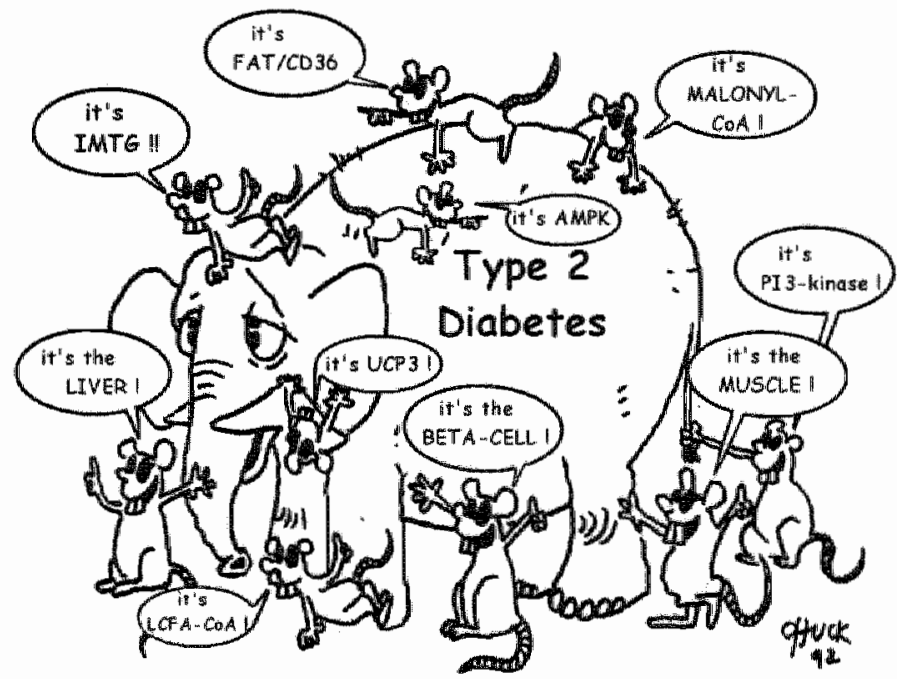

"Our search for the cause of type 2 diabetes is like blind men trying to describe an elephant:

...each of us has our own perspective of what might be the most important lesion..."

(adapted, without permission, from C Ronold Kahn, Banting Lecture 1994) 



\section{Contents}

\section{Chapter 1}

Introduction

\section{Chapter 2}

Study on Lifestyle-intervention and Impaired Glucose Tolerance

Maastricht (SLIM): Study Design and Screening Results

Chapter 3

Subscapular Skinfold Thickness Distinguishes between Transient and Persistent Impaired Glucose Tolerance

\section{Chapter 4}

Study on Lifestyle-Intervention and Impaired Glucose Tolerance Maastricht (SLIM): Preliminary Results after One Year

\section{Chapter 5}

Dietary Intervention and Physical Activity Improve Glucose Tolerance in Subjects at Increased Risk for Developing Type 2 Diabetes Mellitus

\section{Chapter 6}

Plasma Free Fatty Acid uptake and Oxidation are Already Diminished in Subjects at High Risk for Developing Type 2 Diabetes

\section{Chapter 7}

Lifestyle-Intervention and Fatty Acid Oxidation in Glucose Intolerant Subjects

\section{Chapter 8}

Lifestyle Changes and Lipid Metabolism Gene Expression and Protein

Content in Skeletal Muscle of Subjects with Impaired Glucose Tolerance

\section{Chapter 9}

Increased IMCL Content in the $m$. vast is lateralis is Associated with

Glucose Intolerance in Subjects with 1 GT and Diabetes: a 'H-MRS-study

Chapter 10

General Discussion

Summary - Samenvatting

Abbreviations

Nawoord

Curriculum vitae

List of publications 



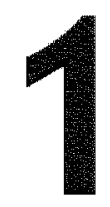

Introduction 


\section{Contents}

\section{DIABETES MELLITIUS}

Type 2 Diabetes Mellitus

Diagnosis

Pathogenesis

Lifestyle factors

Impaired Glucose Tolerance

Prevalence and progression

Risk factors for progression

Prevention of type 2 Diabetes Mellitus

Drug intervention studies

Dietary intervention studies

Lifestyle-intervention studies

Conclusion

\section{FAT METABOLISM}

Fatty Acid Metabolism

Mobilization and transport of fatty acids

Uptake and oxidation of fatty acids

Muscle Triglycerides

Fatty Acid Metabolism and Type 2 Diabetes Mellitus

Free fatty acids

Muscle triglycerides

Fatty acid uptake and oxidation

Cancluding Remarks 


\section{DIABETES MELLITUS}

Diabetes mellitus is rapidly becoming one of the main health issues in the 21 st century. The prevalence has explosively increased the last two decades. Global estimates indicate a further rise from a current 150 million people with diabetes, to 220 million in 2010, and 300 million in 2025 [1,2]. Major contributors to the diabetes epidemic are changes in nutritional and physical activity patterns, i.e. increased dietary fat intake and decreased physical activity, accompanying ongoing globalization [2].

Diabetes mellitus represents a metabolic disorder of multiple etiology characterized by chronic hyperglycemia, with disturbances of carbohydrate, fat and protein metabolism resulting from defects in insulin secretion, insulin action, or both [3]. The long-term effects of diabetes mellitus include progressive development of the specific complications of retinopathy, nephropathy and/or neuropathy. A two- to three-fold incidence of cardiovascular diseases occurs in type 2 diabetic individuals over that in age- and gender-matched non-diabetic persons.

\section{Type 2 Diabetes Mellitus}

Of all forms of diabetes mellitus, type 2 diabetes mellitus (previously also known as non-insulin-dependent diabetes mellitus or adult-onset diabetes) is the most common form, roughly accounting for $90 \%$ of the cases. Type 2 diabetes almost solely accounts for the dramatic increase in the incidence of diabetes worldwide. It is characterized by disorders of insulin action and insulin secretion, either of which may predominate. Insulin may be required for metabolic control. Type 1 diabetes, formerly called insulin-dependent diabetes mellitus or juvenile-onset diabetes, is the second most abundant form. Type 1 diabetes results from pancreatic beta-cell destruction, usually leading to absolute insulin deficiency, requiring exogenous insulin for survival. Other specific types of diabetes are less common, but are those in which the underlying defect or disease can be identified in a relatively specific manner.

\section{Diagnosis}

The diagnosis of diabetes is in most cases made upon the clinical picture of (severe) symptoms and gross hyperglycemia. However, in asymptomatic subjects and for (epidemiological) studies the oral glucose tolerance test (OGTT) is at this time the only recommended diagnostic test [3]. The OCTT should be performed in the morning after an overnight fast of $8-14$ hours. After a fasting blood sample has been collected, the subject has to drink $75 \mathrm{~g}$ glucose dissolved in 250-300 $\mathrm{ml}$ of water. A second blood sample is collected 2 hours after ingestion of the glucose. For the interpretation of the results diagnostic criteria have been made by the WHO [3]. The first widely accepted classification was 


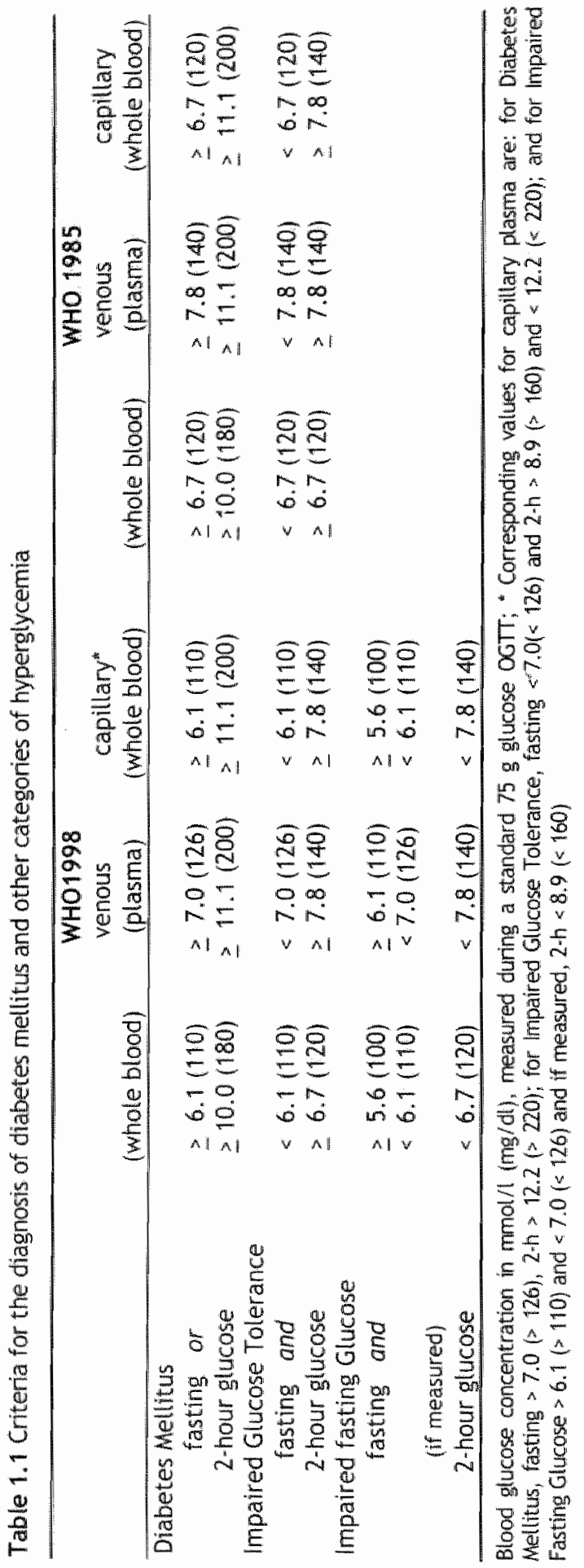


published in 1980 and, in modified form, in 1985. Recently, in 1999, a new classification has been published with as major change a lowering of the fasting plasma glucose concentration to $7.0 \mathrm{mmol} / 1$ for the diagnosis of diabetes (see Table 1.1). Beside criteria for the diagnosis of diabetes the WHO classification also includes criteria for the diagnosis of other forms of hyperglycemia as impaired glucose tolerance (IGT) and impaired fasting glucose (IFG)[3] (see Table 1.1).

\section{Pathogenesis}

Two key features in the pathogenesis of type 2 diabetes mellitus are a decreased ability of insulin to stimulate glucose uptake in peripheral tissues, insulin resistance [4], and the inability of the pancreatic $\beta$-cell to adequately secrete insulin, $\beta$-cell failure [5]. The initial event is believed to be a gradual increasing insulin resistance, although $\beta$-cell failure also plays it part, leading to the development of postprandial hyperglycemia or impaired glucose tolerance (IGT). A subsequent failure of the $\beta$-cell to compensate for the insulin resistance results in both fasting and postprandial hyperglycemia, the state of overt diabetes (see Figure 1.1) [6,7]. The development from nomoglycemia to clinical diabetes takes several decades. Both defects, insulin resistance and $\beta$-cell failure, are caused by a combination of genetic and environmental factors [8]. Environmental factors, such as lifestyle habits (i.e. obesity, physical inactivity and dietary intake), intrauterine malnutrition and toxins may act as initiating factors or progression factors for type 2 diabetes [8].

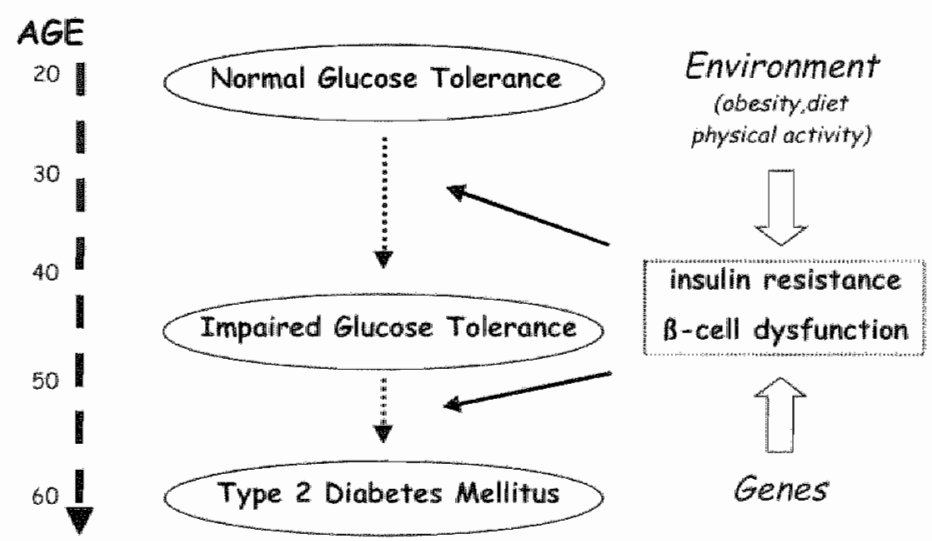

Figure 1.1 Model for progression from normal glucose tolerance to type 2 diabetes mellitus

\section{Lifestyle factors}

Several lifestyle and lifestylemassociated factors are related to the incidence of type 2 diabetes mellitus. Obesity is the single most important risk factor for the development of type 2 diabetes [9]. Beside over-all obesity, body fat distribution, especially increased (intra)abdominal fat, and weight gain throughout adulthood are good predictors of diabetes $[9,10]$. Dietary intake 
patterns also play an important role in the development of type 2 diabetes mellitus. A higher intake of saturated fatty acids and trans-fatty acids could adversely affect glucose metabolism [11]. Both, a reduction in total fat intake and a substitution of unsaturated fatty acids for saturated fatty acids have been shown to improve insulin sensitivity [12-14]. The effects of dietary fat on insulin sensitivity is believed to be mediated through the fatty acid composition of the (skeletal muscle) cell membrane [15]. Furthermore, a low glycenic diet with a high amount of fiben and minimally processed whole grain products lowers the risk of type 2 diabetes [11]. Dietary fibres can reduce the rate of absorption, thereby lowering postprandial glycemic and insulinemic responses [16]. A third well-recognized risk factor for the development of diabetes is the level of physical activity. Increased physical activity, including physical activity of moderate intensity and duration, is associated with substantial reduction in the risk of type 2 diabetes, whereas a sedentary lifestyle is directly related to an increased risk [17-19]. Furthermore cigarette smoking is associated with a small increase, and moderate alcohol and coffee consumption with a decrease, in the risk of diabetes $[20-23]$.

Most lifestyle factors have been considered separately in relation to the risk of type 2 diabetes. However, such factors are typically closely related to each other. Hu et al.[24] assessed the combined impact of a set of lifestyle factors on the risk of diabetes in a large cohort of women by creating low risk groups for these variables. A combination of maintaining a body-mass index of $25 \mathrm{~kg} / \mathrm{m}^{2}$ or lower, eating a diet high in cereal fiber and polyunsaturated fat and low in saturated and trans-fat and glycemic load, exercising regularly, abstaining from smoking, and consuming alcohol moderately, was associated with an incidence of type 2 diabetes that was approximately 90 percent lower than found among those without these factors. These data indicate that the majority of the cases of type 2 diabetes can be prevented by adopting a healthier lifestyle.

\section{Impaired Glucose Tolerance}

Impained glucose tolemance (IGT) was defined by the WHO in 1980 as an intermediate category between normal glucose tolerance and type 2 diabetes mellitus, and is considered as a necessary transition state en route to type 2 diabetes (see Figure 1.1). Several metabolic abnormalities as resistance to insulin action, impaired insulin secretion and abnormalities in endogenous glucose output have been found in subjects with IGT [25-27]. Furthermore, IGT is associated with adverse cardiovascular risk factors, leading to an increased risk for the development of cardiovascular disease [28-30].

IGT is diagnosed with an OGTT, and is defined as a nomal, 1.e. non-diabetic, tasting plasma glucose concentration, and an elevated blood glucose concentration 2 hour after an oral glucose [3] (see Table 1.1). Large intra-subject variability has been observed when glucose tolerance tests are carried out on separate occasions, with $35 \%$ to $76 \%$ of the subjects with $1 \mathrm{GT}$ returning to normal glucose tolerance at re-testing $[311]$. Hovever recent evidence supports 
the hypothesis that IGT is a considerable risk factor, even when it is transient $[32,33]$.

\section{Prevalence and progression}

The prevalence of IGT varies widely between populations, from as low of $2.0 \%$ in rural populations to more than $20 \%$ in high-risk populations [34]. The Dutch Hoorn Study (1989-1992) reported a prevalence of $10.3 \%$ for IGT and $8.3 \%$ for diabetes (known and newly detected) in a 50-74 year old Caucasian population [35].

Much of the interest in the category of impaired glucose tolerance stems from the observation that IGT is associated with a much greater risk of developing diabetes than normal glucose tolerance. A recent analysis of six prospective studies reported a cumulative incidence that ranges from $23 \%$ to $63 \%$ among subjects with IGT followed for 2 to 27 years [36]. Incidence rates were higher among Hispanic, Mexican-American, Pima, and Nauruan populations than among Caucasians. Age, sex and family history of diabetes were generally not related to diabetes progression [36]. In the Dutch Hoorn Study, the odds ratios for developing diabetes after 6 years of follow-up, were 10.0, 10.9, and 39.5, for those having isolated impaired fasting glucose, isolated impaired glucose tolerance, and both IFG and IGT respectively [37].

\section{Risk factors for progression}

Cumulative incidence of type 2 diabetes in those with IGT is strongly related to the fasting plasma glucose concentration and the 2-hour plasma glucose concentration at baseline $[36,37]$. Most important modifiable risk factor for progression from IGT to diabetes is the degree of obesity. Body Mass Index (BMI) at the time of the IGT recognition was a strong predictor of progression from IGT to type 2 diabetes mellitus, independent of fasting and 2-hour blood glucose concentrations [36]. Combined adjusted relative hazard ratio was 1.13 per $4 \mathrm{~kg} / \mathrm{m}^{2}$ increase in BMI. In addition, not only over-all obesity but also central obesity was found to be a risk factor for developing diabetes [36-38|. Beside adiposity, the San Luis Valley Diabetes Study showed that fat consumption significantly predicts diabetes risk in subjects with IGT, after adjusting for obesity and markers of glucose metabolism (i.e. fasting glucose and insulin)[38]. A $40 \mathrm{~g}$ increase in fat intake was associated with a sixfold increase in risk of diabetes.

In summary, subjects with impaired glucose tolerance (IGT) are recognized as an important high risk group for the development of type 2 diabetes mellitus. The large impact of modifiable risk factors as obesily and diet in the etiology of diabetes offer the potential for the development of diabetes preventionprograms.

\section{Prevention of type 2 Diabetes Mellitus}

Over the past 25 year studies have been performed investigating whether intervention-programs could postpone or prevent the progression of $\mathbb{G}$ GT to 
type 2 diabetes mellitus. Several strategies have been used: drug and/or diet, drug therapy alone, or the combination of diet and exercise (lifestyleintervention').

\section{Drug intervention studies}

Two early studies, carried out in the 70s, using hypoglycemic agents in subjects with borderline diabetes, reported no effect on glucose tolerance and/or insulin dynamics [39,40]. Positive effects on glucose tolerance were reported for sulfonylurea treatment $[41,42]$. More recent a positive effect of the alphaglucosidase inhibitor acarbose on postprandial plasma glucose and insulin sensitivity in IGT was reported [43]. The STOP-NIDDM trial assessed the effect of this drug on conversion of IGT to type 2 diabetes in a large cohort in Europe and Canada [44]. After 3.3 years the risk of progression to diabetes was reduced by $25 \%$ in the acarbose treated group [44]. Two large drug-intervention trials, one using the novel anti-diabetic drug troglutazone in women with prior gestational diabetes [45] and the other one using metformin in subjects with IGT [46] reported a protective effect of the drugs on the development of type 2 diabetes. The latter one however, reported an even larger protection from diabetes with an intensive lifestyle intervention program [46].

\section{Dietary intervention studies}

Several studies have reported the effect of dietary interventions on the conversion of glucose intolerance to diabetes. In the Bedford study [47], carbohydrate restriction with or without phenformin had no effect on the diabetes conversion rate in men with borderline diabetes. Two Swedish studies giving more complete dietary advice with or without additional medication reported beneficial effects on glucose metabolism $[4.8,49]$. Ten weeks of dietary intervention, including reduced fat intake and increased complex carbohydrate and fibre-rich food intake, improved glucose control mainly by reducing fasting hyperglycemia [49]. Furthermore, positive effects on insulin sensitivity and glucose metabolism were reported in healthy [12] and glucose intolerant subjects $[50\}$ when saturated fatty acid intake was decreased and monounsaturated fatty acid intake was increased. Thus, not only the amount but also the type of the fat intake may be an important dietary factor.

The Chinese Da Qing IGT and Diabetes Study [51] assessed the single and joint effect of diet and exercise intervention on the development of type 2 diabetes in subjects with IGT. A diet with 55-65 energy (En\%) carbohydrate, 10-15 En\% protein, and $25-30$ En $\%$ fat in combination with weight-loss resulted in a significant reduction in the risk of developing diabetes of $31 \%$ after 6 years of treatment [51]. However, risk reduction was even larger in the other treatment groups: exercise only, and diet and exercise. The Oslo Diet and Exercise Study concluded that, although diet intervention was effective in reversing the development towards the insulin resistance syndrome, the combination of diet and exercise was the most effective [52]. Moreover. Hughes et al. [53] reported that adding an exercise program to a high-carbohydrate, low-fat diet had beneficial effects on postprandial glucose metabolism. 


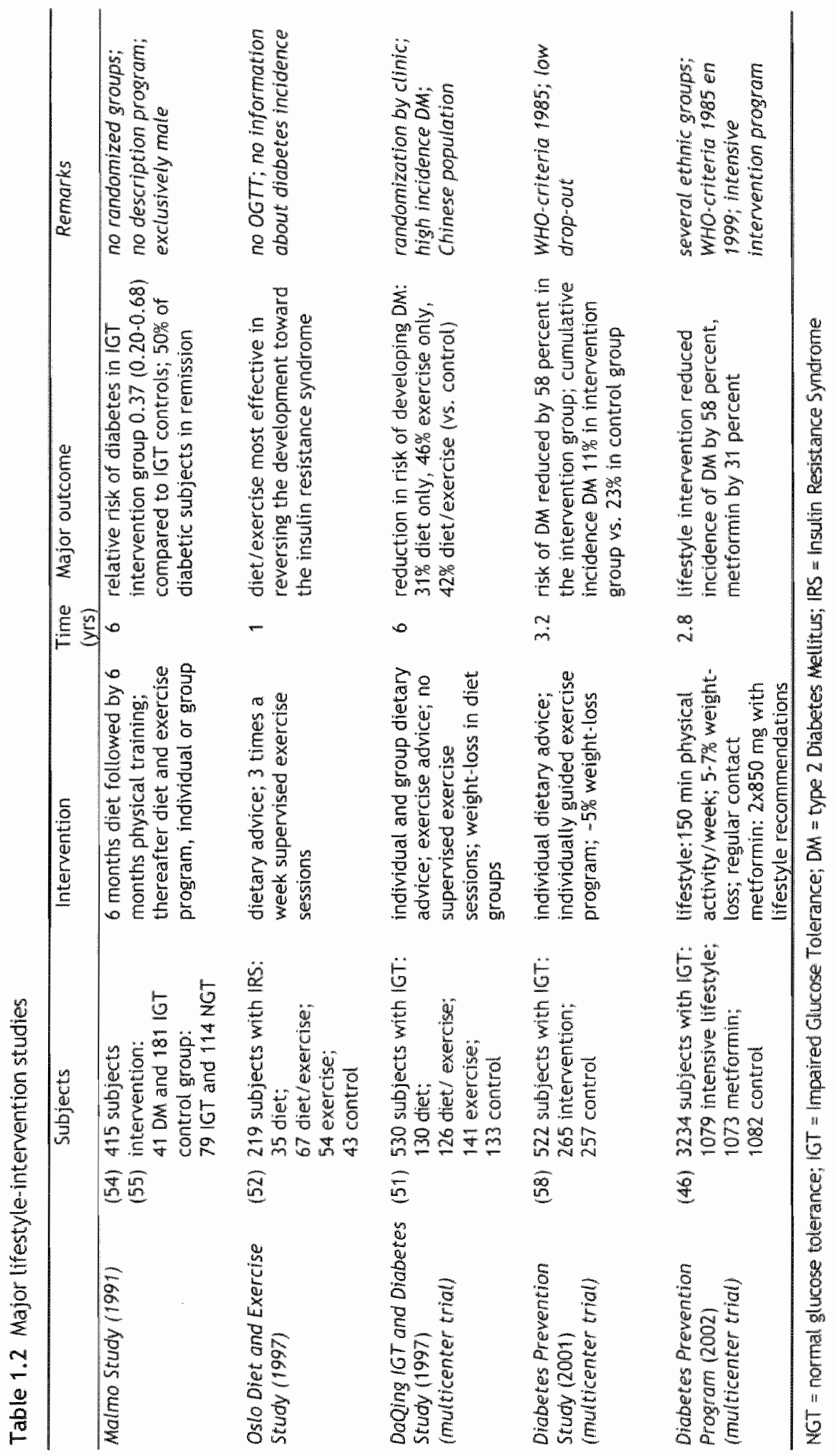


The above data suggest that beneficial effects of dietary changes on (postprandial) glucose metabolism can be expected, whereas adding exercise to the program may further improve glucose homeostasis.

\section{Lifestyle-intervention studies}

Lifestyle-intervention programs are typically made up of a combination of dietary advice, exercise prescription, and weight-loss. Several studies have been performed assessing the effect of a lifestyle-intervention program on the development of diabetes in subjects at increased risk for developing diabetes (see Table 1.2). The first study reporting positive effects of such a combination program was the Malmö study [54]. After 6 year of a combined diet and exercise intervention, $10.6 \%$ of the subjects with IGT had developed diabetes compared to $28.6 \%$ in the IGT control group (relative risk of 0.37 for developing diabetes. in the intervention group)[54]. Furthermore, there was an over-all improvement in cardiovascular risk profile with a reduced mortality in the $1 \mathrm{G} T$ intervention group compared to the IGT routine treatment group, even after 12 years of follow-up [55]. Unfortunately subjects were not randomly assigned to one of the study groups, the description of the intervention program was limited, and only men were participants.

As mentioned eariler, the Chinese Da Qing IGT and Diabetes Study [51] randomly allocated 577 men and women with 1 GT to one of the four study groups: diet only, exercise only, diet and exercise, or control. After 6 year the risk of developing diabetes, corrected for baseline BML and fasting glucose, was reduced by $31 \%$ in the diet group, by $46 \%$ in the exercise group and by $42 \%$ in the diet and exercise group. Although this study led to a significant decrease in the incidence of diabetes, some concerns were raised about the results. Subjects were actually randomized by clinic, not by type of intervention. Furthermore, the cumulative incidence of diabetes was high: $67.7 \%$ after 6 years for the control group [51]. A few other studies reported positive effects of lifestyle changes on insulin resistance [52], blood glucose concentration [56] or blood lipids [57]. However, interpretation of the results of these studies is difficult, due to the small number of subjects [57], lack of a control group [56] or absence of a oral glucose tolerance test $[52,57]$.

Recently, wo major lifestyle-intervention studies reported their final results: the Finnish Diabetes Prevention Study (DPS) in 2001 [58] and the U.S. Diabetes Prevention Program (DPP) in 2002 [46]. In the Finnish DPS, subjects were advised to consume a diet with more than $50 \%$ of daily calories from carbohydrates, less than $30 \%$ from fat, of which no more that $10 \%$ from saturated fat, less than $300 \mathrm{mg}$ cholesterol a day and approximately $1.0 \mathrm{~g}$ protein per $\mathrm{kg}$ ideal body weight per day. Furthermore, a weight reduction of $5 \%$ of initial body weight was aimed at, and subjects were individually guided to increase their level of physical activity to at least 30 minutes a day. After at mean follow-up of 3.2 years the over-all incidence of diabetes was reduced by 58 percent. Risk reduction was directly associated with changes in lifestyle [58]. Favorable changes were also found in blood pressure, serum lipids and anthroponetric indices. Data from the American DPP, aiming at a minimum of 
$7 \%$ weight loss and a minimum of 150 min of physical activity a week, confirm these results. The lifestyle intervention reduced the incidence of diabeles by a

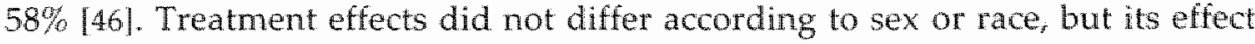
was greater among persons with lower baseline glucose values.

\section{Conclusion}

There is now recent evidence indicating that lifestyle changes in subjects with IGT may help to improve glucose metabolism and thereby reduce or delay the progression from IGT to type 2 diabetes mellitus. It is important to confirm these observations in other populations, with different dietary and physical activity patterns, and different attitudes towards changing lifestyle habits.

\section{FAT METABOLISM}

A role for fatty acids in the pathogenesis of diabetes has been recognized for many years, whereas evidence is now beginning to accumulate that abnormalities in fatty acid metabolism even play a key role.

Fat and carbohydrates are the two main substrates to fulfil energy requirements during rest and exercise. The capacity of the body to store energy as fat is almost unlimited, in contrast to the body's capacity to store carbohydrates. Major organs involved in fatty acid metabolism are adipose tissue, skeletal muscle and the liver.

\section{Fatty Acid Metabolism}

The vast majority of body fat is stored in the adipose tissue as triglycerides (TG), although small depots of TG can also be found in the muscle and the liver. In order to be oxidized, these triglycerides first have to be hydrolyzed to fatty acids (FA). After this mobilization, FA are transported through the circulation and taken up by muscle and liver for either direct oxidation, or reesterification to TG (see Figure 1.2).

\section{Mobilization and transport of fatty acids}

Fatty acids are mobilized via a process called lipolysis. Lipolysis can occur in all triglyceride-storing tissues. However most tissues contain only small amounts of TG, adipose tissue lipolysis is quantitatively the most important. Lipolysis refers to a process in which triglyceride is hydrolyzed, via di- and monoacylglycerol, to FA and glycerol. The rate limiting enzyme is hormone sensitive lipase (HSL). HSL is stimulated by catecholamines and sympathetic nervous system activity, and inhibited by insulin. The formed fatty acids can be released into the circulation, or can be re-esterified back to triglyceride. Once in the plasma they circulate as free fatty acids (FFA) bound to albumin to reach other tissues. 


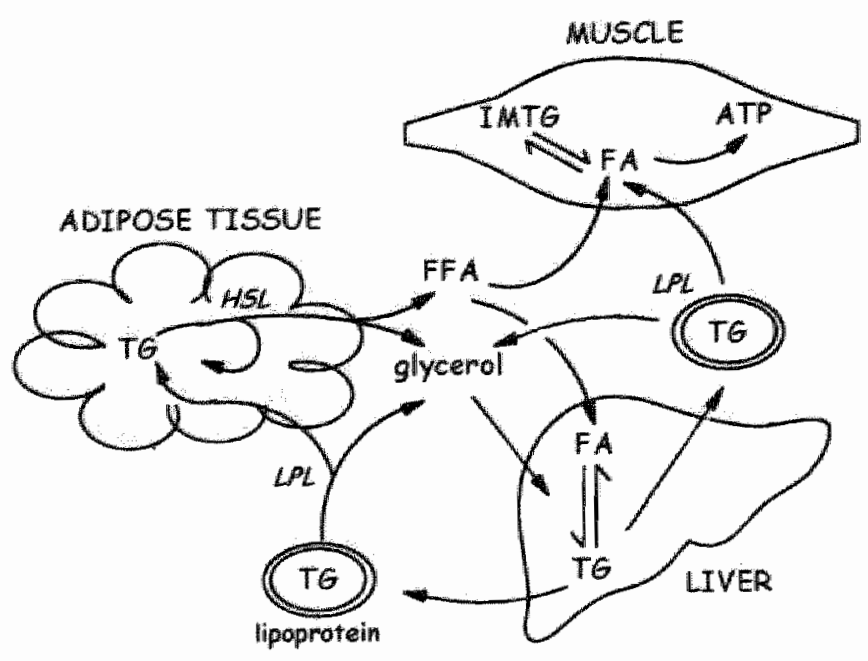

Figure 1.2 Fatty Acid Metabolism

MTG = intramuscular triglycerides; ATP = adenosine tri-phosphate; $F A=$ fatty acid; FA $=$ plasma free fatcy acid; $T G=$ triglyceride; $H S L=$ hormone sensitive lipase; $L P L=$ lipoprotein lipase

\section{Uptake and oxidation of fatty acids}

Skeletal muscle is the most important site concerning the uptake and oxidation of fatty acids, especially in the postabsorptive state and during exercise. The uptake of FA in skeletal muscle was long thought to be a passive process, with the concentration gradient between vascular and myocellular space being the driving force. Evidence is now accumulating that the trans-membrane transport of FA is partly dependent on carriers proteins, such as fatty acid translocase (FAT/CD36) and the plasma membrane bound fatty acid binding protein (FABPpm) [59]. Beside albumin-bound fatty acids, another source of fatty acids for skeletal muscle are triglycerides bound to lipoproteins (VLDL and chylomicrons). These TG first have to be hydrolyzed by lipoprotein lipase (LPL), before fatty acids can be transported into the muscle cell. LPL is located on the luminal surface of the vascular wall. The contribution of these lipoprotein-derived fatty acids to total fatty acid oxidation appears to be limited. [60].

In the cytoplasm, fatty acids are bound to cytoplasmic fatty acid binding protein $(F A B P C$ ) and transported to the site of action, where either (re-) esterification or oxidation to replenish energy stores occurs. At the site of oxidation, the mitochondrion, FA will be activated to fatty acyl-CoA by the enzyme acyl-CoA synthetase (ACS) (see Figure 1.3). Next step is translocation over the nitochondrial membrane by a carnitine-dependent transport system, with two specific enzymes, camitine palmitoyl transferase I (CPT-I, also called carnitine acyl transferase I, CAT-I) and CPT-II (CAT-II) located at the outer-and inner mitochondrial membrane, respectively (see Figure 1.3). CPT-I, the rate 
limiting step for the transport of long-chain FA into the mitochondria, is regulated, in a negative manner, by malonyl-CoA. Malonyl-CoA is in its turn tightly regulated by acetyl-CoA carboxylase (ACC) and malonyl-CoA dehydrogenase (MCD). It has been suggested that the transport of FA across the mitochondrial outer membrane, catalyzed by CPT-I, is an important site of regulating fatty acid oxidation [61].

Inside the mitochondrial matrix, fatty acyl-CoA is stepwise degraded to acetyl $\mathrm{Co} A$ in a process called $\beta$-oxidation (see Figure 1.3). The rate-limiting enzyme catalyzing the final step of the $\beta$-oxidation, is hydroxyacyl-CoA dehydrogenase (HAD). After $\beta$-oxidation, acetyl-CoA enters the tricarboxylic acid cycle (TCAcycle). The initial step of the TCA-cycle is the formation of citrate, a reaction catalyzed by citrate synthase (CS). Subsequent, acetyl-CoA is completely oxidized in a series of biochemical reactions. Finally, hydrogen atoms, bound to nicotinamide-, and flavin adenine dinucleotide (NAD*FAD), released during $\beta$-oxidation and the TCA-cycle are transferred to the respiratory chain, where they give rise to the formation of energy rich phosphates: adenosine triphosphate (ATP).

\section{Muscle triglycerides}

As mentioned above, a small depot of TG is present in skeletal muscle. Hydrolysis of this muscular TG is believed to take place in a similar manner as described for adipose tissue, and is catalyzed by hormone sensitive lipase (HSL)[62]. The liberated fatty acids can enter the same pathways as described for the blood-borne fatty acids. Although the depot of muscle TG is relatively small, it may be metabolically important, accounting for substantial part of total energy expenditure during submaximal exercise [63].

With the introduction of new techniques to study muscle $\mathrm{TG}$, a clear distinction can be made between lipids localized within the myocyte (intramyocellular lipids, IMCL) and lipids localized in adipocytes dispersed between muscle fibers (extramyocellular lipids, EMCL). The latter one, EMCL, has long been regarded as less important while $I M C L$, due to its localization close to mitochondria was considered as the metabolically more important lipid store. With respect to insulin resistance, this viewpoint is under debate, as role for both IMCL and EMCL has been suggested [64].

\section{Fatty Acid Metabolism and Type 2 Diabetes Mellitus}

Although a number of factors have been considered to contribute to the pathogenesis of type 2 diabetes mellitus, one of the key factors is the development of insulin resistance. Most important tissue in the etiology of insulin resistance is skeletal muscle, as it accounts for more than $80 \%$ of insulinstimulated glucose utilization [65]. With the introduction of the glucose fattyacid cycle in 1963 by Randle et al.[66], it is well recognized that fatty acid metabolism plays an important part in the development of (skeletal muscle) insulin resistance. Recently, a prominent role for disturbances in fatty acid oxidation in the development of insulin resistance was suggested [67]. 

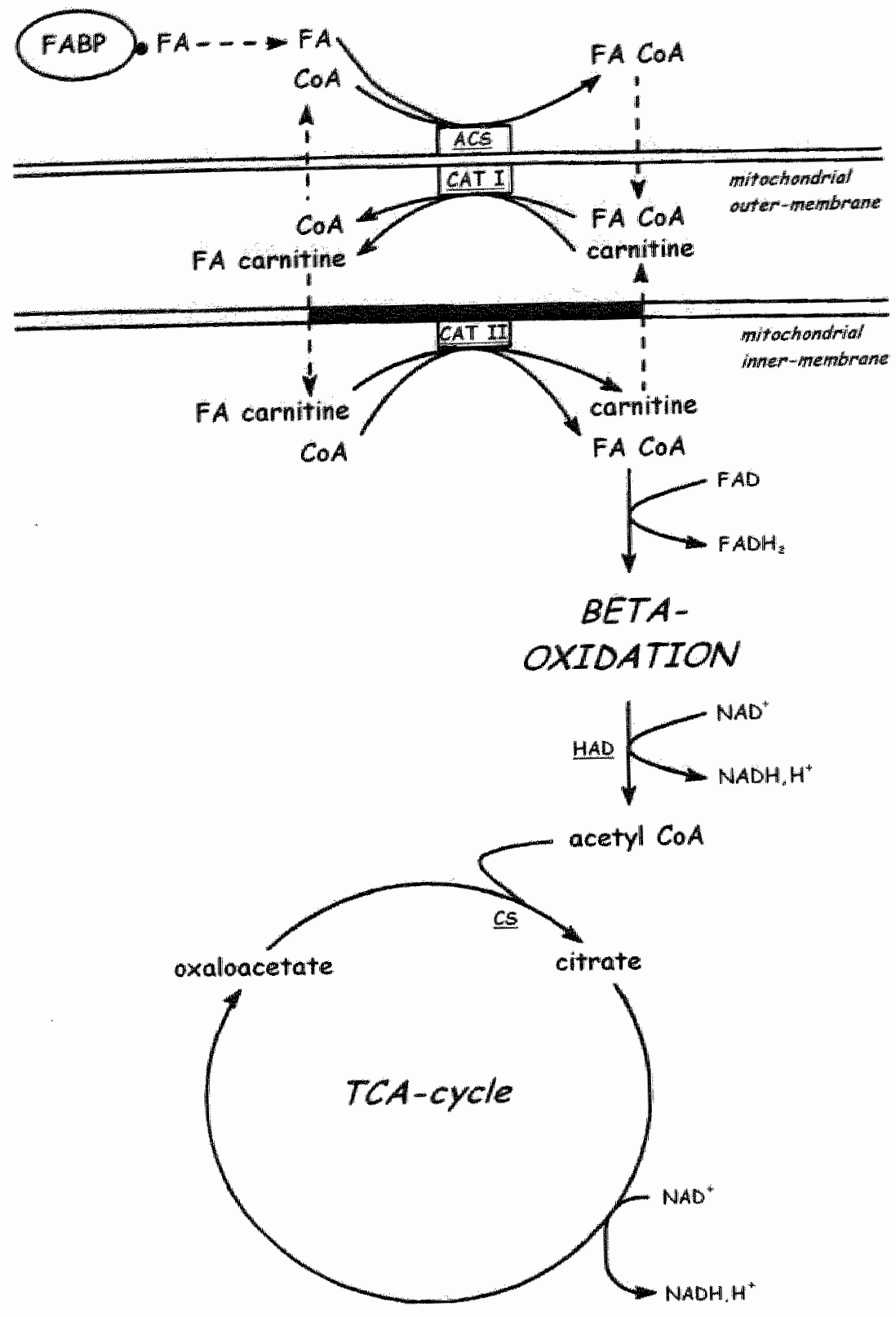

Figure 1.3 Mitochondrial fatty acid handling

FABP $=$ fatty acid binding protein; FA $=$ fatty acyl; $C O A=C o \cdot e n z y m e ~ A ; A C S=$ acyl $C O A$ synthetase; $C A T$ I and $\|$ = carnitine acyl transferase $\|$ and $\|$; HAD = hydroxyacyl-COA dehydrogenase; $C S$ = ctrate synthase: $N A D=$ nicotinamide adenine dinucleotide; $F A D=$ flavin adenine dinucleotide; $T C A=$ tricarboxylic acid cycle 


\section{Free fatty acids}

Plasma free fatty acids (FFA) play a central role in the development of insulin resistance, glucose intolerance and type 2 diabetes [4]. As reviewed by Boden [68], there is enough evidence showing that an acute increase in plasma FFA can induce insulin resistance in non-diabetic and diabetic subjects. While an acute lowering of elevated plasma FFA levels reduced insulin resistance in obese diabetic and non-diabetic subjects [69].

Several mechanisms have been proposed to explain the precise mechanisn responsible for these FFA-induced defects. The glucose fatty-acid cycle, as postulated by Randle et al.[66], coupled an increased lipid availability and fat oxidation to a decreased glucose uptake and oxidation via inhibition of pyruvate dehydrogenase. However, the observation of an early FFA-induced defect in glucose oxidation without a concomitant decrease in insulinstimulated glucose uptake argues against an important role for the Randle-cycle in the development of skeletal muscle insulin resistance [68]. Furthermore, an early decline in glucose-6-phosphate concentration has been reported. suggesting that FFA primarily inhibit glucose transport/phosphorylation $[70,71]$. Other underlying mechanisms may be an accumulation of glucosamine pathway metabolites, altered GLUT4 gene expression or changes in membrane fluidity [68].

Recently, Itani et al.[72] suggested that increased plasma FFA leading to an increased intracellular long-chain fatty acylmCoA (LCFA-CoA) concentration resulting in diacylglycerol (DAG) and triglyceride formation, explained the development of insulin resistance, as DAG is known to activate protein kinase $C$ (PKC) an enzyme that has been linked to insulin resistance. This is an attractive hypothesis, as it couples FFA-induced insulin resistance to an other well-known marker of insulin resistance namely, accumulation of intramuscular triglycerides.

\section{Muscle triglycerides}

Although the depot of muscle TG is relatively small, it may be metabolically important. Muscle of diabetic subjects is characterized by increased levels of lipids $[73,74]$, and skeletal muscle lipid content is inversely related to insulin sensitivity [75]. With the introduction of new techniques to study muscle lipids a distinction could be made between lipid located inside the myocyte (IMCL, intramyocellular lipid) and lipid located outside the myosin (EMCL. extramyocellular lipid).

This new technique, proton nuclear magnetic resonance spectroscopy ('H-MRS), can detect two different resonance frequencies in muscle tissue one corresponding to fat located within the muscle cell (IMCL) and one corresponding to lipids stored in adipocytes around the muscle cell (EMCL) $[76,77]$. 'H MRS is a non-invasive technique, with the advantage of the possibility to measure several times during an experiment and at several locations within the muscle. A second technique is direct visualization of muscle tissue using microscopy in combination with histochemical staining with Oil red $O$. This procedure allows studying muscle lipids in combination 
with other myocellular characteristics, For example, lipid droplets can be studied together with immunolabeling of proteins involved in lipid handling and metabolism [78].

Several studies using 'H-MRS or Oil red $O$, confirmed the earlier observations of a relationship between muscle triglycerides and insulin sensitivity, but now identified the intramyocellular depot as being the most important [79-83]. The finding that IMCL content was already elevated in lean offspring of type 2 diabetic parents suggests that it might play an important role in the pathogenesis of type 2 diabetes [81,82]. The increased lipid content in insulin resistant subjects was independent of muscle fiber type, despite the known large differences in oxidative capacity and insulin sensitivity between fiber types [83]. Furthermore, not only the volume but also the cellular distribution of lipids differed in muscle from (insulin-resistant) obese subjects [84], which can be critically important in relation to disturbances in fatty acid metabolism and insulin resistance.

Further evidence for a close relationship between IMCL and insulin sensitivity stems from the observation that an acute increase of $\mathrm{MMCL}$ content, by infusion of lipid and heparin, resulted in an decreased insulin sensitivity [85,86]. In addition, weight-loss in morbid obese subjects reduced intramuscular fat content, with a concomitant increase in insulin sensitivity [87].

However, there exists a paradox in the relation between IMCL and insulin sensitivity. Muscle of well-trained athletes is characterized by a high insulin sensitivity despite elevated levels of intramuscular triglycerides [88]. It was suggested that the capacity of muscle for lipid oxidation may be an important mediator of the association between excess muscle lipids and insulin resistance [88]. Thus in trained muscle, elevated IMCL in combination with a high oxidative capacity (and periodic turnover) may not disturb insulin sensitivity, while in the untrained (diabetic) muscle, elevated IMCL together with a low oxidative capacity may have a negative impact on insulin sensitivity. This explanation nicely fits in the idea that not stored muscle TG itself causes the insulin resistance, but rather some other lipid metabolites associated with intramuscular triglycerides $[72,89]$. Likely candidates are long-chain fatty acylCOA (LCFA-COA) and diacylglycerol (DAG), as they might interfere with insulin signaling and, thus, GLUT4 translocation to the cell membrane [90,91]. Altogether, muscle triglyceride accumulation is an important determinant of insulin resistance. Although the exact mechanism is still unknown, the dynamics of lipid handling within the muscle could be critically important in the association between muscle triglycerides and insulin resistance.

\section{Faty acid uptake and oxidation}

In contrast to the original proposed principle of Randle, there is now accumulating evidence indicating that skeletal muscle fatty acid uptake and oxidation is decreased in insulin resistance and type 2 diabetes mellitus.

Blaak et al.[92] were the first to report an impaired ability to oxidize fatty acids in muscle of obese (insulin resistant) subjects. Afterwards this observation was confirmed in women with visceral obesity [93], and could be extended to the 
diabetic state 194,95$]$. During moderate-intensity exercise, type 2 diabetic subjects have a diminished plasma FFA oxidation and a higher triglyceride derived FA oxidation at whole body level as compared to weight matched controls 196$]$. Furthermore, there are indications that lipolysis in foream musde is increased in diabetic subjects [95]. Altogether these data suggest a difference in handling of FFA in skeletal muscle between diabetic subjects and healthy controls [97].

The group of Kelley found an increased respiratory quotient across the leg (leg RQ) of diabetic and insulin-resistant obese subjects in the postabsorptive state, indicating an increased glucose oxidation and a decreased lipid oxidation [94,98-100]. During insulin-stimulated conditions however, leg RQ was lower in insulin-resistant subjects compared to healthy controls, indicating a lower glucose oxidation and a higher lipid oxidation in the insulin resistant state [100]. They called this phenomenon "metabolic inflexibility", and speculated that this state was likely to be a key nechanism leading to lipid accumulation within skeletall muscle [101].

In line with the above cited findings, the oxidative capacity of muscle in diabetes and obesity is diminished $[83,95,102]$. The metabolic capacity of insulin resistant skeletal muscle appears to be organized towards fat esterification rather than fat oxidation. [102]. A dysbalance between fatty acid uptake and fatty acid oxidation could easily lead to fat accumulation within skeletal muscle. Considerable weight reduction did not improve the impaired fatty acid oxidation [100,103], neither it did improve the disturbed metabolic capacity for FA handling of the skeletal muscle [102], suggesting that this impaiment reflects a primary defect ather than an adaptation to the type 2 diabetic state.

Severall mechanisms could be responsible for the diminished capacity of the diabetic muscle to oxidize fatty acids. In muscle biopsies from type 2 diabetic patients the content of cytoplasmic fatty acid binding protein (FABPC) was decreased as compared to controls, which could contribute to a decreased utilization and oxidation of plasma FFA 1951. Alterations in other transport proteins, as the membrane-bound FA transporters FAT/CD36 and FATP, could also play a role |104|. Furthemore, as earlier mentioned, insulin-resistant skeletal muscle has a reduced oxidative enzyme activity, leading to a diminished fatty acid oxidation and an increased fatty acid storage 195, 102]. Another mechanism underlying the disturbed FA oxidation could be a diminished activity of CPT-I, a key step in the regulation of fatty acid oxidation. Muscle of insulin-resistant obese subjects showed a reduced activity of CPT-I [102]. An increased concentration of malonyl-CoA, due to dysregulation by acetyl CoA carboxylase (ACC) and malonyl CoA decarboxylase (MCD), or due to hyperglycemia and hyperinsulinemia, can lead to an inhibition of CPT-1, and subsequent a diminished fatty acid oxidation [67]. Recently, an important role is suggested for AMP-activated protein kinase (AMPK), which stimulates both glucose and fatty acid oxidation [105].

To further elucidate the role of disturbances in (skeletal muscle) fatty acid metabolism in the development of type 2 diabetes mellitus, it is important to study lipid dynamics in subjects at increased risk for developing diabeles, i.e. subjects with impaired glucose tolerance (IGT). If disturbances in fatty acid 
metabolism described in diabetes are already present in the glucose intolerant state, this could indicate that the defects might be important etiological factors in the development of type 2 diabetes mellitus. So far, only one study addressed this issue. Turpeinen et al.[106] showed that subjects with IGT had similar myocardial but lowered femoral muscle FFA uptake compared to healthy controls. However, more studies are needed to confirm those results. Furthermore, if ICT is characterized by a disturbed skeletal muscle fatty acid metabolism, it would be interesting to evaluate the effect of (exercise/dietary) intervention programs, since these are known to improve insulin sensitivity and glucose tolerance $[107,108]$.

\section{Concluding remarks}

Skeletal muscle fatty acid metabolism plays a important role in the development of insulin resistance and type 2 diabetes mellitus. Intramuscular triglycerides are a strong marker of insulin resistance. Disturbances in fatty acid oxidation, and/or a dysbalance between FA uptake and oxidation direct fatty acids towards storage rather than oxidation, leading to elevated levels of IMCL. Lipid metabolites associated with IMCL, such as LCFA-COA and DAG, can adversely affect insulin signaling and insulin-mediated glucose uptake.

Alhough abundant data support the prominent role of a disturbed FA metabolism in insulin resistance, important issues still remain unanswered. Which underlying mechanisms are responsible for the disturbed fatty acid oxidation? Are those alterations primary or adaptational, i.e are subjects prone to develop diabetes also characterized by an impaired F A utilization? Can interventions beneficially influence these disturbances in FA metabolism? Further research is needed to address these questions.

\section{OUTLINE OF THIS THESIS}

As described in the first part of this chapter lifestyle(-related) factors play a prominent role in the pathogenesis of IGT and type 2 diabetes mellitus. Therefore, justification of lifestyle-interventions in those at risk is that they may prevent or postpone the onset of type 2 diabetes and related complications. Both the Finnish Diabetes Prevention Study (DPS) and the U.S. Diabetes Prevention Program (DPP) showed that changing dietary and physical activity habits reduce the incidence of diabetes by about $58 \%[46,58]$. However, several issues remain. With regard to compliance and future implementation of such a prevention program it needs to be assessed whether moderate interventions, in agreement with current public health gudelines are effective. In addition, it is imperative to know whether the results achieved by the DPS and DPP are valid for other populations. Confirmation of these results in different populations with a different dietary and physical activity background, and a different attitude towards changing lifestyle-habits is of crucial importance.

The Study on Lifestyle-intervention and IGT Maastricht (SLIM), the leading thread running through this thesis, will address this question in the Dutch 
population. In chapter 2 its rationale and design are described, and data from the population screening are presented. Results after 1 and 2 year of the combined diet and physical activity intervention are discussed in chapters 4 and 5 respectively.

A second aim of SLIM is to elucidate some of the features underlying the changes in glucose tolerance. As discussed in the second part of this chapter, type 2 diabetes is characterized by disturbances in (skeletal muscle) fatty acid metabolism. If these disturbances in fatty acid metabolism are already present in the glucose intolerant state, this could indicate that the defects might be important etiological factors in the development of type 2 diabetes mellitus. This question is addressed in chapter 6 . In the following chapters, the effects of the combined diet and exercise intervention program on (disturbed) skeletal muscle fatty acid metabolism are examined. Changes in glucose and fatty acid uptake and oxidation at rest and during exercise are discussed in chapter 7 , while changes in skeletal muscle gene expression and protein content are discussed in chapter 8. Another important feature of the disturbed fat metabolism in the insulin resistant state is the accumulation of muscle triglycerides. This is the topic of chapter 9 . Finally, in chapter 10 the results and conclusions of the previous chapters are integrated and implications of the work presented in this thesis for understanding the etiology of insulin resistance and (developing) prevention strategies for type 2 diabetes mellitus are discussed.

\section{References}

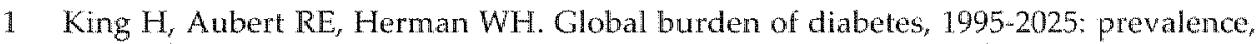
numerical estimates, and projections. Diabetes Care 1998; 21: 1414-31.

2 Zimmet P. Globalization, cocamcolonization and the chronic disease epidemic: can the Doomsday scenario be averted? I hitern Med 2000; 247: 301-10.

3 World Health Organization. Definition, diagnosis and classification of diabetes mellitus. Report of a WHO Consultation. Part 1: Diagnosis and Classification of Diabetes Mellitus. Geneva, Switzerland, 1999. Publication WHO/NCD/NCS/99.2.

4 Reaven GM. Banting lecture 1988. Role of insulin resistance in human disease. Diabetes 1988; 37: 1595-607.

5 Porte D, Jr. Banting lecture 1990. Beta-cells in type II diabetes mellitus. Diabers 1991; 40: $166-80$.

6 Nijpels G. Determinants for the progression from impaited glucose tolerance to noninsulin-dependent diabetes mellitus. Eur/Chn Invest 1998; 28 Suppl 2: 8-13.

7 Saad MF, Knowler WC, Pettitt DJ et al. A two-step model for dewelopment of noninsulin-dependent diabetes. Am J Med 1991; 90: 229-35.

8 Kahn CR. Banting Lecture. Insulin action, diabetogenes, and the cause of type dI diabetes. Diabetes 1994; 43: 1066 84.

9 Chan JM, Rimm EB, Coldiz GA, Stampfer MJ, Willett WC. Obesily, fat distribution, and weight gain as risk factors for clinical diabetes in men. Diobotes Care 1994; 17: $961-9$.

10 Han TS, Feskens EJ, Lean ME, Seidell JC. Associations of body composition with type 2 diabetes mellitus. Diabet Med 1998; 15: 129-35. 
11 Hu FB, van Dam RM, Liu S. Diet and risk of Type II diabetes: the role of types of fat and carbohydrate Diabetologia 2001; 44: 805-17.

12 Vessby $B$, Unsitupa $M$, Hermansen $K$ et al. Substituting dietary saturated for monounsaturated fat impairs insulin sensitivity in healthy men and women: The KANWU Study. Diabetologia 2001; 44:312-9.

13 Swinburn BA, Metcalf PA, Ley SI. Long-term (5-year) effects of a reduced-fat diet intervention in individuals with glucose intolerance. Diabetes Care 2001; 24: 619-24.

14. Perez-Jimenez F, Lopez-Miranda J. Pinillos MD et al. A Mediterranean and a highcarbohydrate diet improve glucose metabolism in healthy young persons. Diabetologia 2001; 44: $2038-43$.

15 Borkman M, Storlien LH, Pan DA et al. The relation between insulin sensitivity and the fatty-acid composition of skeletal-muscle phospholipids. $N$ Engl J Med 1993; 328: $238-44$.

16 Jenkins DJ, Axelsen M, Kendall CW et al. Dietary fibre, lente carbohydrates and the insulin-resistant diseases. Br J Nutr 2000; 83 Suppl 1: $5157-63$.

17 Helmrich SP, Ragland DR, Leung RW, Paffenbarger RS, Jr. Physical activity and reduced occurrence of non-insulin-dependent diabetes mellitus. $N$ Engl I Med 1991; $325: 147-52$.

18 Hu FB, Sigall RJ, Rich-Edwards JW et al. Walking compared with vigorous physical activity and risk of type 2 diabetes in women: a prospective study. JAMA 1999; 282: $1433-9$

19 Hu FB, Leitzmann MF, Stampfer MJ et al. Physical actiwity and television watching in relation to risk for type 2 diabetes mellitus in men. Arch Intern Med 2001; 161: $1542-8$.

20 Feskens EJ, Kromhout D. Cardiovascular risk factors and the 25-year incidence of diabetes mellitus in middle-aged men. The Zutphen Study. Am / Epidemiol 1989; 130: 1101-8.

21. Manson JE, Ajani UA, Liu S, Nathan DM, Hennekens CH. A prospective study of cigarette smoking and the incidence of diabetes mellitus among US male
physicians. Am/Med 2000; 109:538-42.

22 Wei $M$, Gibbons LW, Mitchell TL, Kampert JB, Blair SN. Alcohol intake and incidence of type 2 diabetes in men. Diabetes Care 2000; 23: 18-22. 23 wan Dam RM, Feskens El. Coffee consumption and risk of type 2 diabetes mellitus.
Lance 2002; 360:1477-8. 24. Hu FB, Manson JE, Stampfer MJ et al. Diet, lifestyle, and the risk of type 2 diabetes
mellitus in women. N Engl Med 2001; 345: 790-7.

25 Weyer $C$, Bogardus C, Pratley RE Metabolic characteristics of individuals with impared fasting glucose and/or impaired glucose tolerance. Diabetes 1999; $48: 2197$ -
203 .

26. Pinnenta $W$. Mitrakou $A$, Jensen T et al. Insulin secretion and insulin sensitivity in people with imparred glucose tolerance. Diabet Med 1996; 13: 533-6.

27 Davies MJ, Rayman $G$, Grentell A et al. Loss of the first phase insulin response to intravenous glucose in subjects with persistent impaired glucose tolerance. Diabet
Med 1994; 11:432-6.

28 Chu NF, Lee MM, Wang DI et al. The interrelationship between impaired glucose tolenance and other risk factors for cardiovascular disease: is it a predictor for
cardiovascular disease? / Clin Epideniol 1994; 47:485-93.

29 Sprafka JM, Xue S, Bushhouse SA et al. Cardiovascular disease risk factors and glucose tolerance. The Wadena City Health Study. Am Epidemiol 1992; 2: 647-56. 
30 Rodriguez BL, Curb JD, Burchfiel CM of al Impaired glucose tolerance, diabetes, and cardiowascular disease risk factor profiles in the elderly. The Honolulu Heart Program. Diabetes Care 1996; 19:587-90.

31 Yudkin IS, Alberti KG, McLarty DG, Swai AB. Impaired glucose tolerance. BMI 1990; $301: 397-402$.

32 Aberti KG. Impaired glucose tolerance-fact or fiction. Diabet Med 1996; 13: $56-8$.

33 Saad MF, Knowler WC, Pettitt DJ, Nelson RG, Bennett PH. Transient impaired glucose tolerance in Pima Indians: is it important? BM/ 1988; 297: 1438-41.

34. Alberti KG. The clinical implications of impaired glucose tolerance. Diabe Met 1996; 13: $927-37$.

35 Mooy IM, Grootenhuis PA, de Vries H ef al. Prevalence and deteminants of ghucose intolerance in a Dutch caucasian population. The Hoorn Study. Diabetes Care 1995; 18: 1.270-3.

36 Edelstein SL, Knowler WC, Bain RP of al. Predictors of progression trom impaired glucose tolerance to NIDDM: an analysis of six prospective studies. Diabetes 1997; 46: $701-10$.

37 de Vegt $F$, Dekker JM, Jager A et al. Relation of impaired fasting and postload glucose with incident type 2 diabetes in a Dutch population: The Hoorn Study. JAMA 2001; 285:2109-13.

38 Marshall JA, Hoag S, Shetterly S, Hamman RF. Dietary fat predicts conversion from impaired glucose tolerance to NIDDM. The San Luis Valley Diabetes Study. Diabetes Care 1994: 17: 50-6.

39. Papoz L, Job D, Eschwege E et al. Effect of oral hypoglycaemic drugs on glucose tolerance and insullin secretion in borderline diabetic patients. Diatretologia $1978 ; 15$ : 373-80.

40 Tan MH, Graham CA, Bradley RF, Gleason RE, Soeldner JS. The elfects of long-term therapy with oral hypoglycemic agents on the oral glucose tolerance test dynamics in male chemical diabetics. Diabetes $1977 ; 26: 561-70$.

41 Ratzmann KP, Witt S, Schulz B. The effect of long-term glibenclamide treatment on glucose tolerance, insulin secretion and serum lipids in subjects with impaired glucose tolerance. Diabete Metab 1983; 9: 87-93.

42 Pontiroli $\mathrm{AE}$, Perfetti MG, Pozza G. Acute effect of glipizide on glucose tolerance in obesity and diabetes mellitus (NIDDM). Eur J Clin Pharmacol 1991; 40:23-6.

43 Chiasson JL, Josse RG, Leiter LA ot al. The effect of acarbose on insulin sensitivity in subjects with impared glucose tolerance. Diabeles Care 1996; 19: 1190-3.

44. Chiasson JL, Josse $\mathbb{R} G$, Gomis $\mathbb{R}$ ef al. Acarbose for prevention of type 2 diabetes mellitus: the STOP-NIDDM randomised trial. Lancet 2002; 359: 2072-7.

45 Buchanan TA, Xiang AH, Peters RK et al. Preservation of pancreatic beta-cell function and prevention of type 2 diabetes by pharmacological treatment of insulin resistance in high-risk hispanic women. Diabetes 2002; $51: 2796-803$.

46 Knowler WC, Barrett-Connor $\mathbb{E}$, Fowler SE ef al. Reduction in the incidence of type 2 diabetes with lifestyle intervention or metformin. N Engl/ Mod 2002; 346: 393-403.

47 Jarret RJ, Keen H. Fuller JH, McCartney M. Treatment of borderline diabetes: controlled trial using carbohydrate restriction and phenformin. Br Mod / 1977; 2: $861-5$.

48 Sartor $G$, Schersten B, Carlstrom $S$ et al. Ten-year follow-up of subjects with impared glucose tolerance: prevention of diabetes by tolbutamide and diet regulation. Diabetes 1980; $29: 41-9$.

49 Bizen PO, Melander A, Schersten B, Svensson M. Efficacy of dietary regulation in primary health care patients with hyperglycemia detected by screening. Dinber Med $1988 ; 5: 640-7$. 
50 Sarkkinen. E, Schwab U. Niskanen L el al. The effects of monounsaturated-fat entiched diet and polyunsaturated-fat enriched diet on lipid and glucose metabolism in subjects with impared glucose tolerance. Eur ] Clin Nutr 1996; 50: $592-8$.

51 Pan XR, Li GW, Hu YH ot al. Effects of diet and exercise in preventing NDDDM in people with impaired glucose tolerance. The Da Qing $1 G T$ and Diabetes Sudy. Diabeter Care 1997; $20.537-44$.

52 Torjesen PA, Birkeland KI, Anderssen SA et al. Lifestyle changes may reverse development of the insulin resistance syndrome. The Oslo Diet and Exercise Study: a ranclomized trial. Diabetes Care 1997:20:26-31.

53 Hughes $V A$, Fiatarone MA, Fielding RA et al. Long-term effects of a highcarbohydrate diet and exercise on insulin action in older subjects with impaired glucose tolerance. Am / Clin Mup 1995; 62: 426-33.

54. Eriksson KF, Lindgarde F. Prevention of type 2 (non-insulin-dependent) diabetes mellitus by diet and physical exercise. The 6myear Malmo feasibility study. Diabetologia 1991; 34: 891-8.

55 Eriksson KF, Lindgarde F. No excess 12 -year mortality in men with impaired glucose tolerance who participated in the Mamo Preventive Trial with diet and exercise. Diabetologin 1998; 41: 1010-6.

56 Bourn DM, Mann II, McSkimming BJ, Waldron MA, Wishart JD. Impaired glucose tolerance and NIDDM: does a lifestyle intervention program have an effect? Diabetes Care 1994; 17: 1311-9.

57 Page RC, Handen KE, Cook JT, Tumer RC. Can lite-styles of subjects with impaired glucose tolerance be changed? A feasibility study. Diabet Med 1992; 9:562-6.

58 Tuomilehto J, Lindstrom J, Eriksson JGet al. Prevention of type 2 diabetes mellitus by changes in lifestyle among subjects with impaired glucose tolerance. $N$ Engl Med 2001; 344: 1343-50.

59 Luiken J], Glatz JF, Bonen A. Fatty acid tramsport proteins facilitate fatty acid uptake in skeletal muscle. Can f Apol Physiol 2000; 25:333-52.

60 Jeukendrup AE, Saris WH. Wagenmakers AJ. Fat metabolism during exercise: a neview. Part l: fatty acid mobilization and muscle metabolism. Int / Sports Med 1998; 19: $231-44$.

61 McGarry JD, Brown NF. The mitochondrial carnitine palmitoyltransferase system. From concept to molecular analysis. Eur / Biochem 1997; 244: 1-14.

62 Langfort J. Ploug $\mathrm{T}$, Ihlemann I et al. Expression of hormone-sensitive lipase and its regulation by adrenaline in skeletal muscle. Biochen/ 1999; 340: 459-65.

63 Romijn IA, Coyle EF, Sidossis LS ef al. Regulation of endogenous fat and carbohydrate metabolism in relation to exercise intensity and duration. Am f Plysiol 1993, 265: E380-91.

64 Kenley DE, Goodpaster BH, Storlien L. Muscle iriglyceride and insulin resibtance. Anh Re Non 2002: 22:325-46.

65 Defronzo RA, Jacot $\mathrm{E}$, Jequier $\mathbb{E}$ at al. The effect of insulin on the disposal of intravenous glucose. Results from indirect calorimetry and hepatic and femoral venous catheterization. Diaberes 1981; 30: 1000-7.

66 Randle. PI, Garland PB, Hales CN. Newsholme EA. The glucose fatty-acid cycle: Its role in insulin sensitivity and the metabolic disturbances of diabetes mellitus. Lancet
$1963 ; 7285-7289$.

67 McGarry JD. Banting lecture 2001: dysregulation of fatty acid metabolism in the etiology of type 2 diabetes. Diabetes 2002; $51: 7.18$.

68 Boden G. Free fatty acids, insulin resistance, and type 2 diabetes mellitus. Proc Assac Am Physicians 1999; 111: $241-8$. 
69 Santomauro AT, Boden $G$, silva ME et at. Overnight lowering of free fatty acids with Acipimox improves insulin resistance and glucose tolerance in obese diabetic and nondiabetic subjects. Diabetes $1999 ; 48: 1836-41$.

70 Roden M, Krssak M, Stingl H ef al. Rapid impairment of skeletal muscle glucose transport/phosphorylation by free fatty acids in humans. Diabetes 1999; $48: 358-64$.

71 Roden M, Price TB, Perseghin G et al. Mechanism of free fatty acid-induced insulin resistance in humans. I Clin Imest 1996; 97: 2859-65.

72 Itani $\mathrm{SI}$, Ruderman $\mathrm{NB}$, Schmieder $\mathrm{F}$, Boden $\mathrm{G}$. Lipid-induced insulin resistance in human muscle is associated with changes in diacylglycerol, protein kinase $\mathrm{C}$, and IkappaB-alpha. Diabetes 2002; 51: 2005-11.

73 Stand $\mathrm{E}$, Lotz N, Dexel T, Janka HU, Kolb HJ. Muscle triglycerides in diabetic subjects. Effect of insulin deficiency and exercise. Diabefologin 1980; 18:463-9.

74 Falholt $K$, Jensen I, Lindkaer Jensen $S$ et al. Carbohydrate and lipid metabolism of skeletal muscle in type 2 diabetic patients. Diabet Med 1988; $5: 27-31$.

75 Pan DA, Lillioja S, Kriketos AD et al. Skeletal muscle triglyceride levels are inversely related to insulin action. Diabetes 1997; 46: 983-8.

76 Schick F, Eismann B, Jung WI ef al. Comparison of localized proton NMR signals of skeletal muscle and fat tissue in vivo: two lipid compartments in muscle tissue. Magn Reson Med 1993; 29: 158-67.

77 Boesch C. Slotboom y. Hoppeler $\mathbb{H}$, Kreis $\mathbf{R}$. In vivo determination of intramyocellular lipids in human muscle by means of localized 1H-MR-spectroscopy. Magn Reson Med 1997; 37:484-93.

78 Koopman $R$, Schaart $G$, Hesselink MK. Optimisation of oil red O staining permits combination with immunofluorescence and automated quantification of lipids. Histochem Cell Biol 2001; 116: 63-8.

79 Phillips DI, Caddy S, llic V et a. Intramuscular triglyceride and muscle insulin sensitivity: evidence for a relationship in nondiabetic subjects. Metabolisn 1996; 45: 947-50.

80 Krssak M, Falk Petersen $K$, Dresner $A$ et al. Intramyocellular lipid concentrations are correlated with insulin sensitivity in humans: a $1 \mathrm{H}$. NMR spectroscopy study. Dinbetologia 1999; 42 : 113-6.

81 Perseghin G, Scifo P, De Cobelli F et al. Intramyocellular triglyceride content is a determinant of in vivo insulin resistance in humans: a $1 \mathrm{H}-13 \mathrm{C}$ nuclear magnetic resonance spectroscopy assessment in offspring of type 2 diabetic parents. Diabefes $1999 ; 48: 1600-6$.

82 facob $S$, Machann J, Rett $K$ et al. Association of increased intramyocellular lipid content with insulin resistance in lean nondiabetic offspring of type 2 diabetic subjects. Diabetes $1999 ; 48: 1113-9$.

83 He J, Watkins S, Kelley DE. Skeletal muscle lipid content and oxidative anzym activity in relation to muscle fiber type in type 2 diabetes and obesity. Diaberes 2001 ; 50: $81.7-23$.

84 Malentant $P$, Joanisse DR, Theriault R et al. Fat content in individual muscle fibers of lean and obese subjects. Int / Obes Relat Metab Disord 2001; 25: 1316-21.

85 Bachmann OP, Dahl DB, Brechtel $K$ et al. Effects of intravenous and dietary lipid challenge on intramyocellular lipid content and the relatiom with insulin sensitivity in humans. Diabetes 2001; $50: 2579-84$.

86 Boden $G$, Lebed B, Schatz M, Homko C Lemieux 5 . Effects of acute changes of plasma free fatty acids on intramyocellular fat content and insulin resistance in healthy subjects. Diabetes 2001; 50: 1612-7.

87 Greco AV, Mingrone G. Giancaterini A et al. Insulin resistance in morbid obesity: reversal with intramyocellular fat depletion. Diabetes $2002 ; 51: 144-51$. 
88 Goodpaster BH, He J, Watkins S, Kelley DE. Skelletal muscle lipid content and insulin resistance: evidence for a paradox in endurance-trained athletes. I Clm Endocrinol Medab 2001; 86: 5755-61.

89 Ellis BA, Poynten A, Lowy AJ et al. Long-chain acyl-CoA esters as indicators of lipid metabolism and insulin sensitivity in rat and human muscle. Am / Physiol Endocrinol Metab 2000; 279: E554-60.

90 Prentki M, Corkey $\mathrm{CE}$. Are the beta-cell signaling molecules malonyl-CoA and cystolic long chain acyl-COA implicated in multiple tissue defects of obesity and NIDDM? Diabeles $1996 ; 45: 273-83$.

91 Schmitz-Peiffer C. Signalling aspects of insulin resistance in skeletal muscle: mechanisms induced by lipid oversupply. Cell Signal 2000; 12: 583-94.

92 Blatk EE, Van Baak MA, Kemerink GJ el al. Beta-adrenergic stimulation of energy expenditure and forearm skeletal muscle metabolism in lean and obese men. An I Physiol 1994; 267: E306-15.

93 Colberg SR, Simoneau JA, Thaete FL, Kelley DE. Skeletal muscle utilization of free fatty acids in women with wisceral obesity. $/$ Clin Imost 1995; 95: 1846-53.

94 Kelley DE, Simoneau JA. Impaired free fatty acid utilization by skeletal muscle in mon-insulin-dependent diabetes mellitus. J Chin lnoest 1994; 94: 2349-56.

95. Blaak EE, Wagenmakers A], Clatz IF ef al. Plasma FFA utilization and fatty acidbinding protein content are dininished in type 2 diabetic muscle. Am I Physiol Entocrinol Metab 2000; 279: E146-54.

96 Blaak EE, van Aggel-Leijssen DP, Wagenmakers AJ, Saris WH, van Baak MA. Impaired oxidation of plasma-derived fatty acids in type 2 diabetic subjects during moderate-intensily exercise. Diabetes 2000; 49:2102-7.

97 Blaak EE, Wagennakers AJ. The fate of [U-(13)Clpalmitate extracted by skeletal muscle in subjects with type 2 diabetes and control subjects. Diabetes 2002; 51: 784-9.

98 Kelley DE, Mandarina LJ. Hyperglycemia normalizes insulin-stimulated skeletal muscle glucose oxidation and storage in noninsulin-dependent diabetes mellitus. I Clin Invest 1990; 86: 1999-2007.

99 Mandarino LI. Consoli A, Jain A, Kelley DE. Interaction of carbohydrate and fat fuels in human skeletal muscle: impact of obesity and NIDDM. An / Physial 1996;
270: E463-70.

100 Kelley DE, Goodpaster B, Wing. RR, Simoneau JA. Skeletal muscle fatty acid metabolism in association with insulim resistance, obesity, and weight loss. Am I
Physiol 1999; 277 : E1130-41.

101 Kelley DE, Mandarino LJ. Fuel selection in human skeletal muscle in insulin resistance: a reexamination. Diaber.es 2000; 49:677 83.

102 Simoneau JA, Veerkamp JH, Turcotte LP, Kelley DE. Markers of capacity to utilize fatly acids in human skeletal muscle: relation to insulin resistance and obesity and

103 Blak EE, Wolfenbuttel BH, Saris WH, Pelsers MM, Wagenmakers Al. Weight reduction and the impaired plasma-derived free fatty acid oxidation in type 2

104 Luiken 11 Arum . Findocrimol Metab 2001; 86: 1638-4.4. transporters are related $\mathrm{X}$, Bell RC ot al. Changes in fatty acid transport and Mernb 2002; 283: E612-21. 105 Winder WW. Hardie DG. AMP-activated protein kinase, a metabolic master switch:
possible roles in type 2 diabetes. Am / Phystot 1999; 277: E1-10. 
106 Turpeinen AK, Takala TO, Nuutila $P$ et al Impaired free fatty acid uptake in skeletal muscle but not in myocardium in patients with impaired glucose tolerance: studies with PET and 14(R,S)-[18FIfluoro-6-thia-heptadecanoic acid. Diaberes 1999; 48: 124550.

107 Eriksson J, Lindstron I, Valle T et a. Prevention of Type II diabetes in subjects with imparred glucose tolerance: the Diabetes Prevention Study (DPS) in Finland. Study design and 1-year interim report on the feasibility of the lifestyle intervention programme. Dinbetologia 1999; 42: 793-801.

108 Eriksson J. Tuominen I, Valle Tet al. Aerobic endurance exercise or circuit-type resistance training for individuals with impaired glucose tolerance? Hom Metab Res 1998; 30: $37-41$. 


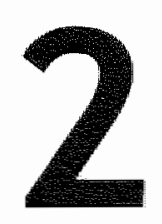

\section{Study on Lifestyle-Intervention and Impaired Glucose Tolerance Maastricht (SLIM): Design and Screening Results}

Marco Mensink, Eefje Corpeleijn, Edith JM Feskens, Margriet Kruijshoop, Wim HM Saris, Tjerk WA de Bruin and Ellen E Blaak

Dept of Human Biology, Nutrition and Toxicology Research Institute NUTRIM, Maastricht University, Maastricht, The Netherland's

Dept of Health and Nutrition, National Institute for Public Health and the Environment, Bilthoven, The Netherlands

Dept of Medicine and Endocrinology, Cardiovascular Research institute CARIM, University Hospital Maastricht, Maastricht, The Netherlands

Diab Res Clin Pract 2003; 61: 49-58 


\begin{abstract}
The Study on Lifestyle-intervention and Impained Glucose Tolerance Maastricht (SLIM) is a 3 year randomized clinical trial designed to evaluate the effect of a combined diet and physical activity intervention program on glucose tolerance in a Dutch population at increased risk for developing type 2 diabetes. Here the design of the lifestyle-intervention study is described and results are presented from the preliminary population screening, conducted between March 1999 and June 2000. In total, 2820 subjects with an increased risk of having disturbances in glucose homeostasis (i.e. age $>40$ years and $B M A l>25 \mathrm{~kg} / \mathrm{m}^{2}$ or a family history of diabetes) underwent a first oral glucose tolerance test (OGTT). Abnormal glucose homeostasis was detected in 826 subjects $(30.4 \%): 226$ type 2 Diabetes (type 2 DM, 8.3\%), 215 impaired Fasting Glucose (IFG, 7.9\%) and 385 Impaired Glucose Tolerance (IGT, 14.2\%). Both increasing age and BMI were strongly related to the prevalence of IGT and diabetes. After a second OGT, 114 subjects with glucose intolerance and in otherwise good health were eligible for participation in the intervention study (SLIM).

The high prevalence of disturbances in glucose homeostasis observed in the preliminary screening underscore the importance of early (lifestyle) interventions in those at risk for developing diabetes. The Study on Lifestyle-intervention and IGT Maastricht (SLIM) will address this topic in the Dutch population.
\end{abstract}


Type 2 diabetes mellitus is rapidly becoming one of the main health issues in the 21st century. Prevalence has explosively increased the last two decades, and global estimates indicate a further rise from a current 150 million people with diabetes, to 300 million in $2025[1,2]$. Impaired glucose tolerance (IGT) is the obligatory transition state preceding type 2 diabetes. Prevalence of IGT varies widely between populations, from as low as $2.0 \%$ in rural populations to more than $20 \%$ in high-risk populations [3]. Cumulative incidence of type 2 diabetes in subjects with IGT ranged from $3.6 \%$ to $8.7 \%$ per year in six prospective studies [4], and is strongly related to the fasting and the 2-hour plasma glucose concentrations at the time of IGT recognition $[4,5]$. Most important modifiable risk factor for progression from IGT to diabetes is obesity. Body Mass Index (BMI) at the time of IGT recognition is a strong predictor of progression, independently of fasting and 2-hour blood glucose concentrations [4]. Dietary factors, especially a high fat intake are also related to the risk of conversion from IGT to diabetes [6].

Several recent studies have reported the feasibility and efficacy of interventions to prevent or delay the progression to type 2 diabetes in subjects with IGT [7-13]. Acarbose [13], as well as metformin [12], have been shown to reduce the incidence of diabetes in a population with IGT. Other studies have focused on the potential of lifestyle changes to reduce the progression rate from IGT to type 2 diabetes. The Finnish Diabetes Prevention Study [11] and the US Diabetes Prevention Program [12] reported that weight-loss, changes in dietary intake, and increased physical activity resulted in a $58 \%$ reduction in the incidence of diabetes after a mean follow-up of only 3 years. Moreover. lifestyle-intervention was much more effective in reducing the incidence of diabetes than pharmacological intervention (i.e. metformin) [12]. It is important to confirm these observations in different populations, with a different dietary and physical activity background, and a different attitude towards changing lifestyle-habits.

The Study on Lifestyle-intervention and Impaired Glucose Tolerance Maastricht (SLIM) is a 3 year randomized clinical trial designed to evaluate the effect of a combined diet and physical activity intervention program on glucose tolerance in a Dutch population at increased risk for developing type 2 diabetes. Furthermore, we will consider changes in anthropometry, aerobic capacity and cardiovascular risk factors. Additional measurements will be performed in subgroups of the study population in search for underlying mechanisms.

The objective of this report is to describe the design of the lifestyle-intervention study and to evaluate the results of the preliminary population screening, from which the subjects were recruited for the intervention study. Data are presented about the prevalence of disturbances in glucose homeostasis in a middle-aged Dutch population.

\section{Methods}

The Study on Lifestyle-intervention and IGT, Maastricht (SLIM), is designed to study whether a diet/physical activity intervention program can improve 
glucose tolerance in subjects with a high risk for developing type 2 diabetes mellitus. Total duration of the study is three years. The Medical Ethical Review Committee of Maastricht University approved the study protocol, and all subjects gave their written informed consent before the start of the study.

\section{Recrutment of subjects}

The recruitment period started March 1999 and was completed at the end of May 2000. Subjects with an increased risk for glucose intolerance, i.e. those of age $>40$ years and a family history of diabetes or a BMI $>25 \mathrm{~kg} / \mathrm{m}^{2}$, were selected from a large existing cohort, monitoring health and disease in the general population [14], and invited to undergo a standard OGTT (glucose load $75 \mathrm{~g}$.)[15]. Blood glucose was measured in capillary blood using the Glucometer Elite (Bayer, Zurich. Schweiz). Furthermore, body weight was measured, without wearing shoes and jackets. Subjects with known diabetes, or those with lasting glucose values $>8.5 \mathrm{mmol} / 1$ did not participate in the OGTT. Those subjects with a 2 -hour blood glucose concentration $>7.8 \mathrm{mmol} / \mathrm{J}$ at the preliminary screening and which were otherwise in good health (i.e. no history of cardiovascular disease, or any (chronic) disease or medication use that makes participation in a lifestyle intervention program impossible) were invited for a second OGTT. During this second OGTT, glucose tolerance was measured in venous plasma. Furthermore a medical history was taken, a physical examination was performed and several additional measurements were performed (see under measurements, below)

For definitive inclusion in the lifestyle-intervention study, mean 2-hour glucose concentration of both OGTTs had to be between 7.8 and $12.5 \mathrm{mmol} / 1$, together with a fasting glucose concentration of less than $7.8 \mathrm{mmol} / 1$. Other inclusion and exclusion criteria for participation in the intervention study are indicated in Table 2.1. To follow changes in glucose tolerance over time, data obtained by the second (venous) OGTT were used as baseline values.

After final recruitment, subjects were randomized to two study groups, the lifestyle intervention group or the control group. Randomization was carried out with stratification for sex and mean 2-hour plasma glucose concentration.

Table 2.1 Inclusion and exclusion criteria lifestyle-intervention study

$\begin{aligned} \text { Inclusion criteria: } & \text { Mean } 2 \text {-hour blood glucose } \geq 7.8 \text { and } \leq 12.5 \mathrm{mmol} / \mathrm{l} \\ & \text { Mean fasting blood glucose } \leq 7.8 \mathrm{mmol} / \mathrm{l} \\ & \text { Caucasian } \\ & \text { Age } 40-70 \text { years }\end{aligned}$

\section{Exclusion criteria: Known diabetes mellitus}

Mean 2-hour blood glucose $>12.5 \mathrm{mmol} / \mathrm{l}$

Mean fasting blood glucose $>7.8 \mathrm{mmol} / \mathrm{l}$

Any chronic illness that makes 5-year survival improbable, or that interferes with glucose tolerance, or makes participation in a lifestyle-intervention impossible

Medication known to interfere with glucose tolerance

Participation in a vigorous exercise and/or diet program 
It was calculated, according the preliminary results after 1 year of the finm DPS [16], that 50-60 subjects per group would be sufficient to deted a 1.0 mmol/1 difference in 2 -hour glucose concentration between groups.

\section{Lifestyle-intervention program}

The intervention program consists of a dietary and physical activity part. Dietary recommendations are based on the Dutch guidelines for a healthy diet (Dutch Nutrition Council, 1992, see Table 2.2). Participants are encouraged to stop smoking and, if necessary, to reduce alcohol intake. Dietary advice is given at regular intervals by a skilled dietician on an individual basis after consideration of a 3-day food record. (see Table 2.2). A body weight loss of 5-7\% is the objective. If subjects do not loose weight on this regimen during the first year, a mild energy restriction is prescribed during the second year. No verylow calorie diet or dietary products are used to loose weight.

Subjects are stimulated to increase their level of physical activity to at least 30 minutes of moderate physical activity a day for at least 5 days a week 117 . Individual advice is given on how to increase daily physical activity (walking, cycling, swimming), and goals are set. Furthermore, subjects are encouraged to participate in an exercise program, especially designed for this study, including components of aerobic exercise training and components of resistance training [18]. Subjects have free access to these training sessions, and are stimulated to

Table 2.2 Details of the dietary intervention

\begin{tabular}{|c|c|c|}
\hline \multicolumn{3}{|c|}{ Dietary Guidelines } \\
\hline & Carbohydrates: & \pm 55 Energy $\%$ \\
\hline & & max. 15-25 Energy\% mono-and di-saccharides \\
\hline & Fat: & 30-35 Energy\% \\
\hline & & $\leq 10$ Energy $\%$ saturated fatty acids \\
\hline & & $<33 \mathrm{mg} / \mathrm{MJ}$ cholesterol, maximal $300 \mathrm{mg}$ a day \\
\hline & Proteins: & 10-15 Energy\% \\
\hline & & $\pm 0.8 \mathrm{~g} / \mathrm{kg}$ bodyweight \\
\hline & Fiber: & $>3 \mathrm{~g} / \mathrm{MJ}$ a day \\
\hline Visit & Tilme & Visit and Topic \\
\hline 1 & 0 & Baseline visit \\
\hline 2 & 4-6 weeks & Discussion baseline food record \\
\hline 3 & 3 months & Fat' \\
\hline 4 & 6 months & 'Carbohydrates' \\
\hline 5 & 9 months & Group-session: "label-reading and 'novel foods' \\
\hline 6 & 12 months & One-Year meeting \\
\hline 7 & 15 months & "Artificial sweeteners" \\
\hline 8 & 18 months & "Special occasions, e.g. a party" \\
\hline 9 & 21 months & Group session: 'a dietary game' \\
\hline 10 & 24 months & Two-Year neeting \\
\hline 11 & 27 monthis & "Vegetarian food" \\
\hline 12 & 30 monthis & "Vitamins and minerals' \\
\hline 13 & 33 months & Group-session: 'ifestyle and diabetes' \\
\hline 14 & 36 months & Three-Year meeting \\
\hline
\end{tabular}


participate at least one hour a week. Participation to the exercise sessions is recorded. Subjects in the control group are informed, orally and written, about the beneficial effects of a healthy diet, weight loss and increased physical activity, whereas no individual advises or programs are provided. No additional appointments are scheduled, apart from the annual visits for followup measurements.

\section{Measurements}

At the start of the study, and every year thereafter several measurements are performed, in both the intervention and control group.

A standard OGTT is performed every year, according to the guidelines described by the WHO [15]. Venous blood samples are immediately centrifuged and plasma is frozen at $-80^{\circ} \mathrm{C}$ until analysis. Plasma glucose and FFA concentrations are measured with a standard enzymatic techniques (Glucose HK 125, ABX diagnostics, Montpellier, France; FFA-C test kit, Wako chemicals, Neuss, Germany, respectively). Plasma insulin concentration is measured with an ELISA assay (Mercodia, Uppsala, Sweden), which shows no cross-reactivity with pro-insulin. Glycated haemoglobin $(\mathrm{HbA})$ is determined with the HPLC technique (reference value for our laboratory $4.4-6.2 \%$ ). Insulin sensitivity is estimated with the HOMA-index and insulin secretion with the insulinogenic index 30 (Insulin30-Insulino)/(glucose 30-glucose0)[19]. Blood lipids are measured with standard enzymatic techniques in fasting serum samples (triglycerides: Sigma, St Louis, USA; cholesterol: cholesterol 100, ABX diagnostics, Montpellier, France; HDL: HDL C Roche, Indianapolis, USA). LDL cholesterol is calculated according to the formula of Friedewald [20].

Body weight is measured on an electronical scale. BMI is calculated as the ratio of weight and height squared $\left(\mathrm{kg} / \mathrm{m}^{2}\right)$. Skinfold measurements are performed to calculate fat mass, fat free mass and body fat percentage [21]. Waist circumference (waist) is measured at the level midway between the lowest rib and the illiacal crest. Hip circumference is measured as the maximum circumference over the buttocks. Sagittal and transverse abdominal diameter are measured with the subject in a recumbent position, at the level of the crista iliaca using a sliding beam caliper.

To evaluate changes in aerobical fitness, an incremental exhaustive exercise test is performed on an electronically braked bicycle ergometer (Lode Excalibur, Groningen, the Netherlands). The test starts at a workload of $0.75 \mathrm{~W} / \mathrm{kgFFM}$ for
3 minutes, followed by 3 minutes at $1.5 \mathrm{~W} / \mathrm{kgFFM}$. Subsequently, workload is
increased every 3 minutes by $0.5 \mathrm{~W} / \mathrm{kgFFM}$. increased every 3 minutes by $0.5 \mathrm{~W} / \mathrm{kgFFM}$ until exhaustion. $\mathrm{O}_{2}$ consumption and $\mathrm{CO}_{2}$ production are measured with an $\mathrm{Oxy}$ con-Beta (Mijhard, Breda, the

At every (ammual) visit a physical examination is performed, including reconding a 12 -lead resting ECG. Blood pressure is measured twice on the right arm with a standard sphygmomanometer, after at least $10 \mathrm{~min}$ of rest. Subjects the morning of the measurements. A 3-day food record not to take these at weekend day) is kept at the start of the day food record (two weekdays and 1 
records are checked by a dietician and intake of nutrients is calculated with a computer program according to the Dutch food table.

\section{Outcome}

Primary outcome measure is the change in glucose tolerance (i.e. 2-hour blood glucose), one of the most important risk factors for progression to diabetes [4]. Secondary outcome measures are changes in fasting plasma glucose concentration, plasma insulin concentration, insulin resistance, $\mathrm{Hb} \mathrm{A}_{1}$ and changes in body weight, body composition and $\mathrm{VO}_{2}$ max. Furthermore changes in cardiovascular risk factors are assessed (blood pressure and blood lipid profile).

\section{Statistical analysis}

Data from the intervention study are analyzed according to the intention-tom treat principle. Differences between groups (over time) are analyzed by umpaired totests or ANOVA (repeated measures). Level of significance is set at 0.05. Results of the preliminary screening were analyzed with ANOVA (differences between categories) and Chi-square-testing (Frequency distribution of disturbances in glucose homeostasis).

\section{Results}

\section{Subjects}

In total 6108 subjects were invited to participate in the preliminary screening. Of those, 2820 subjects were willing to participate in this -first- oral glucose tolerance test (OGTT). Non-response was observed in 3288 cases $(53.8 \%)$. Mean age of the non-responders was $55.7 \pm 0.1$ year, which was significant lower compared to the responders ( $\mathrm{n}=2820$; age $56.8 \pm 0.1 ; \mathrm{P}<0.001$ ). No difference was seen in sex between responders and non-responders $(50.6 \%$ male vs. $50.9 \%$ male respectively $P=n s)$. After considering the selection criteria, 379 men and women were invited for the second OGTT, of whom 177 were willing to do so. Finally, 114 subjects, 64 men and 50 women, were included in the lifestyle intervention study (SLIM).

\section{Preliminary screening}

From the 2820 subjects participating in the screening OGTT, 105 were excluded from the analysis: 48 because of recently diagnosed diabetes; 57 because of noncaucasian ethnicity, non-fasting state, or incomplete data. Results from the remaining 2715 subjects are depicted in Table 2.3. WHO criteria of 1999 for capilary plasma were applied, as the glucometer Elite measures glucose levels equivalent to capillary plasma [15]. Abnormal glucose homeostasis was detected in 826 subjects $(30.4 \%): 226$ subjects with type 2 diabetes (type 2 DM, 8.3\%), 215 with Impaired Fasting Glucose (IFG, 7.9\%) and 385 with Impaired Glucose Tolerance (IGT, $14.2 \%)$. Of the latter group, almost two-third $(\mathrm{n}=244)$ had normal fasting glucose (NFG/IGT) and one-third $(n=141)$ impaired fasting 
Table 2.3 Results of the preliminary screening $(n=2715)$

\begin{tabular}{lcccccc}
\hline & & NGT & IFG & IGT & type 2 DNA & P-value \\
\hline number & $($ \% $(\mathrm{n}))$ & $69.9(1889)$ & $7.9(215)$ & $14.2(385)$ & $8.3(226)$ & \\
sex & $($ \%mate) & 47.5 & 61.2 & 49.1 & 67.8 & $<0.0001$ \\
age & $($ year) & $55.9 \pm 0.2$ & $58.8 \pm 0.4$ & $57.1 \pm 0.5$ & $59.8 \pm 0.4$ & $<0.0001$ \\
BMh & $\left(\mathrm{kg} / \mathrm{m}^{2}\right)$ & $28.0 \pm 0.1$ & $29.7 \pm 0.3$ & $29.5 \pm 0.2$ & $30.6 \pm 0.3$ & $<0.0001$ \\
FBG & $(\mathrm{mmol} / \mathrm{l})$ & $5.2 \pm 0.1$ & $6.3 \pm 0.1$ & $5.8 \pm 0.1$ & $7.4 \pm 0.1$ & $<0.0001$ \\
2h BG & $(\mathrm{mmol} / \mathrm{l})$ & $6.5 \pm 0.1$ & $6.8 \pm 0.1$ & $10.1 \pm 0.1$ & $13.0 \pm 0.2^{*}$ & $<0.0001$ \\
\hline
\end{tabular}

Data are mean * sem; $\mathrm{FBG}=$ Fasting Blood Glucose, $2 \mathrm{~h}$ BG = 2-mour Blood Glucose; + MNOWA, comparison of frequencies was done by a Chilsuare test; subjects with fasting glucose $>8.5 \mathrm{mmol} / \mathrm{t}$ did not underwent an oGIT $(n=28)$

glucose (IFG/IGT). Prevalence of type 2 DM and IFG was higher among men than women. A strong upward trend for age and BMI was seen from NGT to

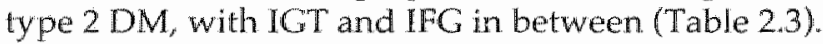

In Table 2.4 the prevalence of NGT, IFG, IGT and type $2 \mathrm{DM}$ is given for age and BMI groups, for men and women separately. In both men and women, prevalence of disturbed glucose homeostasis increased with age, except for IFG which reached the highest prevalence in the age group of 55-59 years. In the population of 65 years and older only $55.5 \%$ of the men and $63.5 \%$ of the women had normal glucose homeostasis. In men and women with a BMI above $30 \mathrm{~kg} / \mathrm{m}^{2}$, diabetes was three times more prevalent and $1 F G$ and $1 G T$ were two times more prevalent, compared to those with a BMI below $27 \mathrm{~kg} / \mathrm{m}^{2}$. Prevalence of newly diagnosed diabetes was almost two times higher in men than in women in each BMI and age group. Likewise, IFG was 1.5 times more frequent in men than in women, which was most pronounced in the age groups below 55 years. Additionally, more women were normoglycemic compared to men $(P<0.001)$.

Table 2.4 Prevalence of disturbances in glucose homeostasis according to age and BAI groups, for men and women separately $(n=2715)$

\begin{tabular}{|c|c|c|c|c|c|c|c|c|c|c|}
\hline & \multicolumn{5}{|c|}{ MEN } & \multicolumn{5}{|c|}{ WOMEN } \\
\hline & $n$ & $\operatorname{DM}(\%)$ & $\operatorname{IGT}(\%)$ & IFG $(\%)$ & NGT $(\%)$ & n & $D M(\%)$ & IGT (\%) & $\operatorname{IFG}(\%)$ & NGT $(\%)$ \\
\hline \multicolumn{11}{|c|}{ (n) } \\
\hline$<50$ & 289 & 6.6 & 8.0 & 6.2 & 79.2 & 254 & 0.8 & 9.1 & 2.4 & 87.8 \\
\hline 50.54 & 256 & 7.8 & 10.2 & 13.7 & 68.4 & 252 & 2.4 & 13.9 & 6.7 & 77.0 \\
\hline $55-59$ & 289 & 11.1 & 14.5 & 12.5 & 61.9 & 281 & 6.8 & 14.6 & 7.8 & 70.8 \\
\hline $60 \cdot 64$ & 301 & 14.0 & 16.3 & 9.0 & 60.8 & 322 & 8.6 & 15.8 & 6.8 & 70.5 \\
\hline$\geq 65$ & 238 & 16.8 & 20.6 & 7.1 & 55.5 & 233 & 10.3 & 19.7 & 6.4 & 63.5 \\
\hline \multicolumn{11}{|l|}{$\begin{array}{l}\text { BMII } \\
<27\end{array}$} \\
\hline$<27$ & 477 & 6.7 & 10.5 & 6.1 & 76.7 & 515 & 3.1 & 10.1 & 4.1 & 82.7 \\
\hline $27 \cdot 30$ & 484 & 8.9 & 10.5 & 9.7 & 70.9 & 415 & 4.1 & 15.7 & 5.5 & 74.7 \\
\hline$\geq 30$ & 412 & 18.9 & 21.4 & 13.8 & 45.9 & 412 & 9.7 & 19.2 & 9.2 & 61.9 \\
\hline Total & 1373 & 11.1 & 13.8 & 9.7 & 65.4 & 1342 & $5.4^{4 * k}$ & 14.6 & $6.1^{*}$ & $73.8^{* * *}$ \\
\hline
\end{tabular}




\section{Discussion}

\section{Lifestyle-intervention}

Justification of lifestyle-intervention studies is that they may prevent or postpone the onset of type 2 diabetes and related complications. Both, the Finnish Diabetes Prevention Study (DPS) and the U.S. Diabettes Prevention Program (DPP) reported that changing dietary and physical activity habits reduce the incidence of diabetes by about 58\% [11,12]. Confirmation of these results in different populations is important. SLM will consider this in a middle-aged Dutch population at increased risk for diabetes. The Dutch population has a low prevalence of obesity [22], and Dutch subjects are known for their relatively high level of physical activity. In 1997 slightly more than one-half of the population was, on average, moderately active for more than half an hour per day [23], compared to about one-third of the US adults [24]. As obesity and physical activity are important factors associated with diabetes, it is important to known whether lifestyle-changes result in a comparable risk reduction in the Dutch population as in the Finnish and American population.

Dietary and physical activity intervention strategies are combined, as earliev reports indicated that the combination is most effective $[25,26]$. The intervention strategy in this randomized study is based on general public health recommendations for nutritional intake and physical activity. A regimen, based on general recommendations, is much more suitable to prevent diabetes, as it is less time consuming and much better tolerated than very intensive intervention programs. Furthermore, we will perform additional measurements in small subgroups of the intervention and control population ( $n=10$ per group) using stable isotopes, indirect calorimetry and muscle biopsies. Since type 2 diabetes and IGT are characterized by disturbances in (skeletall muscle) fatty acid uptake and oxidation [27-29], the question will be addressed whether changes in glucose tolerance are accompanied by changes in (skeletal muscle) fatty acid metabolism. These additional measurements could identify some of the mechanisms underlying the development of insulin resistance and lype 2 diabetes mellitus.

\section{Methodological considerations}

Participation rate was relatively low in the present study, approximately $50 \%$ As subjects were selected from an ongoing monitoring project for health and disease, some 'research-fatigue' could not be excluded, and this could have led to some selection-bias. Classification of the subjects was based on a single OGTT (with the glucometer Elite), and was not confirmed by repeated testing as recommended. Some misclassification might have occurred because of the known high intra-individual variability in glucose levels. However a previous Dutch study showed that the prevalence of IGT and diabetes was not different between the first and the second test [30]. Only when the diagnosis was based on meeting classification criteria at both OGTTs, prevalence decreased. Finally, we tested the consistency in classification between measurements made with 
the glucometer Elite and measurements made with a standard enzymatic technique in venous plasma. Consistency in classification according to the WHO criteria was good $(69 \%$, kappa $0.55, \mathrm{P}<0.001 ; \mathrm{n}=245$; ref. $[31])$.

\section{Preliminary screening}

The results of the preliminary screening confirm the high-risk profile of the population under study. Three out of every ten subjects had a disturbed glucose homeostasis, which is quite comparable with the results reported in the STOPNIDDM trial, also a screening in a high-risk population [32]. Prevalence of IGT and newly diagnosed diabetes in the screening population was higher than reported in the Dutch Hoorn Study over the period 1989-1992 (10.3\% for IGT and $4.8 \%$ for newly diagnosed diabetes [33]). This may reflect the (world-wide) increasing prevalence of disturbances in glucose homeostasis [1], and parallels the increasing prevalence of obesity reported in the Dutch population [22]. However, in the Hoorn Study the old WHO-criteria (1985) were used. Since the fasting glucose level for the diagnosis of diabetes is reduced, this could partly explain the higher prevalence of diabetes in our study, but not the higher prevalence of IGT.

In line with other populations, the present study confirmed that IGT is considerably more prevalent than IFG, and that overlap between the two categories is limited [3]. This limited overlap points towards the difference in metabolic background: IGT is primarily associated with insulin resistance while IFG is associated with a more pronounced defect in insulin secretion and endogenous glucose output [34].

A strong positive relation was observed between increasing age and prevalence of IGT and diabetes. For IFG, the highest prevalence was seen in middle-aged subjects ( $55-59$ year). This is a consistent finding in European populations, particularly among men [3]. The prevalence of disturbances in glucose homeostasis was almost twofold higher in the group with a BMI $>30 \mathrm{~kg} / \mathrm{m}^{2}$ compared to those with a BMI $<30 \mathrm{~kg} / \mathrm{m}^{2}$. This underscores earlier reports, showing dramatic increases in relative risk of diabetes in the highest BMI
groups, compared to the lowest BMI group [35].

Type 2 diabetes is generally more prevalent in women compared to men [1]. In contrast, we observed a prevalence of diabetes being (two times) higher in BMI was reported to be all BMI and age groups. In the Finnmark study [36], however, the relation was dominant risk factor for both sexes. In women, height, HDL, glucose, smoking and phed by other factors as blood pressure, to over-all adiposity, body fat distribul activity. Furthermore, in addition diabetes [35]. Thus, differences in tistribution is an important risk factor for underlie the observed higher prevalence factors, beside age and BMI, can study.

\section{Conclusion}

The high prevalence of disturbances in glucose homeostasis observed in the preliminary screening underscore the importance of early interventions in those 
at risk for developing diabetes. Changes in dietary habits and physical activity have shown to reduce the incidence of diabetes. Additional studies are required to confirm these results in different populations with a different dietary and physical activity background. The Study on Lifestyle-intervention and IGT Maastricht (SLIM) will address this question in the Dutch population.

\section{Acknowledgements}

We are grateful to Rob van. Dam, Tanja Hermans-Limpens, and Ilse Nijs for their work during the preliminary screening. This study is supported by grants from the Netherlands Organization for Scientific Research (ZonMW: 940-35034) and the Dutch Diabetes Research Foundation (DFN: 98.901).

\section{References}

1 King H, Aubert RE, Herman WH. Global burden of diabetes, 1995-2025: prevalence, numerical estimates, and projections. Diabetes Care 1998; 21: 1414-31.

2 Zimmet P. Alberti $K G$, Shaw J. Global and societal implications of the diabetes epidemic. Nature 2001; 414: 782-7.

3 Unwin N, Shaw J, Zimmet P. Alberti KG. Impaired glucose tolerance and impaired fasting glycaemia: the current status on definition and untervention. Diabet Mod 2002: 19: 708-23.

4 Edelstein SL, Knowler WC, Bain RP et al. Predictors of progression from impaired glucose tolerance to NIDDM: an analysis of six prospective studies. Diabetes 1997; 46: 701-10.

5 de Vegt F, Dekker JM, Jager A of al. Rellation of impaired fasting and postload glucose with incident type 2 diabetes in a Dutch population: The Hoorn Study. IAMA 2001; 285: 2109-13.

6 Marshall JA, Hoag S, Shetterly S, Famman RF. Dietary fat predicts conversion from impaired glucose tolerance to NIDDM. The San Luis Valley Diabetes Study. Dinbetes Care 1994; 17: 50-6.

7 Eriksson KF, Lindgarde F. Prevention of type 2 (non-insulin-dependent) diabetes mellitus by diet and physical exercise. The 6-year Malmo reasibilily study. Diabetologin 1991; 34: 891-8.

8 Page RC, Harnden KE, Cook JT, Turner RC. Can life-styles of subjects with impaired glucose tolerance be changed? A feasibility study. Diabes Med 1992; 9:562-6.

9 Bourn DM, Mann II, McSkimming BI, Waldron MA, Wishart JD. Impaired glucose tolerance and NIDDM: does a lifestyle intervention program have an effect? Diabetes Cane 1994; 17: 1311-9.

10 Pan XR, Li GW, Hu YH et al. Effects of diet and exercise in preventing NIDDM in people with impaired glucose tolerance. The Da Qing IGT and Diabetes Study. Diabetes Cure 1997; 20: 537-44.

11. Tuomilehto I, Lindstrom I, Eriksson JG al. Prevention of type 2 diabetes mellitus by changes in lifestyle among subjects with impaired glucose tolerance. $N$ Eng/ / Med 2001; 344: 1343-50.

12 Knowler WC, Barrett-Connor $\mathbb{E}$, Fowler SE et al. Reduction in the incidence of type 2 diabetes with lifestyle intervention or metrormin. N Engl / Mod 2002; 346: 393-403.

13 Chiasson JL, Josse RG, Gomis R et al. Acarbose for prevention of type 2 diabetes mellitus: the STOP-NIDDM randomized trial. Lancet 2002; 359: 2072-7. 
14 van Dam RM, Boer JM, Feskens EJ, Seidell IC. Parental history of diabetes modifies the association betweer abdominal adiposity and hyperglycemia. Diabetes Care $2001 ; 24: 1454-9$.

15 World Heath Organization. Defintion, diagnosis and classification of diabetes mellitus. Report of a WHO Consultation. Part 1: Diagnosis and Classification of Diabetes Mellitus. Geneva, Switzerland, 1999. Publication WHO/NCD/NCS/99.2.

I6 Eriksson I, Lindstrom I, Valle T ef at. Prevention of type II diabetes in subjects with impaired glucose tolerance: the Diabetes Prevention Study (DPS) in Finland. Study design and 1 -year interim report on the feasibility of the lifestyle intervention programme. Diabotologia 1999; $42: 793-801$.

17 American College of Sports Medicine Position Stand. The recommended quantity and quality of exercise for developing and maintaining cardiorespiratory and muscular fitness, and flexibility in healthy adults. Med Sci Sports Exerc 1998; 30: 975 91.

18 Eriksson 1, Tuominen J, Valle T et al. Aerobic endurance exercise or circuit-type resistance training for individuals with impaired glucose tolerance? Hom Metab Res 1998; 30: $37-41$.

19 Albareda M, Rodriguez-Espinosa J, Murugo $M$, de Leiwa $A$, Corcoy $\mathbb{R}$. Assessment of insulin sensitivity and beta-cell function from measurements in the fasting state and during an oral glucose tolerance test. Diabetologia 2000; 43: 1507-11.

20 Friedewald WVT, Levy RI, Fredrickson DS. Estimation of the concentration of lowdensity lipoprotein cholesterol in plasma, without use of the preparative ultracentrifuge. Clin Chem 1972; 18:499-502.

21 Durnin IV. Womersley J. Body rat assessed from total body density and its estimation from skinfold thickness: measurements on 481 men and women aged from 16 to 72 years. Br / Nutr 1974:32:77-97.

22 Visscher TL, Kromhout D, Seidell KC. Long-term and recent time trends in the prevalence of obesity among Dutch men and women. Int I Obes Redat Metab Disord 2002; $26: 1218-24$.

23 Schuit AJ, Feskens EJ, Seidell JC. [Physical activity in relation to sociodemographic variables and health sitatus of adult men and women in Amsterdan, Doetinchem
and Mastricht. Ned Tijdsch Geneeskd 1999; 143: 1559-64.

24 Jones DA, Ainsworth BE, Croft JB et al. Moderate leisure-time physical activity: who is meeting the public health recommendations? A national cross-sectional study.
Arch Fan Med $1998 ; 7: 285-9$.

25 Torjesen PA, Birkeland $\mathrm{KI}$, Anderssen SA et a. Lifestyle changes may reverse development of the insulin resistance syndrome. The Oslo Diet and Exercise Study:
a randomized trial. Dinbefes Care 1997; 20:26-31.

26 Li G, Hu $Y$, Yang $W$ tal. Effects of insulin resistance and insulin secretion on the efficacy of interventions to retard development of type 2 diabetes mellitus: the DA
Qing IGT and Diabetes Study. Diabetes Res Clin Pract 2002; 58 : 193-200.

27 Kelley DE, simoneau IA. Impaired free faty acid utilization by skeletal muscle in non-insulin-dependent diabetes mellitus. J Chn hoest 1994; 94: 2349-56.

28 Blaak EE, Wagenmakers AJ, Glatz JF ot al. Plasma FFA utilization and fatty acidbinding protein content are diminished in type 2 diabetic muscle. Am / Physiol
Endocmol Mofab 2000; 279: E146-54.

29 Mensink M, Blak EE, van Baak MA, Wagenmakers AJ, Saris WH. Plasma free Fatty Acid uptake and oxidation are already diminished in subjects at high risk for
developing type 2 diabetes. Dinbetes $2001 ; 50: 2548-54$. 
30 Mooy JM, Grootenhuis PA, de Vries $H$ et al. Intra-individual variation of glucosen, specific insulin and proinsulin concentrations measured by two oral glucose tolerance tests in a general Caucasian population: the Hoorn Study. Diabltologin 1996; 39: 298-305.

31 Kruijshoop M, Feskens EJM, Blaak EE, Heine RI, de Bruin TWA. Validation of capillary glucose measurements to detect type 2 diabetes mellitus in the general population: The CoDAM-study. Diabelologia 2002; 42: A98 (abstract).

32 Chiasson JL, Gomis R, Hanefeld M ef al. The STOP-NDDDM Trial: an international study on the efficacy of an alpha-glucosidase inhibitor to prevent type 2 diabetes in a population with impaired glucose tolerance: rationale, design, and preliminary screening data. Study to Prevent Non-Insulin-Dependent Diabetes Mellitus. Diabetes Care 1998; 21: 1720-5.

33 Mooy JM. Grootenhuis PA, de Vries Het al. Prevalence and determinants of glucose intolerance in a Dutch caucasian population. The Hoorn Study. Dinbetes Care 1995; 18: $1270-3$.

34 Weyer C, Bogardus C, Pratley RE. Metabolic characteristics of individuals with impaired fasting glucose and for impaired glucose tolerance. Diabetes 1999; 48: 2197. 203.

35 Chan JM, Rimm EB, Colditz GA, Stampler MJ, Willett WC. Obesity, fat distribution, and weight gain as risk factors for clinical diabetes in men. Diabetes Care 1994; 17: $961-9$.

36 Njolstad I, Arnesen E, Lund-Larsen PG. Sex differences in risk factors for clinical diabetes mellitus in a general population: a 12-year follow-up of the Finmmark Study. Am J Epidennol 1998; 147: 49-58. 


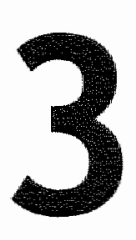

\title{
Subscapular Skinfold Thickness Distinguishes between Transient and Persistent Impaired Glucose Tolerance
}

\author{
Marco Mensink, Edith JM Feskens, Margriet Kruijshoop, \\ Tjerk WA de Bruin, Wim HM Saris and Ellen E Blaak
}

Dept of Human Biology, Nutrition and Toxicology Research institute NUTRIM, Maastricht University, Maastricht, The Netherlands

Dept of Health and Nutrition, National Institute for Public Health and the Environment, Bilthoven, The Netherlands

Dept of Medicine and Endocrinology, Cardiovascular Research Institute CARIM, University Haspital Maastricht, Maastricht, The Netherlands

Diabetic Medicine 2003; 20: 552-557 


\begin{abstract}
The aim of this study was to assess whether adding anthropometric measurements to an oral glucose tolerance test (OGTT) may improve the distinction between transient and persistent IGT. Study subjects were recruited from the SLIM-cohort (Study on Lifestyle-Intervention and IGT Maastricht), a study designed to evaluate whether diet and physical activity intervention can improve glucose tolerance in subjects at risk for diabetes. 108 Subjects with impaired glucose tolerance (IGT) underwent a repeated OGTT 2.4 months after the initial OGTT. According to the second test, subjects were classified as transient IGT, or persistent IGT. Anthropometric measurements, including BMI, waist and hip circumference, sagittal and transverse abdominal diameters and skinfold thickness measurements were done during the second OGTT. Persistent IGT was diagnosed in 47 subjects $(44 \%)$, transient IGT in 40 (37\%), impaired fasting glucose in 8 subjects $(7 \%)$ and diabetes in 13 cases $(12 \%)$. 2-Hour blood glucose levels at the initial OGTT and subscapular skinfold thickness were significantly higher in subjects with persistent IGT (2-hour blood glucose: $9.8 \pm 0.1 \mathrm{mmol} / \mathrm{l}$ vs. $10.2 \pm 0.1 \mathrm{mmol} / \mathrm{L}$ for transient $1 \mathrm{GT}$ and persistent IGT respectively; subscapular skinfold thickness: $25.4 \pm 1.4 \mathrm{~mm}$ vs. $29.8 \pm 1.2 \mathrm{~mm}$ for transient IGT and persistent IGT respectively). After adjustment for age, sex and family history of DM, logistic regression indicated that 2 -hour blood glucose level during the initial OGTT represented the strongest predictor of persistent IGT $(P<0.02)$, followed by subscapultar skinfold thickness $(P<0.05)$. After adjustment for 2 -hour blood glucose levels during the first OGTT, subscapular skinfold thickness remained significantly associated with persistent IGT IOR 1.84; $P<0.05)$.

In conclusion, beside 2 -hour blood glucose level, subscapular skinfold thickness was the best predictor of persistent $16 \pi$, suggesting that adding simple anthropometric measures to oral glucose tolerance testing may improve the distinction between persistent and transient glucose intolerance.
\end{abstract}


Impaired glucose tolerance (IGT) is considered a necessary state en route to type 2 diabetes mellitus. Prevalence of IGT varies widely between populations, from as low of $2.0 \%$ in rural populations to more than $20 \%$ in high-risk populations [1]. Cumulative incidence of diabetes ranges from $23 \%$ up to $63 \%$ among subjects with IGT [2], and is strongly dependent on baseline fasting and 2-hour glucose concentration [3]. Furthermore, IGT is associated with adverse cardiovascular risk factors, leading to an increased risk for the development of cardiovascular disease [4,5]. Therefore, subjects with IGT benefit from (arry) lifestyle-interventions, aimed at the prevention or delay of progression to type 2 diabetes mellitus and cardiovascullar disease $[6,7]$.

IGT can be identified with an oral glucose tolerance test (OGTT). However, about $50 \%$ of the subjects revert to nomal glucose tolerance at re-testing; indicating a poor reproducibility $[8,9]$. Subjects with IGT on both occasions, known as persistent IGT, have a higher risk of developing diabetes compared to those returning to normal glucose tolerance at re-testing (transient $1 \mathrm{GT}$ ) [10,11]. In line with this, subjects with persistent IGT demonstrated loss of the first phase insulin response as an early indicator of beta cell dysfunction while subjects with transient IGT had a normal insulin response [12]. With regard to prevention, il would be useful to distinguish on the basis of one single glucose tolerance test between persistent and transient glucose intolerance. This enables an intervention program to be target those who are at the greatest risk of progression to type 2 diabetes mellitus.

Only a few studies have tried to identify additional factors improving distinction between transient IGT and persistent IGT $[11,13,14]$. The most important predictors were 2-hour blood glucose level, hyperinsulinemia, and over-all obesity (i.e. BMI). However, it has been recognized that not only total body fat content but also body fat distribution, especially an abdominal fat distribution, is an important risk factor for the development of type 2 diabetes mellitus [15-17]. Simple anthropometric measures (e.g. waist circumference, skinfold thickness) could provide additional information to measures of overall body fat content (i.e. BMI), and may have potential predictive value in distinguishing between persistent and transient IGT. Indeed, it has been shown that concurrent use of simple anthropometric assessments may provide a more complete picture of risk of abnormal glucose and insulin regulation [18].

The purpose of the present study was to assess whether adding single or multiple anthropometric measurements, to oral glucose tolerance testing improves the distinction between transient and persistent IGT in middle-aged men and women. Body mass index (BMI), waist and hip circumference, waistto-hip ratio, sagittal and transverse abdominal diameter and skinfold thickness. were used as anthropometric measures.

\section{Material and Methods}

\section{Study Design}

The SLIM-project (Study on Lifestyle-intervention and IGT, Maastricht) is a randomized controlled trial, designed to study whether 3 year diet/physical 
activity intervention program can improve glucose tolerance and prevent type 2 diabetes in subjects with IGT. The study design is described elsewhere (Chapter 2 and ref $[19]$ ). In brief, subjects with an elevated risk for the presence of disturbances in glucose tolerance (age $>40$ and/or a family history of diabetes). but no known diabetes mellitus, were selected from an existing cohort, monitoring health and disease in the Mastricht population, and invited to undergo a first oral glucose tolerance test. Subjects with a capillary 2 -hour glucose levels $>7.8 \mathrm{mmol} / 1$, in otherwise good health, from caucasian ethnicity and willing to participate (after final inclusion) in a lifestyle-intervention program, were invited for a second OGTT $(n=177)$. During the second OGTT several anthropometric measures were performed (see below) and a physical examination was performed. Final inchusion in the intervention study was based on results of both OGTTS in combination with several exclusion criteria.

In this paper we describe the results of 108 subjects with IGT at the first OGTT, who underwent a second OGTT within 2-4 months after the initial test. Subject with impaired fasting glucose (IFG), newly diagnosed type 2 diabetes and high normal values at the first OGTT were excluded from this analysis $(n=69)$. In total, results are described from 57 men (age $57.4 \pm 1.0$ yr., BMI $29.2 \pm 0.5$ $\mathrm{kg} / \mathrm{m}^{2}$ ) and 51 women (age $55.1 \pm 1.1 \mathrm{yr}, \mathrm{BMI} 29.3 \pm 0.5 \mathrm{~kg} / \mathrm{m}^{2}$ ). The Medical Ethical Review Committee of Maastricht University approved the study protocol, and all subjects gave their written informed consent before the start of the study.

\section{Glucose tolerance testing}

Glucose tolerance was tested with a standard oral glucose tolerance test (OGTT). After an ovenight fast (10-12 hour) subjects reported to the laboratory by car or by bus. Fasting blood samples were drawn, after which the subjects received the glucose load $75 \mathrm{~g}$ glucose, dissolved in $250 \mathrm{ml}$ water, AVEBE, The Netherlands). After $2 \mathrm{~h}$ another blood sample was drawn. During the initial OGTT capillary blood was collected, and blood glucose level was determined with a glucometer Elite (Bayer, Germany). Test strips are calibrated to give results equivalent to capillary plasma; this means that $I G T$ is defined as fasting $<7.0 \mathrm{mmol} / 1$ and 2 -hour $>8.9 \mathrm{mmol} / \mathrm{l}$, but $<12.2 \mathrm{mmol} / \mathrm{l}$ according to the WHO [20]. During the second test, blood glucose levels were determined in venous plasma with a standard enzymatic technique automated on the Cobas Fara centrifugal analyzer at $340 \mathrm{~mm}$ (Roche Unikit III. Hoffman-La Roche, Basel, Switzerland). During the second OGTT a lasting blood sample was drawn to laboratory $4.4-6.2 \%$

It is known that glucose levels are higher in capillary blood compared to venous blood or plasma. To validate this approach we measured the consistency in classification according to the WHO criteria [20] between capillary blood and venous plasma in a distinct group of subjects selected from the same cohort as the present study population. During standard OGTT we simultaneously measured in 245 men and women (age $59.3 \pm 6.8$ year, BMI $28.6 \pm 4.2 \mathrm{~kg} / \mathrm{m}^{2}$ ) venous plasma and capillary blood glucose concentration (with the methods as 
described above). Mean difference between capillary and venous plasma glucose was $0.16 \mathrm{mmol} / \mathrm{l}(95 \% \mathrm{Cl} 0.02-0.30)$ and $0.96 \mathrm{mmol} / 1$ (95\% Cl 0.68-1.24) during fasting and at 2 hour post OGIT respectively. These differences closely match the difference between (capillary and venous plasma) cut-off values used for defining IGT according the WHO (fasting $0.0 \mathrm{mmol} / \mathrm{l}$ and 2 -hour 1.1 mmol/1). Consistency in classification according to the WHO criteria between capillary blood and venous plasma was good $69 \%$, kappa 0.55, P 0 0.001; ref. [21]).

\section{Anthropometry}

Anthropometric measurements were done at the day of the second OGTT. Body weight was measured with an electronical scale to the nearest $0.1 \mathrm{~kg}$, with the subject wearing only light clothing. Height was measured with the subject standing on the floor without shoes with the back straight against the wall to the nearest $0.5 \mathrm{~cm}$. BMI was calculated as the ratio of the weight and height squared $(\mathrm{kg} \cdot \mathrm{m}-2)$. Skinfold thickness was measured twice using a skinfold caliper at the triceps, biceps, subscapular and suprailiacal region. The sum of arm skinfold (triceps and biceps) and the sum of trunk skinfold (subscapular and suprailiacal) was computed. Waist circumference (waist) was measured with the subject in standing position at the level midway between the lowest rib and iliacal crest to the nearest $0.5 \mathrm{~cm}$; hip circumference was measured at the maximum circumference over the buttocks to the nearest $0.5 \mathrm{~cm}$. Waist-to-hip ratio (WHR) was computed as the ratio between waist and hip circumference. Sagittal and transverse abdominal diameter were measured with the subject in a recumbent position, at the level of the crista illaca to the nearest mm using a sliding beam caliper. The same person did all the anthropometric measurements.

\section{Classification of subjects}

The results of the second OGTT were interpreted according to the WHOcriteria: IGT: fasting $<7.0 \mathrm{mmol} / \mathrm{l}, 2$-hour $>7.8$ and $<11.0 \mathrm{mmol} / /[20]$. In the subsequent (statistical) analysis comparisons were made between subjects returning to nomal glucose tolerance at the second test (transient IGT) and subjects remaining impaired glucose tolerant (persistent IGT).

\section{Statistical analysis}

Date are expressed as mean \pm standard error (sem). All variables were checked for nomal distribution. Differences between groups were analyzed with an umpaired t-test. The predictive value of anthropometric variables for having transient or persistent IGT was analyzed by means of logistic regression analysis. Dependent (nominal) variable was having persistent $1 G T$ or not. For each anthropometric variable, logistic regression analysis was carried out using sex, age, family history of diabetes and 2-hour glucose at the initial test as covariant. Odds ratios were expressed according to a 1 standard deviation difference in the selected anthropometric variable. Level of significance was set at $\mathrm{P}<0.05$. All analyses were performed. with Statview 5.0 for Macintosh. 
Table 3.1 Results of the second OGTI

\begin{tabular}{lcccc}
\hline & MEN & WOMEN & ALL & \\
\hline Normal Glucose Tolerance & 19 & 21 & 40 & $(37 \%)$ \\
Impaired Fasting Glucose & 6 & 2 & 8 & $(7 \%)$ \\
Impaired Glucose Tolerance & 26 & 21 & 47 & $(44 \%)$ \\
Diabetes Mellitus & 6 & 7 & 13 & $(12 \%)$ \\
Total & 57 & 51 & 108 & $(100 \%)$ \\
\hline
\end{tabular}

Classification according to the WHO criteria 1999

\section{Results}

In total 108 subjects, 57 men and 51 women, participated in both OGTTs. Outcome of the second OGTT is depicted in Table 3.1. Normal glucose tolerance at re-testing was found in 40 subjects (37\%); 1 GT in 47 subjects (44\%), Impaired fasting glucose in 8 subjects $(7 \%)$ and newly diagnosed type 2 diabetes mellitus in 13 subjects $(12 \%)$. When split by sex the number of subjects returning to normal was not different between men and women (see Table 3.1). Only the data from the 40 subjects returning to normal glucose tolerance at remesting (transient IGT) and the 47 subjects remaining IGT (persistent IGT) were used in the following analysis.

Average time between the initial OGTT and the second OGTT was $79 \pm 47$ days (mean $\pm S D$ ), no differences in average time between tests were observed between subjects with transient and persistent glucose intolerance (data not shown). Furthermore no difference in change in body weight between the first and the second OGTT was observed between groups (data not shown).

Anthropometric variables and results of the initial OGTT are depicted in Table 3.2 for transient IGT and persistent IGT. Postload blood glucose concentrations during the initial OGTT were higher in persistent IGT as compared to transient IGT $(P<0.01)$. Fasting blood glucose concentrations during the initial OGTT were also higher in persistent IGT as compared to transient IGT, but this difference did not reach statistical significance $(P=0,09)$. No differences were found in age between both groups. Body weight and BMI did also not differ significant between groups. No statistically significant differences were found. in waist circumference, waist-to-hip matio and sagittal and transverse abdominal diameter between subjects with persistent and transient IGT (see Table 3.2). Subscapular skinfold thickness was higher in persistent IGT compared to transient IGT $(25.4 \pm 1.4 \mathrm{~mm}$ Vs. $29.8 \pm 1.2 \mathrm{~mm}$ for transient IGT and persistent IGT respectively; $\left.P^{3}<0.02\right)$. The summations of peripheral, truncal and all skinfold measurements were not significant different between transient and persistent glucose intolerant subjects.

Logistic regression analysis revealed that the 2 -hour blood glucose level at the initial test was the strongest predictor of persistent IGT (Odds Ratio for 1 SD difference: $2.32 ; \mathrm{P}<0.02)$. To evaluate whether anthropometric measurements were of (additional) predictive value in distinguishing between transient and persistent IGT, logistic regression analysis was performed after adjustment for 
age, sex, family history of DM, and 2-hour blood glucose level at the initial test. Results of logistic regression analysis are shown in Table 3.3; odds ratios and $95 \%$ confidence intervals are given for the presence of persistent glucose intolerance for a 1 standard deviation difference in the selected anthropometric variables. persistent IGT was predicted by an increased subscapular skinfold (OR for 1 SD difference: $1.84 ; \mathbb{P}<0.05$ ). Waist-Hip-ratio (OR 1.73), transverse abdominal diameter and sum of truncal skinfolds were also associated with an increased risk on having persistent $I G T$, but odds ratios were not significantly different from 1. Body weight, BMI, waist circumference, sagittal abdominal diameter and other skinfold thickness measurements were not predictive in this group of subjects.

Table 3.2 Clinical characteristics of subjects with transient and persistent IGT

\begin{tabular}{lcccc}
\hline & & transient IGT & persistent IGT & \\
\hline & & $(\mathrm{n}=40)$ & $(\mathrm{n}=47)$ & P-value \\
sex (M/F) & $19 / 21$ & $26 / 21$ & \\
Age & (year) & $56.4 \pm 1.1$ & $56.2 \pm 1.2$ & $\mathrm{~ns}$ \\
Weight & $(\mathrm{kg})$ & $81.6 \pm 2.4$ & $83.8 \pm 1.7$ & $\mathrm{~ns}$ \\
BMI & $\left(\mathrm{kg} / \mathrm{m}^{2}\right)$ & $28.4 \pm 0.6$ & $29.4 \pm 0.6$ & $\mathrm{~ns}$ \\
& & & & \\
Waist circumference & $(\mathrm{cm})$ & $97.8 \pm 1.8$ & $101 \pm 1.4$ & $\mathrm{~ns}$ \\
WHR & & $0.94 \pm 0.01$ & $0.97 \pm 0.01$ & 0.07 \\
Sagittal abd.dm & $(\mathrm{mm})$ & $233 \pm 5.3$ & $242 \pm 3.8$ & 0.07 \\
Transverse abd.dm & $(\mathrm{mm})$ & $362 \pm 6$ & $376 \pm 4.6$ & 0.07 \\
& & & & \\
biceps SKF & $(\mathrm{mm})$ & $15.0 \pm 1.1$ & $15.6 \pm 1.0$ & $\mathrm{~ns}$ \\
triceps SKF & $(\mathrm{mm})$ & $19.4 \pm 1.6$ & $19.3 \pm 1.3$ & $\mathrm{~ns}$ \\
peripheral SKF & $(\mathrm{mm})$ & $34.4 \pm 2.6$ & $34.9 \pm 2.2$ & $\mathrm{~ns}$ \\
Subscapular SKF & $(\mathrm{mm})$ & $25.4 \pm 1.4$ & $29.8 \pm 1.2$ & 0.02 \\
supra-iliacal SKF & $(\mathrm{mm})$ & $29.7 \pm 1.5$ & $31.3 \pm 1.1$ & $\mathrm{~ns}$ \\
truncal SKF & $(\mathrm{mm})$ & $55.1 \pm 2.7$ & $61.1 \pm 2.0$ & 0.07 \\
sum of SKF & $(\mathrm{mm})$ & $96.0 \pm 3.8$ & $\mathrm{~ns}$ \\
& & $89.5 \pm 4.7$ & & \\
HbA & $(\%)$ & $5.8 \pm 0.1$ & $5.8 \pm 0.1$ & $\mathrm{~ns}$ \\
Initial OGTT & & & & \\
fasting glucose & $(\mathrm{mmol} / \mathrm{l})$ & $5.6 \pm 0.1$ & $5.8 \pm 0.1$ & 0.09 \\
2-hour glucose & $(\mathrm{mmol} / \mathrm{l})$ & $9.8 \pm 0.1$ & $10.2 \pm 0.1$ & $<0.01$ \\
\hline
\end{tabular}

Data are expressed as mean \pm sem ; $B M \mid=$ Body Mass Index; WHR $=$ Waist-to-Hip Ratio; abd.dm m abdominal diameter; SKF = skinfold thickness

\section{Discussion}

The main novel finding of the present study is that subscapular skinfold thickness was a predictor of the presence of persistent IGT, independent of other variables including 2-hour blood glucose level at the initial OGTT, age, sex and family history of diabetes, while other indices of obesity (i.e. BMI, waist) were not, or only weak predictors of persistent IGT. Because subscapular skinfold thickness is related to the subcutaneous fat depot, these data suggest 
that subcutaneous adipose tissue accumulation, especially in the truncal and central regions, is linked to disturbances in glucose tolerance.

The population described in the present study is a sub-population from a larger lifestyle-intervention trial (SLM). Subjects do not necessary reflect the general population, as they were selected to participate in a 3 year lifestyle-intervention trial. Furthermore, the size of the population was relatively small $(n=108)$. Although this can put some limitations on our analysis, it seems unlikely that it would have changed our interpretation of the data.

The oral glucose tolerance test is considered the gold standard in diagnosing glucose intolerance. However the reproducibility is rather poor because of the narrow range of the 2 -hour blood glucose value used for defining IGT (7.8 11.1 mmol/1). Rates of reversion to normal glucose tolerance of one-third to one-half are reported for subjects with $1 \mathrm{GT}[8,9]$. This is in accordance with the results of the present study. In total, 40 out of 108 subjects (37\%) reverted to normal glucose tolerance at re-testing (transient $1 G \mathrm{~T}$ ); whereas 47 subjects (44\%) remained glucose intolerant (persistent IGT). It is suggested that this reversion to normal. glucose tolerance at the second test is not only regression to the mean but can possibly also be explained by a lesser degree of arousal or stress at the second test.

In this study we determined glucose tolerance during the first test in capillary blood and during the second test in venous plasma. It is known that glucose levels are higher in capillary blood compared to venous blood or plasma. However for classification of the subjects we used, at both occasions, the appropriate set of criteria according to the WHO, i.e. capillary criteria for the first OGTT and venous plasma criteria for the second test [20]. We validated this

Table 3.3 Results of the logistic regression analysis ( $n=87$ )

\begin{tabular}{lcccc}
\hline & $(S D)$ & OR & $95 \% \mathrm{Cl}$ & P-value \\
\hline Weight & $(13.4 \mathrm{~kg})$ & 1.08 & $0.66-1.76$ & $\mathrm{~ns}$ \\
BMt & $\left(3.8 \mathrm{~kg} / \mathrm{m}^{2}\right)$ & 1.23 & $0.79-1.89$ & $\mathrm{~ns}$ \\
Waist circumference & $(10.3 \mathrm{~cm})$ & 1.34 & $0.82-2.21$ & $\mathrm{~ns}$ \\
WHR & $(0.075)$ & 1.73 & $0.90-3.29$ & 0.09 \\
Sagittal abd.dm & $(29.5 \mathrm{~mm})$ & 1.29 & $0.81-2.04$ & $\mathrm{~ns}$ \\
Transverse abd.dm & $(34.8 \mathrm{~mm})$ & 1.52 & $0.89-2.58$ & $\mathrm{~ns}$ \\
& & & & \\
biceps SKF & $(6.7 \mathrm{~mm})$ & 1.32 & $0.72-2.42$ & $\mathrm{~ns}$ \\
triceps SKF & $(9.3 \mathrm{~mm})$ & 1.28 & $0.58-2.83$ & $\mathrm{~ns}$ \\
peripheral SKF & $(15.3 \mathrm{~mm})$ & 1.35 & $0.65-2.80$ & $\mathrm{~ns}$ \\
subscapular SKF & $(8.5 \mathrm{~mm})$ & 1.84 & $1.06-3.19$ & 0.03 \\
Suprawiliacal SKF & $(8.4 \mathrm{~mm})$ & 1.12 & $0.70-1.79$ & $\mathrm{~ns}$ \\
truncal SKF & $(15.3 \mathrm{~mm})$ & 1.47 & $0.88-2.47$ & $\mathrm{~ns}$ \\
sum of SKF & $(27.7 \mathrm{~mm})$ & 1.47 & $0.83-2.61$ & $\mathrm{~ns}$ \\
\hline Odds ratios $(\mathrm{ORI})$ & & & & \\
\hline
\end{tabular}

Odds ratios $(O R)$ and $95 \%$ confidence interval $(95 \% \mathrm{Cl})$ of selected variables for a 1 standard deviation (SD) difference with persistent $1 \mathrm{GT}$ as dependent wanable, adjusted for sex, age, family histon af DN
and 2-hour glucose at initial test and 2-hour glucose at initial test; $B M I=$ Body Mass Index; WHR = Waist-to-Hip Ratio; abd.dm $=$
abdominal diameter; $5 K F=$ skinfold thickness 
in a comparable population and observed a good consistency in classification (69\%, kappa $0.55, \mathrm{P}<0.001 ;[21])$. These results indicate that the difference in methods used for measuring blood glucose during OCTT do not change the interpretation of our data.

Although transient IGT indicates a predisposition to diabetes [2], the incidence of diabetes is higher in subjects with persistent IGT [11,22]. Factors predicting persistent glucose intolerance include increased insulin levels, obesity, and positive family history of diabetes $[13,14]$. In the present study, subscapular skinfold thickness was significantly associated with an increased risk of persistent IGT, even after correction for 2 -hour blood glucose levels at the initial test, while measures of (abdominal) obesity were not on only weakly associated with an increased risk of having persistent $1 G T$. These results suggest that body fat distribution is more important than total body fat mass in relation to transient or persistent glucose intolerance. Although waist circumference is an important risk factor for type 2 diabetes mellitus [16], it only predicted weakly the presence of persistent IGT. However it must be taken into consideration that these data are obtained in a relatively small group of middle-aged people $\left(\mathrm{n}=108 ; 56.3 \mathrm{yr}\right.$ ) with an elevated BMI $\left(29.2 \mathrm{~kg} / \mathrm{m}^{2}\right)$. It would be interesting to evaluate in a larger sample the performance of measurement of subscapular skinfold thickness and other anthropometric measures in clinical practice, and try to define cut-of values for subscapular skinfold thickness. Unfortunately the number of subjects in this study is to small to do so.

The debate on which of the abdominal fat compartments, visceral or subcutaneous, is most strongly linked to insulin resistance is still unanswered [23]. Excess supply of free fatty acids (FFA) from visceral fat directly via the portal vein to the liver can have several adverse effect on hepatic metabolism leading to hyperglycemia and hyperinsulinemia [24]. However, although subcutaneous abdominal adipose tissue may be metabolically less active, it is a considerably larger fat mass than the visceral fat compartment [25], resulting in a large release of FFA into the circulation. Abate et a]. [25] concluded that subcutaneous truncal fat plays a major role in obesity-related insulin resistance in men, whereas intraperitoneal fat and retroperitoneal fat had a nole of less importance. An important observation of the present study is that subscapular skinfold thickness, an estimate of subcutaneous (central) fat, predicts the presence of persistent glucose intolerance even after correction for 2-hour blood glucose level during the first test. Measures of total fat mass, as BMI, and measures more correlated to deep visceral fat mass, as waist circumference and sagittal diameter less well predict persistent glucose intolerance. Our observation of a increased subscapular skinfold thickness in persistent IGT is in agreement with other studies showing an association between (subscapular) skinfold thickness and glucose tolerance $[15,18,26]$, this suggests that the subcutaneous abdominal fat depot does contribute to disturbances in glucose homeostasis among overweight subjects.

In summary, our results revealed that in addition to the 2 -hour blood glucose concentration at the initial OGTT, subscapular skinfold thickness was the best predictor of persistent $1 G T$. Indicating that, in middle aged men and women, simple anthropometric measurements can improve the discrimination between 
subjects with transient and persistent IGT, enabling identification those most at risk for developing type 2 diabetes mellitus.

\section{Acknowledgements}

We are grateful to Jos Stegen for his analytical support and Rob van Dam for his support during the statistical analysis. This work was supported by a grant of the Dutch Diabetes Research Foundation (DFN 98.901) and a grant of the Netherlands Organization for Scientific Research (ZonMW 940-35-034).

\section{References}

1 Unwin N, Shaw I, Zimmet $P$. Alberti KG. Impaired glucose tolerance and impaired fasting glycaemia: the current status on definition and intervention. Diabet Med 2002; 19: 708-23.

2 Edelstein SL, Knowler WC, Bain RP et al. Predictors of progression from impaired glucose tolerance to NIDDM: an analysis of six prospective studies. Diabetes 1997; 46: 701-10.

3 de Vegt F, Dekker JM, Jager A et al. Relation of impaired fasting and postload glucose with incident type 2 diabetes in a Dutch population: The Hoorn Study. JAMA 2001; 285: 2109-13.

4 Chu NF, Lee MM, Wang Df et at. The interrelationship between impaired glucose tolerance and other risk factors for cardiovascular disease: is it a predictor for cardiovascular disease? / Clin Epidemiol 1994; 47: 485-93.

5 Rodriguez BL, Curb ID, Burchfiel CM al. Impaired glucose tolerance, diabetes, and cardiovascular disease risk factor profiles in the elderly. The Honolulu Heart Program. Diabetes Care 1996; 19:587-90.

6 "Tuomilehto J, Lindstrom J, Eriksson JG et al. Prevention of type 2 diabetes mellitus by changes in lifestyle among subjects with impaired glucose tolerance. $N$ Engl
Med 200]; $344: 1343-50$.

7 Knowler WC, Barrett-Connor E, Fowler SE et al. Reduction in the incidence of type 2 diabetes with lifestyle intervention or metformin. N Engl / Med 2002; 346:393-4.03.

8 Riccardi $G$, Vaccaro $O$, Rivellese $A$ et al. Reproducibility of the new diagnostic criteria for impaired glucose tolerance. Am / Of Epidemol 1985; 121" 422-9.

9 Ko GT, Chan IC. Woo J al. The reproducibility and usefulness of the oral glucose tolerance test in screening for diabetes and other cardiovascular risk factors. Amm
Chin Bhown 1998; 35:62.7.

10 Salad MF, Knowler WC, Pettitt DI, Nelson RG, Bennett PH. Transient impaired gluose tolerance in Pima Indians: is it important? BMJ 1988; 297: 1438-41.

11 Motala AA, Omar MA, Gouws E Transient impared glucose tolerance in South African Indians does not carry a risk for progression to NIDDM. Diabetes Care 1997;

12 Davies MI. Rayman $G$, Grentell A et al. Loss of the first phase insulin response to intravenous glucose in subjects with persistent impaired glucose tolerance. Diabet

13 Boum DM, Williams SM, Mann II. Distinguishing between persistent and transient impaned glucose tolerance using a prediction model. Diabe Med 1992; $9: 744-8$. 
14 Qiao Q Keinanen-Kiukaanniemi S, Rajala U, Uusimaki A, Kivela SL. Risk for diabetes and persistent impaired glucose tolerance among middleaged Finns. Diabetes Res Clin Pract 1996; 33: 191-8.

15 Feskens EI, Kromhout D. Effects of body fat and its development over a ten-year period on glucose tolerance in euglycaemic men: the Zutphen Study. Int I Epitemtol $1989 ; 18: 368-73$.

16 Seidell $1 C$, Han TS, Feskens E), Lean ME. Narrow hips and broad waist circumferences independently contribute to increased risk of non-insulindependent diabetes mellitus. I Intern Med 1997; 242: 401-6.

17 Wei M, Gaskill SP, Hafner SM, Stern MP. Waist circumference as the best predictor of noninsulin dependent diabetes mellitus (NDDM) compared to body mass index, waist/hip ratio and other anthropometric measurements in Mexican Americans-a 7-year prospective study. Obes Res 1997; 5: 16-23.

18 Sievenpiper JL, Jenkins DI, Josse RG, Leiter LA, Vuksan V. Simple skinfold-thickness measurements complement conventional anthropometric assessments in predicting glucose tolerance. Am) Clin Nutr 2001; 73:567.73.

19 Mensink M, Blaak EE, Feskens EFM, de Bruin TWA, Saris WHM. Study on Lifestyle Intervention and Impaired Glucose Tolerance: Study design. Int / Obes Retat Metals Disord 2000; 24: $\$ 93$ (Abstract).

20 World Health Organization. Definition, diagnosis and classification of diabetes mellitus. Report of a WHO Consultation. Part 1: Diagnosis and Classification of Diabetes Mellitus. Geneva, Switzerland, 1999. Publication WHO/NCD/NCS/99.2.

21 Kruijshoop $M$, Feskens EJM, Blaak EE, Heine Rl, de Bruin TWA. Validation of capillary glucose measurements to detect type 2 diabetes mellitus in the general population: The CoDAM-study. Diabetologia 2002; 42: A98 (Abstract).

22 Nagi DK, Knowler WC, Charles. MA ot al. Early and late insulin response as predictors of NIDDM in Pima Indians with impaired glucose tolerance. Diabetologia $1995 ; 38: 187 \times 92$.

23 Frayn $\mathrm{KN}$. Visceral fat and insulin resistance--causative or correlative? $\mathrm{Br} / \mathrm{Nutr}$ 2000; 83 Suppl 1: $571-7$.

24 Björntorp P. Regional fat distribution-implications for type II diabetes. Int / Obes Relat Metab Disord 1992; 16 Suppl 4: S19-27.

25 Abate N, Garg A, Peshock RM, Stray -Gundersen J, Grundy SM. Relationships of generalized and regional adiposity to insulin sensitivity in men. / Clin lhost 1995: 96: 88-98.

26 Harlan LC, Harlan WR, Landis JR, Goldstein NG. Factors associated with glucose tolerance in adults in the United States. Am / Epridomid 1987; 126: 674-84. 


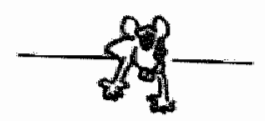




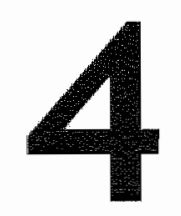

\title{
Study on Lifestyle-Intervention and Impaired Glucose Tolerance Maastricht (SLIM): Preliminary Results after One Year
}

\author{
Marco Mensink, Edith JM Feskens, Wim HM Saris, \\ Tjerk WA de Bruin and Ellen E Blaak
}

Dept of Human Biology, Nutrition and Toxicology Research Institute NUTRIM. Maastricht University, Maastricht, The Netherlands

Dept of Health and Nutrition, National Institute for Public Health and the Environment, Bilthoven, The Netherlands

Dept of Medicine and Endocrinology, Cardiovascular Research Institute CARIM, University Hospital Maastricht, Maastricht, The Netherlands

Int J Obes Relat Metab Disord 2003; 27: 377-384 


\begin{abstract}
Important risk factors for the progression from impaired glucose tolerance (IGT) to type 2 diabetes mellitus are obesity, diet and physical inactivity. The aim of this study was to evaluate the effect of a lifestyle-intervention program on glucose tolerance in Dutch subjects with IGT. In total 102 subjects were studied, randomized into two groups. Subjects in the intervention group received regular dietary advice, and were stimulated to lose weight and to increase their level of physical activity. The control group received only brief information about the beneficial effects of a healthy diet and increased physical activity. Before the start of the intervention and after one year glucose tolerance was evaluated and several other measurements were performed. Body weight loss after 1 year was higher in the intervention group compared to the control group $(-2.7 \pm 0.5 \mathrm{~kg} v \mathrm{v}$. $-0.2 \pm 0.5 \mathrm{~kg} ; \mathrm{P}<0.05$ ). The 2 -hour blood glucose concentration decreased $-0.8 \pm 0.3 \mathrm{mmol} / \mathrm{l}$ in the intervention group and increased $+0.2 \pm 0.3 \mathrm{mmol} / \mathrm{l}$ in the control group $(P<0.05)$. Body weight loss and increased physical fitness $\left(\mathrm{VO}_{2}\right.$ max) were the most important determinants of improved glucose tolerance and increased insulin sensitivity.

It was concluded that a lifestyle-intervention program according to general recommendations is effective in subjects with IGT and induces beneficial changes in lifestyle, which improve glucose tolerance. Body weight loss and increased physical fitness were the most important determinants of improved glucose tolerance and insulin sensitivity.
\end{abstract}


The blood glucose concentration 2 hours after an oral glucose load is an important predictor of progression to type 2 diabetes mellitus [1,2]. A cumulative incidence of progression to diabetes ranging from $23 \%$ to $63 \%$ is reported among subjects with impaired glucose tolerance (IGT) followed for 2 up to 27 years [2]. Therefore, subjects with IGT are an important target group for the prevention of type 2 diabetes mellitus and cardiovascular disease.

Several studies have examined the effect of interventions on the progression from IGT to diabetes. Strategies used were drug and/or diet interventions [3,4], diet and/or exercise [5], or the combination of diet and exercise, often referred to as a lifestyle-intervention [6-9] The Malmö study [6] showed the feasibility of such a lifestyle intervention program, achieving substantial metabolic improvement after 6 years of a combined diet and physical exercise intervention in men with IGT and early-stage type 2 diabetes mellitus. Unfortunately only men were participating in this study and subjects were not randomized to one of the intervention modalities.

The first large, well-controlled, long-term intervention study assessing the impact of lifestyle changes on the progression from IGT to type 2 diabetes mellitus was the Finish Diabetes Prevention Study (DPS) [8]. The risk of diabetes was reduced by 58 percent in the intervention group after a mean duration of follow-up of 3.2 year, and the reduction in incidence was directly associated with changes in lifestyle. The Diabetes Prevention Program (DPP) in the United States, a clinical trial designed to evaluate the safety and efficacy of interventions that may delay or prevent development of diabetes in people at increased risk for type 2 diabetes mellitus, shows a comparable reduction in the incidence of diabetes [9]. Lifestyle changes and treatment with metformin both reduced the incidence of diabetes, however the lifestyle intervention was twice as effective as metformin in reducing the incidence of diabetes [9].

To develop and implement intervention programs it would be useful to assess the relative importance of changes in several lifestyle factors, i.e. dietary intake, body weight and physical activity, on changes in glucose tolerance and the incidence of diabetes. The Chinese Da Qing IGT and Diabetes Study did try to assess the effect of diet alone, exercise alone or the combination of diet and exercise on the development of diabetes [5]. All interwention modalities led to a significant decrease in the incidence of diabetes; proportional hazard analysis suggested that exercise and the combination of diet and exercise were associated with a larger risk reduction than diet alone. However firm conclusions can not be drawn from the latter study because there are concerns about the generalizability of these results to other populations.

The Study on Lifestyle-intervention and Impaired Glucose Tolerance Maastricht (SLIM) is a 3-year intervention study carried out to evaluate the effect of lifestyle-intervention program on glucose tolerance and insulin resistance in subjects at risk for developing type 2 diabetes mellitus. The aim of this paper was to evaluate the effect of this program after the first year. Secondly we aimed to identify which lifestyle or anthropometric factors were most strongly related to changes in glucose tolerance and insulin resistance. 


\section{Methods}

The Study on Lifestyle-intervention and IGT. Maastricht (SLIM), is designed to study whether a diet/physical activity intervention program can improve glucose tolerance in subjects with a risk of developing type 2 diabetes mellitus. Total study duration is thee years.

\section{Recruttment of subjects}

The recrument period started march 1999. Subjects with a risk for glucose intolerance, i.e. those of age $>40$ years and a family history of diabetes or a BMI $>25 \mathrm{~kg} / \mathrm{m}^{2}$, were selected from an existing cohort $[10]$ and invited to undergo a first capillary oral glucose tolerance test (OGTT). Subjects with known or overt diabetes were excluded.

Subjects with an elevated 2-hour blood glucose concentration were invited to undergo a second OGTT. For definitive inclusion in the study, mean 2-hour glucose concentration of both OGTTs had to be between 7.8 and $12.5 \mathrm{mmol} / \mathrm{l}$, together with a non-diabetic fasting glucose concentration, i.e. less than 7.8 mmol/1. Furthermore subjects were excluded according to the following criteria: previously diagnosed diabetes mellitus, other than gestational diabetes mellitus; medication use known to interfere with glucose tolerance (e.g. chronic steroid use); participation in regular vigorous exercise or an intensive weight reduction program during the last year before the start of the study; and any (chronic) disease that makes participation in a lifestyle intervention program impossible, or has an improbable 5-year survival.

After the recruitment, subjects were randomized to one of the two study groups, the intervention group or the control group. Randomization was carried out with stratification for sex and mean 2-hour plasma glucose concentration. The Medical Ethical Review Committee of Maastricht University approved the study protocol, and all subjects gave their written informed consent before the start of the study.

Altogether 177 subjects were recruited from the first screening OGTT and invited to undergo a second OGTT. After the second OGTT 114 subjects (64 men and 50 women) were eligible for the study and have been randomized to one of the two study groups.

\section{Lifestyle-intervention program}

The intervention program consists of a dietary and physical activity part, with visits scheduled at regular interwals throughout the study.

Dietary recommendations are based on the Dutch guidelines for a healthy diet (Dutch Nutrition Council) and consisted of: carbohydrate intake of at least $55 \%$ of total enargy intake (En\%); total fat intake of less than $30-35$ En\%, with less than 10 En\% intake of saturated fatty acids; a cholesterol intake of less than 33 mg per My protein intake of 10-15 En\% and an intake of dietary fibre of at least 3 gram per MJ. A weight-loss of 5-10\% during the first year, depending on the degree of obesity, was initially aimed at. No very-low calorie-diets (VLCD) or 
other weight-loss agents were used throughout the suby. Furthermon participants were encouraged to stop smoking and, if necessary, to reduce alcohol intake. Dietary advice was given by a sklled diehician on an indricual basis after consideration of the individual 3-day food record. The frest vist was 4-6 weeks after randomization, to enable assessment of dietary make as recorded in the baseline 3-day food record. A second visit followed at thee months. Thereatter, every three months a visit was scheduled. An important goal in the dietary intervention was to reduce saturated fat intake, which was discussed at every visit. At the end of every visit goals were set for the next visit, like 'replacing high fat cheese by low-fat cheese" or "using (olive) oil instead of butter during meal preparing'. For the visit at 9 months a group session was scheduled instead of an individual visit.

Subjects were stimulated to increase their physical activity to at least 30 minutes of moderate physical activity a day for at least 5 days a week a recommendation made by the American College of Sports Medicine [11]. At the start of the study the individual amount of physical activity was discussed with a physician. Individual advice was given how to increase their daily physical activity (walking, cycling, swimming) and goals were set. During every visit with the dietician physical activity goals were evaluated, and if necessary, new goals were set. Furthermore, subjects were encouraged to participate in an exercise program, specially designed for this study, consisting of components of aerobic exercise training and components of resistance training. Exercise sessions were supervised by trainers used to working with a group of middleaged people. Subjects had free access to these training sessions and were stimulated to participate at least one hour a week. Intensity of the exercise program was monitored several times and the degree of participation of each individual was recorded by the trainer.

Subjects in the control group were informed about the beneficial effects of a healthy diet, weight loss and increased physical activity, whereas no individual advises or programs were provided. Furthermore, each subject received brief written information about the benefits of a healthy diet and increased physical activity. No additional appointments were scheduled, apart from the visit after 1 year for the annual measurements.

\section{Measurements}

To follow changes in glucose tolerance during the study a standard oral glucose tolerance test (OGTT) with venous blood sampling was performed at the start of the study and at year 1 . After an overnight fast, subjects reported to the laboratory by car or by bus; fasting blood samples were drawn, and subjects received the glucose 1 oad $(75 \mathrm{~g} g l$ ucose, dissolved in $250 \mathrm{ml}$ water $A V E B E$, The Netherlands). After 30 minutes, 1 hour and 2 hour blood sample were drawn for the determination of the blood glucose concentration.

Plasma glucose concentration was measured at baseline with a standard enzymatic technique automated on the Cobas rara centrifugal analyzer (Gucose HK 125, ABX diagnostics, Montpellier, France). Plasma insulin concentration was measured at baseline, 30 min. and 120 min. with an ELISA 
assay (Mercodia, Uppsala, Sweden), which shows no cross-reactivity with proinsulin. Glycated haemoglobin $\left(\mathrm{Hb}_{\mathrm{ic}}\right.$ ) was determined in a fasting plasma sample (reference value for our laboratory $4.4-6.2 \%$ ). Fasting plasma glucose and insulin concentration were used to calculate an index for insulin resistance with the homeostasis model assessment (HOMA-index) described by Matthews et al. [12]. As an indicator for insulin secretion the insulinogenic index 30 was used (Insulin30-Insulin0) / (glucose 30-glucose0) [13].

Anthropometric measurements were performed at the start of the study and after one year. Body weight was measured with an electronical scale to the nearest $0.1 \mathrm{~kg}$, with the subject wearing only light clothing. Height was measured to the nearest $0.5 \mathrm{~cm}$ with the subject standing on the floor without shoes with the back straight against the wall. BMI was calculated as the ratio of the weight and height squared $\left(\mathrm{kg} / \mathrm{m}^{2}\right)$. Body composition was measured using bio-impedance equipment (Hydra, Xitron Utilities, San Diego, USA). Due technical difficulties BIA was performed in 69 subjects ( 31 INT and 38 CON). Waist circumference (waist) was measured with the subject in standing position at the level midway between the lowest rib and the illac crest to the nearest 0.5 cm and hip circumference was measured as the maximum circumference over the buttocks to the nearest $0.5 \mathrm{~cm}$. Waist-to-hip ratio (WHR) was computed as the ratio between waist and hip circumference. Sagittal and transverse abdominal diameter were measured with the subject in a recumbent position, at the level of the crista iliaca to the nearest mm using a sliding beam caliper.

An incremental exhaustive exercise test was performed on an electronically braked bicycle ergometer (Lode Excalibur, Groningen, the Netherlands) to determine the maximal power output ( $W$ max) and maximal peak oxygen consumption $\left(\mathrm{VO}_{2} \mathrm{max}\right)$. The test started at a workload of $0.75 \mathrm{~W} / \mathrm{kgFFM}$ for 3 minutes, followed by 3 minutes at $1.5 \mathrm{~W} / \mathrm{kgFFM}$. Subsequently the workload was increased every 3 minutes by $0.5 \mathrm{~W} / \mathrm{kgFFM}$ until exhaustion; i.e. subjects were no longer able to maintain a pedaling frequency above $60 \mathrm{xpm}$. Throughout the whole experiment, $\mathrm{O}_{2}$ consumption and $\mathrm{CO}_{2}$ production were measured with an Oxycon-Beta (Mijnhardt, Breda, the Netherlands) to define maximal peakVO. Maximal power output was calculated using the time spent on the last workload until exhaustion.

Before the stat of the study and at the visit after 1. year a medical history was. taken and a physical examination was performed, including recording of a 12 lead resting ECG. A 3-day food recond (two weekdays and 1 weekend day) was kept at the start of the study and after one year. Food reconds were checked by a dietician and intake of nutrients was calculated with a computer program using
the Dutch rood table.

\section{Outcome}

In this study, the primary outcome measure is the change in glucose tolerance, defined as the 2-hour blood glucose concentration during the OGTT. Secondary outcome measures are changes in fasting plasma glucose concentration, changes in plasma insullin concentration, changes in insulin resistance (as indicated by the HOMA index) and changes in glycated hemoglobin $\left(\mathrm{Hb} \mathrm{A}_{\mathrm{I}}\right)$ 


\section{Statistical analysis}

Date are expressed as mean \pm standard error (sem). Changes after one year of intervention are calculated and expressed as mean and their $95 \%$ confidence interval. Differences at baseline, at year 1 and differences in mean changes from baseline to year 1 between groups were analyzed with an umpaired t-test. A two-tailed paired ttest was used to analyze differences within groups between baseline and at year 1 . Univariate and stepwise regression analyze were performed to identify the contribution of changes in lifestyle and anthropometric factors to changes in glucose tollerance (2-hour glucose tolerance) and insulin resistance (HOMA-index) in the intervention group. All analyses were performed with Statview 5.0 for Macintosh.

\section{Results}

At the stant of the study 114 subjects were randomized to one of the two study groups. During the first year total drop-out was $10 \%$ (12 subjects). The drop-out rate was higher in the intervention group ( 8 subjects) as compared to the control group (4 subjects). Two subjects dropped out for medical reasons (thyroid disease and cancer) and 10 subjects for motivational reasons (lack of time, too much effort). Baseline characteristics of the subjects who did leave the study did not differ from the 102 subjects completing the first year (data not shown). In this paper the results of the 102 subjects still participating in the study after the first year will be presented and discussed.

Table 4.1 Subject characteristics at baseline $(n=102)$

\begin{tabular}{|c|c|c|c|}
\hline & \multicolumn{2}{|c|}{ BASELINE } \\
\hline & & intervention & control \\
\hline Number (male/female) & & $47(27 / 20)$ & $55(31 / 24)$ \\
\hline Age & (yr.) & $55 \pm 1$ & $58 \pm 1$ \\
\hline Body-weight & $(\mathrm{kg})$ & $86.3 \pm 2.1$ & $83.5 \pm 1.6$ \\
\hline$B M I$ & $\left(\mathrm{~kg} / \mathrm{m}^{2}\right)$ & $29.7 \pm 0.5$ & $29.2 \pm 0.5$ \\
\hline Waist & $(\mathrm{cm})$ & $102.3 \pm 1.6$ & $102.1 \pm 1.2$ \\
\hline Waist-Hip Ratio & & $0.97 \pm 0.011$ & $0.97 \pm 0.01$ \\
\hline Sagittal abd.diameter & $(\mathrm{mm})$ & $247 \pm 4.7$ & $240 \pm 3.9$ \\
\hline Transverse abd.dilameter & $(\mathrm{mm})$ & $376 \pm 5.1$ & $377 \pm 3.8$ \\
\hline Wmax $(n=92)$ & $(W)$ & $151 \pm 6.3$ & $145 \pm 5.5$ \\
\hline $\mathrm{VO}_{2} \max (n=8.5)$ & $(1 / \min )$ & $2.21 \pm 0.09$ & $2.13 \pm 0.08$ \\
\hline Fasting glucose & (mmol/l) & $6.0 \pm 0.1$ & $5.8 \pm 0.1$ \\
\hline 2-Hour glucose & (mmol/l) & $8.8 \pm 0.3$ & $8.6 \pm 0.2$ \\
\hline $\mathrm{HbA}_{1 \mathrm{c}}$ & $(\%)$ & $5.9 \pm 0.1$ & $5.9 \pm 0.1$ \\
\hline Fast insulin & $(\mathrm{mu} / \mathrm{l})$ & $13.7 \pm 1.4$ & $12.3 \pm 0.9$ \\
\hline 2-Hour insulin & $(\mathrm{m} \cup / 1)$ & $94 \pm 8$ & $89 \pm 9$ \\
\hline HOMA-IR index & & $3.75 \pm 0.46$ & $3.24 \pm 0.25$ \\
\hline Insulinogenic index & & $14.1 \pm 1.2$ & $18.5 \pm 4.6$ \\
\hline
\end{tabular}

Data are mean s sem 


\section{Subject characteristics}

Table 4.1 depicts the chanacteristics of the 102 subjects at baseline. No differences were found in baseline characteristics between the groups. Baseline fasting and 2 -hour blood glucose concentration were $6.0 \mathrm{mmol} / \mathrm{l}$ and $8.8 \mathrm{mmol} / 1$ in the intervention group, and $5.8 \mathrm{mmol} / 1$ and $8.6 \mathrm{mmol} / \mathrm{l}$ in the control group.

Reduction in body weight after 1 year was significantly larger in the intervention group as compared to the control group ( $\mathrm{P}<0.01$, see Table 4.2 ). Also a significant larger decrease in waist circumference and sagittal and transverse abdominal diameter was seen in the intervention group as compared to the control group, whereas changes in WHR did not change in both groups (see Table 4.2). As measured with bio-impedance, change in fat mass (FM) was significantly different between groups $(-1.2 \pm 0.6 \mathrm{~kg}$ vs. $+0.5 \pm 0.5 \mathrm{~kg}$ for INT and CON respectively: $\mathrm{P}<0.05 ; \mathrm{n}=69$ ); change in fat free mass was not ($0.6 \pm 0.3 \mathrm{~kg}$ vs. $-1.0 \pm 0.5 \mathrm{~kg}$ for $\mathrm{NT}$ and CON respectively: $\mathrm{P}=\mathrm{ns} ; \mathrm{n}=69 \mathrm{j}$. The intervention group showed a larger increase in $\mathrm{VO}_{2}$ max and Wmax compared to the control group $(P<0.05)$. After 1 year 2 -hour blood glucose concentration was decreased $0.8 \mathrm{mmol} / \mathrm{l}$ in the intervention group $(95 \% \mathrm{Cl}:-1.3 ;-0.2)$ compared to an increase of $0.2 \mathrm{mmol} / 1$ (95\% CI: $-0.4 ;+0.8)$ in the control group $(P<0.05)$. Fasting insulin concentration was $2.5 \mathrm{mU} / 1$ lower after 1 year in the intervention group compared to a slight increase of $0.4 \mathrm{mU} / \mathrm{in}$ the control group ( $P$ for difference in change $<0.01$ ). Insulin resistance, as indicated by the HOMA index, decreased in the intervention group and shghtly increased in the control group ( $P$ for difference in change $<0.05$, see Table 4.2 ). The insulinogenic index, an index of $\beta$ eta-cell function, did not change in both groups.

Table 4.2 One-Year changes in subject characteristics $(n=102)$

\begin{tabular}{|c|c|c|c|c|c|c|}
\hline \multirow{3}{*}{$\begin{array}{l}\text { Body-weight } \\
\text { BMI }\end{array}$} & \multirow{3}{*}{$\begin{array}{c}(\mathrm{kg}) \\
\left(\mathrm{kg} / \mathrm{m}^{2}\right)\end{array}$} & \multicolumn{2}{|c|}{$\begin{array}{c}\text { INTERVENTION } \\
\text { (27 men / } 20 \text { women) }\end{array}$} & \multicolumn{3}{|c|}{$\begin{array}{c}\text { CONTROL } \\
(31 \mathrm{men} / 24 \text { women) }\end{array}$} \\
\hline & & $-2.7 \pm 0.5$ & $(-3.8 ;-1.6)$ & $0.2 \pm 0.5$ & {$[-1.2 ; \div 0.8]$} & Hh \\
\hline & & $-0.9 \pm 0.2$ & $(-1.3 ;-0.5)$ & $-0.0 \pm 0.2$ & $(0.4 ;+0.3)$ & 背数斯 \\
\hline Waist & $(\mathrm{cm})$ & $-3.5 \pm 0.5$ & $(-4.6 ;-2.4)$ & $-1.4 \pm 0.6$ & $(-2.6 ;-0.1)$ & $\#$ \\
\hline Waist-Hip Rattio & & $-0.01 \pm 0.01$ & $(-0.02 ;-0.00)$ & $-0.01 \pm 0.01$ & $(-0.02 ;+0.01)$ & \\
\hline Sagittal abd diameter & $(\mathrm{mm})$ & $-10.5 \pm 2.8$ & $(-16 ; ;-4.8)$ & $* 0.3 \pm 2.4$ & $(-4.5 ; * 5.1)$ & Hat \\
\hline Trans abd.diameter & $(m \mathrm{~m})$ & $-8.7 \pm 2.9$ & $(-14.6 ;-2.9)$ & $-0.3 \pm 1.9$ & $\{-4.1 ;+3.4\}$ & H \\
\hline Wmax $(n=92)$ & rw) & $+2.7 \pm 1.9$ & $(-1.2 ;+6.5)$ & $3.0 \pm 1.7$ & $(-6.5 ;+0.3)$ & \# \\
\hline Vo $\max (n=85)$ & (lumin) & $+0.10=0.03$ & $(+0.04 ;+0.16)$ & $-0.00 \pm 0.03$ & $(-0.06 ; * 0.07)$ & H \\
\hline Fast glucose & (mmonoi/l) & $-0.1 \pm 0.1$ & $(-0.2 ;+0.1)$ & $+0.1 \pm 0.1$ & $(-0.1 ;+0.2)$ & \\
\hline 2-Hour glucose & ("mumol/1) & $-0.8 \pm 0.3$ & $(-1.3 ;-0.2)$ & $+0.2 \pm 0.3$ & $(-0.4 ; \div 0.8)$ & \# \\
\hline$H B A_{t c}$ & (s) & $-0.2 \pm 0.1$ & $(-0.3 \div, 0.1)$ & $-0.1 \pm 0.1$ & $(-0.2 ;-0.0)$ & \\
\hline Fast insulin & (muit) & $-2.5 \pm 0.9$ & $(-4.2 ;-0.7)$ & $+0.4 \pm 0.6$ & $(-0.8 ;+1.6)$ & Hitit \\
\hline 2-Hour insulin & $(m u / l)$ & $-6.7 \pm 7.0$ & $(-20.0 x+6.5)$ & $+15.1 \pm 10.0$ & $(\cdot 5.1 ;+35.2)$ & \\
\hline HOMA-IR index & & $-0.72 \pm 0.29$ & $(-1.3 ;-0.1)$ & $+0.14 \pm 0.18$ & $(-0.2 ;+0.5)$ & $\#$ \\
\hline Insulhinogenic index & & $+1.3 \pm 1.1$ & $(-0.9 i+3.5)$ & $2.5 \pm 4.7$ & $(-12.0 ;+6.9)$ & \\
\hline
\end{tabular}

Data are mean \pm sem $195 \%$ confidence interval), abd, wabdominal; $P$ for difference in change between
groups: $<0.05 ;<0.01 ;$; 4 ; 0.001 


\section{Dietary intake}

Nutrient intake at baseline and after 1 year, calculated from the 3-day food record, is shown in Table 4.3. Baseline values for energy intake, macronutrient intake, alcohol consumption and fibre intake were comparable between groups. At the end of year 1 the intervention group had increased their carbohydrate and fibre intake $(P<0.001)$. Subjects in the intervention group decreased their total fat intake, saturated and monomnsaturated fatty acid intake $(\mathrm{P}<0.001)$ without changing their poly-unsaturated fatty acid intake. Changes in intake of total fat, saturated (SAFA), mono-unsaturated fatty acid (MUFA), carbohydrate and fibres were significant different between groups $(\mathrm{P}<0.05$, see Table 4.3$)$.

\section{Regression analysis}

Finally, we analyzed the impact of changes in risk factors on changes in glucose tolerance and insulin resistance in the intervention group. In Table 4.4 the results of the regression analysis are shown. The change in sagittal abdominal diameter correlated with the change in glucose tolerance $(\mathbb{P}<0.05)$. The change in body weight, $\mathrm{BMI}$ and $\mathrm{VO}_{2}$ max tended to correlate with the change in glucose tolerance $(P<0.10)$. Forward stepwise regression analysis with body weight, sagittal diameter and $\mathrm{VO}_{2} \max$ as independent variables revealed that the change in body weight was most strongly related to the change in glucose tolerance $(+0.18, P<0.05)$. The same procedure was repeated with change in HOMA-index as dependent variable (Table 4.4). Changes in body weight, body composition (waist, WHR and sagittal diameter), aerobic capacity and nutrient intake (total fat and MUFA and SAFA) were related to changes in insulin resistance (all $\mathrm{P}<0.05$ ). Stepwise regression with changes in body weight, sagittal diameter, $\mathrm{VO}_{2} \mathrm{max}$ and fat intake as independent variable showed that both change in body weight $(+0.20, \mathrm{P}<0.01)$ and change in $\mathrm{VO}_{2} \mathrm{max}$ were related to the change in HOMA-index $(-0.003, \mathrm{P}<0.01)$.

Table 4.3 Reported dietary intake

\begin{tabular}{|c|c|c|c|c|c|c|}
\hline & & \multicolumn{2}{|c|}{ BASELINE } & \multicolumn{2}{|c|}{ ONIE-YEAR } & \multirow[b]{2}{*}{$\begin{array}{c}\text { p.t } \\
\text { walue }\end{array}$} \\
\hline & & $\begin{array}{l}\text { intervention } \\
(n=47)\end{array}$ & $\begin{array}{c}\text { control } \\
(m=55)\end{array}$ & $\begin{array}{l}\text { intervertion } \\
(n=47)\end{array}$ & $\begin{array}{c}\text { controt } \\
(n+5 y)\end{array}$ & \\
\hline energy intalke & (Mulday) & $9.1 \pm 0.4$ & $8.5 \pm 0.3$ & $7.9 \pm 0.3$ & $8.2 \pm 0.3$ & 0.02 \\
\hline Carbohydrates & $\left(\mathrm{En}_{n}\right)$ & $42.2 \pm 1.0$ & $43.2 \pm 0.9$ & $46.9 \pm 1.1^{\text {tam }}$ & $43.9 \pm 1.0$ & $<0.01$ \\
\hline Fat & En & $36.2 \pm 0.9$ & $35.7 \div 0.9$ & $31.2 \pm 1.0^{\text {totit }}$ & $34.7 \pm 0.8$ & 0.01 \\
\hline saturated FA & Ens & $14.0 \pm 0.4$ & $13.9 * 0.4$ & $11.2 \pm 0.4^{\text {w.x. }}$ & $13.3 \pm 0.5$ & $<0.01$ \\
\hline MUFA & En & $12.9 \pm 0.4$ & $12.8 \div 0.4$ & $10.8 \pm 0.4^{\text {shex }}$ & $12.4 \pm 0.4$ & $<0.01$ \\
\hline PUFA & $\left.(\operatorname{En})_{n}\right)$ & $6.7+0.4$ & $6.5 \pm 0.3$ & $6.9=0.4$ & $0.5 \pm 0.3$ & ns \\
\hline Cholesterol & $(\operatorname{mg} / \mathrm{MJ})$ & $25.7 \pm 1.4$ & $27.5 \pm 1.6$ & $22.5 \pm 1.2$ & $26.1 \pm 1.3$ & ns \\
\hline Pirotein & $(\mathrm{En} x)$ & $15.7=0.4$ & $16.0 \pm 0.4$ & $17.4 \pm 0.5$ & $16.3 \pm 0.5$ & 0.06 \\
\hline Alcohol & $(\mathrm{En})$ & $5.9 \pm 1.1$ & $5.1 \pm 0.7$ & $4.5 \pm 0.9$ & $5.4 \neq 0.8$ & nis \\
\hline Fiber & $(\mathrm{g} / \mathrm{MU})$ & $2.8 \pm 0.1$ & $2.6 \div 0.1$ & $3.3 \pm 0.1$ w & $2.8 \pm 0.1$ & 0.03 \\
\hline
\end{tabular}

Data are mean \pm sem; FA=Fatty Acid, MUFA=Mono Unsaturated Fatty Acid, PUFA=Poly Unisaturated Fatty Acid $n s=n o t$ signficant; $P<0.001$ for difference within groups between one year and baseline; "P for difference in change over time between grcups ( $\mathrm{t}$-test) 


\section{Discussion}

The Study on Lifestyle-intervention and Impaired Glucose Tolerance Maastricht (SLIM) is carried out to evaluate the effect of lifestyle changes on glucose tolerance in subjects at risk for developing type 2 diabetes mellitus. The 3-year lifestyle intervention program consists of a dietary and physical activity part. In this paper the results after one year of intervention were reported. The main finding is that after one year glucose tolerance was significantly improved in. the intervention group, with a decrease in the 2 -hour blood glucose concentration of $0.8 \mathrm{mmol} / 1$, which is significantly different from the increase of $0.2 \mathrm{mmol} / 1$ found in the control group.

\section{Lifestyle-intervention program}

Several studies have started to evaluate intervention-programs that may delay or prevent the development of type 2 diabetes mellutus in high risk subjects. The Finnish Diabetes Prevention Study was the first well designed large scale imtervention study clearly showing the impact of lifestyle changes on glucose tolerance and the incidence of diabetes [8]. After a mean follow-up time of 3.2 year a risk reduction of $58 \%$ was seen in the intervention group. The recently published US Diabetes Prevention Program showed that lifestyle changes and treatment with metformin both reduced the incidence of diabetes. However, the lifestyle intervention was more effective than metformin [9].

The results of our study demonstrate once again the importance of lifestyle changes on changes in glucose tolerance. Furthermore, they confirm that a lifew style intervention works in a different population. This is important since the (long term) effect of a lifestyle intervention will depend on underlying food and exercise habits, frequency of obesity and IGT and the attitude of the participants towards lifestyle intervention programs. For example, an important difference between the Finnish DPS, the American DPP and the present study is the degree of obesity in the population studied. Average BMI was $29.5 \mathrm{~kg} / \mathrm{m}^{2}$ in our study versus $31.2 \mathrm{~kg} / \mathrm{m}^{2}$ in the Finnish DPS $[8]$ and $33.9 \mathrm{~kg} / \mathrm{m}^{2}$ in the American DPP 191 . As obesify is known as one of the most important risk factors for the progression of IGT to type 2 diabetes mellitus, our results indicate that even in a population with a lower degree of obesity a lifestyle intervention. program can substantially improve glucose tolerance. This is in line with the finding from the American DPP that in subgroups with a different degree of obesity, a comparable risk reduction was found with a lifestyle-intervention [9]. The incidence of type 2 diabetes rises in a graded manner with an increasing 2-hour blood glucose concentration, even at levels below the threshold for ICT 12.141. Thus, a decrease in 2-hour glucose should led to a decreased risk on progression to diabetes. In the Finnish DPS, a reduction of $0.9 \mathrm{mmol} / \mathrm{l}$ in the 2-hour blood glucose concentration after 1 year gave rise to a risk reduction of $58 \%$ in the incidence of diabetes at the end of the study [8]. The change in 2-hour blood glucose concentration found in our study after 1 year was of comparable magnitude $(-0.8 \mathrm{mmol} / 1)$, indicating a considerable reduction in the risk of progression to type 2 diabetes mellitus. 


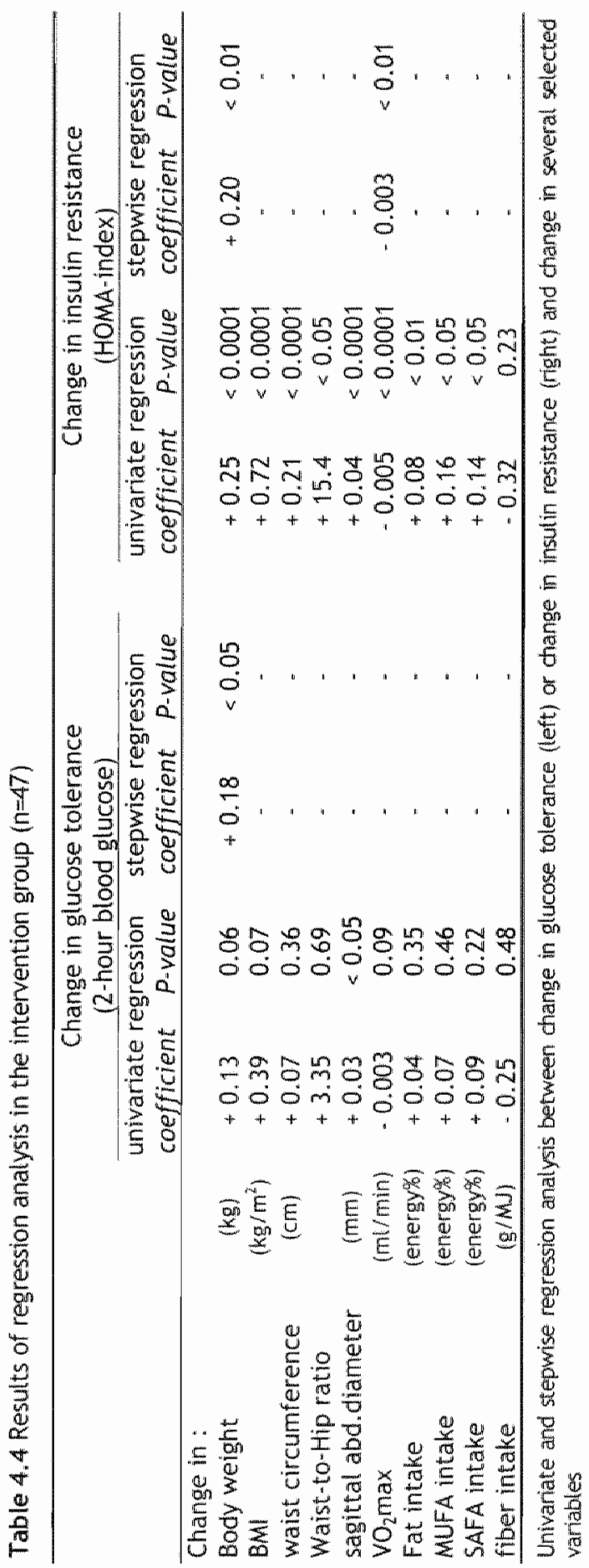




\section{Weight-loss}

In accordance with the results found in earlier studies $[5,8]$ weight-loss was small, but substantial $(-2.7 \mathrm{~kg}$ in the intervention group $v 5.0 .2 \mathrm{~kg}$ in the control group). This is somewhat less than found in the DPS [8] and the DPP [9]. However, as indicated before, our population was less obese (BMI $29.5 \mathrm{~kg} / \mathrm{m}^{2}$ ) as compared to the population of the DPS (BMI $31.5 \mathrm{~kg} / \mathrm{m}^{2}$ ) and the DPP (BMI $33.9 \mathrm{~kg} / \mathrm{m}^{2}$ ). Weight-loss was achieved by dietary advice, based on guidelines for a healthy diet (Dutch Nutrition Council), regular support (every 3 months) and the stimulation to increase the level of physical activity. No severe energy restriction or (very) low calorie diet was prescribed, which often results in large amounts of weight-Joss with a substantial regain after the dieting period. Weiglitwoss was attributable for one-third to loss of fat free mass, and two-third to fat mass. Whether the weight reduction achieved after 1 year can be maintained during the remainder of the study will be seen in the future.

Not only overall body weight decreased, but also abdominal obesity decreased, as reflected by the decrease in waist circumference and sagittal abdominal diameter. This is important, because abdominal obesity is positively associated with progression to type 2 diabetes mellitus [2], and (abdominal) obesity is strongly associated with (cardiovascular) morbidity $[10,15]$. No difference in change in the waist-to-hip ratio was observed as the reduction in weight in the intervention group resulted in both a reduction in waist and hip circumference. The relative small changes in body weight and abdominal fat accumulation seen in the intervention group after 1 year were accompanied by a substantial improvement in glucose tolerance and a reduction in insulin resistance, as indicated by a decreased HOMA-index and fasting insulin concentration. This points out the impact of relative small changes in body weight and abdominal body fat on metabolic improvements.

\section{Diet}

Diet and nutrition play an important part in the development of type 2 diaberes mellitus. Besides total fat and carbohydrate intake the type of fat and carbohydrate appears to be important [16]. A higher intake of polyunsaturated fat and possibly long-chain n-3 fatty acids could be beneficial, whereas a higher intake of saturated fatty acids and trans-fatty acids could adversely affect glucose metabolism [16]. After 1 year subjects in the intervention group had successfully exchanged saturated and mono-unsaturated fat for carbohydrates without changing their polyunsaturated fat intake. Since 5AFA may adversely affect glucose metabolism, this exchange could beneficially influence glucose tolerance. Comparable results were found in the KANWU-study [17], where reducing SAFA and increasing MUFA intake induced a significant improvement in insulin sensitivity in subjects with a lower fat intake $(<37$ En\%). Furthermore fibre intake was increased in the intervention group. A higher amount of dietary fibre seems to improve glycemic and insulinemic responses and lower the risk of type 2 diabetes mellitus [16]. When interpreting data on dietary intake some caution has to be taken into account. Subjects re-ported their food intake by means of a 3 -day food record, which give rise to 
underreporting, especially in obese subjects [18]. Furthermore, changes in the intervention group in dietary intake could reflect more advised dietary change than actual dietary change.

\section{Lifestyle-changes}

To develop and implement intervention programs aiming at the prevention or the delay of the progression from. IGT to diabetes, it is useful to assess the importance of changes in several lifestylle factors, i.e. dietary intake, body weight and physical activity. Our purpose was not to compare several different intervention strategies with each other, but rather to identify which lifestyle and anthropometric factors (as body weight, visceral adiposity, physical fitness and nutritional intake) were most strongly related with changes in glucose tolerance and insulin resistance. An advantage of the present study was that we were able to relate these factors to changes in glucose tolerance, as well as to changes in insulin resistance (HOMA-index). Change in body weight was the most important factor associated with improvement in glucose tolerance and insulin sensitivity in the intervention group. However, besides weight loss there was an additional effect of increased aerobic capacity $\left(\mathrm{VO}_{2} \mathrm{max}\right)$ on the improvement in insulin resistance. An observation comparable to results of the Malmö-study, in which an improvement in glucose tolerance was correlated to both, weight reduction and increased fitness [6]. This effect of increased aerobic capacity or fitness is not surprising regarding the impact of exercise (training) on insulin sensitivity [19].

\section{Conclusion}

The present study showed that a lifestyle-intervention program according to general recommendations is effective and improves glucose tolerance in subjects with IGT, thereby reducing the risk on progression to type 2 diabetes. Body weight loss and increased physical fitness were the most important determinants of improved glucose tolerance and insulin sensitivity.

\section{Acknowledgements}

We want to thank Jos Stegen for all his support during the OGTTs and the analytical measurements. Furthermore we want to thank Tanja Hermans-Limpens, Ilse Nijs and Marja van der Hulst for running the dietary intervention and for all their effort to motivate the subjects to participate. This work was supported by a grant from the Dutch Diabetes Research Foundation (DFN 98.901 ) and the Netherlands Organization for Scientific Research (ZonMW 940-35-034).

\section{References}

1 de Vegt F, Dekker JM, Jager A ct al. Relation of impaired fasting and postload glucose with incident type 2 diabetes in a Dutch population: The Hoom Study. IAMA 2001; 285: 2109-13.

2 Edelstein SL, Knowler WC, Bain RP ef al. Predictors of progression from impaired glucose tolerance to NIDDM: an analysis of six prospective studies. Dinbetes 1997; 46: 701-10. 
3 Sartor $G$, Schersten $B$, Carlstrom $S$ et al. Ten-year follow-up of subjects with impared glucose tolerance: prevention of diabetes by tolbutamide and diet regulation. Diabetes 1980; 29: 41-9.

4 Chiasson JL, Gomis R, Hanefeld M et al. The STOP-NIDDM Trial: an intemational study on the efficacy of an alpha-glucosidase inhibitor to prevent type 2 diabetes in a population with impaired glucose tolerance: rationale, design, and preliminary screening data. Study to Prevent Non-Insulin-Dependent Diabetes Mellitus. Diabetes Care 1998; 21: 1720-5.

5 Pan XR, Li GW, Hu YH et al. Effects of diet and exercise in preventing NIDDM in people with impaired glucose tolerance. The Da Qing IGT and Diabetes Study. Diabeles Care 1997: 20:537-44.

6 Eriksson KF, Lindgarde F. Prevention of type 2 (non-insulin-dependent) diabetes mellitus by diet and physical exercise. The 6-year Malmo feasibility study. Diabetologia 1991; 34:891-8.

7 Bourn DM, Mann J1, McSkimming BJ, Waldron MA, Wishart ID. Impaired glucose tolerance and NIDDM: does a lifestyle intervention program have an effect? Diabetes Care 1994; 17:1311-9.

8 Tuomilehto J, Lindstrom J, Eriksson JGet al. Prevention of type 2 diabetes mellitus by changes in lifestyle among subjects with impaired glucose tolerance. $N$ Engl Med 2001; 344: 1343-50.

9 Knowler WC, Barrett-Connor E, Fowler SE ef al. Reduction in the incidence of type 2 diabetes with lifestyle intervention or metformin. N Engl J Med 2002; 346: 393-403.

10 van Dam RM, Boer JM, Feskens El, Seidell JC. Parental history of diabetes modifies the association between abdominal adiposity and hyperglycemia. Diabetes Care 2001; 24: 1454-9.

11 American College of Sports Medicine Position Stand. The recommended quantity and quality of exencise for developing and maintaining cardiorespiratory and muscular fitness, and flexibility in healthy adults. Med Soi Sports Exerc 1998; 30: 975-
91 .

12 Matthews DR, Hosker JP, Rudenski AS el al. Homeostasis model assessment: insulin resistance and beta-cell function from fasting plasma glucose and insulin concentrations in man. Diabetologia 1985; 28:412-9.

13 Albareda M, Rodriguez-Espinosa I, Murugo M, de Leiva A, Corcoy R. Assessment of insulin sensitivity and beta-cell function from measurements in the fasting state and during an oral glucose tolerance test. Dimbetologif 2000; 43: 1507-11.

14 Sadd MF, Knowler WC, Pettitt DJ, Nelson RG, Bennett PH. Transient impaired ghtucose tolerance in Pima Indians: is it important? BMJ 1988; 297: 1438-41.

15 Seidell JC, Han TS, Feskens E], Lean ME. Narrow hips and broad waist circumferences independently contribute to increased risk of non-insulin. dependent diabetes mellitus. I hitew Med 1997; 242: $401-6$.

16 Hu FB, van Dam RM, Liu S. Diet and risk of type Il diabetes: the rolle of types of fat
and carbohydrate. Dintretologin $2001 ; 44: 805-17$.

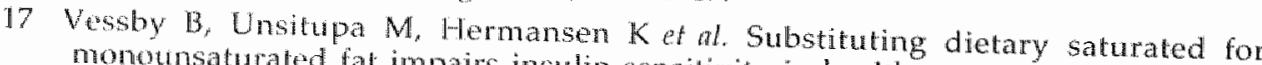
monounsaturated fat impairs insulin sensitivity in healthy men and women: The
KANWU Study. Dinberologin 2001; 44:312-9.

18 Coris AH, Meijer EP. Westerterp KR. Repeated measurement of habitual food intake increases under-reporting and induces selective under-reporting. Br J Nutr 2001; 85:
$629-34$.

19 Ivy IL. Role of exercise training in the prevention and treatment of insulin resistance and non-insulin-dependent diabetes mellitus. Sports Mélicine 1997; 24: 321-36. 


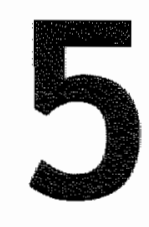

\section{Lifestyle Intervention According to General Recommendations Improves Glucose Tolerance in Dutch Subjects at Risk for Type 2 Diabetes}

Marco Mensink, Ellen E Blaak, Eefje Corpeleijn, Wim HM Saris, Tjerk WA de Bruin and Edith JM Feskens

Dept of Human Biology, Nutrition and Toxicology Research institute NUTRIM, Maastricht University, Maastricht, The Netherlands

Dept of Health and Nutrition, National Institute for Public Health and the Environment, Bilthoven, The Netherlands

Dept of Medicine and Endocrinology, University Hospital Maastricht, Maastricht, The Netherlands 


\begin{abstract}
Obesity, physical inactivity and an unhealthy diet are important risk factors for the development of type 2 diabetes mellitus. Aim of this present study was to evaluate the impact of a 2 -year combined diet and physical activity intervention program, on glucose tolerance in Dutch subjects at increased risk for developing diabetes. The intervention strategy was based upon general public health recommendations. Subjects with glucose intolerance were randomly assigned to either the lifestyle-intervention group or the control group. The intervention group received regular dietary advice and subjects were stimulated to increase their physical activity. The control group received a brief leaflet about healthy diet and increased physical activity only. Primary outcome measure was the change in glucose tolerance. In tatal 88 subjects completed 2 years of intervention ( 40 intervention group, 48 control group, mean BMI $29.4 \mathrm{~kg} / \mathrm{m}^{2}$ ). Subjects in the intervention group reduced their body weight, waist circumference and (saturated) fat intake and improved their aerobic capacity. 2 Hour plasma glucose concentration declined from $8.7 \mathrm{mmol} / 1$ to $8.0 \mathrm{mmol} / \mathrm{l}$ in the intervention group, and rose from $8.6 \mathrm{mmol} / \mathrm{l}$ to $9.4 \mathrm{mmol} / \mathrm{l}$ after 2 year in the control group $(\mathbb{P}<0.01)$. Subjects in the intervention group adherent to both the diet and exercise intervention showed the largest reduction in 2 -hour glucose levels.

In conclusion, a lifestyle intervention program according to general recommendations improves glucose tolerance and hyperinsulinemia also in a less obese and more active population. Furthermore, our results underscore the importance of combining diet and physical activity to improve glucose talerance and insulin resistance.
\end{abstract}


Impaired Glucose Tolerance (IGT) is considered to be a necssary stage en route to type 2 diabetes mellitus. The annual progression rate ranges from $4 \%$ to $8 \%$ in different populations [1,2]. Important factors predictive of the development of diabetes are obesity, dietary habits and lack of physical activity [1-3]. Therefore, changes in lifestyle should have the potential to postpone or prevent the development of type 2 diabetes melitus in high risk subjects, such as those with IGT.

Several studies have reported beneficial effects of lifestyle-intervention programs in high risk populations [4-7]. Recently, two well-controlled clinical trials, the Finnish DPP $\llbracket 6]$ and the US DPS $[7]$, showed that changing dietary habits and increasing physical activity resulted in a risk reduction of almost $60 \%$ in the progression from IGT to type 2 diabetes mellitus after 3 years.

However, several issues remain. As regards compliance and future implementation of such a prevention program it needs to be assessed whether moderate interventions, in agreement with current guidelines for the general population, are effective. Intensive interventions, such as sometimes used in aforementioned studies, are not likely to be adapted. In addition, it is imperative to know whether the results achieved by the DPS and DPP are valid for other populations, notably with a different dietary and physical activity background. The level of physical activity in e.g. the Dutch population is relatively high. In 1997, slightly more than one-half of the population was, on average, moderately active for more than half an hour per day [8], compared, for example, to about one-third of the US adults [9]. Furthermore, the prevalence of obesity in the Dutch population is relatively low compared to other (European) populations [10].

Finally, lifestyle-intervention programs are typically made up of a combination of dietary advice and exercise prescription. Both diet and physical activity are known to play an important rolle in the development of diabetes [11-13]. For a targeted implementation of lifestyle interventions into primary care it is important to know whether a combination of diet and exercise is a more effective approach to prevent development of diabetes, than diet or exercise alone.

Therefore the aim of the present study was to evaluate the impact of a 2 -year combined diet and physical activity intervention program, according to general recommendations, on glucose tolerance in Dutch subjects at increased risk for developing diabetes. In addition, we assessed whether adherence to the dietary intervention, to the physical activity intervention, or to both, is associated with a better improvement in glucose tolerance.

\section{Methods}

\section{Study design and subjects}

The Study on Lifestyle-intervention and IGT, Maastricht (SLIM), is designed to study whether a diet/physical activity intervention program can improve 
glucose tolerance in subjects with a high risk on developing type 2 diabetes mellitus.

Subjects with high risk of glucose intolerance, i.e. those of age $>40$ years and a family history of diabetes or a BMI $>25 \mathrm{~kg} / \mathrm{m}^{2}$, were selected from an existing cohort [14] in the Maastricht area and invited to undergo a first oral glucose tolerance test (OGTT). Those with known or owert diabetes were excluded.

Subjects with an elevated 2 -hour blood glucose concentration were invited for a second OGTT. For definite inclusion in the study, mean 2-hour glucase concentration of both OGTTs had to be between 7.8 and $12.5 \mathrm{mmol} / \mathrm{l}_{\text {, together }}$ with a fasting glucose concentration less than $7.8 \mathrm{mmol} / 1$. Furthermore subjects were excluded according to the following criteria: previously diagnosed diabetes mellitus, other than gestational diabetes mellitus; medication use known to interfere with glucose tolerance; participation in regular vigorous exercise or an intensive weight reduction program during the last year before the start of the study. Presence of any (chronic) disease which hampered participation in a lifestyle intervention program was a reason for exclusion, as was an improbability of a 5-year survival.

Eligible subjects were randomly assigned to the intervention or control group by one of the staff members not involved in the intervention, with the use of a randomization list. Randomization was carried out with stratification for sex and mean 2-hour plasma glucose concentration. Dieticians, trainers and staff members involved in the intervention had to be aware of the group assignment, laboratory staff did not know subjects' group assignment. Power calculations indicated that 2 groups of 40 subjects would sufficient to detect a $1 \mathrm{mmol} / \mathrm{l}$ difference in 2-hour glucose between groups after 2 year of intervention. The Medical Ethical Review Committee of Maastricht University approved the study protocol, and all subjects gave their written informed consent before the start of the study.

Primary outcome measure was a change in glucose tolerance, i.e. 2-hour blood glucose concentration during the OGTT. Secondary outcome measures are changes in fasting plasma glucose concentration, changes in insulin, insulin resistance (HOMA index), glycated hemoglobin $\left(\mathrm{HbA}_{l \mathrm{c}}\right.$ ), and body composition and aerobic capacity. Measurements were performed at baseline, and after 1 and 2 year.

\section{Lifestyle-intervention program}

The intervention program consisted of a dietary and physical activity part, with visits scheduled at regular intervals throughout the study. Dietary recommendations were based on the Dutch guidelines for a healthy diet (Dutch Nutrition Council) and consisted of: carbohydrate intake of at least $55 \%$ of total energy intake (En\%); total fat intake of less than 30-35 En\%, with less than 10 En\% intake of saturated fatty acids; a cholesterol intake of less than $33 \mathrm{mg}$ per MJ; protein intake of 10-15 En\% and an intake of dietary fibre of at least 3 gram per MJ. A body weight loss of $5-10 \mathrm{~kg}$ was aimed at depending on the degree of obesity. Furthermore, participants were encouraged to stop smoking and, if necessary, to reduce alcohol intake. Dietary advice was given by a skilled 
dietician on individual basis, after consideration of an individual 3-day food record. The first visit was 4-6 weeks after randomization. Thereafter, every three months a visit was scheduled.

Subjects were stimulated to increase their physical activity to at least 30 minutes of moderate physical activity a day for at least 5 days a week [15]. At the start of the study individual advice was given how to increase daily physical activity (walking, cycling, swimming), and goals were set. Furthermore, subjects were encouraged to participate in an exercise program, specially designed for this study, with components of aerobic exercise training and resistance training.

Exercise sessions were supervised by trainers. Subjects had free access to these training sessions and were stimulated to participate at least one hour a week.

Subjects in the control group received oral and written information about the beneficial effects of a healthy diet, weight loss and increased physical activity, whereas no individual advice or programs were provided. No additional appointments were scheduled, apart from the visits for the annual measurements.

Two years-successful adherence to the dietary intervention was defined as reaching two or three goals out of the following three dietary goals: total fat intake less than $35 \mathrm{En} \%$, saturated fatty acid intake less than $10 \mathrm{En} \%$ and fibre intake more than $3 \mathrm{gram}$ per MJ. Successful adherence to the physical activity intervention was defined as the participation of at least 1 hour a week in the supervised exercise sessions during the past 2 years of intervention.

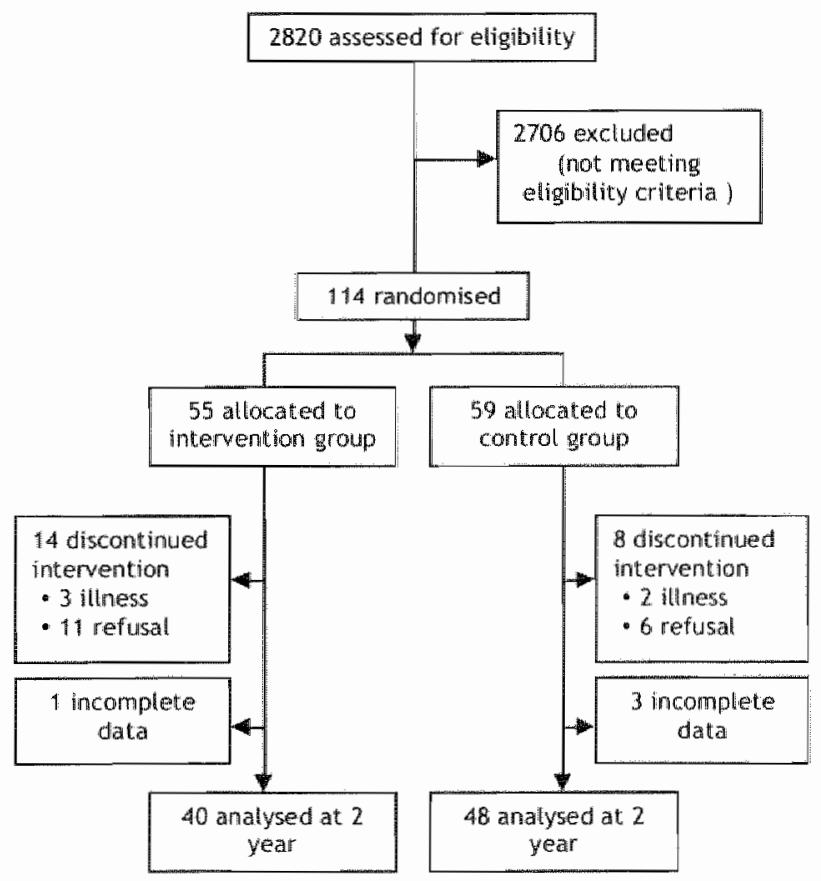

Figure 5.1 Flow chart Lifestyle-intervention study (see text for details) 


\section{Measurements}

To follow changes in glucose tolerance during the study a standard oral glucose tolerance test (OGTT) was performed. Plasma glucose, plasma FFA and serum blood lipids were measured with a standard enzymatic technique automated on the Cobas Fara centrifugal analyzer. LDL cholesterol was calculated according to the formula of Friedewald [16]. Plasma insulin concentration was measured with an ELISA assay (Mercodia, Sweden) which shows no cross-reactivity with pro-insulin. Glycated hemoglobin $\left(\mathrm{HbA}_{1,}\right)$ was determined in a fasting serum sample with the EPLC technique (reference value for our laboratory $4.4-6.2 \%$ ). The HOMA-index was calculated as described by Matthews et al. [17].

Body weight was measured with an electronical scale to the nearest $0.1 \mathrm{~kg}$, with the subject wearing light clothing only. Waist circumference (waist) was measured with the subject in standing position at the levell midway between the lowest rib and the iliacal crest to the nearest $0.5 \mathrm{~cm}$, and hip circumference was measured as the maximum circumference over the buttocks to the nearest 0.5 $\mathrm{cm}$. An incremental exhaustive exercise test was performed on an electronically braked bicycle ergometer to determine the maximal power output and maximal peak oxygen consumption $\left(\mathrm{VO}_{2} \max \right)$.

A 3-day food record (two weekdays and 1 weekend day) was kept in the last 2 weeks before the annual wisit. Food records were checked by a dietician and intake of nutrients was calculated with a validated computer program using the Dutch food table (NEVO).

\section{Statistical analysis}

Analysis was done according to the intention-to-treat principle. Differences between groups were tested with a Students $t$-test for independent samples, or by a chi-square test. Changes over time between groups were assessed with an analysis of variance (ANOVA) for repeated measures. Analysis of covariance (ANCOVA) was used for comparison between multiple groups, with correction for differences in sex and baseline values. A P $<0.05$ was considered statistically significant.

\section{Results}

The trial profile is depicted in Figure 5.1. Screening people for eligibility was started March 1999. First study subject was randomized in June 1999, the last in May 2000. Follow-tup after 2 years of intervention was completed June 2002. In total, 114 subjects were randomized, 55 to the intervention group and 59 to the control group. No differences were seen in baseline characteristics between groups (Table 5.1). 14 subjects in the intervention group (INT) and 8 subjects in the control group (CON) discontinued the study. In 5 cases a medical reason was given, in 17 cases subjects refused to attend the annual visits (11 INT, 6 CON). Another 4 participants had incomplete data after 2 years (1 INT, 3 CON). No differences were seen in age, gender, initial BMI or baseline fasting and 2hour plasma glucose levells between participants and drop-outs (data not shown). 
Table 5.1 Subjects characteristics at baseline $(n=114)$

\begin{tabular}{|c|c|c|c|}
\hline & & INTERVENTION & CONTROL \\
\hline subjects & $(M / F)$ & $55(30 / 25)$ & $59(34 / 25)$ \\
\hline age & (year) & $55.6 \pm 0.9$ & $57.8 \pm 1.0$ \\
\hline weight & $(\mathrm{kg})$ & $86 \pm 1.9$ & $83.7 \pm 1.5$ \\
\hline $\mathrm{BM}$ & $\left(\mathrm{kg} / \mathrm{m}^{2}\right)$ & $29.8 \pm 0.5$ & $29.3 \pm 0.4$ \\
\hline Waist & $(\mathrm{cm})$ & $102.4 \pm 1.5$ & $102.3 \pm 1.1$ \\
\hline Waist-hip-ratio & & $0.97 \pm 0.01$ & $0.97 \pm 0.01$ \\
\hline $\mathrm{VO}_{2} \max$ & $(1 / \mathrm{min})$ & $2.15 \pm 0.08$ & $2.13 \pm 0.08$ \\
\hline fasting glucose & (monalf) & $5.9 \pm 0.1$ & $5.8 \pm 0.1$ \\
\hline 2-hour glucose & (mmol/t) & $8.9 \pm 0.3$ & $8.6 \pm 0.2$ \\
\hline $\mathrm{Hb} A_{1 c}$ & $(\%)$ & $5.9 \pm 0.1$ & $5.9 \pm 0.1$ \\
\hline fasting insulin & $(\mathrm{mu} / \mathrm{l})$ & $13.8 \pm 1.3$ & $12.1 \pm 0.8$ \\
\hline 2-hour insulin & $(\mathrm{mU} / \mathrm{t})$ & $91.3 \pm 6.7$ & $97.5 \pm 8.1$ \\
\hline HOMA & & $3.8 \pm 0.4$ & $3.2 \pm 0.2$ \\
\hline
\end{tabular}

Data are mean \pm sem; $(M / F)=$ Male/Female

No serious adverse events were observed in the intervention group during the 2 years of follow up. Analysis after 2 years of intervention was performed according to intention-to-treat, and included 40 intervention subjects and 48 control subjects.

\section{Dietary intake}

Subjects in the intervention group successfully reduced their intake of total and saturated fatty acids and increased their fibre and carbohydrate intake (Table 5.2). Changes over time in carbohydrate, fat and saturated fatty acid intake, were significantly different between groups ( $P<0.01$ for interaction), while fibre intake tended to be higher in the intervention group $(P=0.07)$.

\section{Subject characteristics}

Table 5.3 shows the changes in characteristics after 1 and 2 years of intervention $(n-88)$. Significant differences between the intervention and control group were found for changes in body weight ( $P<0.01$, for interaction), BMI $(P<0.01)$ and waist circumference $(P=0.02)$. Mean weight-loss in the intervention group was $2.4 \pm 0.7 \mathrm{~kg}$ after 2 year, compared to a weight-loss of $0.1 \pm 0.5 \mathrm{~kg}$ in the control group. Aerobic capacity $\left(\mathrm{VO}_{2}\right.$ max) increased in the intervention group, and decreased in the control group $(P=0.04)$. Importantly, 2-hour plasma glucose concentration declined from $8.7 \pm 0.3 \mathrm{mmol} / \mathrm{l}$ at baseline to $8.0 \pm 0.4 \mathrm{mmol} / \mathrm{l}$ after 2 year in the intervention group, compared to an increase from $8.6 \pm 0.3$ mmol/1 at baseline to $9.4 \pm 0.4 \mathrm{mmol} / 1$ after $2 \mathrm{yr}$. in the control group $(\mathrm{P}<0.01$; see Figure 5.2). Normal glucose tolerance was present in $50 \%$ of the subjects in the intervention group (20/40) after 2 year compared to $29 \%$ in the control group (16/48; $\mathrm{P}<0.05)$. Insulin sensitivity, expressed as HOMA-index, improved in the intervention group, and deteriorated in the control group $(P=0.05)$. 
Table 5.2 Reported dietary intake ( $n=88$ )

\begin{tabular}{|c|c|c|c|c|c|c|c|}
\hline & & \multirow[t]{2}{*}{ BASELINE } & \multirow[t]{2}{*}{ Y YEAR } & \multirow[t]{2}{*}{2 YEAR } & \multicolumn{3}{|c|}{ ANOVA } \\
\hline & & & & & group & time & interact. \\
\hline Carbohydrate & INT & $41.9 \pm 1.1$ & $47.0 \div 1.3$ & $47.4 \pm 0.9$ & 0.06 & $<0.01$ & $<0.01$ \\
\hline$(E n \%)$ & CON & $42.9 \pm 1.0$ & $42.9 \pm 1.1$ & $43.7 \pm 0.9$ & & & \\
\hline Fat & INT & $36.6 \pm 1.0$ & $31.1 \pm 1.1$ & $31.8 \pm 0.8$ & $<0.01$ & $<0.01$ & $<0.01$ \\
\hline (End) & CON & $35.9 \pm 1.0$ & $35.4 \pm 0.9$ & $35.6 \pm 0.6$ & & & \\
\hline SAFA & INT & $14.2 \pm 0.4$ & $11.1 \pm 0.5$ & $11.1 \pm 0.4$ & $<0.01$ & -0.01 & $<0.01$ \\
\hline$(E n \%)$ & CON & $14.1 \pm 0.5$ & $13.6 \pm 0.5$ & $14.1 \pm 0.3$ & & & \\
\hline Cholesterol & $\mathbb{N N T}$ & $26.6 \pm 1.6$ & $22.4 \pm 1.2$ & $22.5 \pm 1.1$ & 0.10 & $<0.01$ & ns \\
\hline$(m g / k J)$ & CON & $27.6 \pm 1.7$ & $26.9 \pm 1.5$ & $26.0 \pm 1.8$ & & & \\
\hline Protein & INT & $15.9 \pm 0.5$ & $17.7 \pm 0.5$ & $17.5 \pm 0.4$ & $<0.05$ & $<0.05$ & 0.07 \\
\hline$(\operatorname{En} \%)$ & CON & $15.8 \pm 0.4$ & $16.3 \pm 0.6$ & $16.1 \pm 0.4$ & & & \\
\hline Fiber & $\| N T$ & $2.8 \pm 0.1$ & $3.3 \pm 0.2$ & $3.1 \pm 0.1$ & $<0.01$ & $<0.01$ & 0.07 \\
\hline$(\mathrm{g} / \mathrm{MU})$ & $\mathrm{CON}$ & $2.6 \pm 0.1$ & $2.7 \pm 0.1$ & $2.7 \pm 0.1$ & & & \\
\hline
\end{tabular}

Data are mean \pm sem; En\% $=$ Energy $\%$, SAFAmaturated fatty acids

Fasting insulin $(P=0.08)$, fasting glucose $(P=0.12)$, and HbA $A_{1 c}(P=0.32)$ were not significantly different between groups over time, but trends tended to be favorable in the intervention group. Serum triglycerides reduced during the study in the intervention group compared to an increase among controls $(\mathbb{P}<0.01)$, whereas no differences between intervention and control group were observed in total, HDL and LDL cholesterol.

Table 5.3 Change in subjects characteristics $(n=88)$

\begin{tabular}{|c|c|c|c|c|c|c|c|}
\hline & & \multirow[t]{2}{*}{ BASELINE } & \multirow[t]{2}{*}{1 YEAR } & \multirow[t]{2}{*}{2 YEAR } & \multicolumn{3}{|c|}{ ANOVA } \\
\hline & & & & & time & group & interact. \\
\hline $\begin{array}{l}\text { weight } \\
\text { (kg) }\end{array}$ & $\begin{array}{l}\text { INT } \\
\text { CON }\end{array}$ & $\begin{array}{l}87.8 \pm 2.4 \\
82.7 \pm 1.6\end{array}$ & $\begin{array}{l}84.6 \pm 2.3 \\
82.5 \pm 1.4\end{array}$ & $\begin{array}{l}85.4 \pm 2.3 \\
82.6 \pm 1.5\end{array}$ & $<0.01$ & ins & $<0.01$ \\
\hline $\begin{array}{l}B M M \\
\left(\mathrm{~kg} / \mathrm{m}^{2}\right)\end{array}$ & $\underset{C O N}{\mathbb{N N T}}$ & $\begin{array}{l}30.1 \pm 0.6 \\
28.8 \pm 0.5\end{array}$ & $\begin{array}{l}29.0 \pm 0.6 \\
28.7 \pm 0.4\end{array}$ & $\begin{array}{l}29.3 \pm 0.6 \\
28.8 \pm 0.4\end{array}$ & $<0.01$ & ns & $<0.01$ \\
\hline $\begin{array}{l}\text { Waist } \\
(\mathrm{cm})\end{array}$ & $\begin{array}{l}\text { INT } \\
\text { CON }\end{array}$ & $\begin{array}{l}103.0 \pm 1.9 \\
101.2 \pm 1.1\end{array}$ & $\begin{array}{r}99.2 \pm 1.9 \\
100.0 \pm 1.2\end{array}$ & $\begin{array}{l}101.0 \pm 1.8 \\
100.6 \pm 1.2\end{array}$ & $<0.01$ & ns & 0.02 \\
\hline $\begin{array}{l}\text { volmax } \\
\text { (l/min) }\end{array}$ & $\begin{array}{l}\mathbb{N N T} \\
\text { CON }\end{array}$ & $\begin{array}{l}2.21 \pm 0.10 \\
2.16 \pm 0.09\end{array}$ & $\begin{array}{l}2.38 \pm 0.11 \\
2.20 \pm 0.09\end{array}$ & $\begin{array}{l}2.39 \pm 0.10 \\
2.11 \pm 0.09\end{array}$ & ns & ns & 0.04 \\
\hline $\begin{array}{l}\text { fast glucose } \\
\text { (mmolli) }\end{array}$ & $\begin{array}{l}\text { INT } \\
\text { CON }\end{array}$ & $\begin{array}{l}5.9 \pm 0.1 \\
5.8 \pm 0.1\end{array}$ & $\begin{array}{l}5.8 \pm 0.1 \\
5.9 \pm 0.1\end{array}$ & $\begin{array}{l}6.1 \pm 0.2 \\
6.3 \pm 0.1\end{array}$ & $<0.01$ & ns & 0.12 \\
\hline $\begin{array}{l}\text { 2-h glucose } \\
\text { (momolli) }\end{array}$ & $\begin{array}{l}\text { INT } \\
\text { CON }\end{array}$ & $\begin{array}{l}8.7 \pm 0.3 \\
8.6 \pm 0.3\end{array}$ & $\begin{array}{l}7.8 \pm 0.3 \\
8.9 \pm 0.3\end{array}$ & $\begin{array}{l}8.0 \pm 0.4 \\
9.4 \pm 0.4\end{array}$ & ns & $<0.05$ & $<0.01$ \\
\hline $\begin{array}{l}\text { Hbatc } \\
\text { (o) }\end{array}$ & $\begin{array}{l}\mathbb{N N T} \\
\text { CON }\end{array}$ & $\begin{array}{l}5.9 \pm 0.1 \\
6.0 \pm 0.1\end{array}$ & $\begin{array}{l}5.7 \pm 0.1 \\
5.8 \pm 0.1\end{array}$ & $\begin{array}{l}5.9 \pm 0.1 \\
5.9 \pm 0.1\end{array}$ & ns & $<0.01$ & 0.32 \\
\hline $\begin{array}{l}\text { fast insulin } \\
\text { (mu/l) }\end{array}$ & $\begin{array}{l}\text { INT } \\
\text { CON }\end{array}$ & $\begin{array}{l}14.5 \pm 1.6 \\
12.1 \pm 0.9\end{array}$ & $\begin{array}{l}11.5 \pm 1.1 \\
12.3 \pm 1.0\end{array}$ & $\begin{array}{l}12.3 \pm 1.0 \\
13.9 \pm 1.7\end{array}$ & ns. & ns & 0.08 \\
\hline HOMA & $\begin{array}{l}\text { INT } \\
\text { CON }\end{array}$ & $\begin{array}{l}4.0 \pm 0.5 \\
3.2 \pm 0.3\end{array}$ & $\begin{array}{l}3.1 \pm 0.3 \\
3.3 \pm 0.3\end{array}$ & $\begin{array}{l}3.5 \pm 0.4 \\
3.9 \pm 0.5\end{array}$ & ns & ns & 0.05 \\
\hline $\begin{array}{l}\text { tot cholesterol } \\
\text { (mmolli) }\end{array}$ & $\begin{array}{l}\text { INT } \\
\text { CON }\end{array}$ & $\begin{array}{l}5.1 \pm 0.1 \\
5.2 \pm 0.1\end{array}$ & $\begin{array}{l}5.1 \pm 0.1 \\
5.4 \pm 0.1\end{array}$ & $\begin{array}{l}5.4 \pm 0.1 \\
5.6 \pm 0.1\end{array}$ & $\propto 0.01$ & $\mathrm{~ns}$ & ns \\
\hline $\begin{array}{l}\text { triglycerices } \\
(\mathrm{mm} \text { moll })\end{array}$ & $\begin{array}{l}\mathrm{INT} \\
\mathrm{CON}\end{array}$ & $\begin{array}{l}1.67 \pm 0.23 \\
1.51 \pm 0.12\end{array}$ & $\begin{array}{l}1.65 \pm 0.26 \\
1.70 \pm 0.20\end{array}$ & $\begin{array}{l}1.37 \pm 0.14 \\
1.75 \pm 0.19\end{array}$ & $\mathrm{~ns}$ & $\mathrm{~ns}$ & $<0.01$ \\
\hline
\end{tabular}

Data are mean \pm sem; interact. $=$ grotup $\times$ time interaction 


\section{Diet and/or exercise}

To assess the separate or combined effects of diet and exercise, the changes in several variables were compared between subjects fully compliant to the dietary intervention $(n=10)$, exercise intervention $(n=9)$, both diet and exercise intervention ( $n=10)$ and neither diet nor exercise $(n=11)$ (see methods section for criteria). As shown in Figure 5.3, the combination of diet and exercise resulted in a significantly larger weight-loss, $-6.2 \pm 1.6 \mathrm{~kg}$, and larger reduction in waist circumference, $-5.7 \pm 2.0 \mathrm{~cm}$ after 2 year compared to the other subgroups $(\mathrm{P}<0.01$; adjusted for sex and baseline values). Changes in fasting insulin were greatest in the group compliant to diet and exercise $(\mathbb{P}<0.05)$. Also, changes in 2-hour plasma glucose, were more pronounced in the diet and exercise group (mean change in 2-hour glucose $-1.9 \pm 0.6 \mathrm{mmol} / \mathrm{l} ; \mathrm{P}=0.09$ ). Reduction in plasma triglycerides after 2 year was most pronounced in the diet and exercise group $(-0.44 \pm 0.17 \mathrm{mmol} / 1$ for diet and exercise, vs. $-0.31 \pm 0.27 \mathrm{mmol} / 1,-0.18 \pm$ $0.14 \mathrm{mmol} / 1$ and $+0.02 \pm 0.10 \mathrm{mmol} / 1$ for non, diet alone and exercise alone respectively; $\mathrm{ANOVA} \mathrm{P}=0.14$ ).

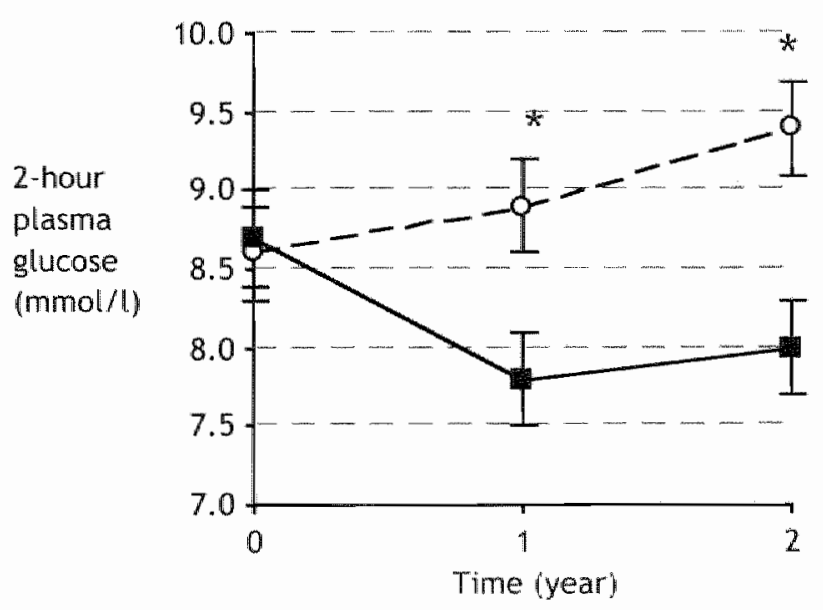

Figure 5.2 Two-hour plasma glucose concentration for intervention group (black squares, solid line) and control group (open circles, dotted line) at baseline and after 1 and 2 years of follow-up; Data are mean \pm sem; ${ }^{*} P<0.01$ intervention vs. control group

\section{Discussion}

The present study showed that a combined dietary and physical activity intervention program, according to general recommendations, improved glucose tolerance in a population at risk for developing type 2 diabetes. After 2 years, postload blood glucose concentration was reduced from $8.7 \mathrm{mmol} / \mathrm{l}$ to $8.0 \mathrm{mmol} / 1$ in the intervention group, compared to an increase from $8.6 \mathrm{mmol} / 1$ to $9.5 \mathrm{mmol} / 1 \mathrm{in}$ the control group. This indicates that the risk of developing type 2 diabetes mellitus is reduced. Interestingly, subjects adherent to both, the 
diet and exercise intervention, showed the largest reduction in 2 -hour blood glucose levels and fasting insulin levels and the largest reduction in body weight and waist circumference, indicating that the combination of diet and exercise is most effective in improving the metabolic profile.

\section{General recommendations}

The intervention strategy we used in this randomized trial was based on general public health recommendations. The dietary intervention program was designed according to guidelines from the Dutch Nutrition Council, and was not supported by (very) low energy diets or other dieting agents. Furthermore, low to moderate intensity physical activity for $30 \mathrm{~min}$ a day was prescribed, instead of high intensity exercise. Such a regimen, based on general recommendations, is much more suitable to prevent diabetes, as it is less time consuming and much better tolerated than very intensive intervention programs. This is important, considering the fact that most subjects at increased risk for developing diabetes are middlle-aged and are more or less obese.
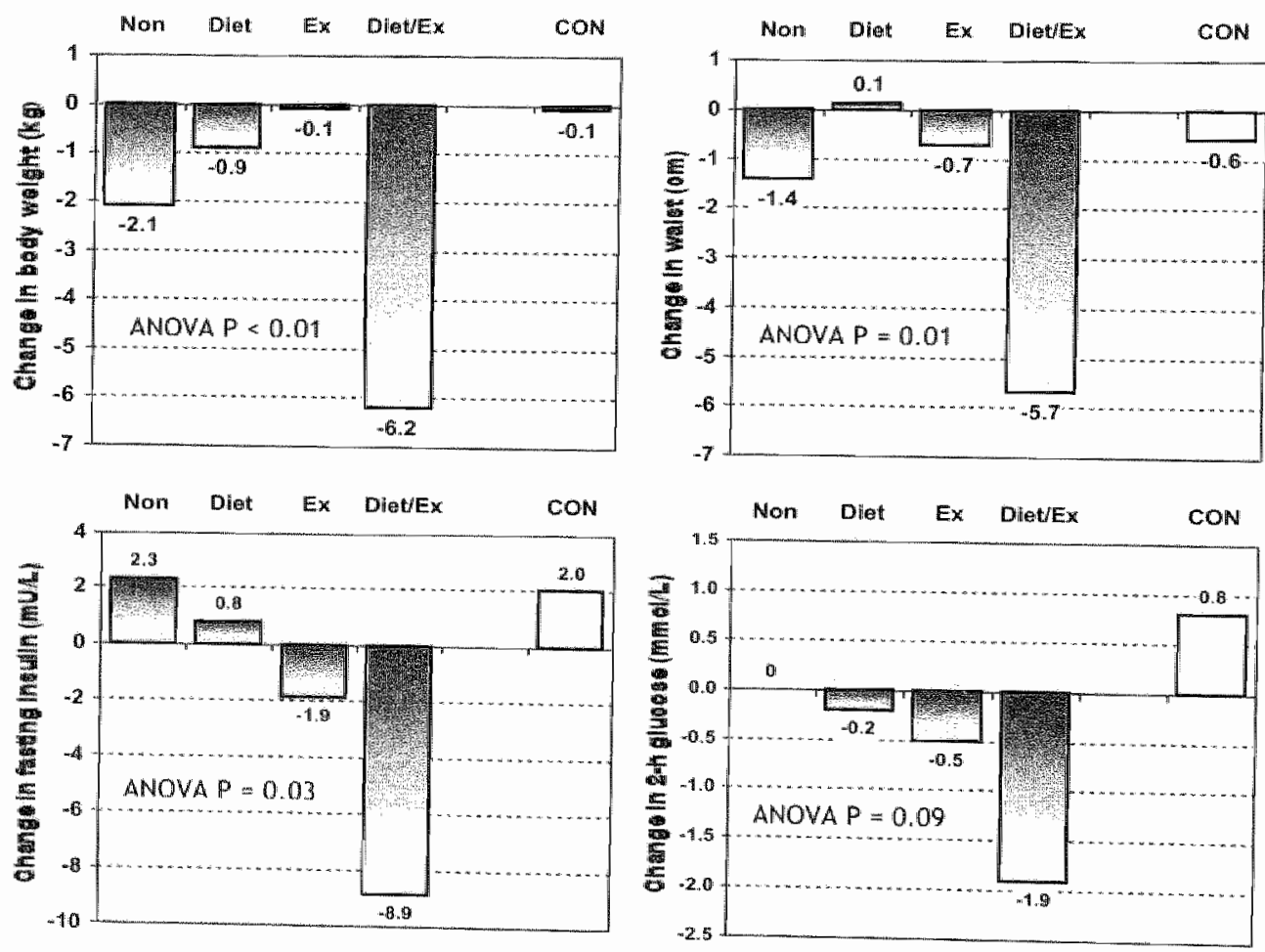

Figure 5.3 Changes after 2 years of follow up in body weight (top-left), waist circumference (top-right), fasting insulin (bottom-left) and 2 -hour glucose (bottom-right) in subjects in the intervention group fully compliant to the dietary program (Diet), exercise program (Ex), diet and exercise intervention (Diet/Ex) or neither (Non); As a reference
changes in the control group are given (open bars) 


\section{Lifestyle-intervention}

In the last decade, several studies have shown the efficacy of lifestyleintervention programs in reducing the incidence of type 2 diabetes $[4-7 \mid$. The Finnish Diabetes Prevention Study (DPS) [6] and the US Diabetes Prevention Program (DPP)[7] reported, after a mean follow-up of 3 years, a risk reduction of $58 \%$ in the dietary and physical activity intervention group. Consistent with these reports, our findings clearly show the impact of changes in diet and physical activity on glucose tolerance. Our observed reduction in 2-hour blood glucose of $0.9 \mathrm{mmol} / 1$ after 1 year in the present study is comparable with the reduction after 1 year reported in the interim-paper of the DPS 18. The Dutch population has a low prevalence of obesity compared to other (European) populations [10]. Our study population was less obese (mean BMI $29.4 \mathrm{~kg} / \mathrm{m}^{2}$ ) compared to the Finnish (BMI $31 \mathrm{~kg} / \mathrm{m}^{2}$ ) and the American study population (mean BMI $34 \mathrm{~kg} / \mathrm{m}^{2}$ ). Furthermore Dutch subjects are known for their relatively high level of physical activity. Thus, our results indicate that a modest lifestyle-intervention program is effective in a less obese, more active population, and leads to a comparable improvement in glucose tolerance.

Beside the lifestyle approach, several studies have investigated the effect of early drug interventions to prevent or delay the conversion from IGT to type 2 diabetes. The STOP-NIDDM trial showed that acarbose, an $\alpha$-glucosidase inhibitor, reduced the risk of diabetes by $25 \%$ after 3.3 years [19]. Metformin, a biguanide, reduced the risk of diabetes substantially in the American DPP $(31 \%)$, whereas the lifestyle-intervention was much more effective $(58 \%)[7]$. Thus, although drug-intervention reduces the incidence of diabetes, lifestyle changes reduce the incidence to a much larger extent.

Our lifestyle-intervention program not only improved glucose tolerance but also successfully reduced (abdominal) adiposity (body weight and waist circumference) and improved aerobic fitness ( $\mathrm{VO}_{2} \mathrm{max}$ ). Furthemore serum triglycerides were reduced in the intervention group. Results of a meta-analysis of prospective studies showed that for each mmol/l triglycerides increase the risk for cardiovascular disease increases with $14 \%$ for men and $37 \%$ fo women, independent of i.e. HDL-cholesterol [20]. Fasting triglycerides are also a risk factor for the development of type 2 diabetes $[21]$.

\section{Diet and/or exercise}

What determines the success of a lifestyle-intervention program? Is it predominantly the dietary intervention, the physical activity part, or the combination of both? Only a few studies addressed this question. The Oslo Diet and Exercise Study concluded that the combination of diet and exercise was most effective [22], whereas the Chinese Da Qing IGT and Diabetes Study observed no additional benefit of combining diet and exercise, because diet or exercise alone were equally effective 15]. The current findings indicated that the combination is more effective than diet or exercise alone. Subjects adherent to both. diet and exercise, showed the highest improvement in glucose tolerance, i.e. $1.9 \mathrm{mmol} / \mathrm{l}$ after 2 years, which is considerably higher than the $0.8 \mathrm{mmol} / 1$ 
observed for the intervention group as a whole, and would, in theory, convert the ICi status to nomal.

\section{Mechanisms}

What explains the beneficial effect of lifestyle changes on glucose tolerance? A considerable larger reduction in body weight and waist circumference was obserwed in those adherent to both diet and exercise. This increased (abdominal) weight-loss is probably an important mediator of the improved glucose tolerance. Adding physical exercise to a (diet-induced) weight-loss program is important, since it improves weight-maintenance on the long-term [23]. Apart from this, acute exercise as well as exercise training enhance insulin stimulated GLUT4 translocation and results in an improved glucose uptake by muscle [24]. Furthermore, exercise training improves the ability to oxidize fatty acids in skeletal muscle [25]. This is important as the insulin resistant state is characterized by an impaired capacity to oxidize fatty acids $[26,27]$, which could play an important role in the development of type 2 diabetes [28]. The increased maximal oxygen consumption in the intervention group, as compared to the control group, reflects the better aerobic capacity due to physical training. Changes in dietary intake could also explain the improved glucose tolerance, in a direct manner, as well as via concomitant weight-loss. Both, a reduction in total fat intake and a substitution of unsaturated fatty acids for saturated fatty acids improve insulin sensitivity [11]. Additionally, an increased fiber intake is inversely associated with the risk of diabetes [12]. All together, several mechanisms, each acting on distinct aspects of insulin resistance, can explain the beneficial effect of a combined diet and physical activity intervention program on glucose tolerance.

\section{Conclusion}

The present findings clearly show the impact of lifestyle changes on glucose tolerance in a Dutch population at increased risk for diabetes. It shows that a moderate lifestyle intervention program according to general public health recommendations is effective in a population with a relatively low obesity rate and a relatively high level of physical activity. Furthermore, our results underscored the importance of combining diet and physical activity to improve glucose tolerance. Awareness of the impact of early lifestyle interventions in those at increased risk for diabetes should be raised, to enable development of strategies to reduce the burden of type 2 diabetes mellitus.

\section{Acknowledgements}

We want to thank los Stegen for his support during the numerous OGTTS and the analytical measurements. Furthermore we want to thank Tanja HermansLimpens, Ilse Nijs and Marja van der Hulst for their help with the dietary intervention and their efforts to motivate the subjects to participate.

This work was supported by a grant from the Dutch Diabetes Research Foundation (DFN 98.901 ) and the Netherlands Organization for Scientific 
Research (ZonMW 940-35-034). The RIVM Monitoring projects were financially supported by the Ministry of Public Health, Welfare and Sports.

\section{References}

1 Edelstein SL; Knowler WC, Bain RP et al. Predictors of progression from impaited glucose tolerance to NIDDM: an analysis of six prospective studies. Diabetes 1997: 46: $701-10$.

2 de Vegt F, Dekker JM, Jager A et al. Relation of impained fasting and postload glucose with incident type 2 diabetes in a Dutch population: The Hoorn Study. TAMA 2001; 285: 2109-13.

3. Hu FB, Manson JE, Stampfer MI of al. Diet, lifestyle, and the risk of type 2 diabetes mellitus in women. N Engl / Med 2001; 345: 790-7.

4 Eriksson $\mathrm{KF}$, Lindgarde $\mathbb{F}$. Prevention of type 2 (non-insulin-dependent) diabetes mellitus by diet and physical exercise. The 6-year Malmo feasibility study. Diabetologia 1991; 34: 891-8.

5 Pan XR, Li GW, Hu YH et al. Effects of diet and exercise in preventing NIDDM in people with impaired glucose tolerance. The Da Qing IGT and Diabetes Study. Diabetes Care 1997; 20: 537-44.

6 Tuomilehto J, Lindstrom J. Eriksson JG ot al. Prevention of type 2 diabetes mellitus by changes in lifestyle among subjects with impared glucose tolerance. $N$ Engl I Med 2001; 344: 1343-50.

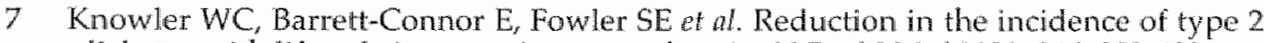
diabetes with lifestyle intervention or metformin. N Engl / Med 2002; 346:393-403.

8 Schuit A], Feskens E), Seidell JC. [Physical activity in relation to sociodemographic variables and health status of adult men and women in Amsterdam, Doetinchem and Maastricht]. Ned Tijdsctw Geneeskd 1999; 143: 1559-64.

9 Jones DA, Ainsworth BE, Croft $\mathbb{B}$ ef al. Moderate leisure-time physical activity: who is meeting the public health recommendations? A national crossmectional study. Arch Fam Med 1998; 7; 285m.

10 Visscher TL, Kromhout D, Seidell JC. Longuterm and recent time trends in the prevalence of obesity among Dutch men and women. Int I Obes Relat Metab Disord $2002 ; 26: 1218-24$.

1.1. Vessby $B$, Unsitupa M, Hermansen $K$ ef al. Substituting dietary saturated for monounsaturated fat impairs insulin sensitivity in healthy men and women: The KANWU Study, Diabetologia 2001; 44: 312-9.

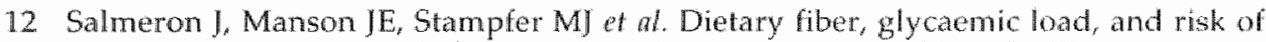
non-insulin-dependent diabetes mellitus in women. / AMA 1997; 277: 472-7.

13 Hu FB, Sigal RI, Rich-Edwards JW at al. Walking compared with vigorous physical activity and risk of type 2 diabetes in women: a prospective study. IAMA 1999: 282: 1433-9.

14 van Dam RM, Boer JM, Feskens E), Seidel! IC. Parental history of diabetes nodifies the association between abdominal adiposity and hyperglycemia. Diabetes Care 2001; $24: 1454-9$.

15 American College of Sports Medicine Position Stand. The recommended quantity and quality of exercise for developing and maintaining cardiorespiratory and muscular fitness, and flexibility in heathy adults. Med Sci Sporls Exerc 1998; 30: 975 91.

16 Friedewald WT, Levy RI, Fredrickson DS. Estimation of the concentration of low density lipoprotein cholesterol in plasma, without use of the preparative ultracentrifuge. Clin Chem 1972; 18: 499-502. 
17 Matthews DR, Hosker JP, Rudenski AS et al. Homeostasis model ascessment: insulin resistance and beta-cell function from fasting plasma glucose and insulin concentrations in man. Diabetologia 1985; $28: 412-9$.

18 Eriksson], Lindstrom I, Valle $\mathbb{T}$ et al Prevention of type II diabetes in subjects with impaired glucose tolerance: the Diabetes Prevention Study (DPS) in Finland. Study design and 1 -year interim report on the feasibility of the lifestyle intervention programme. Dinbetologia 1999; $42: 793-801$.

19 Chilasson JL, Josse RG, Gomis R et al. Acarbose for prevention of type 2 diabetes mellitus: the STOP-NIDDM randomized trial. Lancet 2002; 359:2072-7.

20 Hokanson JE. Austin MA. Plasma triglyceride level is a risk factor for cardiowascular disease independent of high-density lipoprotein cholesterol level: a meta- analysis of population-based prospective studies. J Cardiovasc Risk 1996; 3: $213-9$.

21 Lee ET, Welty TK, Cowan LD et al. Incidence of diabetes in American Indians of three geographic areas: the Strong Heart Study. Diabetes Care 2002; 25 : 49-54.

22 Torjesen PA, Birkeland KI, Anderssen SA et al. Lifestyle changes may reverse development of the insulin resistance syndrome. The Oslo Diet and Exercise Study: a randomized trial. Diabetes Care $1997 ; 20: 26-31$.

23 Tremblay $A$, Doucet $E$, Imbeault P. Physical activity and weight maintenance. Int Obes Relat Metab Disord 1999; 23 Suppl 3 : 550-4.

24 Borghouts LB, Keizer HA. Exercise and insulin sensitivity: a review. Int I Sports Med 2000: $21: 1-12$.

25 Jeukendrup AE, Saris WH, Wagenmakers AJ. Fat metabolism during exercise: a review-part 11: regulation of metabolism and the effects of training. Int 7 Sports Med $1998 ; 19: 293-302$.

26 Blaak EE. Wagenmakers A.J. Glatz JF of al. Plasma FFA utilization and fatty acidbinding protein content are diminished in type 2 diabetic muscle. Am J Physiol Endocrinol Metab 2000; 279: E146-54.

27 Merisink M, Blaak EE, van Baak MA, Wagenmakers $A J$, Saris WH. Plasma free Fatty Acid uptake and oxidation are already diminished in subjects at high risk for developing type 2 diabetes. Diabetes 2001; 50: 2548-54.

28 McGarry ID. Banting lecture 2001: dysregulation of fatty acid metabolism in the etiology of type 2 diabetes. Diabetes $2002 ; 51: 7-18$. 


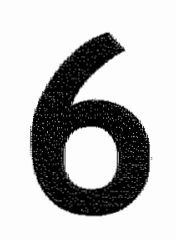

\section{Plasma Free Fatty Acid Uptake and Oxidation are Already Diminished in Subjects at High Risk for Developing Type 2 Diabetes}

Marco Mensink, Ellen E Blaak, Marleen A van Baak, Anton JM Wagenmakers and Wim HM Saris

Dept of Human Biology, Nutrition and Toxicology Research Institute NUTRIM, Maastricht University, Maastricht, The Netherlands

Diabetes 2001; 50: 2548-2454 


\begin{abstract}
Type 2 diabetes mellitus is characterized by a diminished capacity to utilize and oxidize fatty acids (FA) in skeletal muscle. The objective of this study was to investigate to what extent these disturbances in FA metabolism are already present in subjects at high risk for developing diabetes (i.e. Impaired Glucose Tolerance, (GT). Components of fatty acid metabolism were measured in male IGT subjects during postabsorptive conditions and during $60 \mathrm{~min}$ of exercise (50\% VO $\mathrm{V}_{2}$ max) with the use of the stable isotope tracer [U. ${ }^{13} \mathrm{C}$ ]palmitate in combination with indirect calorimetry, and compared those to previously published findings in male type 2 diabetic and male obese subjects. No differences were found between groups in energy expenditure and in total fat and carbohydrate axidation. Rate of appearance and rate of disappearance of plasma FFA were lower in IGT and type 2 diabetic subjects compared to obese subjects $(P<0.05)$. Plasma FFA oxidation was lower in IGT and type 2 diabetic subjects compared to obese subjects at rest and tended to be lower during exercise (rest: $3.7 \pm 0.3,4.4 \pm 0.6$ and $6.9 \pm 1.0 \mu \mathrm{mol} / \mathrm{kgFFM} / \mathrm{min}, P<0.01$; exercise: $15.0 \pm 1.7,14.1 \pm 1.9$ and $19.6 \pm 1.5 \mu \mathrm{mol} / \mathrm{kgFFM} / \mathrm{min}$ for IGT, type 2 $D M$ and obese subjects respectively, $P=0.07$ ). Triglyceride-derived FA oxidation however was elevated in $I G T$ and type 2 diabetic subjects during exercise $13.6 \pm$ $1.4,1.4 \pm 1.4$ and $-4.0 \pm 2.0 \mu \mathrm{mol} / \mathrm{kgFFM} / \mathrm{min}$ for $1 \mathrm{GT}$, type $2 \mathrm{DM}$ and obese subjects respectively; $P<0.05$ ).

These data demonstrate that male subjects with a prediabetic condition (i.e. IGT) have the same defects in fatty acid utilization as subjects with type 2 diabetes mellitus, suggesting that these disturbances may play an important role in the development from IGT to type 2 diabetes mellitus.
\end{abstract}


Increased circulating levels of plasma free fatty acid (FFA), a common finding in type 2 diabetic subjects, have been identified as an important factor associated with insulin resistance and development of type 2 diabetes mellitus, and seems to be related to common risk factors for coronary heart diseases including hypertriglyceridaemia, hyper-apo $B$ and increased coagulation activity [1]. In the liver an increased delivery of FFA can impair insulinmediated suppression of hepatic glucose output [2], increase synthesis of very low density lipoproteins (VLDL) [1] and diminish hepatic insulin clearance (3). Chronically ellevated levels of circulating FFA may also reduce insulin secretion by the $\beta$-cell of the pancreas $[4,5]$.

Elevated FFA concentrations may result from increased fasting rates of lipolysis, which seem to result from both the enlarged adipose tissue stores and an impaired insulin-mediated suppression of lipolysis 161 . On the other hand defects in FFA uptake and/or oxidation could also result in elevated circulating levels of PFA. Colberg et al.[7] reported that in visceral obese women there was a negative relation between visceral fat content and postabsorptive FFA utilization by skeletal muscle. Similar results were shown by Kelley and coworkers $[8,9]$ using the leg balance technique in combination with indirect calorimetry. They reported a diminished uptake of plasma FFA and a diminished oxidation rate of fatty acids in the postabsorptive state in patients with type 2 diabetes mellitus in comparison with lean healthy subjects. We have shown in (obese) type 2 diabetic patients that the uptake and oxidation of plasma FFA is diminished in the forearm muscles in the postabsorptive state and during $\beta$-adrenergic stimulation $[10 \rrbracket$. Type 2 diabetic subjects also had a diminished plasma FFA oxidation and a higher triglyceride derived fatty acid oxidation at whole body level as compared to weight matched controls during rest and moderate-intensity exercise $\left(50 \% \mathrm{VO}_{2} \mathrm{max}\right)[11]$.

Skeletal muscle is believed to be the main site responsible for the impaired fatty acid utilization and oxidation, because of its large mass and since lipids are the principal oxidative substrate of skeletal muscle after an overnight fast and during moderate intensity exercise. A misbalance between (free) fatty acid uptake and (free) fatty acid could easily lead to fat accumulation within skeletal muscle. Indeed skeletal muscle triglyceride content is increased up to sixfold in patients with diabetes mellitus [12,13]. Furthermore the content of intramuscular triglycerides (IMTG) shows a strong negative correlation with the degree of insulin resistance (i.e. insulin-stimulated glucose disposal [14,15].

Thus there is a lot of evidence indicating that disturbances in muscle fatty acid utilization may play an important role in the etiology of insulin resistance and type 2 diabetes mellitus. However, it is difficult to assess the pathophysiological abnormalities leading to type 2 diabetes when the type 2 diabetic state has already developed, since it is impossible to differentiate between primary factors and adaptational responses. Subjects with an impaired glucose tolerance (IGT) have an elevated risk for the development of type 2 diabetes nellitus. Within 10 year up to $50 \%$ of the subjects with IGT become diabetic [16]. If the disturbances in (skeletal muscle) fatty acid metabolism described above are already present in the glucose intolerant state, this could indicate that the 
defects might be important etiological factors in the development of type 2 diabetes mellitus.

Therefore the objective of this study was to investigate to what extent disturbances in fatty acid metabolism found in the diabetic state were already present in subjects at high risk for developing type 2 diabetes mellitus (1.e. IGT). We measured components of fatty acid metabolism with the use of stable isotope tracers in combination with indirect calorimetry in $I G T$ subjects and compared those to previously published findings in type 2 diabetic subjects and obese subjects, during postabsorptive conditions and during 60 min of moderate intensity exercise [11].

\section{Methods}

\section{Subjects}

Seven obese nomoglycemic (Obese), seven impaired glucose tolerant (IGT) and seven type 2 diabetic male subjects (type 2 DM) were studied. Impaired glucose tolerance was determined during a 2 hours oral glucose tolerance test according to the WHO-criteria (1985). Type 2 diabetes mellitus was diagnosed with an OGTT. Diabetic subjects were treated with diet alone $(n=3)$ or diet together with sulphonylureas $(n=4)$; blood glucose lowering medication was witheld for 2 days before the experiment. Subjects had no other health problems besides the diabetes / IGT, and did not use other medication. Before the start of the study a medical history and physical examination was performed, and a resting ECG was taken. The participants did not perform regular intensive exercise or followed a strict diet or weight reduction program for the last year before the start of the study. Subjects were selected from different cohorts and matched as close as possible for body composition and aerobic capacity. See Table 6.1 for subject characteristics. The Medical Ethical Review Committee of Maastricht University approved the study protocol, and all subjects gave their written informed consent before the start of the study.

Table 6.1 Subject characteristics

\begin{tabular}{|c|c|c|c|c|c|}
\hline & & $\begin{array}{c}\text { Obese } \\
(n=7)\end{array}$ & $\begin{array}{l}\mathrm{IGT} \\
(\mathrm{n}=7)\end{array}$ & $\begin{array}{c}\text { Type 2 DM } \\
(\mathrm{n}=7)\end{array}$ & ANOVA \\
\hline age & (year) & $45.1 \pm 1.7$ & $58.3 \pm 2.4^{*}$ & $51.3 \pm 3.4$ & $P<0.01$ \\
\hline body weight & (kg) & $100.8+3.7$ & $93 \pm 3.3$ & $110.8 * 7.1$ & $\mathrm{~ms}$ \\
\hline body fat & $(\%)$ & $35 \pm 1.2$ & $33 \pm 1.2$ & $36.6 \pm 1.3$ & ns \\
\hline FFM & $(\mathrm{kg})$ & $65.6 \pm 2.9$ & $62.3 \pm 2.3$ & $70.1 \pm 4.2$ & ns \\
\hline waist & $(\mathrm{cm})$ & $109 \pm 2.8$ & $109 \pm 1.7$ & $120 \pm 3.9$ & $P<0.05$ \\
\hline WHR & & $1.04 \pm 0.04$ & $1.04 \pm 0.01$ & $1.06 \pm 0.03$ & nis \\
\hline $\mathrm{VO}_{2} \max$ & $(\mathrm{ml} / \mathrm{kgFFM} / \mathrm{min})$ & $41.5 \pm 1.2$ & $39.6 \pm 0.9$ & $36.2 \pm 2.9$ & ns \\
\hline Wimax & (W/kgFFM) & $2.88 \pm 0.1$ & $2.54 \pm 0.1$ & $2.63 \pm 0.2$ & ns \\
\hline $\begin{array}{l}\text { fasting glucose } \\
\text { FFA }\end{array}$ & $\begin{array}{c}(\mathrm{mmol} / \mathrm{l}) \\
(\mathrm{\mu mol} / \mathrm{l})\end{array}$ & $\begin{array}{l}5.3 \pm 0.1 \\
727 \pm 69\end{array}$ & $6.2 \pm 0.4$ & $7.7 \pm 0.58^{*} \#$ & $P<0.01$ \\
\hline OPth & & & $571 \pm 93$ & $770 \pm 95$ & ns \\
\hline
\end{tabular}




\section{Pre-test}

Before the start of the experiment an incremental exhaustive exercise test was pertiformed on an electronically braked bicycle ergometer (Lode, Groningen, the Netherlands) to determine the maximal aerobic power output (Wmax) and oxygen consumption $\left(\mathrm{VO}_{2}\right.$ max). The test started at a workload of $0.75 \mathrm{~W}$ per $\mathrm{kg}$ fat free mass (FFM) for 3 minutes, followed by 3 minutes at $1.5 \mathrm{~W}$ per $\mathrm{kg} F \mathrm{FM}$. Thereafter the workload was increased every 3 minutes by $0.5 \mathrm{~W}$ per $\mathrm{kg}$ FFM until exhaustion ( $R Q$ above 1.1 and no further increase in oxygen uptake). Throughout the whole experiment heart rate, $\mathrm{O}_{2}$ consumption and $\mathrm{CO}_{2}$ production were measured to determine maximal $\mathrm{VO}_{2}$ and heart rate. Maximal power output was calculated using the time spent on the last workload before exhaustion.

\section{Body composition}

Body weight was determined on an electronical scale; body composition was determined by hydrostatic weighing with simultaneous lung volume measurement (Volugraph 2000, Mijnhardt, Bunnik, the Netherlands), and calculated according to Siri [17]. Waist and hip circumference measurements were made with subjects standing in the upright position to the nearest $1 \mathrm{~cm}$, half way the spina iliaca and the last rib, and at the level of the trochanter major, respectively.

\section{Study design}

Each subject participated in random order in two different trials, separated by at least one week. Subjects were asked not to participate in any (exhausting) physical activity the last three days before the trials to exclude changes in substrate metabolism induced by the last bout of exercise. They also were asked not to consume any products of high natural ${ }^{13} \mathrm{C}$-abundance during the last week before both tests as this may disturb the ${ }^{13} \mathrm{C} /{ }^{12} \mathrm{C}$ measurement in blood and expired air [18]. In the palmitate-test total fat and carbohydrate oxidation as well as several parameters of fat metabolism were determined by means of the stable isotope technique with a $\left[\mathrm{U}^{13} \mathrm{C}\right]$ palmitate tracer (protocol 1) in the postabsorptive state while resting supine on a comfortable bed in a room kept at $21-23^{\circ} \mathrm{C}$, and during submaximall exercise $\left(50 \% \mathrm{VO}_{2} \mathrm{max}\right)$. During a separate test the stable isotope tracer $\left[1,2-{ }^{13} \mathrm{C}\right]$ acetate was infused to determine the acetate recovery factor necessary for correction of palmitate oxidation rates for loss of label in the tricarboxylic acid cycle and bicarbonate pool (protocol 2) 119].

\section{Protocol 1}

Subjects reported to the laboratory at 8.00 and came to the lab by car or by bus, after an overnight fast (starting at 22.00 hour the evening before). Two canulas were inserted, one into a forearm vein for the infusion of palmitate and one in retrograde direction into a contralateral dorsal hand vein for blood sampling. The canulated hand was placed in a hot box where air was circulated at $60^{\circ} \mathrm{C}$ in order to obtain arterialized venous blood. Background blood and breath 
samples were taken 30 minutes after placement of the catheters. Then, at $t=0$ minutes an intravenous dose of $0.085 \mathrm{mg} / \mathrm{kg} \mathrm{NaH}{ }^{13} \mathrm{CO}_{3}$ was given to prime the bicarbonate pool, followed by a constant rate continuous infusion of [U${ }^{43} \mathrm{Clpalmitate}(0.0067 \mu \mathrm{mol} / \mathrm{kg} / \mathrm{min}$ ) via a calibrated infusion pump (IVAC560 pump, IVAC, San Diego, CA) till the end of the resting period $(0-120 \mathrm{~min})$. During the last 20 minutes of the resting period $(t=100,110$ and $120 \mathrm{~min}$ ) breath and blood samples were taken. Thereafter, exercise was started at $50 \%$ of the pre-determined individual $\mathrm{VO}_{2} \max (\sim 45 \% \mathrm{Wmax})$ for 1 . hour $(120-180 \mathrm{~min})$. The rate of infusion of $\left[\mathrm{U}-{ }^{13} \mathrm{C}\right]$ palmitate was doubled at the start of the exercise. During the last 20 minutes of exercise blood and breath samples were taken $(t=160,170$ and $180 \mathrm{~min}$ ) The palmitate tracer (potassium salt of [U${ }^{13} \mathrm{Clpalmitate,} \mathrm{99 \%}$ enriched; Cambridge Isotope laboratories, Andover, MA) was dissolved in heated sterile water and passed through a $0.2 \mu \mathrm{m}$ filter into $5 \%$ warm human serum albumin (Central Blood Bank, the Netherlands) to make a $0.65 \mathrm{mmol} / 1$ solution. The exact infusion rate of $\left[\mathrm{U}^{13} \mathrm{C}\right]$ palmitate was determined for each experiment by measuring the concentration of the infusate (see Biochemical Methods).

\section{Protocol 2}

During this trial the same regime as described for Protocol 1 was followed with the exception that in place of a $\left[U-{ }^{13} \mathrm{C}\right]$ palmitate tracer a $\left[1,2-{ }^{13} \mathrm{C}\right]$ acetate tracer was infused. A priming dose of $\mathrm{NaH}^{13} \mathrm{CO}_{3}(0,085 \mathrm{mg} / \mathrm{kg})$ was given, followed by a constant rate continuous infusion of $\left[1,2-{ }^{3} \mathrm{C}\right]$ acetate at 0.046 $\mu \mathrm{mol} / \mathrm{kg} / \mathrm{min}$ during rest $(0-120 \mathrm{~min})$ and twice during exercise $(120-180 \mathrm{~min})$, thereby giving the same ${ }^{13} \mathrm{C}$-infusion rate as for palmitate. At the same time points as described in protocol 1 breath samples were obtained, no blood samples were drawn. The acetate tracer (sodium salt of $\left[1,2-{ }^{13} \mathrm{C}\right]$ acetate, $99 \%$ enriched; Cambridge Isotope laboratories, Andover, MA) was dissolved in $0.9 \%$ saline, and was infused at the same ${ }^{13} \mathrm{C}$ infusion rate per time unit as that for the palmitate tracer.

\section{Breath, blood and urine sampling}

Breath samples were obtained by having the subjects breathe normally for at least 3 min into a mouthpiece connected to a 6.75 -liter mixing chamber and then collecting a breath sample into a $20 \mathrm{ml}$ vacutainer tube (Becton Dickinson, Meyland Cedex, France) in order to determine the enrichment of $\mathrm{CO}_{2}\left({ }^{13} \mathrm{C} /{ }^{12} \mathrm{C}\right.$ ratio). $\mathrm{VO}_{2}$ and $\mathrm{VCO}_{2}$ were determined by means of open-circuit spirometry (Oxycon $\beta$, Mijnhardt, Bunnik, the Netherlands) during the resting period and the last 30 min of exercise. Arterialized blood samples were collected in EDTAcontaining tubes on ice and were immediately centrifuged at $3000 \mathrm{rpm}$ at $4^{\circ} \mathrm{C}$, and the plasma was put away in liquid nitrogen and stored at $-80^{\circ} \mathrm{C}$ until analysis. Urine was collected overnight in containers with $\mathrm{H}_{2} \mathrm{SO}_{4}$ to determine nitrogen excretion for calculating the nonprotein respiratory exchange ratio. Biochemical methods. Breath samples were analyzed for ${ }^{13} \mathrm{C} /{ }^{12} \mathrm{C}$ ratio by injecting $20 \mu$ of the gaseous head space into a gas chromatograph-isotope ratio
mass spectrometer (GC-IRMS; Finnigan MAT 252; Finnigan, Bremen, 
Germany). Total plasma FFA, glucose and infusate acetate concentrations were measured using standard enzymatic techniques automated on the Cobas Fara centrifugal analyzer at $340 \mathrm{~nm}$ (for FFA: FFA-C test kit, Wako chemicals, Neuss, Germany; for glucose: Roche Unikit III, Hoffman-La Roche, Basel, Switzerland; for acetate: kit no 148261 Boehringer Mannheim, Mannheim, Germany). For the determination of plasma palmitate concentration and enrichment, FFA were extracted from plasma, isolated by thin layer chromatography, and derivatized to their methyl esters. Palmitate concentrations were determined on an analytical GC with ion-flame detection using heptadecanoic acid as an internal standard; on average palmitate concentration was $25 \pm 1 \%$ of total FFA concentration. Isotopic enrichment of palmitate was determined by GC-IRMS after online combustion of fatty acids to $\mathrm{CO}_{2}$ (Finnigan MAT 252), with correction for the extra methyl group in the derivate. The concentration of infusate palmitate was determined as described above for plasma samples.

\section{Calculations}

The metabolic rate was calculated from $\mathrm{VO}_{2}$ and $\mathrm{VCO}_{2}$ according to the equation of Weir [20]. Carbohydrate (c) and fat ( $f$ ) oxidation rates were calculated from $\mathrm{VO}_{2}$ and $\mathrm{VCO}_{2}$ and urinary nitrogen excretion [21]. Protein oxidation (as calculated from nitrogen excretion) was assumed to be similar during the overnight fasted state and during exercise.

Total fatty acids oxidation was calculated by converting the rate of fat oxidation (triglyceride oxidation) to its molecular equivalent, with the assumption of the average molecular weight of triglyceride to be $860 \mathrm{~g} / \mathrm{mol}$, and multiplying the molar rate of triglyceride oxidation by three because each molecule contains three moles of fatty acids.

Enrichment of breath $\mathrm{CO}_{2}$ and plasma palmitate and acetate is given as tracer/tracee ratio (TTR).

\section{TTR $=\left({ }^{13} \mathrm{C} /{ }^{12} \mathrm{C}\right)$ sample- $\left({ }^{13} \mathrm{C} /{ }^{12} \mathrm{C}\right)$ background.}

Fractional recovery of label in breath $\mathrm{CO}_{2}$, derived from the infusion of labeled acetate is calculated as follows:

\section{acetate recovery $=\left(\mathrm{TTRCO}_{2} * \mathrm{VCO}_{2}\right) / 2 \mathrm{~F}$}

where $F$ is the infusion rate of acetate ( $\mathrm{mmol} / \mathrm{min}$ ), and the number 2 in the denominator is to correct for the number of ${ }^{13} \mathrm{C}$ molecules in acetate. $V \mathrm{CO}_{2}$ is the expired $\mathrm{CO}_{2}$ in $\mathrm{mmol} / \mathrm{min}$.

During the last $20 \mathrm{~min}$ of the resting period (time points 110 and $120 \mathrm{~min}$ ) a physiological and isotopic steady state was present, and therefore Steele's equation for steady state was applied to calculated palmitate rate of appearance (Ra) and rate of disappearance (Rd).

\section{palmitate $\mathrm{Ra} / \mathrm{Rd}=(\mathrm{F} / \mathrm{TTR}$ plasma palmitate $)-\mathrm{F}$}

where $F$ is the infusion rate of palmitate in $\mu \mathrm{mol}$ per min.

During the last $20 \mathrm{~min}$ of the exercise period (160-170 and $170-180 \mathrm{~min})$ the single pool non-steady state equations of Steele adapted for use with stable isotopes were used to calculate Ra and Rd of palmitate. 


$$
\text { Ra palmitate }=\frac{\mathrm{F}-\mathrm{V}\left[\mathrm{C}_{2}+\mathrm{C}_{1} / 2\right]\left[\left(\mathrm{TTR}_{2}-\mathrm{TTR}_{1}\right) /\left(\mathrm{t}_{2}-\mathrm{t}_{1}\right)\right]}{\left(\mathrm{TTR}_{2}+\mathrm{TTR}_{1}\right) / 2}
$$

\section{Rd palmitate $=R a-V\left(C_{2}-C_{1}\right) /\left(t_{1}-t_{2}\right)$}

where $\mathrm{F}$ is the infusion rate ( $\mu \mathrm{mol} / \mathrm{kg} / \mathrm{min}), V$ is the volume of distribution which was assumed to be $0.0401 / \mathrm{kg} ; C_{1}$ and $C_{2}$ are the palmitate concentrations at times $t_{1}$ and $t_{2}$ respectively.

The Ra and Rd of $\mathbb{F}$ during rest and exercise respectively were calculated by dividing the palmitate flux and palmitate $R a$ and $R d$ by the fractional contribution of palmitate to the total FA concentration.

The percent of infused $\left[\mathrm{U}^{-3} \mathrm{C}\right]$ palmitate oxidized was calculated with the formula:

$$
\% \text { infused tracer oxidized }=\frac{\left(\operatorname{TTRCO}{ }_{2}^{*} \mathrm{VCO}_{2}\right)}{\left(16^{* /} \mathrm{F}^{*} \text { acetate recovery }\right)}{ }^{*} 100 \%
$$

where $\mathrm{F}$ is the infusion rate of palmitate ( $\mu \mathrm{mol} / \mathrm{min}$ ) and the number 16 in the denominator is to correct for the number of ${ }^{13} \mathrm{C}$ molecules in palmitate. $\mathrm{VCO} \mathrm{C}_{2}$ is the expired $\mathrm{CO}_{2}$ in $\mu \mathrm{mol} / \mathrm{min}$.

At the end plasma FFA oxidation, expressed in $\mu$ mol/min was calculated:

\section{plasma FFA oxidation = RdFFA * infused palmitate tracer oxidized}

The fatty acid oxidation from plasma triglycerides (TG) and intramuscular triglycerides was calculated according to:

\section{TG-derived FA oxidation = total FA oxidation - plasma FFA oxidation}

\section{Statistical analysis}

Data are presented as mean $I$ sem. Oxidation rates and $R a$ and $R d$ are expressed as $\mu \mathrm{mol} / \mathrm{kgFFM} / \mathrm{minute}$. Differences between groups were analyzed by a twomway analysis of variance. Changes in concentration of metabolites over lime were analyzed with a repeated-measures analysis of variance. Statistical significance was set at $P<0.05$. In case of significance a scheffe posthoc test was performed.

\section{Results}

\section{Subject characteristics and exercise intensity}

Subjects were matched for body composition and aerobic capacity, there were no significant differences in \%bodyfat, fat free mass (FFM) and maximal aerobic power (see Table 6.1). Type 2 DM subjects had a llarger waist circumference compared to IGT and obese subjects, waist-to-hip ratio lhowever was not different. IGT-subjects tended to have a lower body weight $(P=0.06)$. IGT- 
subjects were older than the obese subjects $(\mathrm{P}<0.01)$. Fasting blood glucose level was $7.7 \pm 0.5 \mathrm{mmol} / 1$ in type $2 \mathrm{DM}$, which was significantly elevated in comparison with Obese and IGT $(\mathrm{P}<0.01)$.

During the last 20 minutes of exercise oxygen consumption reached a plateau (data not shown). No differences were observed in axygen consumption between groups during exercise $(1.55 \pm 0.07,1.36 \pm 0.06$ and $1.35 \pm 0.11 \mathrm{l} / \mathrm{min}$ for Obese, IGT and type 2 DM). During the last 20 minutes of exercise mean relative workload was comparable $(57.8 \pm 3.6,55.2 \pm 2.1$ and $54.9 \pm 4.6$ $\% \mathrm{VO}_{2}$ max for Obese, IGT and type $2 \mathrm{DM}$ ).

\section{Arterialized concentrations of metabolites}

Plasma glucose levels were higher during rest in type 2 DM subjects (Table 6.2; $P<0.05)$. During exercise blood glucose levels declined in type $2 \mathbb{D M}(\mathrm{P}<0.05)$ and remained stable in Obese and IGT subjects, differences between groups in blood glucose concentration were no longer significant during exercise. Insulin levels were elevated in type 2 diabetes at rest and during exercise $(P<0.05)$.

Insulin levels declined as a result of exercise ( $P<0.01$ ), decline was not different between groups. Circulating levels of plasma FFA were not different between groups, nor at rest neither during exercise (Table 6.2). Plasma FFA levels increased during the exercise period $(\mathrm{P}<0.01)$, and kept increasing throughout the whole exercise period in all three groups to the same extend.

Table 6.2 Arterialized plasma concentrations of circulating metabolites

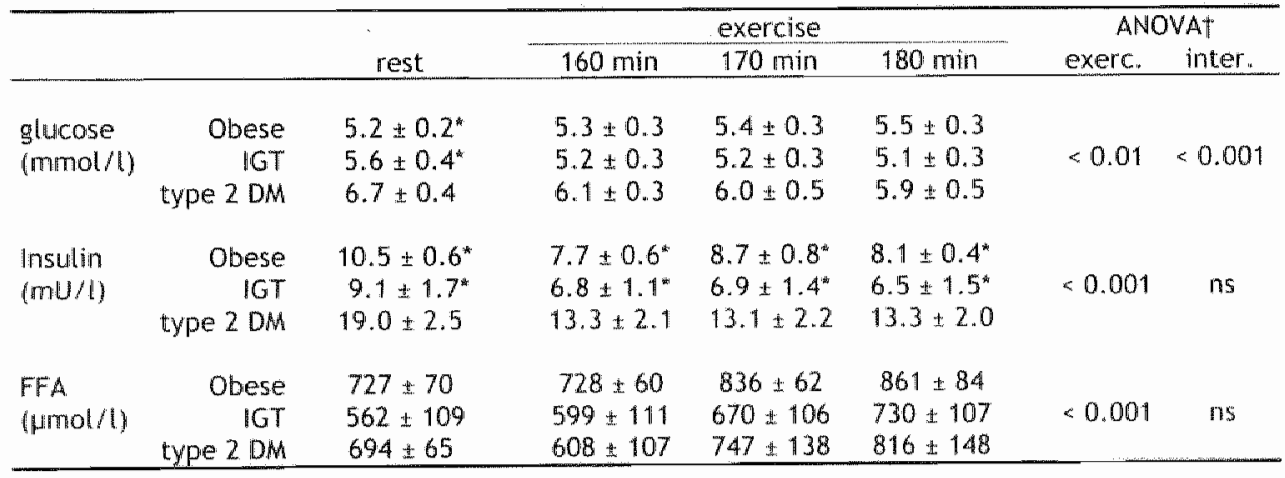

Date are mean \pm sem; $\uparrow$ repeated measures $A N O V A$, inter. $=$ group $\times$ exercise interaction; * significant different from type 2 DM $(P<0.05)$

\section{Substrate utilization and energy expenditure}

Whole-body energy expenditure and total fat and carbohydrate oxidation reached a plateau during the last 20 min of exercise (data not shown). Energy expenditure was comparable in all three groups during resting conditions and during exercise (rest: $6.45 \pm 0.34,5.23 \pm 0.17$ and $5.65 \pm 0.49 \mathrm{~kJ} / \mathrm{min}$ for Obese, IGT and type $2 \mathrm{DM}$; exercise: $31.8 \pm 1.5,27.8 \pm 1.4$ and $27.7 \pm 2.3 \mathrm{~kJ} / \mathrm{min}$ for Obese, IGT and type 2 DM respectively). During exercise energy expenditure increased 4-5 times. Respiratory exchange ratio was also not significantly 
different between groups during rest and exercise (rest: $0.79 \pm 0.01,0.83 \pm 0.01$ and $0.80 \pm 0.02 ;$ exercise: $0.88 \pm 0.02,0.85 \pm 0.01$ and $0.87 \pm 0.01$ for Obese, $1 \mathrm{GT}$ and type 2 DM respectively). No significant differences were observed between groups in tolal carbohydrate oxidation (rest: $1.28 \pm 0.28,1.94 \pm 0.28$ and $1.45 \pm$ 0.30 ; exercise $18.3 \pm 2.04,14.1 \pm 1.38$ and $13.8 \pm 1.63 \mathrm{mg} / \mathrm{kgFFM} / \mathrm{min}$ for Obese, IGT and type 2 DM respectively) and fat oxidation (rest: $1.40 \pm 0.15,0.91 \pm 0.11$ and $1.20 \pm 0.18$; exercise $4.47 \pm 0.59,5.24 \pm 0.57$ and $4.56 \pm 0.60 \mathrm{mg} / \mathrm{kgFFM} / \mathrm{min}$ for Obese, IGT and diabetes) as measured with indirect calorimetry.

Plasma palmitate "C-enrichment was slightly elevated in IOT subjects compared to obese and type 2 diabetic subjects at rest $(P<0.05$ ), however during the exercise period these differences were no longer significant. Acetate recovery gradually increased, both during rest and exercise (Figure 6.1). No differences were found in acetate recovery factor (ARF) between groups under resting conditions, during exercise ARF tended to be higher in Obese subjects compared to IGT and type 2 DM subjects $(P=0.07$, Figure 6.1$)$.

Rate of appearance (Ra) and rate of disappearance (Rd) of plasma FFA were significantly different ( $P<0.05$ ) between groups under baseline and exercise

conditions. Both, Ra and Rd were highest in obese subjects and comparable in IGT and type 2 DM subjects (Figure 6.2).

Baseline and exercise-induced total FA oxidation were not different among groups (Figure 6.3 upper panel). Plasma FFA oxidation was decreased in IGT and type 2 DM compared to Obese at rest ( $P<0.05$, Figure 6.3 middle panel). During exercise there was a tendency towards a lower plasma FFA oxidation in IGT and type 2 DM ( $P=0.07$, Figure 6.3 middle panel). Triglyceride-derived FA oxidation was not different during rest $(\mathrm{P}=0.17$. Figure 6.3 lower panel), while during exercise triglyceride-derived FA oxidation was elevated in IGT and type 2 DM in comparison with Obese ( $P<0.05$, Figure 6.3 lower panel).

The percentage of the $\mathrm{Rd}$ which was oxidized during rest and exercise was not significantly different among groups (rest: $40.0 \pm 4.0 \%, 35.6 \pm 2.0 \%$ and $34.1 \pm$ $2.5 \%$ for Obese, IGT and type $2 \mathrm{DM}, \mathrm{P}=0.28$; exercise $72.1 \pm 1.5 \%, 76.8 \pm 5.1 \%$ and $70.8 \pm 3.9 \%$ for Obese, IGT and type $2 \mathrm{DM}, \mathrm{P}=0.52$ ).

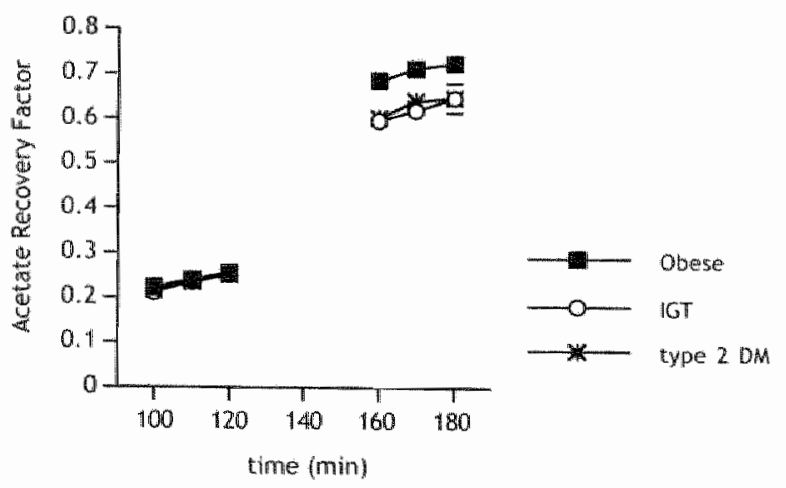

Figure 6.1 Acetate recovery at rest (100-120 min) and during exercise (160-180 min); Data are mean \pm sem; $\mid G T=$ impaired glucose tolerance, type $2 D M=$ type 2 diabetes mellicus 


\section{Discussion}

Disturbances in fatty acid utilization and oxidation may play an important role in the development of obesity and insulin resistance. Type 2 diabetic subjects have a reduced uptake and oxidation of plasma free fatty acid (FFA) by muscle during fasting conditions and during $\beta$-adrenergic stimulation $[8,10]$. Recently these findings were extended towards moderate-intensity exercise [11]. So far no information is available whether these disturbances are primary factors or adaptational responses to the diabetic state. The results of the present study showed for the first time that in subjects at high risk for the development of type 2 diabetes mellitus, i.e. subjects with an impaired glucose tolerance, disturbances in fatty acid uptake and oxidation are present. During baseline conditions, plasma FFA oxidation was impaired in IGT and type 2 diabetic subjects compared to body weight matched controls. During moderate-intensity exercise plasma FFA oxidation tended to be lower in IGT and type 2 DM than in obese controls ( $P=0.07)$, whereas triglyceride-derived fatty acid oxidation was higher in glucose intolerant and type 2 diabetic men in comparison with obese men. Thus, impairments in fatty acid oxidation are already present in a prediabetic state (i.e. IGT), suggesting that these disturbances possibly play a role in the progression from IGT to type 2 diabetes mellitus.

Oxidation rates of (plasma) fatty acid were determined with use of the stable isotope $\left[\mathrm{U}-{ }^{13} \mathrm{C}\right]$ palmitate in conbination with indirect calorimetry. To correct for the loss of ${ }^{13} \mathrm{C}$ label due to fixation in products of the tricarboxylic acid cycle and the bicarbonate pool Sidossis introduced the acetate recovery factor (ARF) [19]. Failure to use the ARF may lead to a substantial underestimation of plasma FFA oxidation. A recent study pointed out that the acetate recovery factor needs to be determined in every subject because of the large inter-individual variation, especially during exercise [22]. In the present study the acetate recovery factor tended to be lower in the glucose intolerant and diabetic state
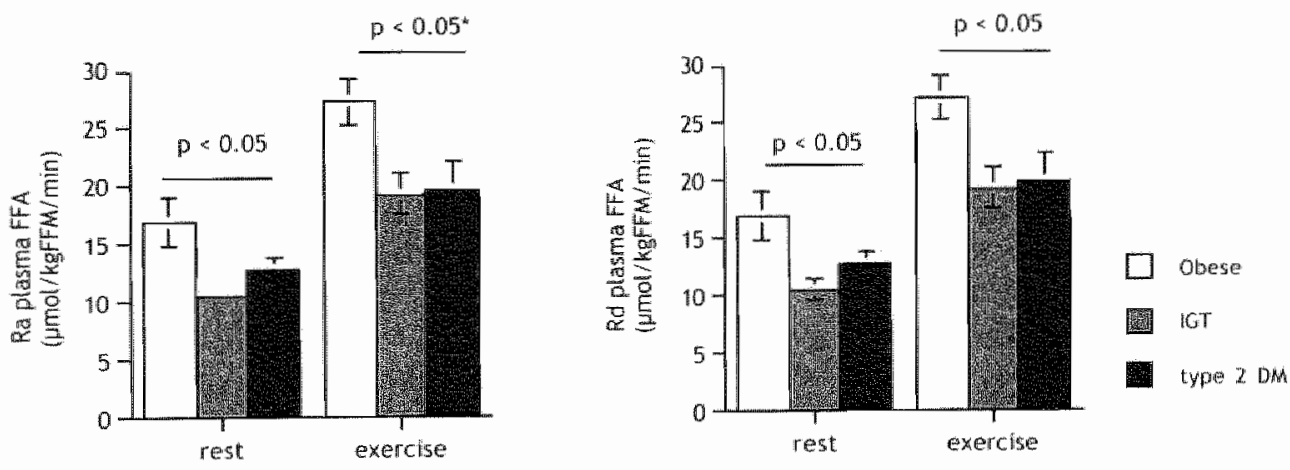

Figure 6.2 Rate of appearance (Ra) and disappearance (Rd) of plasma FFA at rest and during exercise; Acetate recovery factor and isotopic enrichment; Data are mean \pm sem. IGT = impaired glucose tolerance, type $2 \mathrm{DM}=$ type 2 diabetes mellitus; "ANOVA 
during exercise compared to obese controls $(P=0.07)$. This is in agreement with previous work showing a lower ARF in type 2 diabetic patients [11,22]. The explanation for this is not fully understood, but it is suggested that an increased rate of gluconeogenesis in the IGT or diabetic state leads to additionalloss of ${ }^{13} \mathrm{C}$-label from the tricarboxylic acid cycle and thus a lower acetate recovery factor. This study again stresses the importance of individual determination of the ARF to improve estimations of plasma substrate oxidation.

\section{Subjects}

Obese. glucose intolerant and type 2 diabetic subjects were matched according to body composition and aerobic capacity. However IGT subjects were older than obese and type 2 diabetic subjects $(58.3 \pm 2.4$ yr. for IGT $v s .45 .1 \pm 1.7$ and $51.3 \pm 3.4 \mathrm{yr}$. for obese and type $2 \mathrm{DM}, \mathrm{P}<0.01$ ) Ageing is associated with a diminished ability to use fat as a fuel during exercise $[23,24]$, however those observations were made comparing young adults (20-33 yrs.) with middleaged (50-55 yrs.) or elderly subjects (66-79 yrs.). Furthermore, disturbances in fat utilization in the elderly are (partly) related to a decline in physical activity observed with ageing [24]. In this study no differences in aerobic capacity ( $\mathrm{OO}_{2} \mathrm{max}$ ) were present between groups. Also during the exercise period no significant differences in absolute and relative workload, oxygen consumption, and energy expenditure existed. This seems to suggest that the muscle oxidative capacity (mitochondrial density) was matched too. Thus, on basis of the comparable $\mathrm{VO}_{2} \mathrm{max}$ and the relatively small age differences, it seems highly unlikely that this age difference has disturbed the results of the present study.

\section{Fatty acid metabolism}

Total fat and carbohydrate oxidation were not different between the groups throughout the experiment. This is in agreement with other work showing that whole body fat and carbohydrate oxidation were not different in diabetic subjects compared to obese and lean subjects during rest and exercise [25,26]. As indicated above, plasma fatly acid uptake and oxidation is lowered, and triglyceride-derived FA oxidation (intramyocellular lipids (IMCL) or VLDL triglyceride oxidation) is elevated in $1 \mathrm{GT}$ and diabetic subjects compared to obese controls. Thus, although whole body fat oxidation is the same, there is a redistribution of the source of fatty acids oxidized. Skeletal muscle is by far the most important tissue responsible for uptake and oxidation of lipids, especially during exercise. Increased levels of muscle triglycerides, as reported in diabetic subjects [12,13] and most likely also in IGT subjects, could lead to increased rates of riglyceride-derived FA oxidation in muscle by a mass action effect, as utilization of muscle triglycerides during exercise is directly related to the content at rest in diabetic subjects [13]. This would explain the higher rate of triglyceride-derived fatty acid oxidation in glucose intolerant and diabetic subjects found in this study. It can be speculated that the tendency towards increased triglyceride-derived FA oxidation may be one of the mechanism linking increased IMTC content towards insulin resistance, as discussed in more detail below. 

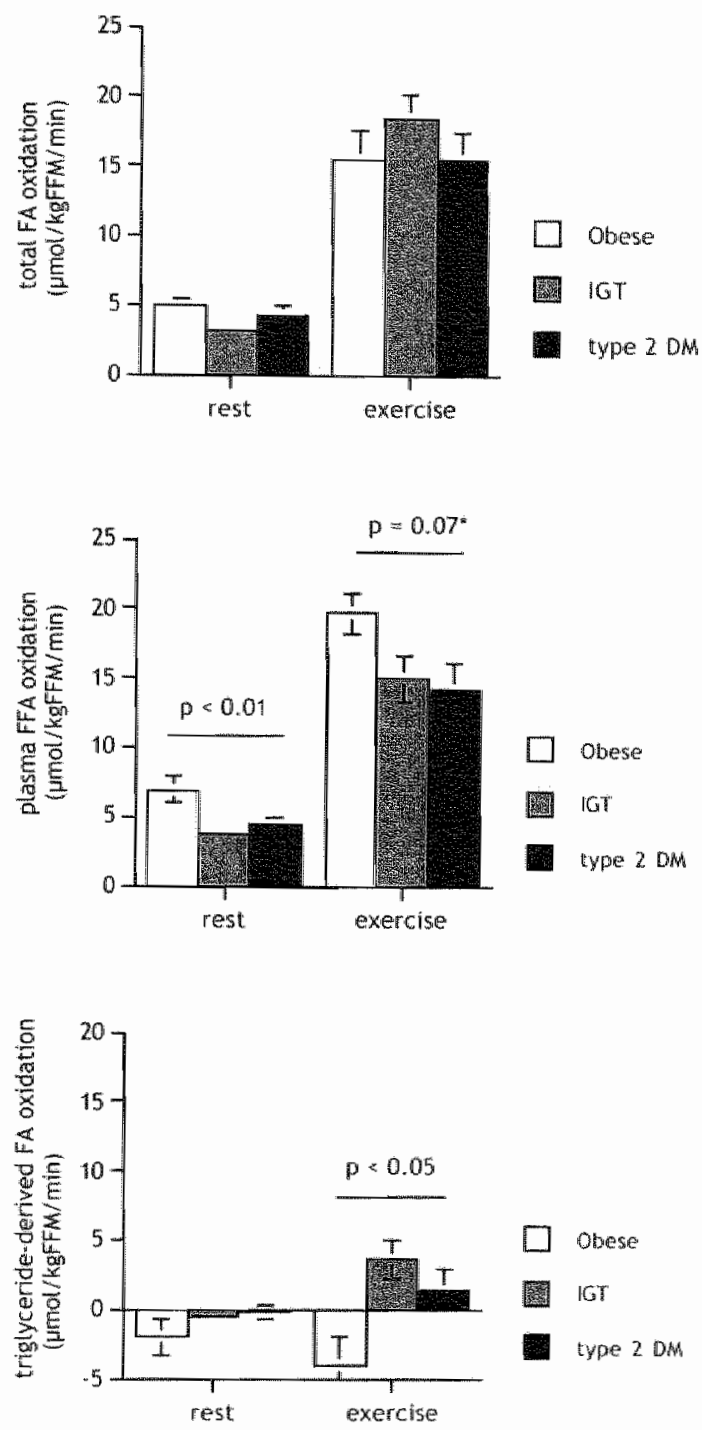

Figure 6.3 Total FA oxidation (top), plasma FFA oxidation (middle) and triglyceride-derived FA oxidation (bottom) at rest and during exercise; Data are mean \pm sem; "Difference between groups tested with ANOVA 
In the present study rate of appearance of plasma FFA was lower in IGT and type 2 diabetic subjects compared to (weightmatched) obese subjects. Type 2 diabetes mellitus is frequently accompanied by obesity, which makes it difficult to ascertain the impact of diabetes itself on lipolysis and FFA release. For that reason diabetic subjects must be compared with body composition-matched controls, as done in this study. Jansson et al. [27] using microdialysis, concluded that adipose tissue lipolysis (expressed per unit fat mass) was not different between well-controlled type 2 diabetic subjects and weight matched controls. The lower Ra FFA found in the present study can most likely be explained by a difference in the fraction of FFA undergoing re-esterfication in adipose tissue and not by differences in adipose tissue lipolysis.

Impaired glucose tolerance is considered as a prediabetic state, a necessary transition state en route to type 2 diabetes mellitus. Up to $15 \%$ of the people diagnosed with IGT develop diabetes each year [16]. It would be of use if subjects at risk for progression to type 2 DM could be identified. Major risk factors for progression from IGT to type 2 diabetes mellitus are basal and 2 hour glucose level, basal (pro)insulin level, age and obesity [16]. The results of the present study suggest that an impaired skeletal muscle fatty acid metabolism could be another important factor in the progression of IGT to type 2 DM. An increased physical activity in combination with a healthy diet and weight loss improved glucose tolerance in a Finnish study [28]. One could speculate that changes in FA metabolism as a consequence of the change in lifestyle (partly) explain the improved glucose tolerance.

\section{Underlying mechanisms}

Several mechanisms may explain the observed impaired plasma FFA uptake and oxidation in IGT and type 2 diabetes. The rate of appearance (Ra) and disappearance (Rd) of plasma FFA was lower throughout the experiment in IGT and type 2 diabetic subjects compared to obese subjects $(P<0.05)$. This diminished Ra of plasma FFA could lead to a diminished uptake and subsequent oxidation of plasma FFA. The lower rate of appearance of plasma FFA may possibly be explained by an increased reesterfication of FA in adipose tissue, or by differences in regulation of lipolysis between obese subjects and obesity-associated lype 2 diabetic subjects. However the present study can not be conclusive about this. The fraction of the Rd oxidized was not different between groups which means that once taken up plasma FFA are oxidized to the same extent in all groups suggesting that the uptake of plasma FFA is more impaired than its oxidation.

A second factor that may play a role in the disturbed uptake and oxidation of plasma FFA is a lowered transport of FFA across the membrane. Alterations in content or expression of transport proteins could influence the capacity of the muscle to ullize lipids. In muscle biopsies from type 2 diabetic patients the content of cytoplasmic fatty acid binding protein (FABPC) was decreased as compared to controls, which could contribute to the decreased utilization and oxidation of plasma FFA [10]. More studies however are needed to better 
understand the role and the importance of fatty acid transporters in the disturbances in muscle lipid metabolism as found in the diabetic state.

Thirdly, subjects with IGT may have increased stores of intramyocellular lipids (IMCL), as seen in diabetic subjects [12]. Enlarged stores of triglycerides within the muscle in combination with an increased rate of lipolysis, as a result of a mass action effect, can flood the (pre)diabetic muscle with FFA and lead to an increased concentration of FFA in the muscle cell. Indeed, we recently observed an increased release of glycerol from the forearm muscle of type 2 diabetic subjects, suggesting an increased lipolysis of intramuscular triglycerides $\mid 10]$. Elevated levels of fatty acids within the cytosol of the muscle cell would diminish the blood tissue FFA concentration gradient, which is a very important determinant of plasma fatty acid uptake and oxidation, and may explain the impaired uptake and oxidation of plasma fatty acid found in subjects with IGT and type 2 diabetes. This is a very attractive hypothesis because elevated levels of $\mathbb{F F A}$ in the cell could also interfere with insuln signaling and disturb insulin-stimulated glucose uptake [29]. Interestingly, the tendency towards increased triglyceride-derived FA oxidation found in this study may link increased. IMCL content and utilization to decreased insulinstimulated glucose uptake (insulin resistance). However more studies are needed to draw more definitive conclusions.

\section{Conclusion}

This study showed that the previously reported disturbances in fatty acid utilization in type 2 diabetes mellitus $[8,11]$ are already present in a prediabetic state, i..e. in subjects with impaired glucose tolerance. During rest and exercise plasma FFA uptake and oxidation were diminished in IGT an type 2 DM whereas triglyceride-derived FA oxidation was increased during exercise in IGT and type 2 DM compared to obese subjects. An increased intramuscular triglyceride content, a diminished FFA transport capacity or a decreased Ra of plasma FFA could be involved in the impaired plasma FFA uptake and oxidation. These data demonstrate that male subjects with milder forms of hyperglycemia (i.e. Impaired Glucose Tolerance) have the same defects in fatty acid utilization as subjects with type 2 diabetes mellitus, suggesting that these disturbances may play an important role in the progression from IGT to type 2 diabetes mellitus

\section{Acknowledgements}

We thank Jos Stegen and Annemie Gijssen for their analytical support. This study was supported by a grant from the Netherlands Organization for Scientific research (ZonMW 940-35-034) and the Dutch Diabetes Research Foundation (DFN 98.901 ). 


\section{References}

1 Frayn KN, Willams CM, Amer P. Are increased plasma non-esterified fatty acid concentrations a risk marker for coronary heart disease and other chronic diseases? Clint Sci (Colch) $1996: 90: 243-53$.

2 Lewis GF, Vranic M, Harley P, Giacca A. Fatty acids mediate the acute extrahepatic effects of insulin on hepatic glucose production in humans. Diabetes 1997; 46:1111-9.

3 Hennes MM, Dua A, Kissebah AH. Effects of free fatty acids and glucose on splanchnic insulin dynamics. Diabetes 1997; 46: 57-62.

4 Carpentier A, Mittelman SD, Bergman RN, Giacca A, Lewis GF. Prolonged elevation of plasma free fatty acids impairs pancreatic beta-cell function in obese nondiabetic humans but not in individuals with type 2 diabetes. Diabetes 2000; $49: 399-408$.

5 Prentki M, Corkey BE. Are the beta-cell signaling molecules malonyl-CoA and cystolic long-chain acyl COA implicated in multiple tissue defects of obesity and NIDDM? Diabetes 1996; 45: 273-83.

6 Saloranta C, Groop L. Interactions between glucose and FFA metabolism in man. Diabetes/Metabolism Reviews 1996; 12: 15-36.

7 Colberg SR, Simoneau $\| A$, Thaete FL, Kelley DE. Skeletal muscle utilization of free fatty acids in women with wisceral obesity. J Clm Invest 1995; 95: 1846-53.

8 Kelley DE, Simoneau JA. Impaired free fatty acid utilization by skeletal muscle in non-1nsulin-dependent diabetes mellitus. J Clin Invest 1994; 94: 2349-56.

9 Kelley DE, Goodpaster B, Wing RR, Simoneau JA. Skeletal muscle fatty acid metabolism in association with insulin resistance, obesity, and weight loss. Am I Phystiol 1999: 277: E1130-41.

10 Blaak EE, Wagenmakers AJ, Glatz JF et al. Plasma FFA utilization and fatty acidbinding protein content are diminished in type 2 diabetic muscle. Am / Physiol Endocrinol Metab 2000; 279: E14:6-54.

11 Blaak EE, van Aggel-Leijssen DPC, Wagenmakers AJM, Saris WHM, van Baak MA. Impaired Oxidation of Plasma-Derived Fatty Acids in Type 2 Diabelic Subjects During Moderate-Intensity Exercise. Diabetes 2000; 49: 2102-2107.

12 Falholt $K_{\text {, Jensen }} I_{s}$ Lindkaer Jensen $S$ ef al. Carbohydrate and lipid metabolism of skeletal muscle in type 2 diaberic patients. Diaber Med 1988; 5:27-31.

13 Standl $\mathrm{E}$, Lotz $\mathrm{N}$, Dexel T, Janka HU, Kolb HJ. Muscle triglycerides in diabetic subjects. Effect of insulin deficiency and exercise. Dinbetologin 1980; 18: 463-9.

14 Jacob $S$, Machann J, Rett $K$ ot al. Association of increased intramyocellular lipid content with insulin resistance in lean nondiabetic offspring of type 2 diabetic subjects. Dinbetes 1999; 48: 1113-9.

15 Pan DA, Lillioja S, Kriketos AD al. Skeletal muscle triglyceride levels ate inversely related to insulin action. Dirbetes 1997; 46: 983-8.

16 Alberti $\mathrm{KG}$. The clinical implications of impaired glucose tolerance. Diabet Med 1996; $13: 927-37$.

17 Siri W. The gross composition of the body. Adv Bio Med Physiol 1956; 4: 239-280.

18 Wagenmakers AJ, Rehrer NJ. Brouns $\mathbb{P}$, Saris WH, Halliday D. Breath $13 \mathrm{CO} 2$ background enrichment during exercise: dietrelated differences between Europe and America. / Appl Plysiol 1993; 74: 2353-7.

19 Sidossis LS, Coggan AR, Gastaldelli A, Wolfe RR. A new correction factor for use in tracer estimations of plasma fatty acid oxidation. Ain / Physiol 1995; 269: E649-56.

20 Weir J. New methods for calculating metabolic rate with special reference to protein metabolism. Physiol (London) 1949; 109: 1-9.

21 Frayn KN. Calculation of substrate oxidation rates in vivo from gaseous exchange.। Appl Plysiol 1983; $55: 628-34$. 
22 Schrauwen P, Blak EE, Van Aggel-Leijsen DP, Borghouts LB, Wagenmakers AJ. Determinants of the acetate recowery factor: implications for estimation of I. Clsubstrate oxidation. Clin Sci (Colch) 2000; 98: 587-592.

23 Sial $S$, Coggan AR, Hickner RC, Klein S. Training-induced alterations in tat and carbohydrate metabolism during exercise in elderly subjects. An / Physiol 1998; 274: E785-90.

24 Blaak EE. Adrenergically stimulated fat utilization and ageing [editorial]. Ann Med 2000; 32: 380-2.

25 Kang J. Kelley DE, Robertson RJ et al. Substrate utilization and glucose turnover during exercise of varying intensities in individuals with NIDDM. Med Sci Sports Exerc 1999; 31: 82-9.

26 Colberg SR, Hagberg IM, McCole SD er al. Utilization of glycogen but not plasma glucose is reduced in individuals with NIDDM during mild-intensity exercise. Appl Physiol 1996; 81: 2027-33.

27 Jansson PA, Smith U, Lonnroth P. Microdialysis assessment of adipose tissue metabolism in post-absorptive obese NIDDM subjects. Eur / Clin Intest 1995; 25: $584-9$.

28 Eriksson I, Lindstrom J, Valle $\mathrm{T}$ et al. Prevention of type II diabetes in subjects with impared glucose tolerance: the Diabetes Prevention Study (DPS) in Finland. Study design and 1-year interim report on the feasibility of the lifestyle intervention programme. Diabetologia 1999; 42:793-801.

29 Schmitz Peiffer C. Signalling aspects of insulin resistance in skeletal muscle. mechanisms induced by lipid oversupply. Cell Signal 2000; 12: 583-594. 


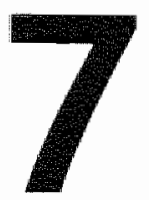

\title{
Lifestyle-Intervention Prevents a Further Impairment in Fatty Acid Oxidation in Subjects with IGT during Exercise
}

\author{
Marco Mensink, Ellen E Blaak, Anton JM Wagenmakers \\ and Wim HM Saris
}

Dept of Human Biology Nutrition and Toxicology Research Institute NUTRIM, Maastricht University, Maastricht, The Netherlands 


\begin{abstract}
Free fatty acid oxidation is disturbed in subjects with type 2 diabetes mellitus and impaired glucose tolerance (IGT). Weight reduction does not improve these impairments. As exercise training is known to increase fatty acid oxidation, we investigate whether a combined diet and physical activity intervention program can improve the impaired fatty acid oxidation in subjects with IGT. Sixteen subjects with IGT were studied before and after 1 year of a lifestyle-intervention program ( 9 intervention, INT; 7 controls, CON). Intervention subjects received regularly dietary advice and were stimulated to increase their level of physical activity. Glucose tolerance, anthropometric characteristics and substrate utilization were evaluated before and after 1 year of intervention. Substrate oxidation was measured at rest and during moderate intensity exercise ( $-55 \%$ $\mathrm{VO}_{2} \mathrm{max}$ ) using indirect calorimetry in combination with stable isotope infusion. After 1 year no differences were seen in substrate utilization at rest. During exercise, total fat and plasma free fatty acid oxidation were slightly improved in the intervention group and decreased in the control group, with the change being significantly different between groups (change after $1 \mathrm{yr}$ : $\mathbb{\| N T}+2.0 \pm 1.4$ and $+1.9 \pm 0.9 \mu \mathrm{mol} / \mathrm{kg} / \mathrm{min} ; \mathrm{CON}-3.5 \pm 1.6$ and $-1.8 \pm 0.5 \mu \mathrm{mol} / \mathrm{kg} / \mathrm{min}$ for total and plasma free fatty acid respectively; $P<0.05$ ).

In conclusion, a combined diet and physical activity intervention program can prevent a further deterioration of disturbances in fatty acid oxidation in subjects with IGT during exercise. It is speculated that this may have a beneficial effect on glucose tolerance and insulin resistance.
\end{abstract}


Disturbances in skeletal muscle fatty acid metabolism may play an important role in the development of insulin resistance and type 2 diabetes mellitus $[1,2]$. Several studies have shown that the uptake and oxidation of FA is impaired in insulin resistant (viscerall) obese subjects [3] and type 2 diabetic subjects [4-6!. Using the forearm model in combination with stable isotope infusion we showed that the uptake and oxidation of plasma FFA was impaired in type 2 diabetic subjects compared to obese controls in the overnight fasted state with and without $\beta$-adrenergic stimulation. Type 2 diabetic subjects also had a diminished plasma derived FA oxidation and a higher triglyceride derived fatty acid oxidation during moderate-intensity exercise compared to obese controls [6]. An misbalance between uptake and oxidation of FA could lead to accumulation of lipids within the muscle. It is known that accumulation of intramyocellular lipids (IMCL) is strongly associated with insulin resistance $[7,8]$.

It is difficult to assess the pathophysiological abnormalities leading to type 2 diabetes when the type 2 diabetic state has already developed, since it is impossible to differentiate between primary factors and adaptational responses. Considerable weight reduction did not improve the abnormalities in fatty acid metabolism in type 2 diabetic and obese subjects, suggesting that the abnormal fatty acid metabolism is primary rather than acquired [9]. This is also supported by our recent finding that in men with impaired glucose tolerance (IGT) the uptake and oxidation of plasma FFA was diminished at rest and during exercise [10]. In a PET study, Turpeinen et al. [11] concluded the same, subjects with IGT had similar myocardial but lowered femoral muscle FA uptake compared to healthy controls. Thus, impaiments in fatty acid uptake and oxidation are already present in a prediabetic state (i.e. IGT), from which it could be speculated that these disturbances play a role in the progression from IGT to type 2 diabetes mellitus.

It is known that endurance exercise training can dramatically alter the capacity to oxidize fatty acids [12-14]. Sial et al [13] demonstrated that in elderly subjects, exercise training increased total fat oxidation without a change in lipolysis or FFA availability. Comparable data were found in obese and healthy lean subjects using a low intensity exercise program for only a few hours weekly [12,14], a regimen much more applicable for (obese) insulin resistant subjects. If (low intensity) exercise training has similar effects on fat oxidation in type 2 diabetic or glucose intolerant subjects as in healthy volunteers, the inclusion of physical activity in an intervention program may be able to compensate for the lack of improvement found in fatty acid utilization after weight reduction alone.

So far little information is available about the effect of intervention programs on the disturbed faty acid metabolism found in IGT and type 2 diabetes. As indicated above, we previously reported a diminished plasma derived FA oxidation in subjects with IGT [10]. In the present study a comparable group of glucose intolenant subjects was studied before and after 1 year of a lifestyle intervention program. Data were compared with a group of control subjects with IGT matched for body composition and aerobic fitness. Our aim was to investigate whether a combined diet and physical activity intervention program 
is able to compensate for the impaired (plasma free) fatty acid oxidation in subjects with IGT, at rest as well as during exercise.

\section{Methods}

\section{Subjects}

Study on Lifestyle-intervention and IGT, Maastricht (SLIM) is designed to study whether a diet/physical activity intervention program can improve glucose tolerance in subjects with a high risk on developing type 2 diabetes mellitus. A detailed description of the study can be found elsewhere [15]. In the present study, sixteen subjects with IGT participating in the larger intervention trial underwent additional measumements to evaluate the effect of this lifestyleintervention program on substrate utilization and oxidation at rest and during cxercise, 9 from the intervention group ( 5 male, 4 female) and 7 subjects from the control group ( 5 male, 2 femall)(for characteristics see Table 7.1 ). Subjects had no health problems and did not use any medication which could interfere with substrate metabolism. The Medical Ethical Review Committee of Maastricht University approved the study protocol, and all subjects gave their written informed consent before the start of the study.

Table 7.1 Subject characteristics at baseline

\begin{tabular}{|c|c|c|c|c|}
\hline & & INTERVENTION & CONTROL & \\
\hline number (M/F) & & $9(5 / 4)$ & $7(5 / 2)$ & \\
\hline Age & $\left(y r_{0}\right)$ & $54.3 \pm 1.8$ & $62.4 \pm 1.7$ & $H$ \\
\hline Body-weight & $(\mathrm{kg})$ & $84.6 \pm 3.9$ & $80.1 \pm 3.1$ & \\
\hline Bodyfat & $(\%)$ & $34.0 \pm 2.0$ & $32.9 \pm 2.9$ & \\
\hline$B M I$ & $\left(\mathrm{~kg} / \mathrm{m}^{2}\right)$ & $29.3 \pm 0.6$ & $27.9 \pm 1.2$ & \\
\hline Waist-Hip Ratio & & $0.97 \pm 0.02$ & $0.97 \pm 0.03$ & \\
\hline $\mathrm{VO}_{2} \max$ & $(1 / \mathrm{min})$ & $2.22 \pm 0.17$ & $2.22 \pm 0.15$ & \\
\hline Fasting glucose & $(\mathrm{mmol} / 1)$ & $6.1 \pm 0.5$ & $5.7 \pm 0.2$ & \\
\hline 2-Hour glucose & $(\mathrm{mmol} / \mathrm{l})$ & $8.4 \pm 0.4$ & $8.4 \pm 0.2$ & \\
\hline Fasting insulin & $(\mathrm{mU} / \mathrm{l})$ & $13.8 \pm 2.4$ & $13.5 \pm 2.7$ & \\
\hline HOMA-IR index & & $3.9 \pm 1.0$ & $3.4 \pm 0.6$ & \\
\hline
\end{tabular}

Data are mearl 1 sem; $P<0.01$ between groups

\section{Lifestyle-intervention}

The intervention program consists of a dietary and physical activity part. Dietary recommendations were based on the Dutch guidelines for a healthy diet ( 155 En\% carbohydrates; $<30-35$ En\% fat intake, with < 10 En\% intake of saturated fatty acids; a cholesterol intake of less than $33 \mathrm{mg}$ per MJ; protein intake of 10-15 En\% and an intake of dietary fibre of at least 3 gram per MJ). Goall for body weight was a BMI of less than $25 \mathrm{~kg} / \mathrm{m}^{2}$, but for practical reasons a body weight loss of $5-10 \mathrm{~kg}$ was aimed at depending on the degree of obesity. Dietary advice was given by a skilled dietician on an individual basis every 
three months. Subjects were stimulated to increase their physical activity to at least 30 minutes of moderate physical activity a day for at least 5 days a week. Individual advice was given how to increase their daily physical activity (walking, cycling, swimming) and goals were set. Furthermore, subjects were encouraged to participate in an exercise program, consisting of components of aerobic exercise training and components of resistance training. Subjects in the control group were informed about the beneficial effects of a healthy diet, weight loss and increased physical activity, whereas no individual advice or programs was provided. No additional appointments were scheduled.

Before and after 1 year of the lifestyle-intervention program measurements were done of glucose tolerance, maximal aerobic capacity, body composition and substrate utilization at rest and during exercise.

\section{Glucose tolerance testing}

A standard oral gilucose tolerance test (OGTT), with blood-sampling at $t=0$, $\mathrm{t}=30, \mathrm{t}=60$ and $\mathrm{t}=120 \mathrm{~min}$, was performed to measure glucose tolerance. Fasting plasma glucose $(\mathrm{mmol} / \mathrm{l})$ and insulin concentration $(\mathrm{mU} / \mathrm{l})$ were used to calculate an index for insulin resistance with the homeostasis model assessment (HOMA-index) described by Matthews et al. [16].

\section{Pre-test}

An incremental exhaustive exercise test was performed on an electronically braked bicycle ergometer (Lode, Groningen, the Netherlands) to determine the maximal aerobic power output ( $W$ max $)$ and oxygen consumption $\left(\mathrm{VO}_{2} \mathrm{max}\right)$. The test started at a workload of $0.75 \mathrm{~W} / \mathrm{kgFFM}$ for 3 minutes, followed by 3 minutes at $1.5 \mathrm{~W} / \mathrm{kgFFM}$. Thereafter the workload was increased every 3 minutes by $0.5 \mathrm{~W} / \mathrm{kgFFM}$ until exhaustion (RQ above 1.1 and no further increase in oxygen uptake). During the experimental trials, subjects exercised before and after 1 year at the same absolute workload. i.e. $55 \%$ baseline $\mathrm{VO}_{2} \max$.

\section{Body composition}

Body weight was determined on an electronic scale; body composition was determined by hydrostatic weighing with simultaneous lung volume measurement (Volugraph 2000, Mijnhardt, Bunnik, the Netherlands), and calculated according to Siri [17]. Waist and hip circumference measurements were made to the nearest $1 \mathrm{~cm}$ with subjects standing in upright position, half way between the iliac spine and the last rib, and at the level of the trochanter major, respectively.

\section{Substrate utilization}

Subjects participated before and after 1 year in two stable-isotope trials, separated by at least one week (Protocol 1 and 2). Trials were performed in random order. Subjects were asked not to participate in any (exhausting) physical activity the last three days before the trials to exclucle changes in 
substrate metabolism induced by the last bout of exercise. They also were asked not to consume any products of high natural ${ }^{13} \mathrm{C}$-abundance during the last week before both tests as this may disturb the ${ }^{13} \mathrm{C} /{ }^{12} \mathrm{C}$ measurement in blood and expired air \18】.

\section{Protocol 1}

Subjects came to the laboratory after an overnight fast at 8.00. Two cannulae were inserted, one into a forearm vein for the infusion of tracers and one in retrograde direction into a contralateral dorsall hand vein for blood sampling. The canulated hand was placed in a hot box in order to obtain arterialized venous blood. Background blood and breath samples were taken 30 minutes after placement of the cannulae. At $t=0$ an intravenous dose of $0.085 \mathrm{mg} / \mathrm{kg}$ $\mathrm{NaH}^{3} \mathrm{CO}_{3}$ was given to prime the bicarbonate pool, followed by a constant rate continuous infusion of $\left[U-{ }^{13} \mathrm{C}\right]$ palmitate $(0.0067 \mu \mathrm{mol} / \mathrm{kg} / \mathrm{min})$. After 60 minutes a continuous infusion of $\left[6,6{ }^{2} \mathrm{H}_{2}\right] \mathrm{glucose}(0.3 \mu \mathrm{mol} / \mathrm{kg} / \mathrm{min})$ was started after a priming dose had been given $(18 \mu \mathrm{mol} / \mathrm{kg} / \mathrm{min})$. Tracers were administered via a calibrated infusion pump (IVAC560 pump, IVAC, San Diego, $C A$ ). During the last 20 minutes of the resting period $(t=100,110$ and $120 \mathrm{~min}$ ) breath and blood samples were taken and $\mathrm{VO}_{2}$ and $\mathrm{VCO}_{2}$ production were determined. Thereafter, exercise was started $\left( \pm 55 \% \mathrm{VO}_{2}\right.$ max $)$ for 1 hour (120-180 min). [L ${ }^{19} \mathrm{C}$ palmitate infusion was doubled at the start of the exercise. During the last 20 minutes blood and breath samples were taken $(t=160,170$ and $180 \mathrm{~min}$ ).

\section{Protocol 2}

During this trial the same regime was followed as described for Protocol 1 with the exception that instead of $\left[U_{m}{ }^{13} \mathrm{C}\right]$ palmitate, $\left[1,2-{ }^{13} \mathrm{C}\right]$ acetate tracer was infused, to determine the acetate recovery factor necessary for correction of palmitate oxidation rates [19]. After the priming dose of $\mathrm{NaH}^{1 / 3} \mathrm{CO}_{3}$ a constant rate continuous infusion was started of $\left[1,2-{ }^{13} \mathrm{C}\right]$ acetate at $0.046 \mu \mathrm{mol} / \mathrm{kg} / \mathrm{min}$ during rest $(0-120 \mathrm{~min})$, and double this rate during exercise $(120-180 \mathrm{~min})$, thereby giving the same ${ }^{1}$ C-infusion rate as for palmitate. At the same time points as described in protocol 1 breath samples were obtained, no blood samples were drawn.

\section{Tracers}

The [U-13CIpalmitate tracer (99\% enriched; Cambridge Isotope laboratories, Andover, MA, USA) was dissolved in heated sterile water and passed through a $0.2-\mu \mathrm{m}$ filter into $5 \%$ warm human serum albumin (Central Blood Bank, the Netherlands) to make a $0.65 \mathrm{mmol} / \mathrm{l}$ solution. The $\left[6,6-{ }^{2} \mathrm{H}_{2}\right] \mathrm{glucose}$ and $\left[1,2-{ }^{13}\right.$ C]acetate tracer $(99 \%$ entiched, Cambridge Isotope laboratories, Andover. MA) were dissolved in $0.9 \%$ saline to make a $18.7 \mathrm{mmol} / \mathrm{l}$ and $3.0 \mathrm{mmol} / \mathrm{l}$ solution respectively. The exact infusion rate of [U- ${ }^{13}$ C]palmitate, $\left[6,6-{ }^{2} \mathrm{H}_{2}\right]$ glucose and $\left[1,2-{ }^{13} \mathrm{C}\right]$ acetate were determined for each experiment by measuring the concentration of the infusate (see Biochemical Methods). 


\section{Breath, blood and urine sampling}

Breath samples were obtained by having the subjects breathe nomally for at least 3 min into a mouthpiece connected to a 6.75-liter mixing chamber and then collecting a breath sample into a $20 \mathrm{ml}$ vacutainer tube (Becton Dickinson, Meyland Cedex, France) in order to determine the enrichment of $\mathrm{CO}_{2}\left({ }^{13} \mathrm{C} /{ }^{12} \mathrm{C}\right.$ ratio). $\mathrm{VO}_{2}$ and $\mathrm{VCO}_{2}$ were determined by means of open-cincuit spirometry (Oxycon $\beta$, Mijnhardt, Bunnik, the Netherlands) during the resting period and the last 30 min of exercise. Arterialized blood samples were collected in EDTAcontaining tubes, and were immediately centrifuged at $3000 \mathrm{rpm}$ at $4^{\circ} \mathrm{C}$; the plasma was frozen in liquid nitrogen and stored at $-80^{\circ} \mathrm{C}$ until analysis. Urine was collected overnight to determine nitrogen excretion for calculating the nonprotein respiratory exchange ratio.

\section{Biochemical methods}

Breath samples were analyzed for ${ }^{15} \mathrm{C} /{ }^{12} \mathrm{C}$ ratio by injecting $20 \mu$ of the gaseous head space into a gas chromatograph-isotope ratio mass spectrometer (GCIRMS; Finnigan MAT 252; Finnigan, Bremen, Germany). Total plasma FFA, gincose and infusate acetate concentrations were measured using standard enzymatic techniques (for FFA: FFA-C test kit, Wako chemicals, Neuss, Germany; for glucose: Roche Unikit III, Hoffman-La Roche, Basel, Switzerland; for acetate: kit no 148261 Boehringer Mannheim, Mannheim, Germany). Insulin concentration during the experimental trial was measured using a double antibody RIA (Insulin RIA-100, Kabi Pharmacia, Uppsala, Sweden); plasma insulin levels during the OGTT were measured with an ELISA assay (Mercodia, Uppsala, Sweden). For the determination of plasma palmitate concentration and enrichment, FFA were extracted from plasma, isolated by thin layer chromatography, and derivatized to their methyl esters. Palmitate concentrations were determined on an analytical GC with ion-flame detection using heptadecanoic acid as an internal standard; on average palmitate concentration was $27 \pm 1 \%$ of total FFA concentration. Isotopic enrichment of palmitate was determined by GC-IRMS after online combustion of fatty acids to $\mathrm{CO}_{2}$ (Finnigan MAT 252, Bremen, Germany), with correction for the extra methyl group in the derivate. The concentration of infusate palmitate was determined as described above for plasma samples. For determination of

glucose enrichment in plasma, aliquots of EDTA plasma were extracted with methanol:chloroform and chloroform:water. The clear water layer was dried and a butylboronic acid-acetyl-derivate was made. Subsequently, the enrichment of the glucose derivate was determined by electron ionization/gas chromatography mass spectrometry (Finnigan INCOS XL, San Jose, CA, USA).

\section{Calculations}

Metabolic rate was calculated from $\mathrm{VO}_{2}$ and $\mathrm{VCO}_{2}$ according to the equation of Weir [20]. Carbohydrate and fat oxidation rates were calculated from $\mathrm{VO}_{2}$ and $\mathrm{VCO}_{2}$ and urinary nitrogen excretion [21]. Protein oxidation (as calculated from nitrogen excretion) was assumed to be similar during the overnight fasted state and during exercise. Total fatty acid oxidation was calculated by converting the 
rate of fat oxidation (triglyceride oxidation) to its molecular equivalent, with the assumption of the average molecular weight of triglyceride to be $860 \mathrm{~g} / \mathrm{mol}$, and multiplying the molar rate of triglyceride oxidation by three.

Enrichment of breath $\mathrm{CO}_{2}$ and plasma palmitate, acetate and glucose is given as tracer/tracee ratio (TTR $=\left({ }^{13} \mathrm{C} /{ }^{12} \mathrm{C}\right)$ sample- $\left({ }^{13} \mathrm{C} /{ }^{12} \mathrm{C}\right)$ background). Fractional recovery of label in breath $\mathrm{CO}_{2}$, derived from the infusion of labeled acetate was calculated as follows: acetate recovery $=\left(\mathrm{TTRCO}_{2}{ }^{*} \mathrm{VCO}_{2}\right) / 2 \mathrm{~F}$, where $\mathrm{F}$ is the infusion rate of acetate, and the number 2 in the denominator is to correct for the number of ${ }^{13} \mathrm{C}$ molecules in acetate.

Rate of appearance ( $\mathrm{Ra}$ ) and rate of disappearance (Rd) were calculated according to Steele's equation for steady state (palmitate at rest), and Steele"s single pool non-steady state equations adapted for use with stable isotopes (palmitate during exercise, and glucose at rest and during exercise) [22]. Volume of distribution was assumed to be $0.0401 / \mathrm{kg}$ for palmitate and $0.1601 / \mathrm{kg}$ for glucose. Ra and Rd of FFA were calculated by dividing palmitate Ra and Rd by the fractional contribution of palmitate to the total plasma FFA concentration. Percent of infused $\left[\mathrm{U}^{13} \mathrm{C}\right]$ palmitate oxidized was calculated with the formula: $\%$ infused tracer oxidized $=\left(\left(\mathrm{TTRCO}{ }^{*} \mathrm{VCO}_{2}\right) /\left(16^{*} \mathrm{~F}^{*} \text { acetate recovery }\right)\right)^{*} 100 \%$, where $\mathbb{F}$ is the infusion rate of palmitate and the number 16 in the denominator is to correct for the number of ${ }^{13} \mathrm{C}$ molecules in paimitate. Plasma FFA oxidation was calculated as: $\mathbb{R}_{\text {dFFA }}{ }^{*} \%$ infused palmitate tracer oxidized; triglyceridederived FA oxidation as: total FA oxidation-plasma FFA oxidation. During exercise the $\mathrm{Rd}$ of glucose is identical to the measured oxidation rate [23], therefore, muscle glycogen oxidation rates during exercise are calculated as: total glucose oxidation-plasma glucose oxidation.

\section{Statistical analysis}

Data are presented as means \pm sem. Oxidation rates and $R a$ and $R d$ are expressed as $\mu \mathrm{mol} / \mathrm{kgFFM} / \mathrm{min}$. Differences between groups were analyzed with a two tailed student's t-test for umpaired data, changes within groups with a two tailed student's t-test for paired data. Changes in concentration of metabolites over time between groups were analyzed with a two-way repeatedmeasures analysis of variance. Statistical significance was set at $P<0.05$.

\section{Results}

\section{Subjects characteristics}

No differences were found in baseline body weight, BMl, body composition and maximal aerobic capacity between groups (see Table 7.1). Subjects in the control group were older of age (INT $54.3 \pm 1.8$ year; CON $62.4 \pm 1.7$ year, $P<0.01)$. Baseline glucose tolerance and insulin resistance were comparable (see Table 7.1).

After 1 year body weight, body composition, aerobic capacity, and insulin resistance showed a tendency to improve in the intervention group, however differences between groups were not statistically significant (Table 7.2). 
Table 7.2 Change in subject characteristics

\begin{tabular}{lccc}
\hline & & $\begin{array}{c}\text { INTERVENTION } \\
(\mathrm{n}=9)\end{array}$ & $\begin{array}{c}\text { CONTROL } \\
(\mathrm{n}=6)\end{array}$ \\
\hline $\begin{array}{l}\text { body-weight } \\
\text { bodyfat }\end{array}$ & $(\mathrm{kg})$ & $-0.8 \pm 1.1$ & $+1.0 \pm 0.9$ \\
$\mathrm{BM}$ & $(\mathrm{\%})$ & $-0.3 \pm 0.9$ & $+0.2 \pm 1.0$ \\
Waist-Hip Ratio & $\left(\mathrm{kg} / \mathrm{m}^{2}\right)$ & $-0.3 \pm 0.4$ & $+0.3 \pm 0.4$ \\
& & $-0.02 \pm 0.01$ & $+0.02 \pm 0.01$ \\
VO ${ }_{2}$ max & $(\mathrm{l} / \mathrm{min})$ & $+0.03 \pm 0.06$ & $-0.03 \pm 0.07$ \\
fast glucose & $(\mathrm{mmol} / \mathrm{l})$ & $+0.1 \pm 0.1$ & $+0.1 \pm 0.1$ \\
2-hour glucase & $(\mathrm{mmol} / \mathrm{l})$ & $+0.3 \pm 0.4$ & $+0.5 \pm 0.8$ \\
fasting insulin & $(\mathrm{mu} / \mathrm{l})$ & $-0.4 \pm 1.5$ & $+2.9 \pm 2.4$ \\
HOMA-IR index & & $-0.1 \pm 0.5$ & $+0.8 \pm 0.6$ \\
\hline
\end{tabular}

Data are mean \pm sem; $P<0.01$ between groups

Waist-to-hip-ratio decreased more in the intervention group compared to the control group (INT $-0.02 \pm 0.01 ; \mathrm{CON}+0.02 \pm 0.01, \mathrm{P}<0.05$ ). No significant differences were observed in change in nutritional intake between groups after 1 year (data not shown). Relative workload at baseline and after 1 year of intervention was comparable between groups (INT: before $51.5 \pm 2.1 \%$, after $52.6 \pm 3.0 \% \mathrm{VO}_{2} \max ; \mathrm{CON}$ : before $56.5 \pm 1.3 \%$ after $57.4 \pm 3.0 \% \mathrm{VO}_{2} \max$ ). During the last 20 minutes of exercise oxygen consumption had reached a plateau.

\section{Arterialized concentrations of metabolites}

Table 7.3 depicts the concentration of circulating glucose, FFA and insulin at rest and during the last 20 min of exercise before and after 1 year, for both groups. No differences were observed between groups. Plasma FFA levels increased and insulin levels decreased throughout the exercise period to the same extent in both groups (ANOVA time-effect $\mathrm{P}<0.05$ ). Plasma palmitate, expressed as a fraction of total FFA, was not different nor between groups neither before and after 1 year (mean $27 \pm 1 \%$ of total FFA).

\section{Tracer kinetics}

Plasma glucose TTR at rest and during exercise and plasma palmitate TTR during exercise slightly decreased over time (data not shown), therefore Steele's non- steady state equations were used to calculate substrate kinetics. No differences were observed between groups in plasma palmitate and glucose TTR. Furthermore no differences were found between baseline and year one in plasma palmitate and glucose TTR (data not shown). No significant differences in acetate recovery factor were observed between groups at rest or during exercise (data not shown).

\section{Energy expenditure and substrate oxidation}

Energy expenditure, expressed per kg FFM, was comparable between groups and did not differ between groups, before and after 1 year at rest (INT: before: 
Table 7.3 Circutating metabolites

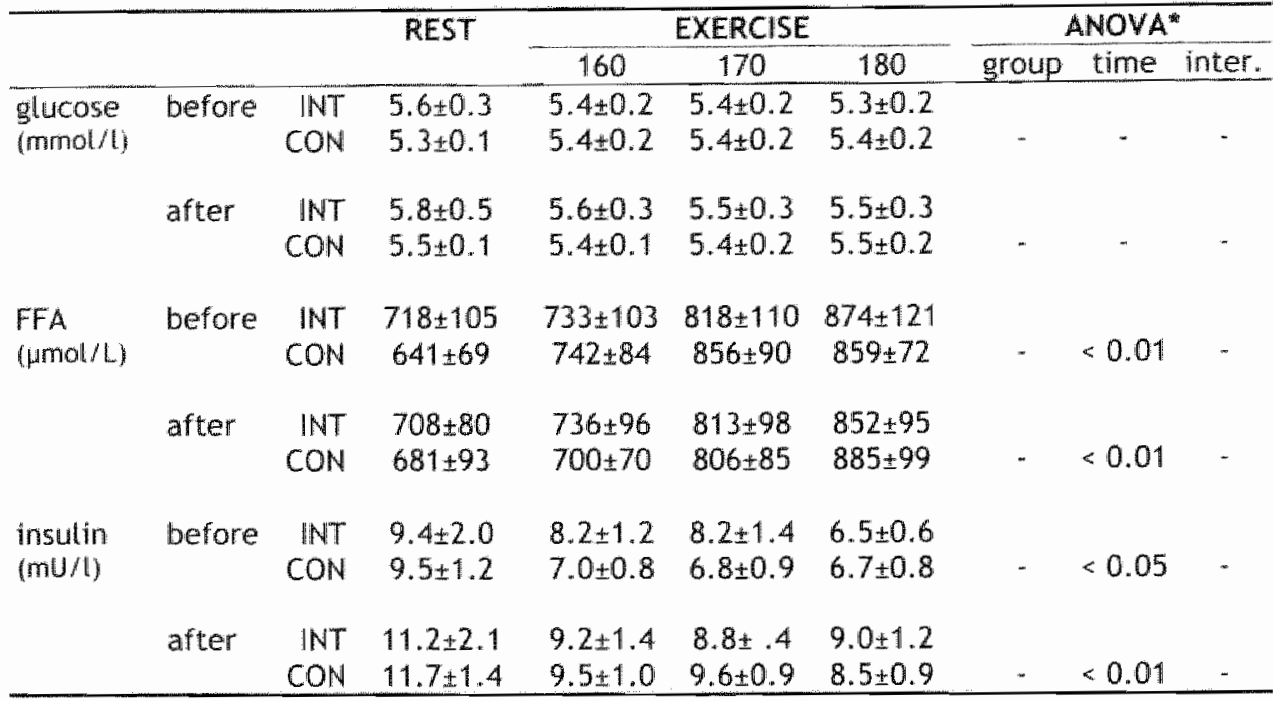

Date are mear \pm sem. * ANOWA repeated measures; inter. = group $\times$ time interaction:

$0.091 \pm 0.004$, after: $0.087 \pm 0.003 \mathrm{~kJ} / \mathrm{kgFFM} / \mathrm{min}$ CON: before $0.086 \pm 0.002$, after $0.085 \pm 0.003 \mathrm{~kJ} / \mathrm{kgFFM} / \mathrm{min} ; \mathrm{P}=\mathrm{NS}$ ) and during moderate intensity exencise: (INT: before: $0.41 \pm 0.03$, after $0.43 \pm 0.03 \mathrm{~kJ} / \mathrm{kgFFM} / \mathrm{min}$ : CON: before $0.48 \pm 0.02$, after $0.48 \pm 0.03 \mathrm{~kJ} / \mathrm{kgFFM} / \mathrm{min} ; \mathrm{P}=\mathrm{NS}$ ). Rate of appearance and disappearance of glucose and fatty acids were comparable between groups, before and after 1 year of the lifestyle intervention program (see Table 7.4).

Beside a slightly elevated fatty acid oxidation (expressed per FFM) in the control group $(P<0.05$ ), no differences were observed between groups in substrate oxidation at baseline (see Table 7.4). After one year of intervention changes in substrate oxidation at rest were not different between intervention and control group (Table 7.5). During exercise total carbohydrate and glycogen oxidation were increased in the control group after 1 year, whereas these variables slightly decreased in the intervention group, with the change after 1 year being significantly different between groups $(P<0.05)$. Total FA and plasma FFA oxidation during exercise were increased in the intervention group and decreased in the control group after 1 year $(P<0.05$ for difference in change; see Table 7.4).

In Figure 7.1 oxidation rates during exercise are given, expressed as relative contribution to energy expenditure (En\%). Change after 1 year is given between brackets (expressed as En\%). No differences between groups were observed at baseline. Total carbohydrate and glycogen oxidation were decreased in the intervention group and increased in the control group after 1 year $(P<0.05$ for difference in change). Total FA and plasma FFA oxidation were increased in the intervention group and decreased in the control group after 1 year $(\mathbb{P}<0.05$ for difference in change). No differences were observed in the change in triglyceride-derived FA oxidation. 
Table 7.4 Substrate kinetics for intervention $(n=9)$ and control group $(n=7)$

\begin{tabular}{lccccc}
\hline & \multicolumn{2}{c}{ BASELINE } & \multicolumn{2}{c}{ ONE-YEAR } \\
& intervention & control & intervention & control \\
\hline \multicolumn{1}{c}{ REST } & & & & & \\
plasma Glucose Ra & $16.5 \pm 1.5$ & $17.5 \pm 0.7$ & $15.8 \pm 1.5$ & $16.6 \pm 1.3$ \\
plasma Glucose Rd & $17.4 \pm 1.3$ & $17.7 \pm 0.5$ & $17.2 \pm 1.7$ & $17.1 \pm 1.3$ \\
plasma FFA flux & $14.6 \pm 2.1$ & $12.1 \pm 1.3$ & $15.7 \pm 1.8$ & $12.2 \pm 1.4$ \\
\multicolumn{1}{c}{ EXERCISE } & & & & & \\
plasma Glucose Ra & $27.4 \pm 1.6$ & $29.5 \pm 2.9$ & $26.0 \pm 2.3$ & $29.3 \pm 2.7$ \\
plasma Glucose Rd & $27.7 \pm 1.8$ & $29.3 \pm 3.0$ & $26.7 \pm 2.5$ & $28.4 \pm 2.9$ \\
plasma FFA Ra & $22.5 \pm 2.6$ & $21.5 \pm 1.8$ & $24.3 \pm 2.3$ & $21.8 \pm 1.5$ \\
plasma FFA Rd & $22.5 \pm 2.6$ & $21.5 \pm 1.8$ & $24.3 \pm 2.3$ & $21.8 \pm 1.5$ \\
\hline
\end{tabular}

Data are mean \pm sem and expressed as ( $\mu$ mol $/ \mathrm{kgFF} / \mathrm{min}$ ); Ra = rate of appearance, Rd = rate of disappearance

\section{Discussion}

Several studies have shown that the uptake and oxidation of FA is impaired in type 2 diabetic patients $[4,5]$ and in the prediabetic condition of impaired glucose tolerance (IGT) [10]. In the present study, subjects with IGT were restudied after 1 year of a lifestyle intervention program. Most important finding was that subjects in the intervention group maintained their capacity to oxidize (plasma free) fatty acids, while in the control group (plasma free) fatty acid oxidation was decreased. Thus, a combined diet and physical activity intervention program may be able to prevent a further impairment in fatty acid utilization in subjects with IGT.

\section{Lifestyle intervention}

Changes in body composition and insulin resistance after 1 year of intervention found in this study mimicked the results seen after 1 year in the larger intervention trial (SLIM: Study on Lifestyle-intervention and IGT, Maastricht), but were less pronounced (SLIM: intervention group $(\mathrm{n}=47)$ : body weight $-2.7 \pm 0.5 \mathrm{~kg}, \mathrm{VO}_{2} \max +0.10 \pm 0.03 \mathrm{~d} / \mathrm{min}, 2$-hour glucose $-0.8 \pm 0.3 \mathrm{mmol} / \mathrm{l}$; control group $(\mathrm{n}=55)$ body weight $-0.2 \pm 0.5 \mathrm{~kg}, \mathrm{VO}_{2} \max -0.0 \pm 0.03 \mathrm{l} / \mathrm{min}, 2$. hour glucose $+0.2 \pm 0.3 \mathrm{mmol} / 1 ; \mathrm{P}<0.05$ for difference in change; see Mensink et al.[15]). In this smaller (sub)study, differences after 1 year between groups were not significantly different. This can be explained by the small number of subjects participating in the present study. To detect statistical significant differences in such parameters as insulin resistance (measured by an OGTT) and body composition, larger groups are required. For the purpose of this study, substrate utilization and oxidation, group size is sufficient.

\section{Substrate oxidation}

Main novel finding of the present study was that after one year of a lifestyle intervention program, subjects in the intervention group maintained their 


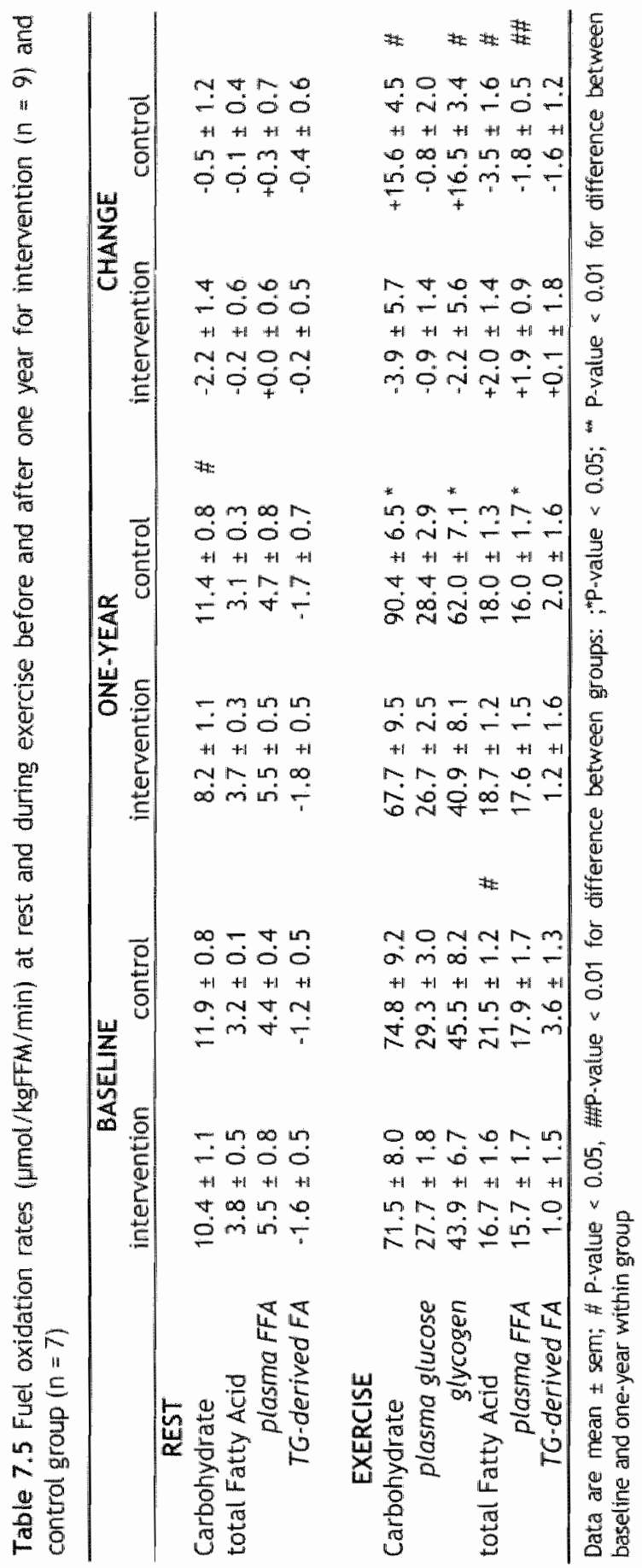


capacity to oxidize (plasma free) FA during exercise, while in the control group (plasma free) FA oxidation was decreased. It has been shown that substantial weight loss did not improve the impaired capacity to utilize plasma FFA in type 2 diabetic subjects [9]. Our data indicate that a combined program of aerobic exercise, changes in diet composition and weight-loss may be able to compensate for the impaired oxidation of (plasma free) FA, compared to the lack of improvement found after weight-loss per se. It is possible that the positive effects on tat metabolism can be ascribed to the inclusion of physical activity in the program. Indeed, it has been shown that aerobic exercise training can increase fat oxidation in different populations [12-14]. A 16 week training program increased fat oxidation during exercise in elderly subjects (mean age $74 \mathrm{yr}_{\text {. }}$ ), which was likely related to alterations in skeletal. muscle fatty acid metabolism [13]. Comparable data were found in healthy lean [12] and obese [14] men following low-intensity training sessions for only a few hours weekly, a regimen more comparable to the present intervention program. The observed maintenance, or even slight improvement of the capacity to oxidize (plasma free) fatty acids in the intervention group suggests that the positive effects of exercise also can be translated to the prediabetic condition of impaired glucose tolerance. Secondly, beside weight reduction the diet intervention program was directed towards a reduction of the amount of fat, particularly saturated fat in the diet. Changes in dietary composition can also have an effect on substrate utilization and oxidation. For example a change in the dietary polyunsaturated:saturated fat ratio can modulate the oxidation of fat and carbohydrate not only acutely after a meal but also after chronic feeding [24].

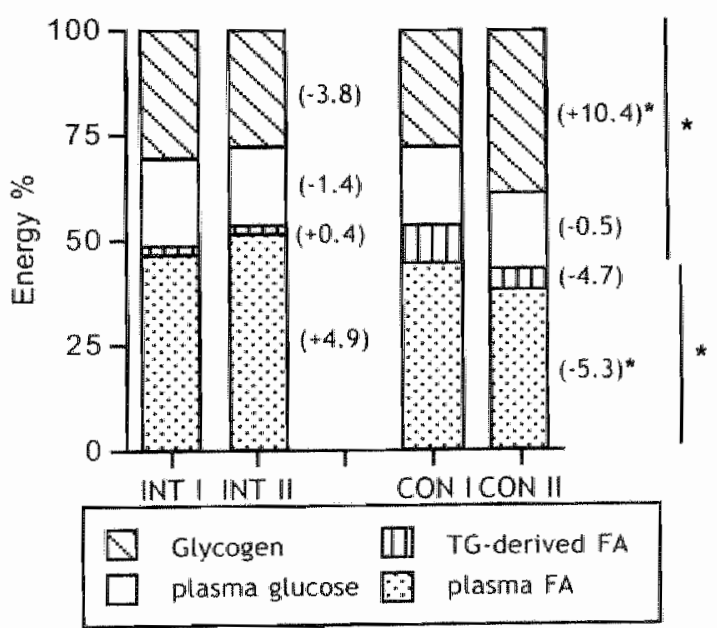

Figure 7.1 Fuel oxidation during exercise for intervention $(n=9)$ and control group $(n=7)$; Data are expressed as relative contribution to energy expenditure (Energy\%). Change over time is depicted between brackets. " $P<0.05$ between groups 
Thus, the present study shows, for the first time, that the combination of an increased level of physical activity, weight-loss and a change in dietary composition can slow down or even reverse the worsening of disturbances in fatty acid metabolism in the prediabetic condition of IGT. This could be important in relation to the development of insulin resistance and the progression from IGT to type 2 diabetes mellitus.

\section{Underlying mechanisms}

What could explain the effect of this lifestyle-intervention program on fatty acid oxidation? Several mechanisms could be responsible for the diminished capacity of the (pre)diabetic muscle to oxidize fatty acids. An increased concentration of malonyl-CoA possibly due to dysregulation by acetyl $\mathrm{CoA}$ carboxylase (ACC) and malonyl COA decarboxylase (MCD) or hyperglycemia, leading to inhibition of CPT-1 has been suggested to explain the diminished ability to oxidize fatty acids $[2,25]$. In line with this, Schrauwen et al. [12] showed that a minimal amount of physical activity significantly decreased $A C C-2$ mRNA expression in human skeletal muscle and increased fat oxidation. Furthermore, endurance training increases skeletal muscle capillarization and mitochondrial density [26] and increases the activity of several enzymes involved in fatty acid transport, transfer of fatty acids into mitochondria (CPT) and B-oxidation (HAD) [27,28]. Muscle biopsy data indicate that the insulinresistant skeletal muscle is characterized by a diminished content of oxidative enzymes $[5,29]$. Thus, an increase (or maintenance) in (mitochondrial) enzyme activity could be responsible for the differences in fatty acid oxidation between groups found in this study after 1 year of intervention.

What could be the relevance of disturbances in fatty acid oxidation in relation to the development of insulin resistance and glucose intolerance or type 2 diabetes mellitus? Disturbances in the ability of the muscle to oxidize fatty acids will lead to an accumulation of fatty acyl COA within the cytosol of the muscle cell. Long chain fatty acyl COA (LCFA-COA) itself, or through conversion to diacylglycerol (DAG) could interfere with insulin signaling by activation of protein kinase C (PKC), leading to a decreased insulin stimulated glucose uptake, i.e. insulin resistance [30]. Furthermore, increased levels of fatty acyl COA will give rise to increased stores of intramyocellular lipids (IMCL), a feature strongly associated with the insulin resistance state $[7,8]$. Finally elevated levels of fatty acids within the cytosol of the muscle cell would diminish the blood tissue FA concentration gradient, which is a very important determinant of plasma fatty acid uptake, and may explain the impaired uptake of plasma fatty acid found in subjects with IGT and type 2 diabetes [10]. One could speculate that the maintained, or slightly improved capacity to oxidize (plasma free) FA found in this study is one of the mechanism explaining the beneficially effect of lifestyle-intervention programs on glucose tolerance and subsequent risk of progression to type 2 diabetes. 


\section{Conclusion}

After 1 year of a combined diet and physical activity intervention program, the intervention group showed a maintenance of the capacity to oxidize (plasma free) fatty acids during exercise as compared to a reduced capacity in the control group. This indicates that a lifestyle intervention program can prevent a further deterioration of disturbances in fatty acid metabolism found in subjects with IGT. It is speculated that this may be one of the mechanisms explaining the positive effects of a lifestyle-intervention program on glucose tolerance and insulin resistance.

\section{Acknowledgments}

We thank Jos Stegen and Annemie Gijssen for their analytical support. This study was supported by a grant from the Dutch Diabetes Research Foundation (DFN 98.901) and the Netherlands Organization for Scientific Research (ZonMW 940-35-034).

\section{References}

1 MoGarry $\int \mathrm{D}$. What if Minkowski had been ageusic? An alternative angle on diabetes. Science 1992; 258: 766-70.

2 MoGarry JD. Banting lecture 2001: dysregulation of Catty acid metabolism in the etiology of type 2 diabetes. Diaberes $2002 ; 51: 7-18$.

3. Colberg SR, Simoneau JA, "Thaete FL, Kelley DE. Skeletal muscle utilization of free fatty acids in women with visceral obesity [see comments]. I Clin linest 1995; 95: 1846-53.

4 Kelley $\mathrm{DE}$, Simoneau JA. Impaned free fatty acid utilization by skeletal muscle in non-insulin-dependent diabetes mellitus. J Clin Invest 1994; 94: 2349-56.

5 Blaak EE, Wagenmakers Al, Glatz JF el al. Plasma FFA utilization and fatty acidbinding protein content are dininished in type 2 diabetic muscle. Am I Physiol Endocrind Metab 2000; 279: E146-54.

6 Blaak EE, van Aggel-Leissen DPC, Wagenmakers AMM, Saris WHM, van Baak MA. Impaired Oxidation of Plasma-Derived Fatly Acids in Type 2 Diabetic Subjects During Moderate-Intensity Exercise. Diabetes 2000; 49: 2102-2107.

7 Pan DA, Lillioja $S$, Kriketos $A D$ ef al. Skeletall muscle triglyceride levels are inversely related to insulin action. Diobetes $1997 ; 46: 983-8$.

8 Virkamaki A, Korsheninnikova E, Seppala-Lindroos A et al. Fintramyocellular lipid is associated with resistance to in vivo insulin actions on glucose uptake, antilipolysis, and early insulin signaling pathways in human skeletal muscle. Dinbetes 2001; 50 : $2337-43$

9 Blaak EE, Wolffenbuttel BH, Saris WH, Pelsers MM, Wagenmakers AJ. Weight reduction and the impained plasma-derived free fatty acid oxidation in type 2 diabetic subjects. / Cin Endocrinol Mctab 2001; 86: 1638-44.

10 Mensink M, Blaak EE, van Baak MA, Wagenmakers A), Saris WH. Plasma free Fatty Acid uptake and oxidation are already dimmished in subjects at high risk for developing type 2 diabetes. Diabeles $2001 ; 50: 2548-54$. 
11 Turpeinen AK, Takala TO, Nuutila P et al. Impaired free fatty acid uptake in skeletal muscle but not in myocardium in patients with impaired glucose tolerance: studies with PET and 14(R,S)-[18F]fuoro-6-thia-heptadecanoic acid. Diabetes 1999: $48: 1245$ 50 .

12 Schrawwen P. Van Aggel-Leissen DP, Hul Get al. The Effect of a 3-Month LowIntensity Endurance Training Program on Fat Oxidation and Acetyl-CoA Carboxylase-2 Expression. Diabetes 2002; 51 : 2220m6.

13 Sial $S$, Coggan $A R$, Hickner $R C_{x}$ Klein S. Training-induced alterations in fat and carbohydrate metabolism during exercise in elderly subjects. Am / Physiol 1998; 274: $\mathrm{E} 785-90$

14 Van Aggel-Leigsen DP, Saris WH, Wagenmakers A. Senden JM, Van Baak MA. Effect of exercise training at different intensities on fat metabolism of obese men. I Appl Physidol 2002; 92 : 1300-9.

15 Mensink M, Feskens EI, Saris $W_{2}$ De Bruin TW, Blaak EE. Study on Lifestyle Intervention and Impaired Glucose Tolerance Maastricht (SLIM): preliminary results after one year. Int J Obes Relat Metab Disord 2003; 27: 377-84.

16 Matthews DR, Hosker IP, Rudenski AS et al. Homeostasis model assessment: insulin resistance and beta-cell function from fasting plasma glucose and insulin concentrations in man. Diabetologia 1985; $28,412-9$.

17 Siri W. The gross composition of the body. Adv Bio Med Physiol 1956, 4:239-280.

18 Wagenmakers Al, Rehrer NJ, Brouns F, Saris WH, Halliday D. Breath $13 \mathrm{CO}_{2}$ background enrichment during exercise: diet-related differences between Europe and America. J Appl Physiol 1993; 74:2353-7.

19 Sidossis LS, Coggan AR, Gastaldelli A, Wolfe RR. A new correction factor for use in lracer estimations of plasma fatty acid oxidation. Am / P/mysiol 1995; 269: E649-56.

20 Weir J. New methods for calculating metabolic rate with special reference to protein metabolism. J Physid (London) 1949; 109: 1-9.

21. Frayn KN. Calculation of substrate oxidation rates in vivo from gaseous exchange.) Appl Physiol 1983; 55: 628-34.

22 Wolfe RR. Calculation of substrate kimetics. (1992). Calculation of substrate kinetics. new York, Wiley-Liss.

23 Jeukendrup AE, Raben A, Gijsen A et al. Glucose kinetics during prolonged exercise in highly trained human subjects: effect of glucose ingestion. I Physiol (Lond) 1999; 515 ( P t 2): 579-89.

24 Jones PI, Schoeller DA. Polyunsaturated:saturated ratio of diet fat influences energy substrate utilization in the human. Motabolism 1988; 37: 145-51.

25 Ruderman NB, Saha AK, Vavvas D, Witters LA. Malonyl-CoA, fuel sensing, and insulin resistance. Ann ) Physio 1999; 276: E1-E18.

26 Holloszy 10, Coyle EF. Adaptations of skeletal muscle to endurance exercise and their metabolic consequences. I Appl Physiol 1984; 56:831-8.

27 Kiens B, Esser-Gustavsson B, Christensen NJ, Saltin B. Skeletal muscle substrate ulilization during submaximal exercise in man: effect of endurance training. I Physiol 1993; 469: 459-78.

28 Kiens B. Effect of endurance training on fatty acid metabolism: local adaptations. Med Soi Sports Exerc 1997; 29:640-5.

29 Simoneau JA, Veerkamp JH, Turcotte LP, Kelley DE. Markers of capacity to utilize fatty acids in human skeletal muscle: relation to insulin resistance and obesity and effecte of weight loss. Faseb / 1999; 13:2051-60.

30 Schmitzeiffer $C$. Signalling aspects of insulin resistance in skeletal muscle. mechanisms induced by lipid oversupply. Cell Signal 2000; 12: 583-594. 


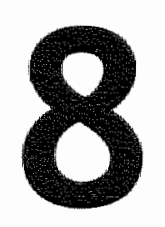

\section{Lifestyle Changes and Lipid Metabolism Gene Expression and Protein Content in Skeletal Muscle of Subjects with Impaired Glucose Tolerance}

Marco Mensink, Ellen E Blaak, Hubert Vidal, Tjerk WA de Bruin, Jan FC Glatz, Wim HM Saris

Dept of Human Biology, Nutrition and Toxicology Research Institute NUTRIM, Maastricht University, Maastricht, The Netherlands

INSERM Unit 449, Faculty of Medicine R. Laennec, Lyon, France

Dept of Medicine and Endocrinology, University Hospital Maastricht, Maastricht, the Netherlands

Dept of Physiology, Maastricht University, Maastricht, The Netherlands

Diabetologia 2003; in press 


\begin{abstract}
Skeletal muscle of (pre)diabietic patients is characterized by a diminished capacity to handle fatty acids. A diminished content of several enzymes involved in fatty acid transport and oxidation have been suggested to underlie these defects. Aim of the present study was to investigate whether the combination of dietary advice, increased physical activity and weight-loss improves lipid metabolic gene and protein expression in skeletal muscle of subjects with impaired glucose tolerance (IGT). Before and after 1 year of a lifestyleintervention program, expression of several genes and proteins involved in lipid metabolism were measured in muscle biopsies from subjects in the intervention $(\| N T ; n=7)$ and control group (CON; $n=6)$. After 1 year the intervention group had an improved glycemic control and reduced body fatness compared to controls. Significant differences were observed for change in acetyl-COA carboxylase 2 and uncoupling protein 2 expression between groups (ACC. 2 : $-16.8 \pm 12.4 \%$ vs. $+51.5 \pm 32.3 \%$ for INT and CON respectively: $P<0.05)($ UCP2: $-26.9 \pm 10.3 \%$ vs. $+10.5 \pm 6.2 \%$ for $I N T$ and CON respectively; $\mathbb{P}<0.05)$. Change in 3 -hydroxyacyl. CoA dehydrogenase pratein content tended to be different between groups $(+3.2 \pm 1.1$ vs. $-0.9 \pm 1.9 \mathrm{U} / \mathrm{mg}$. Ww for INT and CON, $\mathrm{P}=0.07)$

In conclusion, lifestyle changes leading to an improved glycemic control and reduced adiposity, resulted in a down-regulation of ACC-2 and UCP2 expression and in an increase in HAD protein content, reflecting a better capacity to utilize fatty acids.
\end{abstract}


Skeletal muscle has an important role in the overall utilization and oxidation of fatty acids (FA), because of its large mass, and since lipids are the principal oxidative substrate after both an overnight fast and during moderate intensity exercise. Type 2 diabetes mellitus is characterized by abnormalities in skeletal muscle glucose and lipid metabolism 11. Uptake and oxidation of (nonesterified) fatty acids are diminished under postabsorptive conditions in type 2 diabetes [2,3] and impaired glucose tolerance (IGT) [4], while during postprandial conditions there is impaired suppression of muscle plasma FFA uptake in type 2 diabetes compared to controls [2], faworing increased storage of lipids. Indeed, the diabetic muscle is characterized by increased levels of triacylglycerol (intramyocellular lipids, IMCL) [5,6], which is strongly associated with the degree of insulin resistance, even in non-diabetic subjects $[7,8]$. Thus, alterations in FA metabolism can play an important role in the development of insulin resistance and type 2 diabetes mellitus [1,9].

Several mechanisms have been suggested to underlie the diminished capacity of the (pre)diabetic muscle to oxidize fatty acids. Several studies have shown that the insulin-resistant skeletal muscle is characterized by a diminished content of proteins / enzymes involved in fatty acid transport (cylosolic fatty acid binding protein, FABPC), $\beta$-oxidation ( 3 -hydroxy fatty-acyl CoA dehydrogenase, HAD) and the Krebs cycle (citrate synthase, CS) [3,10]. The metabolic capacity of the insulin-resistant skeletal muscle appears to be organized towards fat esterification rather than oxidation [10]. Reduced activity of the rate-limiting step in fatty acid oxidation, carnitine-palmitoyl transferase 1 (CPT-1), either to decreased expression or more pronounced inhibition by malonyl-CoA, have been suggested to explain the diminished ability to oxidize fatty acids [11]. Finally, a role is suggested for uncoupling proteins (UCP) in the disturbed fatty acid handling in type 2 diabetes [12,13].

Weight reduction is known to improve insulin sensitivity and reduce the degree of glucose intolerance. However substantial (dietary-induced) weight reduction did not improve the disturbed plasma-derived FA oxidation in type 2 diabetic subjects [14]. Neither did weight reduction correct the metabolic derangement's of skeletal muscle partitioning fat towards esterification rather than oxidation, in obese non-diabetic subjects [10]. On the other hand, physical exercise is a potent enhancer of insulin sensitivity and also increases the capacity of the skeletal muscle to oxidize fatty acids. The enhanced fat oxidation after exercise training is associated with upregulated genes involved in FA uptake such as membrane-associated FA binding protein (FABPPm) and FA translocase (FAT/CD36) [15,16], and genes involved in FA oxidation, as CPT-1, acetyl-CoA carboxylase (ACC) and HAD 116-18]. Therefore it can be speculated that combining exercise and weight-loss could be an effective strategy because this would have the potential to compensate for the impaired capacity to oxidize fatty acids and stimulate expression of genes involved in lipid metabolism in skeletal. muscle of insulin resistant subjects, in comparison to the lack of improvement after weight-loss alone. Moreover, another important environmental factor regulating gene expression is nutrient-intake. Especially the fatty acid composition of dietary lipids has a marked effect on gene expression, and influences fuel homeostasis in liver and skeletal muscle [19]. 
Therefore, we addressed in this study the question whether the combination of dietary advice, increased physical activity and moderate weight-loss, a so-called lifestyle-intervention, improves the lipid metabolic mRNA and protein profile of skeletal muscle in subjects with IGT. Epidemiological studies have shown that such a lifestyle intervention program, based on general public health recommendations reduces the progression from IGT to diabetes with almost $60 \%$ over a 3 year period [20,21]. Before and after one year of a lifestyleintervention program skeletal muscle lipid metabolism related gene and protein expression was measured in biopsies from the m. vastus lateralis.

\section{Methods}

\section{Subjects}

The Study on Lifestyle-intervention and IGT, Maastricht (SLTM) is designed to study whether a diet/physical activity intervention program may improve glucose tolerance in subjects with a high risk on developing type 2 diabetes mellitus. A detailed description of the study can be found elsewhere [22]. In the present study, thirteen subjects with IGT participating in the larger intervention trial underwent additional measurements to evaluate the effect of this lifestyleintervention program on skeletal. muscle gene expression and protein content, 7 from the intervention group ( 4 male, 3 female) and 6 subjects from the control group $(6$ male). Subjects had no health problems and did not use any medication which could interfere with substrate metabolism. Before and after 1 year of a lifestyle-intervention program measurements were performed of glucose tolerance, body composition and maximal aerobic capacity, and muscle biopsies were taken. Due to inadequate biopsy material we could not measure mRNA and protein level in one subject from the control group. The Medical Ethical Review Committee of Maastricht University approved the study protocol, and all subjects gave their written informed consent before the start of the study.

\section{Lifestyle-intervention}

The intervention program consists of a dietary and physical activity part. Dietary recommendations were based on the Dutch guidelines for a healthy diet ( \pm 55 En\% carbohydrates; $<30-35$ En\% fat intake, with $<10$ En\% intake of saturated fatty acids; a cholesterol intake of less than $33 \mathrm{mg}$ per MJ; protein intake of $10-15 \mathrm{En} \%$ and an intake of dietary fibre of at least 3 gram per MJ). Goal for body weight was a BMI of less than $25 \mathrm{~kg} / \mathrm{m}^{2}$, but for practical reasons a body weight loss of 5-10 kg was aimed at depending on the degree of obesity. Dietary advice was given by a skilled dietician on an individual basis every three months. Subjects were stimulated to increase their physical activity to at least 30 minutes of moderate physical activity per day for at least 5 days a week. Individual advice was given how to increase their daily physical activity (walking, cycling, swimming) and goals were set. Furthermore, subjects were encouraged to participate in an exercise program, consisting of components of aerobic exercise training and components of resistance training. 
Subjects in the control group were informed about the beneficial effects of a healthy diet, weight loss and increased physical activity, whereas no individual advises or programs were provided. No additional appointments were scheduled.

\section{Measurements}

A standard 75 gram oral glucose tollerance test (OGTT), with blood-sampling at $t=0, t=30, t=60$ and $t=120$ min, was performed to measure glucose tolerance and insulin levels. Body weight was determined on an electronic scale; body composition was determined by hydrostatic weighing with simultaneous lung volume measurement (Volugraph 2000, Mijnhardt, Bunnik, the Netherlands), and calculated according to Siri [23]. Waist circumference was measurements to the nearest $1 \mathrm{~cm}$ with subjects standing in upright position, half way the spina iliaca and the last rib.

An incremental exhaustive exercise test was performed on an electronically braked bicycle ergometer to determine maximal aerobic capacity (VO $\mathrm{O}_{2}$ ax). The test started at a workload of $0.75 \mathrm{~W}$ per $\mathrm{kg}$ fat free mass (FFM) for 3 minutes, followed by 3 minutes at $1.5 \mathrm{~W} / \mathrm{kgFFM}$. Thereatter, the workload was increased every 3 minutes by $0.5 \mathrm{~W} / \mathrm{kgFFM}$ until exhaustion ( $\mathrm{RQ}$ above 1.1 and no further increase in oxygen uptake).

Needle muscle biopsies were taken before and after 1 year, percutaneously from the m. vastus lateralis after an overnight fast, using the Bergstrom method with suction [24]. Biopsies were immediately frozen in liquid nitrogen and stored at $-80^{\circ} \mathrm{C}$ until analysis.

\section{Biochemical methods}

Blood samples were collected in sodium fluoride (glucose) or heparin (insulin) containing tubes on ice and were immediately centrifuged at $4^{\circ} \mathrm{C}$; plasma was stored at $-80^{\circ} \mathrm{C}$ until analysis. Plasma glucose concentration was measured with a standard enzymatic technique automated on the Cobas Fara centrifugal analyzer (Glucose HK 125, ABX diagnostics, Montpellier, France). Plasma insulin concentration was measured with an ELISA assay (Mercodia, Uppsala, Sweden》, which shows no cross-reactivity with pro-insulin.

\section{Quantification of MRNA levels}

For determination of the expression of camitine palmitoyl transferase-2 (CPT-2), carnitine palmitoyl transferase-1 muscle form (CPT-1m), acetyl Co-enzyme A carboxylase-2 (ACC-2), lipoprotein lipase (LPL), peroxisome proliferaloractivated receptor-a (PPAR $\alpha$ ), uncoupling protein 2 (UCP-2), uncoupling protein 3 (UCP-3), total RNA was isolated using the acid phenol method of Chomozynski and Sachi [25] with an additional DNAse digestion step with concomitant acid phenol extraction and ethanol precipitation. The level of specific mRNA was determined using either RT-competitive PCR assays (CPT2 and $A C C 2$ ) or real-time RT-PCR assays (CPTImuscle, LPL, PPARo, UCP2 and total UCP3). For both competitive and real time PCR, the first strand CDNA was synthesized with the specific reverse primers and from $0.14 \mathrm{~g}$ of total RNA in 
experimental conditions that warranted optimal efficiency of the reaction [26]. During the competitive PCR, Cy-5 5"-end labeled sense primers were used to generate fluorescent $\mathbb{P C R}$ products that were analyzed with an automated laser fuorescence DNA sequencer (ALFexpress, Pharmacia, Upsala, Sweden) in $4 \%$ denaturing polyacrylamide gels. The initial concentration of target mRNA was determined at he competition equivalence point as previously described [26]. The real-time PCR was performed using a LightCycler (Roche Diagnostics, Meylan, France) with the FastStart DNA Master SYBR Green kit (Roche Diagnostics). After amplification, a melting curve analysis was performed to verify the specificity of the reaction. For quantification, a standard curve was systematically generated with 6 different amounts $(150$ to 30,000 molecules/tube) of purified target CDNA cloned in the PGEM plasmid (Promega). The analysis was performed using the LightCycler software (Roche Diagnostics). The list of the primers used for the different RT-PCR assays is available in Table 8.1 .

Table 8.1 List of primers used for the different RT-PCR assays

\begin{tabular}{|c|c|c|}
\hline Names & forward primers & reverse primers \\
\hline PPAR & $5^{\prime}-G C T-A T C-A T T-A C G-G A G-T C C-A C G-3^{\prime}$ & 5-AGC-TGC-GGT-CGC-ACT-TGT-CA-3' \\
\hline UCP-2 & 5'GAC-CTA-TGA-CCT-CAT-CAA-GG-3' & 5-ATA-GGT-GAC-GAA-CAT-CAC-CAC-G-3" \\
\hline UCP-3 & 5-ATG-GAC-GCC-TAC-AGA-ACC-AT-3" & $5^{\circ}-C T G-G G C-C A C-C A T \cdot C T T-T A T-C A-3^{\prime}$ \\
\hline mCPT-1 & 5-TAC-AAC-AGG-TGG-TT-GAC-A-3: & 5-CAG-AGG-TGC-CCA-ATG-ATG-3' \\
\hline CPT -2 & 5-TTA-AAG-ACA-GCA-CTC-AGA-CC-3' & 5-GTT-TTC-ATG-GTG-GCA-TCA-AAC-3: \\
\hline$A C C-2$ & $5^{\circ} \cdot G G-T G G-A G A-T G A-A C C-G A C-T T C-3^{\circ}$ & $5^{\prime}-A C T-C T C-C T C-C T T-C C T-C G A-T G-3^{\prime}$ \\
\hline LPL & 5-GGT-CGA-AGC-ATT-GGA-ATC $\times C A G-3^{\prime}$ & 5-TAG-GGC-ATC-TGA-GAA-CGA-GTC-3' \\
\hline
\end{tabular}

\section{Protein expression}

For determination of protein content, muscle biopsies were homogenized in icecold tris-EDTA buffer at pH 7.4. Homogenates were subsequenty sonificated for 15 seconds, 4 times. Membrane protein fatty acid translocase/CD36 (FAT/CD36) was measured by an sandwich-type ELISA [27]. For the determination of the cytosolic proteins, the homogenates were centrifuged at $10000 \mathrm{~g}$ for 2 min to remove cell debris (of membranes). Tissue content of muscle type cytosolic tatty acid binding protein (FABPc) in skeletal muscle was measured by means of an ELISA (Hycult Biotechnology, Uden, Netherlands), using recombinant human FABPC as standard [28]. Citrate synthase (CS) was determined according to the method of Sherperd and Garland [29], whereas 3-hydroxyacylcoA dehydrogenase (HAD) was assayed according to Bergmeyer [30].

\section{Statistical analysis}

Data are presented as means tsem. Differences between groups were analyzed with a two tailed sludent's t-test for unpaired data. Pearson correlation 
coefficients were calculated to assess the relation between changes in bodyweight, waist circumference, $\mathrm{VO}_{2} \max$ and 2-hour glucose on one side and changes in expression of genes and proteins on the other side. Statistical significance was set at $\mathbb{P}<0.05$.

Table 8.2 Baseline characteristics

\begin{tabular}{lcrrr}
\hline & & intervention & control & P-value \\
\hline $\mathrm{n}$ & (male/femalle) & $7(4 / 3)$ & $6(6 / 0)$ & \\
age & $($ year) & $54.4 \pm 2.2$ & $57.2 \pm 3.6$ & 0.52 \\
body weight & $(\mathrm{kg})$ & $93.7 \pm 6.7$ & $84.0 \pm 3.7$ & 0.26 \\
waist & $(\mathrm{cm})$ & $107.0 \pm 4.2$ & $100.4 \pm 2.3$ & 0.22 \\
VOtmax & $(\mathrm{m} / \mathrm{kg} / \mathrm{min})$ & $26.3 \pm 1.6$ & $29.9 \pm 1.4$ & 0.12 \\
$2-\mathrm{h}$ glucose & $($ mmol/i) & $8.4 \pm 0.7$ & $9.4 \pm 0.8$ & 0.34 \\
FFA & $($ Hmol/ $)$ & $545 \pm 34$ & $582 \pm 53$ & 0.55 \\
\hline
\end{tabular}

Data are mean \pm sem

\section{Results}

\section{Subjects}

A.ll 13 subjects participating in this study were participants from an ongoing intervention trial [31], evaluating the effect of lifestyle changes on glucose tolerance; seven from the intervention group ( 4 men; 3 women) and six from the control group (6 men). Baseline characteristics are depicted in Table 8.2. There were no significant differences in baseline characteristics between groups.

The intervention group included male and female subjects, while the control group included only male subjects. Analyzing the results in males only, however, resulted in comparable differences in gene expression and protein content between control and intervention group. Because of the small numbers in both groups we included the results obtained in the females in our analysis.

Changes after 1 year are depicted in Table 8.3. Body weight and waist circumference had decreased in the intervention group and had increased in the control group. The change in waist circumference after 1 year was significanty different between groups $(-3.5 \pm 1.0 \mathrm{~cm} v \mathrm{~s} .+0.3 \pm 1.1 \mathrm{~cm}$ for intervention and control respectively: $\mathrm{P}=0.04)$. After 1 year, 2 -hour plasma glucose and fasting insulin tended to decrease in the intervention group, compared to a slight increase in the control group $(\mathrm{P}=\mathrm{ns})$. Additionally, 2 -hour insulin decreased in the intervention group and increased in the control group $(-15.8 \pm 5.3 \mathrm{mU} / \mathrm{Vs}$. $+41.8 \pm 22.1 \mathrm{mU} / \mathrm{I}$ for intervention and control respeclively; $\mathrm{P}=0.03$ ).

\section{Gene Expression}

Relative changes after 1 year in genes involved in lipid metabolism in skelelal muscle, are depicted in Figure 8.1. CPT-2 was upregulated in the intervention group, but this increase this was not different from the increase observed in the control group after 1 year $(P=0.33$ ). Differences in change in gene expression between groups were observed for $\mathrm{ACC}-2$ and $\mathrm{UCP}-2$. Both were downregulated in the intervention group and upregulated in the control group 
after 1 year (relative change: ACC-2*-16.8 $\pm 12.4 \%$ vs $+51.5 \pm 32.3 \%$ for intervention and control respectively; $\mathbb{P}<0.05$ )(relative change: UCP-2: $-26.9 \pm$ $10.3 \%$ vs $+10.5+6.2 \%$ for intervention and control respectively; $\mathrm{P}<0.05)$. No differences were observed in change in expression of CPT-1 muscle. LPL, PPARa and UCP3total between groups (Figure 8.1).

\section{Protein content}

Changes in content of proteins involved FA transport, $\beta$-oxidation and the Krebs-cycle are displayed in Figure 8.2. HAD tended to increase after 1 year of intervention in the active group, and slightly decreased in the control group $(+3.2 \pm 1.1 \mathrm{U} / \mathrm{mg}$. ww vs. $-0.9 \pm 1.9 \mathrm{U} / \mathrm{mg}$. ww respectively: $\mathrm{P}=0.07$ for difference in change). No significant differences were seen in FABPC, CS and FAT/CD36 between groups after 1 year.

\section{Correlation between changes in subjects characteristics and IRRNA and protein levels}

Correlation between changes in body-weight, waist circumference, $\mathrm{VO}_{2}$ max and 2-hour glucose and changes in expression of genes and proteins were calculated. Correlation was observed between change in UCP2 and waist, change in HAD and 2-hour glucose and between change in FABPC and 2-hour glucose (see Figure 8.3). A decrease in UCP2 expression was associated with a decreased waist circumference after 1 year $(R=0.71 ; P<0.01)$. Furthermore, an increase in FABPC and HAD protein content both tended both to be correlated with a decrease in postload glucose concentration $R=-0.57$ and $r=-0.56$ respectively; $P=0.06$ ). Other changes in subject characteristics were not (significant) correlated to any changes in gene and protein expression.

Table 8.3 Changes after 1 year in subjects characteristics

\begin{tabular}{lcccl}
\hline & & intervention & control & P-value \\
\hline body weight & $(\mathrm{kg})$ & $-1.5 \pm 1.2$ & $+0.8 \pm 0.8$ & 0.15 \\
Waist & $(\mathrm{cm})$ & $-3.5 \pm 1.0$ & $+0.3 \pm 1.1$ & 0.03 \\
VO 2 max & $(\mathrm{m} / / \mathrm{kg} / \mathrm{min})$ & $+1.6 \pm 1.0$ & $-0.9 \pm 1.0$ & 0.12 \\
2-h glucose & $(\mathrm{mmol} / \mathrm{l})$ & $-0.6 \pm 0.8$ & $+1.0 \pm 0.8$ & 0.19 \\
fast insulin & $(\mathrm{mu} / \mathrm{l})$ & $-1.7 \pm 2.0$ & $+3.3 \pm 1.7$ & 0.09 \\
2li insulin & $(\mathrm{mu} / \mathrm{l})$ & $-15.8 \pm 5.3$ & $+41.8 \pm 22.1$ & 0.02 \\
fast FFA & $(\mathrm{mmol} / \mathrm{l})$ & $-125 \pm 46$ & $-79 \pm 28$ & 0.46 \\
triglycerides & $(\mathrm{mmol} /)$ & $-0.31 \pm 0.22$ & $+0.40 \pm 0.21$ & 0.03 \\
\hline
\end{tabular}

Dota are mean it sem:

\section{Discussion}

Skeletal muscle of (pre)diabetic patients is characterized by a diminished capacity to handle fatty acids [2-4]. A diminished muscle content of several enzymes involved in fatty acid transport and oxidation has been suggested to underlie these defects $[3,10]$. Body weight reduction per se did not correct the metabolic derangement's in skeletal muscle in type 2 diabetic and obese nondiabetic subjects $[10,14]$. In the present study the effect on the expression of 


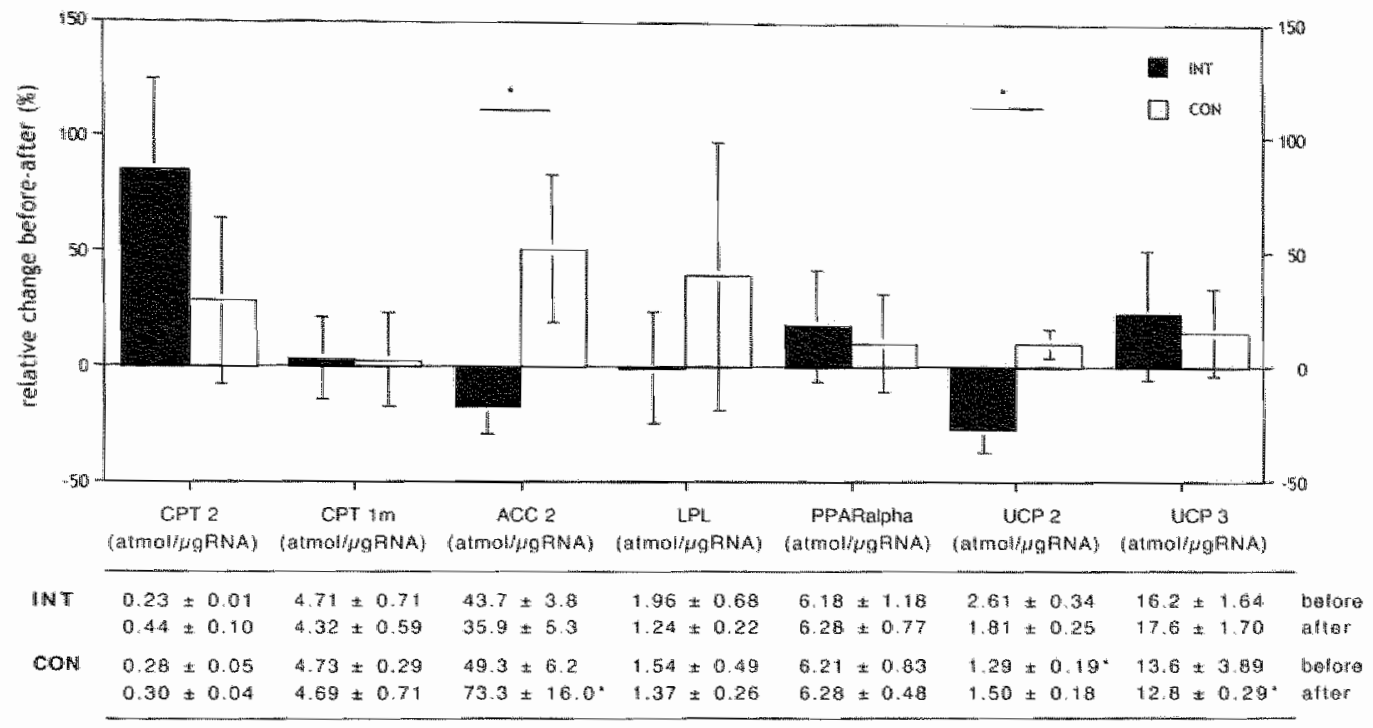

Figure 8.1 Skeletal muscle gene expression; Relative change ( $\%$ ) and absolute levels (table)

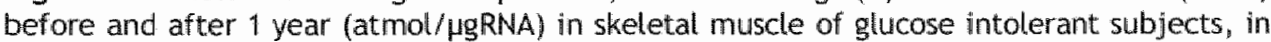
the intervention ( $\mathbb{N} T$ ) and control group $\left(\square C O N\right.$ ); Data are mean $\pm \operatorname{sem}^{*} \mathrm{P}<0.05$ between groups

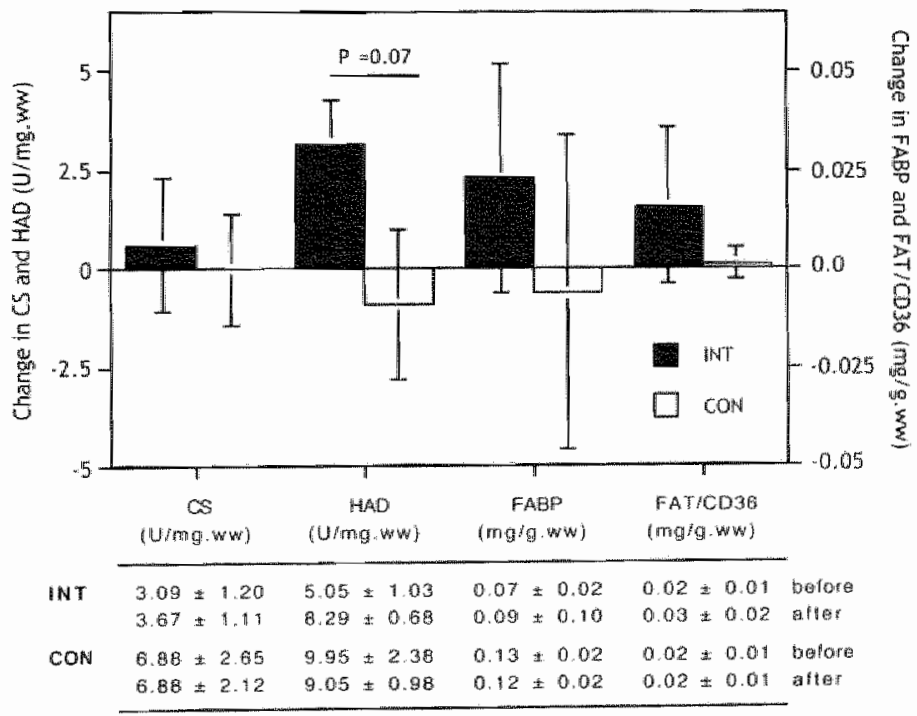

Figure 8.2 Skeletal muscle protein content; Change and absolute levels (table) before and after 1 year in skeletal muscle of glucose intolerant subjects, in the intervention ( INT) and control group ( $\square$ CON); Data are mean \pm sem 
genes and proteins involved in lipid metabolism was examined in skeletal muscle biopsies of subjects with impaired glucose tolerance (IGT), before and after one-year of a combined diet and exercise intervention program, knowing to improve glucose tolerance and decrease the degree of insulin resistance [22]. Interestingly, expression of several genes involved in (skeletal muscle) lipid metabolism was altered after 1 year of intervention. ACC-2 mRNA had decreased in the intervention group but increased in the control group, while UCP-2 mRNA and HAD protein content tended to an increase in the intervention group compared to controls. Therefore, a combined diet and exercise intervention program that leads to an improved metabolic profile, can induce alterations in expression of selected genes and proteins involved in lipid metabolism in muscle of glucose intolerant subjects, generally reflecting a better capacity to handle fatty acids.

\section{Lifestyle-intervention}

Our lifestyle-intervention program resulted in several marked changes in subjects characteristics after 1 year. Despite the small number of subjects, significant differences were observed in changes in waist circumference and in 2hour insulin levels already. Both variables decreased in the intervention group and (slightly) increased in the control group. Changes in body weight, glucose tolerance, and insulin levels in this study mimicked the results seen after 1 year in the larger intervention trial, but were less pronounced (large trial: intervention group $(\mathrm{n}=47)$ : body weight $-2.7 \pm 0.5 \mathrm{~kg}, 2-\mathrm{h}$ glucose $-0.8 \pm 0.3$ $\mathrm{mmol} / \mathrm{l}$, fasting insulin $-2.5 \pm 0.9 \mathrm{mU} / \mathrm{l}$; control group $(\mathrm{n}=55)$ body weight -0.2 $\pm 0.5 \mathrm{~kg}, 2$-hour glucose $+0.2 \pm 0.3 \mathrm{mmol} / \mathrm{l}$, fasting insulin $+0.4 \pm 0.6 \mathrm{mU} / \mathrm{l} ; \mathrm{P}<$ 0.05 for difference in change; see ref. [22]). These results confirm the known beneficial effects of changing dietary habits and improving physical activity on glucose tolerance and subsequent progression to type 2 diabetes mellitus $[20,21]$.

\section{Fatty acid metabolism gene and protein expression}

Skeletal muscle of subjects with type 2 diabetes or the prediabetic condition of IGT is characterized by a reduced capacity to oxidize (plasma free) FA [2-4]. This impared fatty acid oxidation can be an important mechanism underlying the development of insulin resistant state [1,9]. Simoneau et al.[10] reported reduced activities of several key enzymes involved in FA oxidation (CS, HAD and CPT) in muscle biopsies of insulin resistant obese individuals, and concluded that the insulin-resistant muscle is organized toward fat esterification rather than oxidation. Weight-loss, induced by a dietary intervention, did not improve this situation [10]. In the present study we combined a dietary intervention with an exercise protocol, resulting in several (small) changes in the lipid metabolic profile of skeletal muscle of subjects with IGT compared to controls with IGT. Acetyl-CoA carboxylase-2 (ACC-2) slightly decreased in the intervention group and increased in the control group $(\mathrm{P}<0.05$ for difference in change). Our data nicely match with the observation that a 3month low-intensity endurance training program decreased ACC-2 mRNA expression and improved fat oxidation in healthy non-obese men [18].ACC-2 plays an important role in the control of fatty acid oxidation, it catalyses 

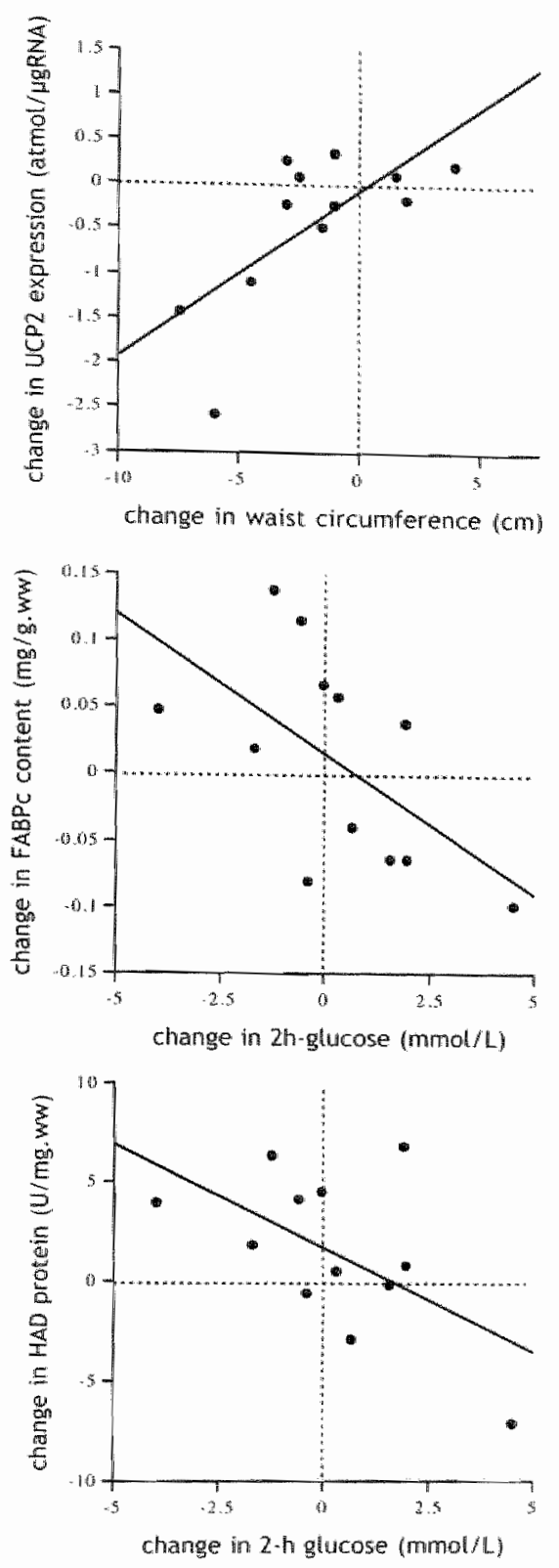

Figure 8.3 Simple correlation between change in waist and change in UCP2 expression (top) $(r=0.71, P<0.01) ;$ change in 2-hour glucose and change in FABPC protein content (middle) $(r=0.57, P=0.06)$; change in 2 -hour glucose and change in HAD protein (bottom) $(r=-0.56, P=0.06)$ 
the formation of malonyl-CoA, an intermediate that inhibits the activity of CPT1. CPT-1 is responsible for the transport of fatty acyl-CoA into mitochondria.. Although changes in $\mathrm{CPT}-1$ mRNA levels were not different between groups in our study, we can not rule out a difference in protein level or activity of CPT-1. It is tempting to speculate that the observed differences in ACC-2 expression underlie, via malonyl-CoA and CPT-1, the corresponding changes in insulin resistance and glucose tolerance.

The combination of a decreased ACC-2 expression and an increased HAD protein content $(\mathrm{P}=0.07)$ after 1 year suggests an improved capacity to oxidize fatty acids in the intervention group. This nicely matches with our observation done in a comparable group of subjects, that total fat oxidation and plasma free fatty acid oxidation during exercise were slightly improved in the intervention group and decreased in the control group after 1 year of this lifestyleintervention program (Mensink et al, unpublished data; see Chapler 7). Furthermore, an association between increased HAD protein content and improved glucose tolerance (i.e. decreased 2-hour glucose) was seen in the present study. The inclusion of exercise in the protocol is most probably responsible for the observed changes seen in our study, since weight-loss per se has been reported not to change the expression of several important genes involved in skeletal muscle lipid metabolism [10]. Moreover, exercise (training)is a powerful stimulator of lipid oxidation by increasing the expression of genes which encode for key enzymes in lipid metabolism [16].

Another interesting observation is the difference found in UCP-2 expression between groups after 1 year: a decrease in the intervention group and an increase in the control group. In addition, a decrease in UCP-2 mRNA expression after 1 year was associated with a reduced abdominal adiposity, i.e. reduced waist circumference. Our laboratory recently reported a reduction in UCP2 mRNA expression after substantial weight-loss in type 2 diabetic subjects [13]. UCP-2 expression is increased in skeletal muscle of diabetic patients [32], and, as shown here, decreases after a diet and exercise intervention program.

Beside changes in the capacity to oxidize fat, an impaired capacity to transport farty acids has been suggested to play a role in the impaired capacity to utilize fat in skeletal muscle of insulin resistant subjects [3]. Although FAT/CD36 and FABPc were increased in the intervention group, the changes after 1 year were not statistically different from the control group. However, the change in FABPC protein content was correlated to an improved glucose tolerance (i.e. decreased 2-hour glucose), suggesting that FA transport is related to an improvement in glucose tolerance. Further studies are needed to elucidate the role of FA transport (i.e. FAT/CD36 and FABPC) in the development of insulin resistance.

\section{Conclusion}

Earlier studies have shown that skeletal muscle of (pre)diabetic patients is characterized by a diminished capacity to utilize fatty acids [2-4]. Body weight reduction per se did not correct these metabolic derangement's [10,14]. In this study, a one-year combined diet and physical activity intervention program improved the metabolic profile of glucose intolerant subjects compared to 
controls. This improvement was paralleled by a decreased expression of $\mathrm{ACC}-2$ mRNA and UCP-2 mRNA and an increased HAD proten content. These changes indicate a better capacity to utilize fatty acids in skeletal muscle. This improved handling of lipids by muscle could be one of the mechanisms underlying the beneficial effects of lifestyle-changes on glucose tolerance.

\section{Acknowledgements}

We thank Jos Stegen, Paulette Vallier, Emmanuelle Loizon and Maurice Pelsers for their analytical support. This study was supported by a grant from the Dutch Diabetes Research Foundation (DFN, 98.901) and the Netherlands Organization for Scientific Research (ZonMW, 940-35-034)

\section{References}

1 Kelley DE, Mandarino LJ. Fuel selection in human skeletal muscle in imsulin resistance: a reexamination. Diabetes $2000 ; 49: 677-83$.

2 Kelley DE, Simoneau JA. Impaired free fatty acid utilization by skeletal muscle in non-insulin-dependent diabetes mellitus. J Cim Invest 1994; 94: 2349-56.

3 Blaak EE, Wagenmakers AJ, Glatz JF ef al. Plasma FFA utilization and fatty acidbinding protein content are diminished in type 2 diabetic muscle. An I Physiol Endocrinol Metab 2000; 279: E146-54.

4 Mensink M, Blaak EE, van Baak MA, Wagenmakers AI, Saris WH. Plasma free Fatty Acid uptake and oxidation are already diminished in subjects at high risk for developing type 2 diabetes. Diabetes 2001; 50: 2548-54.

5 Falholt $K$, Jensen I, Lindkaer Jensen $S$ et al. Carbohydrate and lipid metabolism of skeletal muscle in type 2 diabetic patients. Diabet Med 1988; 5: 27-31.

6 Goodpaster BH, He I, Watkins S, Kelley DE. Skeletal muscle lipid content and insulin resistance: evidence for a paradox in endurancemtrained athletes. I Clin Endocrinol Metnb 2001; 86:5755-61.

7 Pan DA, Lillioja $S$, Kriketos AD et al. Skeletal muscle triglyceride levels are inversely related to insulin action. Diabetes 1997; 46:983-8.

8 Perseghin $G$, Scito $P$, De Cobelli F ef al. Intramyocellular iriglyceride content is a determinant of in wivo insulin resistance in humans: a $1 \mathrm{H}-13 \mathrm{C}$ nuclear magnetic resonance spectroscopy assessment in offspring of type 2 diabetic parents. Dirhetes $1999 ; 48: 1600-6$.

9 McGarry ID. Banting lecture 2001: dysregulation of fatty acid metabolism in the etiology of type 2 diabetes. Diabctes $2002 ; 51: 7-18$.

10 Simoneau JA, Veerkamp JH, Iurcotte LP, Kelley DE. Markers of capacity to utilize fatty acids in human skeletal muscle: relation to insulin resistance and obesily and effects of weight loss. Faseb / 1999; 13:2015 L-60.

11 Ruderman NB, Saha AK, Vavvas D, Witters LA. Malonyl-CoA, fuel sensing, and insulin resistance. Am I Physiol 1999; 276: Ell-E18.

12 Simoneau JA, Kelley $D E$, Neverova $M$, Warden CH. Overexpression of muscle uncoupling protein 2 content in human obesity associates with reduced skeletal muscle lipid utilization. Faseb Joumal 1998; 12: 1739-45.

13 Schrauwen. P. Schaart G, Saris WH et al. The effect of weight reduction on skeletat muscle UCP2 and UCP3 mRNA expression and UCP3 protein content in type II diabetic subjects. Diabetologia 2000; 43: 1408-16. 
14 Blakk EE, Wolfenbuttel BH, Saris WH, Pelsers MW, Wagenmakers AJ. Weight reduction and the impaired plasma-derived free fatty acid oxidation in type 2 diabetic subjects. / Clin Endocrinol Metab 2001; 86: 1638-44.

15 Kiens B. Effect of endurance training on fatty acid metabolism: local adaptations. Med Sci Sports Exerc 1997; 29:640-5.

16 Tunstall RJ, Mehan KA, Wadley GD et al. Exercise training increases lipid metabolism gene expression in human skeletal muscle. An / Physiol Endocrinal Metal 2002; 283; E66-72.

17 Spina $\mathbb{R J}$. Chi MM, Hopkins MG et al. Mitochondrial enzymes increase in muscle in response to 7-10 days of cycle exercise. / Appl Physiol 1996; 80:2250-4.

18 Schrawen $\mathbb{P}$, Van Aggel-Leissen DP. Hul G et al. The Effect of a 3-Month LowIntensity Endurance Training Program on Fat Oxidation and Acetyl-CoA Carboxylase-2 Expression. Diabetes 2002; $51: 2220-6$.

19 Clarke SD, Gasperikova D, Nelson C, Lapillonne A, Heird WC. Fatty acid regulation of gene expression: a genomic explanation for the benefits of the mediterranean diet. Ann N Y Acad Sci 2002; 967: 283-98.

20 Tuomilehto 1 . Lindstrom I, Eriksson $1 G$ et al. Prevention of type 2 diabetes mellitus by changes in lifestyle among subjects with impaired glucose tolerance. $N$ Engl J Med 2001; 344: 1343-50.

21. Knowler WC, Barrett-Connor E, Fowler SE et al. Reduction in the incidence of type 2 diabetes with lifestyle interwention or metformin. N Engl/ Med 2002; 346:393 403.

22 Mensink M, de Bruin TWA, Saris WHM, Feskens EFM, Blaak EE. Improved glucose tolerance after one year of a lifestyle intervention program in middleaged men and womem at risk for developing type 2 diabetes mellitus: Study on LifestyleIntervention and Impair red Glucose Tolerance Maastricht (SLIM). Diabetes 2002; 51. supplement 2: A234 (Abstract).

23 Sin W. The gross composition of the body. Adv Bio Med Physiol 1956; 4: $239-280$.

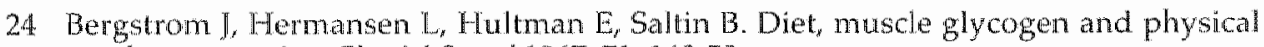
performance. Acta Physiol Scand 1967; 71: 140-50.

25 Chomczynski $P$, Sacchi $N$. Single-step method of RNA isolation by acid guanidinium thiocyanate-phenol-chloroform extraction. Anal Biochem 1987; 162: 156-9.

26 Auboeut D, Vidal $H$. The use of the reverse transcription-competitive polymerase chain reaction to investigate the in wivo regulation of gene expression in small tissue samples. Anal Biochm 1997; 245: 141-8.

27 Pelsers MM, Lutgerink JT, Nietwenhoven FA ef al. A sensitive immunoassay for rat fatty acid translocase (CD36) using phage antibodies selected on cell transfectants: abundant presence of tatty acid translocase/CD36 in cardiac and red skeletal muscle and up- regulation in diabeles. Bochers/1999; 337:407-14.

28 Wodzig KW, Pelsers MM, van der Vusse GJ, Roos W, Glatz JE. One-step enzymem lirked immumosorbent assay (ELISA) for plasma fatly acid-binding protein. Am Clin Biochen 1997; 34: 263-8.

29 Shepherd D, Garland PB. The kinetic properties of citrate symthase from rat liver mitochondria. Biochem / 1969; 114:597-610.

30 Bergmeyer H. 3-Hydroxyacyl CoA dehydrogenase. Lactate dehydrogenase. In: (eds). Methots of Erzymatic Analysis. Academic: New York, 1974

31 Mensink M, Blaak EE, Feskens EFM, de Bruin TWA, Satis WHM. Study on Lifestyle Intervention and Impaired Glucose Tolerance: Study design. Intemational foumal of Obesily Ant Related Metabolic Disorters 2000; 24: S93 (Abstract).

32 Vidal H, Langin D. Andreelli F of al. Lack of skeletail muscle uncoupling protein 2 and 3 mRNA induction during fasting in type-2 diabetic subjects. An I Physion 1999; 277: $\mathbb{E} 830-7$. 


\section{9}

\section{Increased IMCL Content in the $m$.}

vastus lateralis is Associated with Glucose Intolerance in Subjects with IGT and Diabetes:

\section{a ${ }^{1}$ H-MRS-study}

Marco Mensink, Gijs H Goossens, Marianne E Kooi, Wim HM Saris and Ellen E Blaak

Dept of Human Biology, Nutrition and Toxicology Research Institute NUTRIM, Maastricht University, Maastricht, The Netherlands

Dept of Radiology, University Hospital Maastricht, Maastricht, The Netherlands 


\begin{abstract}
An increased skeletal muscle lipid content is recognized as an important feature of insulin resistance and type 2 diabetes mellitus. In the present study the relationship between intramyocellular lipid ( $M M C L)$ content and measures of insulin resistance, glucose tolerance and body composition was determined in twenty-four obese men with a history of impaired glucose tolerance lage $58.2 \pm$ $6.9 \mathrm{yr}$; BMI $29.9 \pm 3.0 \mathrm{~kg} / \mathrm{m}^{2}$ ). Muscle lipid content was measured with proton magnetic resonance spectroscopy ( ${ }^{1} \mathrm{H}$-MRS) in the $m$. vastus lateralis. Results of the OGTT revealed that 6 subjects were normal glucose tolerant (NGT) at the time of the test, 10 subjects were glucose intolerant (IGT) and 5 subjects were diagnosed with type 2 diabetes mellitus (DM). IMCL content was lowest in the IGT subjects, and higher in both NGT and diabetic subjects: $1.27 \pm 0.45 \%$, $0.55 \pm 0.36 \%$ and $1.06 \pm 0.13 \%$ for NGT, IGT and diabetes (ANOVA P < 0.01 ). No association was found between IMCL content and measures of adiposity (BMI, \%body fat, waist and WHR), circulating lipids (FFA and triglycerides) and aerobic capacity $\left(\mathrm{VO}_{2} \mathrm{max}\right)$. A positive correlation was observed between postload glucose and IMCL content in IGT and diabetic subjects $(r=0.74, P<0.01)$, but not in NGT subjects $(r=0.07, P=0.90)$.

In conclusion, an increased $I M C L$ content in the $m$. vastus lateralis was associated with higher postload glucose levels in subjects with IGT and type 2 diabetes, but mot in subjects who returned during the last year from IGT to normal glucose tolerance. Factors, as (lipid) oxidative capacity, could underlie these differences, and modulate the association between $\mathrm{MCL}$ and glucose tolerance or insullin sensitivity.
\end{abstract}


An increased skeletal muscle lipid content is recognized as an important feature of insulin resistance and type 2 diabetes mellitus [1-3]. With the introduction of ${ }^{3} \mathrm{H}$ magnetic resonance spectroscopy ("H-MRS) a distinction could be made between triglycerides located inside the myocyte (intramyocellular lipid, IMCL) and located outside the myocyte (extramyocellular lipid, EMCL) [4].

Several studies have reported a strong relation between an increased IMCL content and a decreased insulin sensitivity in normal weigh non-diabetic individuals, obese non-diabetic individuals and lean offspring of type 2 diabetic parents [5-9]. This relation was independent of other measures as BMI, WHR and total body fatness. Beside insulin sensitivity, IMCL content was also found to be related to body fatness and body composition in European males, but not in South Asian males [8]. All these studies measured this relationship in normoglycemic subjects. Sparse information is avalable about the relation between muscle triglycerides and insulin sensitivity in hyperglycemic subjects. Factors as accompanying $\beta$-cell failure and persistent hyperglycemia and insulinemia could potentially alter the relationship between MCL and insulin resistance and/or glucose tolerance. There is some evidence that the negative relationship between IMCL and insulin sensitivity is still present in the diabetic state $[10,11]$. However, the observation of markedly increased levels of $1 \mathrm{MCL}$, in subjects with impaired glucose tolerance and diabetes compared to normoglycemic subjects with a comparable degree of insulin resistance [12], suggests that the relation between $I M C L$ and insulin sensitivity disappears when subjects become hyperglycemic.

Almost all studies assessing muscle triglycerides with ${ }^{1} \mathrm{H}$-MRS performed their measurements in the lower leg (e.g. soleus, tibialis anterior and/or gastrocnemius muscle). As fiber type is an important deteminant of muscle triglyceride content, observations made in one muscle(group) would not necessarily reflect the situation in another muscle(group) $[3,13]$. For example, a higher IMCL content was observed in the soleus muscle of offspring from diabetic parents, but not in the tibialis anterior muscle [5]. Since most of the biochemical and histochemical information on muscle metabolism originates from (biopsies of the w. vastus lateralis, it is important to quantify muscle triglycerides with 'H-MRS in this muscle. First reponts from our group and others indicate that, at least in lean individuals, it is possible to accurately measure IMCL content in the $m$. vastus lateralis $[9,14]$. Data about the quantification of IMCL in the $m$. vastus lateralis of obese (pre)-diabetic subjects is lacking at the moment.

The aim of the present study was to determine the relationship between IMCL. content and measures of insulin resistance, glucose tolerance and body composition in obese men with (a history) of impaired glucose tolerance. IMCL. content was measured with 'H-MRS in the m. vastus lateralis and both, reproducibility and variability of IMCL quantification was determined.

\section{Methods}

Subjects

Twenty-four male subjects participated in this study (age $58.2 \pm 6.9$ years; BMI 
$\left.29.9 \pm 3.0 \mathrm{~kg} / \mathrm{m}^{2}\right)$. Subjects were a cross-sectional selection of participants in an ongoing lifestyle-intervention program (see for details Chapter 2 and ref. [15]), and had all at least one OGTT in the IGT range during the past year (i.e. fasting glucose $<7.0 \mathrm{mmol} / 1$ and 2-hour plasma glucose between $7.8-11.1 \mathrm{mmol} / \mathrm{l}$ ).

Subjects reported three times to the research institute for the measurement of glucose tolerance and body composition, maximal aerobic capacity and muscle triglyceride content. The Medical Ethical Review Committee of our institute approved the study protocol, and all subjects gave their written informed consent before the start of the study.

\section{Glucose tolerance}

Glucose tolerance was tested with a standard oral glucose tolerance test (OGTT). After an overnight fast (10-12 hour) subjects reported to the laboratory by car or by bus. Fasting blood samples were drawn, after which the subjects received the glucose load (75 g glucose, dissolved in $250 \mathrm{ml}$ water, AVEBE, The Netherlands). After 2 hour another blood sample was drawn.

Plasma glucose, plasma FFA and serum trigllycerides were measured with a standard enzymatic technique automated on the Cobas Fara centrifugal analyzer (Glucose HK 125, ABX diagnostics, Montpellier, France; FFA-C test kit, Wako chemicals, Neuss, Germany; Sigma, St Louis, USA). Fasting insulin was measured by means of an ELISA assay which showed no cross-reactivity with pro-insullin (Mercodia, Uppsala, Sweden). Fasting plasma glucose and insulin concentration were used to calculate an index for insulin resistance with the homeostasis model assessment (HOMA-index) described by Matthews et al. [16].

\section{Body composition}

Body weight was measured with an electronical scale to the nearest $0.1 \mathrm{~kg}$, with the subject wearing light clothing only. Waist circumference (waist) was measured with the subject in standing position at the level midway between the lowest rib and the iliacal crest to the nearest $0.5 \mathrm{~cm}$, and hip circumference was measured as the maximum circumference over the buttocks to the nearest $0.5 \mathrm{~cm}$. Body fat percentage was calculated measuring skinfold thickness according to the method of Durnin and Womersley [17].

\section{Maximal aerobic capacity}

An incremental exhaustive exercise test was performed on an electronically braked bicycle ergometer to determine the maximal power output and maximal peak oxygen consumption $\left(\mathrm{VO}_{2} \mathrm{max}\right)$.

\section{Muscle triglycerides}

IMCL and EMCL content were measured in the m. vastus lateralis with ${ }^{1} \mathrm{H}-\mathrm{MRS}$ after a period of at least 1 day in which subjects refrained from exhaustive physical exercise. Measurements were performed on a $1.5 \mathrm{~T}$ whole body scanner (Intera, Philips Medical Systems, Best, the Netherlands) with a flexible surface 
coil wrapped around the upper leg. Transversal scout images were made with a T2 weighted TSE sequence. Voxel positions avoided adipose tissue deposits within muscle as much as possible. 'H-MRS spectra from the regions of interest were acquired using a point-resolved spectroscopy (PRESS) sequence with the following acquisition parameters: TR/TE $3000 / 25$ ms, 16 phase cycles, 128 averages, 1024 data points over $1000 \mathrm{~Hz}$ spectral width. The voxel volume was $(12 \times 11 \times 18) \mathrm{mm}^{3}$. The water signal was suppressed using Chemically Selective Saturation (CHESS). The unsuppressed water signal was subsequently measured in the same voxel under the same shimming conditions and was used as a reference signal.

The spectra were fitted in the time domain using a nonlinear least-squares algorithm (AMARES [18]) in the jmrui software package [19,20]. Six peaks were fitted in total, namely three peaks for extramyocellular lipids (EMCL) and three peaks for IMCL. Prior knowledge of the relative peak positions and area ratios has been used as constraints in order to increase the accuracy and reliability of the fitting procedure (as described in ref. [14]). The signals were corrected for $T 1$ and $T 2$ relaxation using the $T 1$ and $T 2$ relaxation times as detemined by Schick et al. [21]. The corrected area of the $\mathrm{CH}_{2}$ peak of IMCL was expressed relative to the area of the water peak. Two or three different voxel positions were measured in every subject, and IMCL and EMCL content were averaged.

Coefficient of variation of IMCL. Coefficient of variation (CV) was calculated as SD/mean * 100\%. Reproducibility of the IMCL/EMCL determination (withinvoxel coefficient of variation, $C V_{\text {within }}$ ) was measured in three subjects, by performing two subsequent measurements with the subjects leaving the magnet between the measurements. The voxel was placed at the same position for the second measurement. Variability of the IMCL/EMCL content (between voxel coefficient of variation, $C V_{\text {between }}$ ) was calculated as the variation between different voxel positions in the same subjects $(n=11)$.

\section{Statistics}

Data are expressed as mean \pm sem. Simple regression analysis was performed to examine relations between EMCL / IMCL content and selected anthropometric and biochemical variables. Partial correlation was calculated between IMCL/EMCL and 2-hour glucose, controlling for differences in adiposity (i.e. BMT). Level of significance was set at $P<0.05$.

\section{Results}

\section{HH-MRS}

A 'H-MRS spectrum typical for this study population is shown in Figune 9.1. Owing to technical difficulties or inadequate separation between the $\mathrm{CH}_{2}$ peak of IMCL and EMCL, three subjects had no valid spectrum and were excluded from the final analysis; ten subjects had only one valid spectrum measured, and eleven subjects had two or more valid spectra measured. 


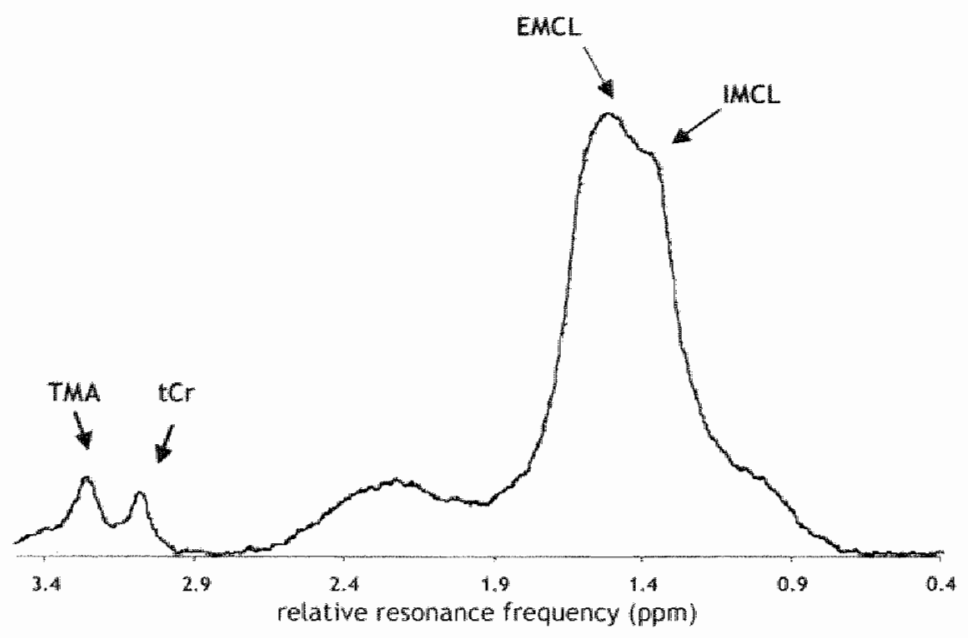

Figure 9.1 Typical 1H-MRS spectrum of the vastus lateralis muscle in a middle-aged overweight subject. TMA = trimethylammonium compounds, $\mathrm{tCr}=$ total creatine; $\mathrm{EMCL}=$ $\mathrm{CH} 2$-peak of extramyocellular lipid; $\mathrm{MCL}=\mathrm{CH2}$-peak of intramyocellular lipid

The within voxel coefficient of variation $\left(\mathrm{CV}_{\text {within }}\right.$ ) was $17.4 \pm 13.6 \%$ (mean $\pm S D$ ) for IMCL $(n=3)$. The between voxel coefficient of variation $\left(\mathrm{CV}_{\text {betwen }}\right)$ was 29.8 $\pm 31.3 \%($ mean \pm SD) for IMCL $(n=11)$.

\section{Subjects}

In total 24 malle subjects with a history of glucose intolerance participated in this study. In three cases no valid measurement of IMCL could be obtained. Final analysis was performed in 21 men. Results of the OGTT revealed that 6 subjects were normal glucose tolerant at the time of the test, 10 subjects were glucose intolerant and 5 subjects were diagnosed with diabetes (according the WHO criteria of 1999). Subjects characteristics are depicted in Table 9.1. Diabetic subjects were older compared to IGT and NGT subjects, and, by definition, had increased postload glucose values (ANOVA, $\mathrm{P}<0.05$ ). IMCL content was lowest in the IGT subjects, and higher in both NGT and diabetic subjects: $1.27 \pm 0.18 \%, 0.55 \pm 0.11 \%$ and $1.06 \pm 0.06 \%$ for NGT, IGT and diabetes respectively (ANOVA P $<0.01$ ); mean EMCL content was $3.31 \pm 0.64 \%, 2.61 \pm$ $0.44 \%$ and $3.30 \# 0.24 \%$ for $\mathrm{NGT}, \| \mathrm{GT}$ and diabetes respectively (ANOVA $P=0.49$ ). Furthermone, although not significant, NGT subject had an increased BMIl and higher aerobic capacity compared to IGT and diabetic subjects.

\section{Regression analysis}

Correlation coefficients ( $r$ ) between IMCL content and several selected subjects characteristics are shown in Table 9.2. No association was found between IMCL 
Table 9.1 Subjects characteristics

\begin{tabular}{|c|c|c|c|c|c|}
\hline & & NGT & IGT & $\mathrm{DM}$ & ANOVA \\
\hline$n$ & & 6 & 10 & 5 & \\
\hline age & (years) & $50.3 \pm 1.9$ & $58.7 \pm 1.4$ & $63.4 \pm 2.8$ & $<0.01$ \\
\hline $\mathrm{BMI}$ & $\left(\mathrm{kg} / \mathrm{m}^{2}\right)$ & $31.5 \pm 1.3$ & $28.9 \pm 1.0$ & $29.1 \pm 1.2$ & 0.25 \\
\hline body fat & $(\%)$ & $32.5 \pm 1.3$ & $32.5 \pm 1.2$ & $31.4 \pm 1.5$ & 0.85 \\
\hline waist & $(\mathrm{cm})$ & $107.4 \pm 4.2$ & $104.4 \pm 2.6$ & $104.2 \pm 3.1$ & 0.76 \\
\hline WHR & & $1.03 \pm 0.03$ & $1.00 \pm 0.01$ & $1.03 \pm 0.02$ & 0.54 \\
\hline fast glucose & (mmol/l) & $5.9 \pm 0.1$ & $5.9 \pm 0.2$ & $7.0 \pm 0.7$ & 0.07 \\
\hline 2-hi glucose & $(\mathrm{mmol} / \mathrm{l})$ & $7.0 \pm 0.4$ & $9.0 \pm 0.3$ & $11.9 \pm 0.3$ & $<0.01$ \\
\hline fast insulin & $(m \cup / l)$ & $12.6 \pm 3.2$ & $10.6 \pm 1.6$ & $15.6 \pm 2.6$ & 0.34 \\
\hline HOMA & & $3.3 \pm 0.8$ & $2.8 \pm 0.5$ & $5.0 \pm 1.0$ & 0.14 \\
\hline FFA & (kmol/li) & $428 \pm 62$ & $496 \pm 47$ & $460 \pm 73$ & 0.69 \\
\hline triglycenides & (mmol/l) & $1.74 \pm 0.43$ & $1.64 \pm 0.31$ & $1.91 \pm 0.48$ & 0.89 \\
\hline $\mathrm{VO}_{2} \max$ & $(\mathrm{m} / / \mathrm{kgFFM})$ & $46.4 \pm 3.2$ & $42.0 \div 2.5$ & $39.2 \pm 1.2$ & 0.21 \\
\hline $\mathrm{IMCL}$ & $(x)$ & $1.27 \pm 0.18$ & $0.55 \pm 0.11$ & $1.06 \pm 0.06$ & $<0.01$ \\
\hline EMCL & $(\%)$ & $3.31 \pm 0.64$ & $2.61 \pm 0.44$ & $3.30 \pm 0.24$ & 0.49 \\
\hline
\end{tabular}

Data are mean \pm sem

content and measures of adiposity (BMI, o body fat, waist and WHR), insulin resistance and glucose tolerance (fasting and 2-hour glucose, insulin and HOMA), circulating lipids (FFA and triglycerides) and aerobic capacity $\left(\mathrm{VO}_{2} \mathrm{max}\right)$. However, when omitting subjects who returned to normal glucose tolerance $(n=6)$, elevated postload glucose levels were closely related to an increased IMCL content in the $\mathrm{m}$. vastus lateralis $(\mathrm{r}=0.74, \mathrm{P}<0.01$; see Figure 9.2). Partial correlation between IMCL content and 2-hour glucose, controlling for adiposity (i.e. BMI), revealed that IMCL was still associated to 2 -hour plasma glucose $(r=0.73, P<0.01)$. Furthermore a weak positive correlation was observed between total body fatness and $\mathrm{EMCL}$ content $(r=0.51, \mathbb{P}=0.06)$.

\section{Discussion}

After the introduction of ${ }^{1} \mathrm{H}$ magnetic resonance spectroscopy (H-MRS) for lipid measurements in muscle, this technique has been applied to measure IMCL and EMCL in the soleus muscle, tibialis anterior muscle and/or gastrocnemius muscle. Since most of the work performed on muscle metabolism originates from (biopsies of) the m. oastus laterais, we quantified in the present study IMCL and EMCL in this muscle in a group of men with a history of impaired glucose tolerance. The most important novel finding is that an increased IMCL content in the $m$. vastus lateralis is associated with a higher postload glucose levels in subjects with IGT and type 2 diabetes, but not in subjects who returned during the last year from IGT to normoglycemia.

\section{Methodological considerations}

With $\mathrm{H}$-MRS a differentiation can be made between $1 M C L$ and $E M C L$ in the muscle, with the separation between IMCL and EMCL being optimal when 
Table 9.2 MCL correlation coefficients

\begin{tabular}{lcc}
\hline & $\begin{array}{c}\text { All } \\
(n=2 \|)\end{array}$ & $\begin{array}{c}\text { IGT/DM } \\
(\mathrm{n}=15)\end{array}$ \\
\hline age & -0.28 & 0.24 \\
BMI & 0.23 & 0.20 \\
body fat & 0.02 & 0.23 \\
waist & -0.02 & -0.03 \\
WHR & -0.03 & -0.02 \\
fast glucose & 0.03 & 0.21 \\
2.hour glucose & -0.02 & $0.74^{\text {ti. }}$ \\
fast insulin & 0.12 & 0.39 \\
HOMA & 0.10 & 0.35 \\
FFA & 0.06 & -0.12 \\
triglycerides & 0.19 & 0.44 \\
VO, & 0.20 & 0.37 \\
\hline
\end{tabular}

Simple correlation ( $r$ ) between $M M C L$ and several selected variables for all subjects (left) and $1 G T$ and dialbetes only (right); $* 0<0.01$

muscles containing fibers parallel to the main anatomical axis if the muscle is parallel to the magnet (i.e. the gastrocnemius muscle) [4]. Therefore ${ }^{\text {H-MRS is }}$ often performed in muscles of the lower extremity. However since most of the work on muscle metabolism is performed in the m. vastus lateralis, it is important to quantify IMCL and EMCL with ${ }^{1} \mathrm{H}-\mathrm{MRS}$ in this muscle. The present results confirm data from our own lab [14] and from Virkamäki et al. [9], concluding that it is possible to quantify IMCL with ${ }^{1} \mathrm{H}$-MRS in the m. vastus lateralis. The observed reproducibility for $I M C L(C V$ willa $: 17.4 \pm 13.6 \%)$ is relatively high compared to the reported $4.0-11.8 \%$ for measurements in the calf muscles [22], and the $4-6 \%$ measured in muscle biopsies of the fn. vastus lateralis [23]. Reproducibility in lean trained males, measured in our lab under the same conditions was within the expected range (CV IMCL $6.0 \pm 8.2 \%,[14])$. The increased $C V$ in the present population can partly be explained by the smaller ratio of $I M C L$ to EMCL in obese subjects, leading to inaccuracies in the fitting procedure for IMCL. (EMCL/IMCL ratio 5.2 in the present population and 0.63 in lean trined males, personal observation MK). These fitting difficulties forced us to exclude several spectra from further analysis.

Beside reproducibulity, the variability of the IMCL measurement is important, especially when comparing various subjects. A CV of $29.8 \pm 31.3 \%$ was observed for IMCL between two or thee different voxel positions in the same subject. Hwang et al. [24] observed an intrasubject CV of IMCL ranging from $13-20 \%$ for the tibialis anterior, tibilais posterior and soleus muscle. This variation resembles the variation obtained when measuring (intramuscular) triglyceride content in multiple muscle biopsies or in different aliquots from a single biopsy: $23.5 \%$ and $31 \%$ respectively [23,25]. This variation in IMCL content was said to result from contamination with extramyocellular lipids (i.e. adipose tissue) and/or methodological variation. Since ${ }^{1} \mathrm{H}$-MRS separates between intra- and extramyocellular fat, our data support the idea that this is partly real (physiological) variation and not exclusively contamination with 
extramyocellular fat and for methodological. The variable storage of triglycerides between skeletal muscle fiber types, with the highest fraction in type I fibers, followed by Ila and IIb and the known intrinsic variation in fiber composition within a muscle, could easily underlie this variation $[3,24]$. Combining multiple measurements is the best option dealing with this variability, which is a clear advantage of the noninvasive ${ }^{1} H$-MRS technique.

\section{Glucose tolerance and muscle triglycerides}

Muscle triglycerides have shown to tightly correlate with insulin sensitivity (i.e. insulin stimulated glucose disposal) in nomoglycemic subjects [5-9]. Furthermore, most studies report a higher (intra)myocellular lipid content in diabetic subjects compared to controls [1,3]. In our population, we observed the lowest IMCL content in IGT subjects, and a higher IMCL in both NGT and diabetic subjects. However, as all subjects were participants in a lifestyleintervention study, and were diagnosed as having IGT in the recent past, those with NGT are a distinct (metabolic) group, as they returned from $\mathbb{I G T}$ to normoglycemia. The higher aerobic capacity in this group could be a reflection of this. Moreover those subjects with NGT actually increased their aerobic capacity $\left(\mathrm{VO}_{2} \mathrm{max}:+254 \pm 125 \mathrm{ml} / \mathrm{min}, \mathrm{P}=0.09\right)$ compared to a minor change in IGT and diabetic subjects $\left(\mathrm{VO}_{2} \mathrm{max}+37 \pm 51 \mathrm{ml} / \mathrm{min}, \mathrm{P}=0.48\right)$. Two recent studies concluded that the (lipid) oxidative capacity may be an important mediator of the association between lipid accumulation and insulin resistance $[26,27]$. It could be speculated that the improved aerobic capacity in those returning to NGT altered the relation between IMCL and postload glucose levels. The observation of a clear association between increased IMCL levels and a decreas-

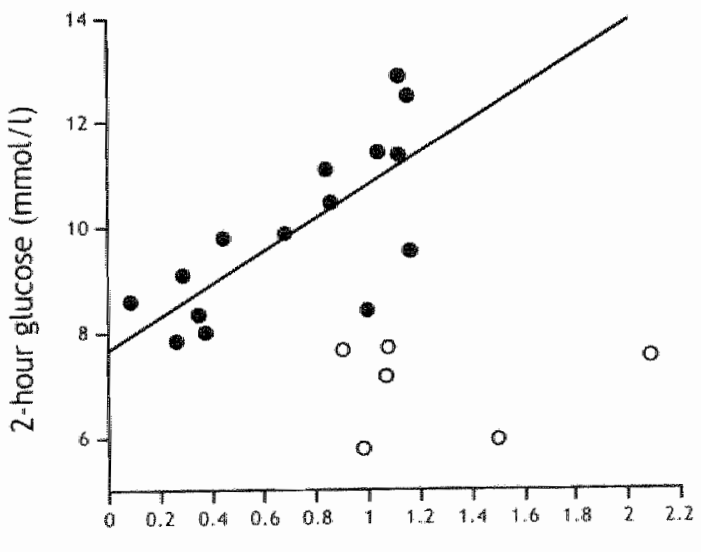

IMCL content $(\%)$

Figure 9.2 Association between $\mathrm{MCL}$ and 2 -hour glucose for IGT and diabetes (- filled circles and solid line: $r=0.74, P<0.005$ ) and for normoglycemic subjects (O open circles: $r$ $=0.07, P=0.90)$ 
ed glucose tolerance (i.e. higher postload glucose) in IGT and diabetic subjects, but no association in those returning to normoglycemia supports this idea (see Figure 9.2).

Several studies reported elevated levels of muscle triglycerides in diabetes, however, only few studies actually measured the association between IMCL and insulin sensitivity in subjects with (overt) hyperglycemia [10,11]. Anderwald and co-workers [11] observed that in type 2 diabetic patients insulin sensitivity correlated negatively with IMCL in the tibialis anterior muscle, an observation comparable with our finding of an association between increased $I \mathrm{MCL}$ levels and a decreased glucose tolerance, even after controlling for obesity (i.e. BMI). On the other side, the group of McGarry observed markedly increased levels of IMCL in subjects with IGT and particularly diabetes compared to normoglycemic subjects with a comparable degree of insulin resistance [12]. This indicates that in the hyperglycemic state the association between increased IMCL and insulin sensitivity is less clear, and they suggested that further increases are associated with impaired $\beta$-cell function and overt hyperglycemia [12]. These apparent discrepancy between the latter study and our data may result from differences in the degree and duration of the hyperglycemia of the individuals studied, since the subjects in our study had only mild hyperglycemia (fasting glucose 5.9 and $7.0 \mathrm{mmol} / 1$ for IGT and diabetes).

Although muscle triglyceride accumulation is an important determinant of insulin resistance, the current opinion is that not IMTG itself causes the insulin resistance, but rather some other lipid metabolites associated with intramuscular triglycerides $[28,29]$. Likely candidates are long-chain fatty acylCOA (LCFA-COA) and diacylglycerol (DAG), as they might interfere with insulin signaling and, thus, GLUT4 translocation to the cell membrane [30,31].

Adiposity and muscle triglycerides. IMCL content was found not to be related to the degree of adiposity. Forouhi et al. [8] found an association between IMCL and obesity. However, in that study IMCL was measured in the (triglyceriderich) soleus muscle. The only other study measuring IMCL in the m. vastus Iateralis reported no differences with respect to BMI, visceral and subcutaneous fat between healthy men with a high or low IMCL content [9]. That IMCL is not per se related to over-all body fat is nicely illustrated in patients with lipodystrophy. Despite almost no detectable adipose tissue in these patients, IMCL content was two times higher compared to controls [32]. A weak positive association was found between adiposity (i.e. \%bodyfat) and EMCL content. The amount of EMCL measured with 'H-MRS increases rapidly when (visible) surrounding adipose tissue is included in the voxell [4]. In obese (sedentary) subjects, it was usually not possible to completely avoid this, which could explain the observed association between EMCL and \%bodyfat.

\section{Conclusion}

IMCL content can be quantified with 'H-MRS in the m. vastus tateralis of middleaged obese subjects with (a history of) hyperglycemia, although the accuracy of the measurements is lower than observed in (lean) healthy individuals. This is 
important since most of the work on skeletal muscle metabolism originates from (muscle biopsies of) the $m$. vastus lateralis. Most important novel finding was that an increased IMCL content in the montus lateralis was associated with higher postload glucose levels in subjects with IGT and type 2 diabetes, but not in subjects who returned from IGT to nomoglycemia during the last year. Factors, as (lipid) oxidative capacity, could underlie these differences, and modulate the association between IMCL and glucose tolerance or insulin sensitivity.

\section{References}

1. Falholt K, Jensen I, Lindkaer Jensen S et al. Carbohydrate and lipid metabolism of skeletal muscle in type 2 diabetic patients. Diabet Med 1988; $5: 27-31$.

2 Goodpaster BH, Theriault R, Watkins SC, Kelley DE. Intramuscular lipid content is increased in obesity and decreased by weight-loss. Metabolism 2000; 49:467-472.

3 He J. Watkins S, Kelley DE. Skeletal muscle lipid content and oxidative enzyne activity in relation to muscle fiber type in type 2 diabetes and obesity. Diabetes 2001; 50: $817-23$

4 Boesch $C$, slotboom J. Hoppeler $H$, Kreis $\mathbb{R}$. In vivo determination of intramyocellular lipids in human muscle by means of localized "H-MR-spectroscopy. Magu Reson Med 1997; 37: 484-93.

5 Perseghin G, Scifo P, De Cobeili F et al. Intramyocellular triglyceride content is a determinant of in vivo insulin resistance in humans: a ${ }^{1} \mathrm{H}-\mathrm{C} \mathrm{C}$ nuclear magnetic resonance spectroscopy assessment in oftspring of type 2 diabetic parents. Diabets $1999 ; 48: 1600-6$.

6 Jacob $S$, Machann J, Rett $K$ et al. Association of increased intramyocellular lipid content with insulin resistance in lean nondiabetic offspring of type 2 diabetic subjects. Diabetes 1999; 48; 1.113-9.

7 Krsak M. Falk Petersen $K$, Dresner A at al. Intramyocellular lipid concentrations are correlated with insulin sensitivity in humans: TH NMR spectroscopy study. Dinbetologia 1999; $42: 113-6$.

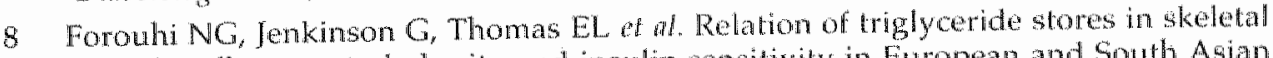
muscle cells to central obesity and insulim sensitivity in European and South Asian men. Diabetologia 1999; 42 : $932-5$.

9 Virkamaki A, Korsheninnikova E, Seppala-Lindroos A at al. lntramyocellular lipid is associated with resistance to in vivo insulin actions on glucose uplake, antilipolysis, and early insulin signaling pathways in human skeletal muscle. Diabetes 2001; 50 : $2337-43$.

10 Levin K, Daa Shroeder H, Alford FP, Beck-Nielsen H. Morphometric documentation of abnormal intramyocellular fat storage and reduced glycogen in obese patients with type II diabetes. Diabetologia $2001 ; 44: 824-833$.

11 Anderwald C, Berrmoider E, Krssak M ef al. Effects of insulin treatment in type 2 diabetic patients on intracellular lipid content in liver and skeletal muscle. Diabetes 2002; 51: 3025-3032.

12 McGarry JD. Banting lecture 2001: dysregulation of fatty acid metabolism in the etiology of type 2 diabetes. Diabetes 2002; $51: 7-18$. 
13 Rico-Sanz ]. Thomas EL, Jenkinson $G$ et al. Diversity in levels of intracellular total creatine and triglycerides in human skeletal muscle observed by "H.MRS. I App Physiol 1999; 87: 2068-2072

14 Schrawwen-Hinderling VB, Schrawwen $\mathbb{P}$, Hesselink MKC et al. The increase in intramyocellular lipid content is a very early response to training. I Clin Endo Metab 2003; (in press).

15 Mensink M, Blatk EE, Feskens EFM, de Bruin TWA, Saris WHM. Study on Lifestyle Intervention and Impaired Glucose Tolerance: Study design. Int / Obes Relat Metab Disord 2000:24: 993 (Abstract).

16 Matthews DR, Hosker JP, Rudenski AS at al. Homeostasis model assessment: insulin resistance and beta-cell function from fasting plasma glucose and insulin concentrations in man. Diabetologia $1985 ; 28: 412-9$.

17 Durnin IV, Womersley J. Body fat assessed from total body density and its estimation from skinfold thickness: measurements on 481 men and women aged from 16 to 72 years. Br I Nutr 1974; 32: 77-97.

18 Vanhamme L, van den Boogaart A, Van Huffel S. Improved method for accurate and efficient quantification of MRS data with use of prior knowledge. J Magr Reson 1997; 129: $35-43$.

19 Naressi $\mathrm{A}$, Couturier $\mathrm{C}$, Devos JM et al. Java-based graphical user interface for the MRUl quantitation package. Magma 2001; 12: 141-52.

20 http://www mruiabos/mrui/.

21 Schick F, Eismann B, Jung Wl et al. Comparison of localized proton NMR signals of skeletal muscle and fat tissue in wivo: two lipid compartments in muscle tissue. Magn Reson Med 1993; 29: 158-67.

22 Rico-Sanz J, Hajnal JV, Thomas EL et al. Intracellular and extracellular skeletal muscle triglyceride metabolism during alternating intensity exercise in humans. $f$ Physiol (Lond) 1998; 510:615-22.

23 Wendling PS, Peters SI. Heigenhauser GJ, Spriet LL. Variability of triacylglycerol content in human skeletal muscle biopsy samples. I Appt Plysiol 1996; 81: 1150-5.

24 Hwang JH, Pan JW, Heydari S, Hetherington HP, Stein DT. Regional differences in intramyocellular lipids in humans observed by in wivo $1 \mathrm{H}-\mathrm{MR}$ spectroscopic imaging. J Appl Physiol 2001; 90: 1267-74.

25 Steffensen $\mathrm{CH}_{*}$ Roepstorff C, Madsen M, Kiens B. Myocellular triacylglycerol breakdown in females but not in males during exercise. An / Physiol Endocrinol Melab 2002; 282: E634-42.

26 Goodpaster BH, He J. Watkins S, Kelley DE. Skeletal muscle lipid content and insulin resistance: evidence for a paradox in endurance-trained athletes. I Clin Eudocrimol Metab 2001; 86:5755-61.

27 Perseghin $G$, Scifo P. Danna $M$ of al. Normal insulin sensitivity and IMCL content in overweight humans are associated with higher fasting lipid oxidation. An / physiol Endocinol Me ab 2002; 283: E556-64.

28 Ellis BA, Poynten A, Lowy Al of al. Long chain acyl-CoA esters as indicators of lipid metabolism and insulin sensitivity in rat and human muscle. Am I Physiol Endocrinol Mefab 2000; 279: E554-60.

29 Itani SI, Ruderman NB, Schmieder $\mathbb{F}$, Boden G. Lipü-induced insulin resistance in human muscle is associated with changes in diacylglycerol, protein kinase $C_{\text {s }}$ and lkappaB-alpha. Diabestes 2002; 51: 2005-11.

30 Prentki $M$, Corkey BE. Are the beta-cell signaling molecules malonyl-CoA and cystolic long-chain acyl-CoA implicated in multiple tissue defects of obesity and NIDDM? Dinbetes 1996; 45: 273-83. 
31 Schmitz-Peiffer C. Signalling aspects of insulin resistance in skeletal muscle: mechanisms induced by lipid oversupply. Coll Signal 2000; 12:583-94.

32 Szczepaniak LS, Babcock EE, Schick F of al. Measurement of intracellular triglyceride stores by $\mathrm{H}$ spectroscopy: validation in vivo. Am / Physiol 1999; 276: E977-89. 
$47^{2}$ 


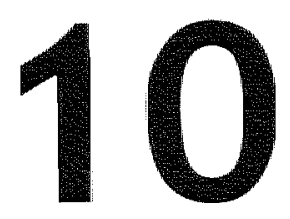

General Discussion 


\section{Contents}

\section{IMPAIRED GLUCOSE TOLERANCE}

Prevalence

Lifestyle-intervention

Type of intervention

Public health guidelines

Weight loss, Diet and/or Exercise?

Other intervention strategies

Concluding remarks and recommendations

\section{FAT METABOLISM}

Disturbances in fatty acid metabolism in IGT and diabetes

Role of skeletal muscle fatty acid metabolism in the etiology of insulin resistance

Lifestyle changes and disturbances in fatty acid metabolism

Concluding remarks and suggestions for future research 
The prevalence of type 2 diabetes mellitus has explosively increased the last two decades, and is rapidly becoming one of the main health issues in the 21 st century [1,2]. Major contributors to the diabetes epidemic are changes in nutritional and physical activity patterns, i.e increased dietary fat intake and decreased physical activity [3]. It was calculated that the combination of maintaining a body-mass index of $25 \mathrm{~kg} / \mathrm{m}^{2}$ or lower, eating a healthy diet (i.e. high in cereal fiber and polyunsaturated lat, low in saturated and trans-fats and low in glycemic load), exercising regularly, abstaining from smoking, and consuming alcohol moderately, was associated with an incidence of type 2 diabetes that was approximately 90 percent lower than the incidence found among women without these factors [4]. This indicates that the majority of the cases of type 2 diabetes can be prevented by adopting a healthier lifestyle.

Leading thread running through this thesis is research performed within the Study on Lifestyle-intervention and IGT Maastricht (SLIM). SLIM evaluates the effect of a combined diet and physical activity intervention program on glucose homeostasis, body composition and aerobic capacity, as well as on (skeletal muscle) fatty acid metabolism, an important metabolic factor involved in the development of insulin resistance and type 2 diabetes. In this general discussion, the results obtained in the different parts of the study will be discussed and integrated. First, the impact of lifestyle changes on glucose tolerance and the development of diabetes will be considered, and implications of the current findings for intervention strategies to reduce the burden of type 2 diabetes mellitus will be discussed. In the second part of this chapter, the role of fatty acids and their metabolism in relation to insulin resistance and glucose intolerance will be reviewed, and a hypothesized mechanism underlying this relation will be presented.

\section{IMPAIRED GLUCOSE TOLERANCE}

\section{Prevalence}

Recent predictions indicate that the prevalence of diabetes in adults world-wide will increase from an estimated $4.0 \%$ in 1995 to $5.4 \%$ by the year 2025 [1]. The prevalence of the prediabetic condition of impaired glucose tolerance (ICT) varies widely between populations, from as low of $2.0 \%$ in nural populations to more than $20 \%$ in high-risk populations [5]. Most recent data for the Dutch population were those obtained in the the Hoom Study over the period 1989 $1992[6]$. A prevalence of $10.3 \%$ for $1 \mathrm{GT}$ and $8.3 \%$ for diabetes $(3.6 \% \mathrm{known}$ and $4.8 \%$ newly delected diabetes) was observed in this $50-74$ year old Caucasian population. Results of the preliminary screening of SLIM (chapter 2) indicates that in a high risk population the prevalence of disturbances in glucose homeostasis is even higher: newly detected type 2 diabetes $8.3 \%$, impaired fasting glucose (IFG) $7.9 \%$ and impaired glucose tolerance $14.2 \%$. The degree of obesity and increasing age were both strongly related to the prevalence of diabetes, IFG and IGT. However, in the Hoom Study the old WHO-criteria 
(1985) were used. Since the fasting glucose level for the diagnosis of diabetes is reduced, this could partly explain the higher prevalence of diabetes in our study, but not the higher prevalence of $\mathrm{IGT}$.

The diagnosis of IGT is classically made with an oral glucose tolerance test (OGTT). Large intra-subject variability has been observed when glucose tolerance tests are carried out on separate occasions, with $35 \%$ to $76 \%$ of the subjects with IGT returning to normal ghucose tolerance at re-testing (so called transient IGT) $[7,8]$. In chapter 3, we described a group of 108 men and women with IGT, who underwent a second OGTT within 2 months after the initial test. Transient IGT was observed in $37 \%$ of the cases, while $44 \%$ remained IGT at retesting (i.e. persistent IGT). A minority was classified as IFG (7\%) and diabetes (12\%) at re-testing. Subjects with persistent IGT have a higher risk of developing diabetes compared to those with transient IGT $[9,10]$. Only a few studies tried to identify additional factors which could improve the distinction between those with transient and those with persistent IGT. A higher two-hour blood glucose concentration, hyperinsulinemia and over-all adiposity were the most important factors predicting persistent IGT [10-12]. In chapter 3, an increased subscapular skinfold thickness was identified as another important, but easy to measure biomarker distinguishing between transient and persistent IGT. As subscapular skinfold thickness is an estimate of subcutaneous (central) fat, these results suggest a link between the subcutaneous fat depot and disturbances in glucose homeostasis.

\section{Lifestyle-intervention}

Much of the interest for the category of impaired glucose tolerance stems from the observation that 1GT, transient as well as persistent, is associated with a much greater risk of developing diabetes than normal glucose tolerance $[9,13,14]$. A cumulative incidence of diabetes up to $63 \%$ is reported among those with IGT [14]. The large impact of modifiable risk factors as obesity, diet and physical inactivity in the etiology of diabetes offer the potential for the development of diabetes prevention-programs in subjects with IGT.

Two major lifestyle-intervention studies recently reported their final results: the Finnish Diabetes Prevention Study (DPS) in 2001 [15] and the U.S. Diabetes Prevention Program (DPP) in 2002 [16]. Both studies clearly showed that after a mean follow-up of on average 3 years the over-all progression from IGT to type 2 diabetes mellitus was reduced by 58 percent in the lifestyle-intervention group $[15,16]$. Consistent with this, our study showed an improvement in glucose tolerance after 1 and 2 year in the intervention group. while a deterioration was seen in the control group (chapter 4 and 5).

Most important risk factor for the progression from IGT to type 2 diabetes is the blood glucose concentration 2 hour after an oral glycemic load [14]. This is illustrated in Figure 10.1, which shows that, in a group of Pima-indians, the risk of developing diabetes over a five-year period alteady increases at 2-hour plasma glucose levels below the threshold of IGT (i.e. $<7.8 \mathrm{mmol} / \mathrm{l}$ ) [17]. Furthermore, this figure nicely illustrates that the reduction observed in SLIM 


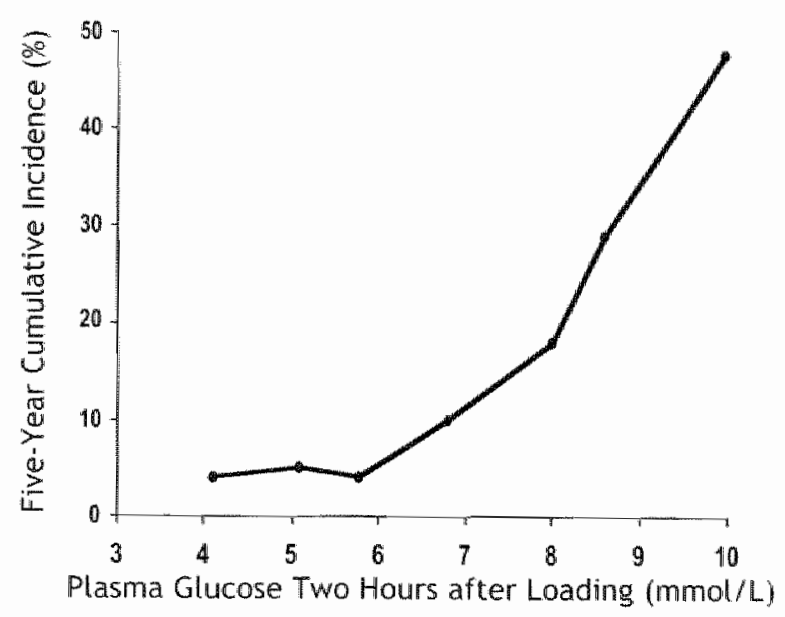

Figure 10.1 Five year cumulative incidence of diabetes according to 2-hour plasma glucose Level at baseline in Pima indians; dotted line indicates cut-off point between NGT and IGT (7.8 mmol/l) (Adapted from Saad et al. [17])

of $0.9 \mathrm{mmol} / \mathrm{l}$ after 1 year and $0.8 \mathrm{mmol} / 1$ after 2 years in 2-hour plasma glucose (chapter 4 and 5), reflects a substantial reduction in the risk of developing diabetes.

The intervention strategy used in SLIM (chapter 2) was quite comparable with the approach of the Finnish DPS [18]. The intervention subjects in the DPS had seven dietary sessions during the first year (compared to five for SLIM) aimed at reducing weight, the intake of saturated fat and increasing the intake of dietary fibre. Furthermore, in the DPS subjects were individually guided to increase their physical activity (compared to a combination of individual advice and group sessions for SLIM). Results after 1 year of intervention for both studies are depicted in Table 10.1 (see ref. [18] and chapter 4). Both studies showed small but substantial reductions in body weight, fat mass and abdominal adiposity. Although weight loss was somewhat larger in the DPS, the decrease in 2-hour plasma glucose after 1 year was comparable in both studies ( $-0.9 \pm 1.6 \mathrm{mmol} / \mathrm{I}$ vs. $-0.8 \pm 1.8 \mathrm{mmol} / 1$ for DPS and SLIM), indicating that this type of (lifestyle)-intervention results in a comparable improvement in glucose tolerance in distinct European populations.

Confirmation of the results from the Finnish DPS and the American DPP in another population (i.e. the Dutch population) is very important because the risk profiles of diabetes and the (attitude towards) intervention strategies are different in different populations. Compared to the population studied in the Finnish DPS [15] and the American DPP [16], the population studied in SLIM was less obese (BMI: DPS $31.1 \mathrm{~kg} / \mathrm{m}^{2} ;$ DPP $34.0 \mathrm{~kg} / \mathrm{m}^{2} ;$ SLIM $29.4 \mathrm{~kg} / \mathrm{m}^{2}$ ). In addition, the prevalence of obesity in The Netherlands is lower than for example the prevalence of obesity in the United States, England and Germany [19]. Furthermore the Dutch population is known for its relatively high level of 
Table 10.1 One year results Finnish DPS and SLIM

\begin{tabular}{|c|c|c|c|c|c|}
\hline & & \multicolumn{2}{|c|}{ Finnish DPS [18] } & \multicolumn{2}{|c|}{ SLIM } \\
\hline number & n/women) & $112(44 / 68)$ & & $47(31 / 24)$ & \\
\hline Weight & $(\mathrm{kg})$ & $-4.7 \pm 5.5$ & $(-5,8 ;, 3,7)$ & $-2.7 \pm 3.7$ & $(-3,8 ;-1,6)$ \\
\hline Fat mass & (kg) & $-2.5 \pm 3.9$ & $(-3,4 ;-1,7)$ & $-2.3 \pm 2.9$ & $(-3.2 ;-1.5)$ \\
\hline Waist circum. & $(\mathrm{cm})$ & $-3.5 \pm 5.1$ & $(\cdot 4,4 ; \cdot 2,5)$ & $.3 .5 \pm 3.8$ & $(-4,6 ;-2,4)$ \\
\hline Hip circum. & $(\mathrm{cm})$ & $-3.5 \pm 4.8$ & $(-4,4 ;-2,6)$ & $-2.4 \pm 4.0$ & $(-3.6 ;-1.2)$ \\
\hline Sagittal dm. & $(\mathrm{cm})$ & $-2.8 \pm 3.4$ & $(-3,4 ;-2,1)$ & $-4.1 \pm 1.9$ & $(-1,6 ;-0,5)$ \\
\hline Transverse $\mathrm{dm}$ & $(\mathrm{cm})$ & $-1.0 \pm 2.2$ & $(-1,5 ;-0,6)$ & $-0.9 \pm 2.0$ & $(-1,5 ;-0,3)$ \\
\hline fast glucose & (mmol/l) & $0.0 \pm 0.8$ & $(-0,2 ; 0,1)$ & $-0.1 \pm 0.5$ & $(=0,2 ; 0,1)$ \\
\hline 2-hour glucose & (mmoll/l) & $.0 .9 \pm 1.6$ & $(-1,2 ;-0,6)$ & $-0.8 \pm 1.8$ & $(-1,3 ;-0,2)$ \\
\hline total cholesterol & (mmollt) & $-0.2 \pm 0.6$ & $(-0,36 ; 0,11)$ & $0.0 \pm 0.6$ & $(-0.17 ; 0.17)$ \\
\hline HDL-cholesterol & (mmolis) & $0.05 \pm 0.17$ & $(0,02 ; 0,09)$ & $-0.04 \pm 0.13$ & $(-0.08 ;-0.01)$ \\
\hline triglycerides & $(\mathrm{mmol} / \mathrm{l})$ & $-0.21 \pm 0.61$ & $(-0,34 ;-0,08)$ & $-0.36 \pm 4.44$ & $(-1.68 ; 0.96)$ \\
\hline
\end{tabular}

Data are mean change \pm SD $(95 \%$ conficlence hinterval $)$; *different methods used: near-infrared spectroscopy/bio-impedance (DPS) and skinfold measurements (SLIM)

physical activity. In 1997 slightly more than one-half of the Dutch population was, on average, moderately active for more than half an hour a day [20], compared, for example, to about only one-third of the US adult population [21]. Thus, our results confirm that a lifestyle-intervention program is effective in improving glucose tolerance. Of more importance is the observation in our study that a lifestyle-intervention is effective in a population with a relatively low obesity rate and a relatively high level of physical activity.

\section{Type of intervention}

\section{Public health guidelines}

Another important conclusion from SLIM is that a lifestyle intervention according to general public health recommendations are effective in improving glucose tolerance. As described in chapter 2 our intervention strategy was based on general public health recommendations, and was not supported by (very) low energy diets or dietary supplements, and did include moderate intensity physical activity instead of high intensity exercise. The intervention program was moderately intensive for both participants and supervisors (i.e. health care professionals). Although aiming at comparable intervention goals, the US Diabetes Prevention Program [22] did use a much more intensive lifestyle-intervention approach compared to SLIM (and the Finnish DPS). The two major goals of the DPP were a minimum of $7 \%$ weight loss and a minimum of 150 min of physical activity a week similar in intensity to brisk walking [22]. To achieve these goals, an intensive intervention was designed and features as individual case management, frequent contact, a structured core-curriculum 
and strategies for dealing with nonadherent participants were included. This intensive intervention program was after 3 years highly successful, by reducing the incidence of diabetes by $58 \%$ [16]. These results would support the idea that only intensive programs are effective in reducing the burden of diabetes [23].

On the other side however, the Finnish DPS and SLIM, revealed that, at least in a European population, a less intensive program can be (equally) effective in improving glucose tolerance and reducing the incidence of diabetes (115] and chapter 5). In line with our conclusion, it was shown that (diet plus) lifestyle physical activity was as effective in inducing health benefits as more structured aerobic exercise [24,25]. A clear advantage of a less intensive lifestyleintervention strategy, is that it is much more suitable for implementation in community settings, especially in obese, sedentary populations. This in contrast to the DPP intervention program, which was not designed to be translated for use in community settings [22].

\section{Weight loss, Diet and/or Exercise?}

Adiposity (i.e. BMI) is an important risk factor associated with the progression from IGT to diabetes, and as we showed in chapter 4 weight-loss was most strongly related to an improved glucose tolerance after 1 year of intervention. Interestingly, a recently published randomized controlled trial concluded that either modality, caloric restriction alone or daily exercise without caloric restriction, is an effective strategy for reducing obesity and improwing insulin resistance in moderately obese man [26]. So, should (extensive) weight-loss be the main focus in a diabetes prevention program?

It is known that in the long term the effectiveness of (intensive) weight-loss programs is rather poor, despite adjuvant strategies as group therapy, behavior modification and active follow-up $[27,28]$. Furthermore, it is now recognized that it is worthwhile to motivate overweight people to lose even a modest amount of weight (5-10\%), since this helps to reduce cardiovascular risk factors and improves glycemic control [29-31]. The results of our study and other lifestyle-intervention studies support this conclusion [15,32]. We observed a mean weight-loss of $-3.1 \pm 0.6 \mathrm{~kg}$ after 1 year and $-2.4 \pm 0.7 \mathrm{~kg}$ after 2 year, which was associated with an improved glucose tolerance and a decreased insulin resistance (chapter 5). This implies that a lifestyle-intervention program should primarily focus at changing lifestyle(-habits) and improving glycemia and cardiovascular risk factors, and not aiming at a large weight-loss per se.

Apart from weight-loss, diet and physical activity have a direct link to insulin resistance and glucose tolerance. Exercise (training) enhances insulin stimulated glucose uptake (insulin sensitivily) [33] and improves the ability to oxidize fatty acids in skeletal muscle 134 ]. Furthermore, a reduction in total fat intake and a substitution of unsaturated fatty acids for saturated fatty acids (without concomitant weight-loss) also improves insulin sensitivity 135]. Although evidence is now accumulating that a combined diet and physical activity intervention program can reduce the incidence of diabetes, only a few studies addressed the question if the combination is more effective than diet or exercise alone $[32,36,37]$. The Oslo Diet and Exercise Study concluded that the combina- 


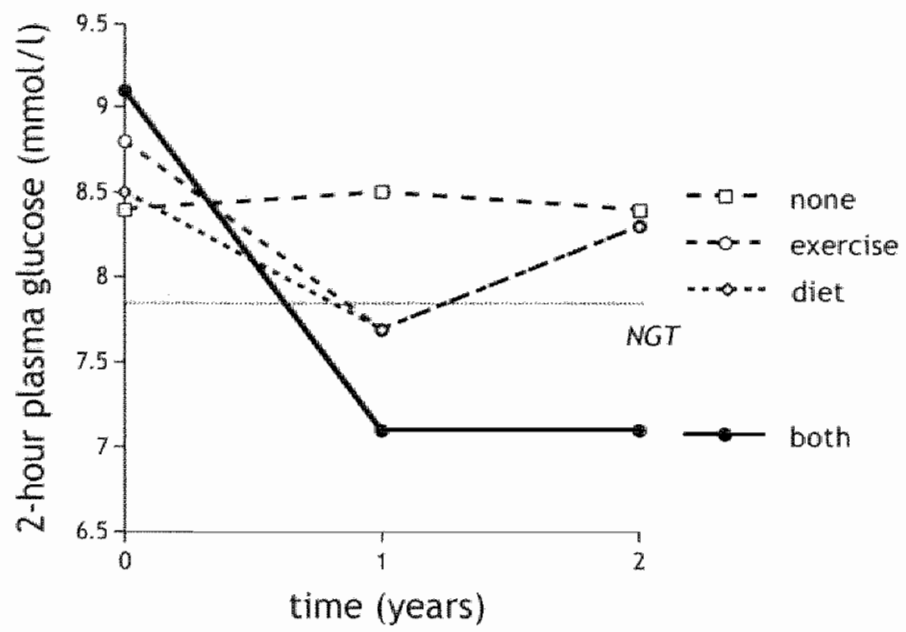

Figure 10.2 Glucose tolerance at baseline and after 1 and 2 years of intervention in subjects adherent to the dietary intervention (diet), exercise intervention (exercise), both interventions (both) or mon-compliant at all (none). Dotted line indicates cut-off value between NGT and IGT (7.8 mmol/l)

tion of diet and exercise was most effective |36|, whereas the Chinese Da Qing IGT and Diabetes Study observed a tendency for an additional benefit of combining diet and exercise [32,37]. In chapter 5, glucose tolerance was compared between subjects in the intervention group adherent to the dietary intervention, to the exercise intervention, to both, or to neither (see also Figure 10.2). Subjects adherent to both parts of the intervention program, diet and exercise, showed the largest improvement in glucose tolerance, and had on. average been returned to normal glucose tolerance after 1 and 2 year of intervention (i.e. 2 -hour glucose $<7.8 \mathrm{mmol} / 1$ ) (Figure 10.2). These results support the conclusion that the combination of diet and exercise is more effective that diet or exercise alone in improving glucose tolerance and reducing the progression from IGT to diabetes.

\section{Other intervention strategies}

An alternative approach to prevent or postpone the development of type 2 diabetes mellitus is a drug intervention in those at risk for diabetes. Both, acarbose, an a-glucosidase inhibitor [38], and metformin, a biguanide [16], reduced the risk of diabetes substantially in subjects with IGT compared to placebo (25\% and $31 \%$ respectively). In the TRIPOD study [39], the insulinsensitizing agent troglitazone was administered to women with previous gestational diabetes. After 30 months the incidence of diabetes was reduced by $>50 \%$. The protective effect was associated with the preservation of pancreatic $\beta$-cell function, and persisted at least 8 months after discontinuation of the medication [39]. Thus, drug-interventions reduce the incidence of diabetes 
substantially, however, as concluded from the DPP, lifestyle changes reduced the incidence to a much larger extent [16].

Interestingly, a large multi-center trial has been recently started assessing the effect of a standard lifestyle-intervention with or without additional drug administration on the incidence of diabetes and cardiovascular disease [40].

Finally, for a successful implementation of a diabetes prevention program in a primary health care setting both patients and health care professionals should be aware of the significance of the disease (i.e. IGT) and its management (i.e. lifestyle-changes). A recent paper describing the general practitioners' knowledge of and attitudes to IGT, revealed that $47 \%$ was unaware of the increased risk of progression to diabetes and the majority was uncertain about the prevalence of the disease and how to manage these patients best [41]. These results clearly indicates that awareness of the (clinical) significance of impaired glucose tolerance and the effectiveness of lifestyle-interventions should be raised to achieve a successful implementation of strategies to prevent or postpone type 2 diabetes mellitus and its complications.

\section{Concluding remarks and recommendations}

The work presented in the first part of this thesis clearly shows the beneficial impact of a combined diet and physical activity intervention program on glucose tolerance in a population at risk for developing type 2 diabetes mellitus. Moreover, it was shown that a moderate lifestyle intervention program according to general public health recommendations is effective in a population with a relatively low obesity rate and a relatively high level of physical activity. Lifestyle changes are a very effective mean of delaying or preventing type 2 diabetes. It was calculated that this type of lifestyle-intervention may prevent one case of diabetes per seven persons for three years [16], or one case per 22 persons treated for one year [15].

According to the results obtained in the Study on Lifestyle-intervention and IGT Maastricht (SLIM) and other lifestyle-intervention trials the following recommendations for (developing) public health strategies to reduce the burden of diabetes can be given:

1. Screening a high-risk population (i.e age above 40 years and a BMII $>25$ $\mathrm{kg} / \mathrm{m}^{2}$ or a family history of diabetes) is an effective mean to identify subjects who would benefit from a lifestyle-intervention program, since almost one out of every thee subjects will manifest a disturbed glucose homeostasis.

2. A lifestyle intervention program aiming at delaying or preventing the development of diabetes must include dietary and physical activity goals.

3. Substantial weight-loss should not be the main focus, since even a modest reduction in body weight $(5-10 \%)$ is associated with an improvement in glucose tolerance; promotion of a healthy lifestyle should be the primary goal. 
4. A lifestyle intervention according to general public heath recommendations for dietary intake and the amount of physical activity are effective in improving glucose tolerance and reducing the incidence of diabetes.

5. Awareness of the (clinical) significance of impaired glucose tolerance and the effectiveness of lifestyle-interventions in preventing diabetes and its complications should be raised.

\section{FAT METABOLISM}

Since the introduction of the glucose fatty-acid cycle in 1963 by Randle and coworkers [42], it is well recognized that the fatty acid metabolism plays an important part in the development of (skeletal muscle) insulin resistance. Evidence is now accumulating that disturbances in fatty acid metabolism in skeletal muscle play an even more prominent role in the development of type 2 diabetes mellitus, with (the process of) lipid accumulation within the muscle as central feature [43]. In (small) subgroups of the larger intervention trial several aspects of (skeletal muscle) lipid metabolism were studied, to obtain more information about the role of a disturbed FA metabolism in the etiology of diabetes, and to address the question whether changes in FA metabolism could underlie the lifestyle-intervention induced improvements in glucose intolerance and insulin resistance.

\section{Disturbances in fatty acid metabolism in IGT and diabetes}

Several studies have shown that the uptake and/or oxidation of FA under postabsorptive conditions is impaired in insulin resistant (visceral) obese subjects [44] and type 2 diabetic patients [45,46]. During moderate-intensity exercise, obese type 2 diabetic subjects have a diminished plasma FFA oxidation and a higher triglyceride derived fatty acid oxidation at whole body level as compared to obese controls [47]. Interestingly, in non-obese type 2 diabetic patients plasma FFA oxidation during exercise was found not to be impaired, suggesting that the role of disturbances in fat metabolism in the etiology of insulin resistance differs between obese and non-obese diabetic patients [48].

It is difficult to assess the pathophysiological abnormalities leading to type 2 diabetes when the type 2 diabetic state has already developed, since it is impossible to differentiate between primary factors and adaptational responses. The observation that considerable weight reduction did not improve the abnormalities in fatty acid metabolism in diabetes [49], suggests that the abnormal fatty acid metabolism is primary rather than acquired. Therefore we evaluated in chapter 6 to what extent disturbances in fatty acid metabolism found in the diabetic state were already present in subjects at high risk for developing type 2 diabetes mellitus (i.e. subjects with IGT). It was concluded that at rest and during moderate intensity exercise plasma FFA oxidation was reduced in (obese) subjects with IGT and diabetes compared to weight-matched 
controls. This is in line with the results found by Turpeinen et al. [50], subjects with IGT had similar myocardial but lowered femoral muscle FFA uptake compared to healthy controls (measured with PET-scan). These data demonstrate that male subjects with milder forms of hyperglycemia (IGT) have the same defects in fatty acid utilization as subjects with type 2 diabetes mellitus, suggesting that these disturbances may play an important role in the development of IGT and type 2 diabetes mellitus.

An imbalance between uptake and oxidation of plasma FFA could lead to accumulation of lipids within the muscle. It is known that accumulation of intramyocellular lipids (IMCL) is strongly associated with insulin resistance 151531, and it is repeatedly shown that skeletal muscle lipid content is increased in diabetes [54-56]. However, only a few studies evaluated the relation between lipid accumulation and insulim resistance in subjects with (overt) hyperglycemia $[57,58]$. These reports indicate that in type 2 diabetic patients insulin sensitivity correlated negatively with IMCL content in muscle [57,58], an observation comparable with our finding of an association between increased $1 M C L$ levels and a decreased glucose tolerance, independently from measures of obesity (chapter 9). Interestingly, the association between muscle lipid content and postload glucose was no longer present when subjects who returned (from IGT) to normal glycemia during the last year were included. Those subjects were successtul in improving their glucose tolerance, most probably by changing lifestyle habits (as reflected by the higher aerobic capacity), which could have altered the relation between lipid content and insulin sensitivity. For example, muscle of well-trained athletes is characterized by a high insulin sensitivity despite elevated levels of intramuscular triglycerides 159]. It has been suggested that the muscle's capacity for lipid oxidation, which was increased in trained subjects, may be an important mediator of the association between excess muscle lipids and insulin resistance. A comparable suggestion was done by Perseghin et al. 600 , who observed preservation of insulin sensitivity in overweight subjects, in combination with increased lipid oxidation and maintenance of normal. IMCL content. Thus elevated IMCL in combination with a high (lipid) oxidative capacity ('trained' muscle) may not disturb insulin sensitivity, while elevated IMCL together with a low (lipid) oxidative capacity ('untrained' muscle) may have a negative impact on insulin sensitivity. These results underscore the important role of (skeletal muscle) hipid oxidation in determining the development of insulin resistance, and not the level of IMCL per se in the first place

\section{Role of skeletal muscle fatty acid metabolism in the etiology of insulin resistance (Figure 10.3)}

Accumulation of triglycerides within the skeletal muscle is closely related to insulin resistance, moreover it is more tightly correlated to insulin resistant glucose uptake than other well-known features of insulin resistance as BMI, waist-to-hip ratio or total body fat $151-53,611$. Evidence, however, is accumulating that not IMTG itself causes insulin resistance, but rather some 
other lipid metabolites associated with intramuscular triglycerides, i.e. longchain fatty acyl-COA (LCFA-COA), diacylglycerol (DAG) and/or ceramide [6266]. This would also explain the somewhat paradoxical observation of increased lipid stores in highly insulin sensitive individuals participating in regular exercise [59]. A high lipid oxidative capacity, and perhaps its periodic utilization, would prevent accumulation of long-chain acyl metabolites within the myocyte (despite high IMCL) and thereby prevent the development of insulin resistance.

It has been suggested that LCFA-CoA can directly reduce glucose flux in the muscle, by inhibiting hexokinase, the first enzyme of glucose metabolism in muscle $\mid 67]$. Furthermore, LCFA-CoA have been shown, at least in the liver and in animal models, to alter the activity of several key enzymes involved in glucose and lipid metabolism (as reviewed in [64]). A second lipid metabolite associated with insulin resistance is DAG $[65,66]$. DAG is an activator of the protein kinase C family (PKC). Activation of (certain) PKC isozymes is strongly associated with insulin-resistance, possible through interference with insulinreceptor substrate-1. (IRS-1) [65]. Finally, LCFA-COA (i.e. palmitoy]-CoA) is a precursor of ceramide, a signaling molecule which has been implicated in insulin resistance. Ceramide induces an inhibition of protein kinase $B$ (PKB), one of the downstream targets of the insulin signaling pathway, thereby inhibiting GLUT-4 translocation [65].

Thus, accumulation of lipid (metabolites) within the muscle could induce insulin resistance, through direct effects on glucose utilization by altering enzyme activities or through interference with insulin signaling. However, what causes lipid accumulation?

Muscle lipid accumulation could occur because of increased availability and uptake of fatty acids or because of impaired muscle fatty acid oxidation (see Figure 10.3). Increased delivery of FA as systemic free fatty acids or as hydrolysis product of lipoprotein lipase (LPL) action on chylomicrons and VLDL may be an important determinant of the etiology of insulin resistance $[68,69]$. Artificial elevation of systemic fatty acids results, after severall hours, to a marked reduction in insulin sensitivity [70,71], which was, as shown recently, accompanied by increased DAG mass and PKC activity [66].

On the other hand, prolonged inhibition of FA oxidation resulted in accumulation of muscle triglycerides and impaired insulin mediated glucose uptake $[72]$, while an increased lipid oxidation was combined with maintenance of normal muscle triglyceride content and preservation of insulin sensitivity in overweight subjects [60]. Evidence is accumulating that fatty acid oxidation is diminished in skeletal muscle of type 2 diabetic subjects $[45,46]$, while intramuscular lipids are elevated [54-56]. As discussed in chapter 6, the prediabetic condition of IGT is characterized by the same defects in FA oxidation as observed in diabetes, suggesting rather a primary defect than a consequence of the diabetic state $[73,74]$.

A decreased content or activity of important enzymes of $\beta$-oxidation (hydroxyacyl dehydrogenase, HAD), the TCA-cycle (citrate synthase, CS) and electron transport (cytochrome $\mathrm{C}$ oxidase, $\mathrm{COX}$ ) in muscle of diabetic subjects could underlie this FA oxidation defect $[46,75]$, possibly reflecting a more or less im- 


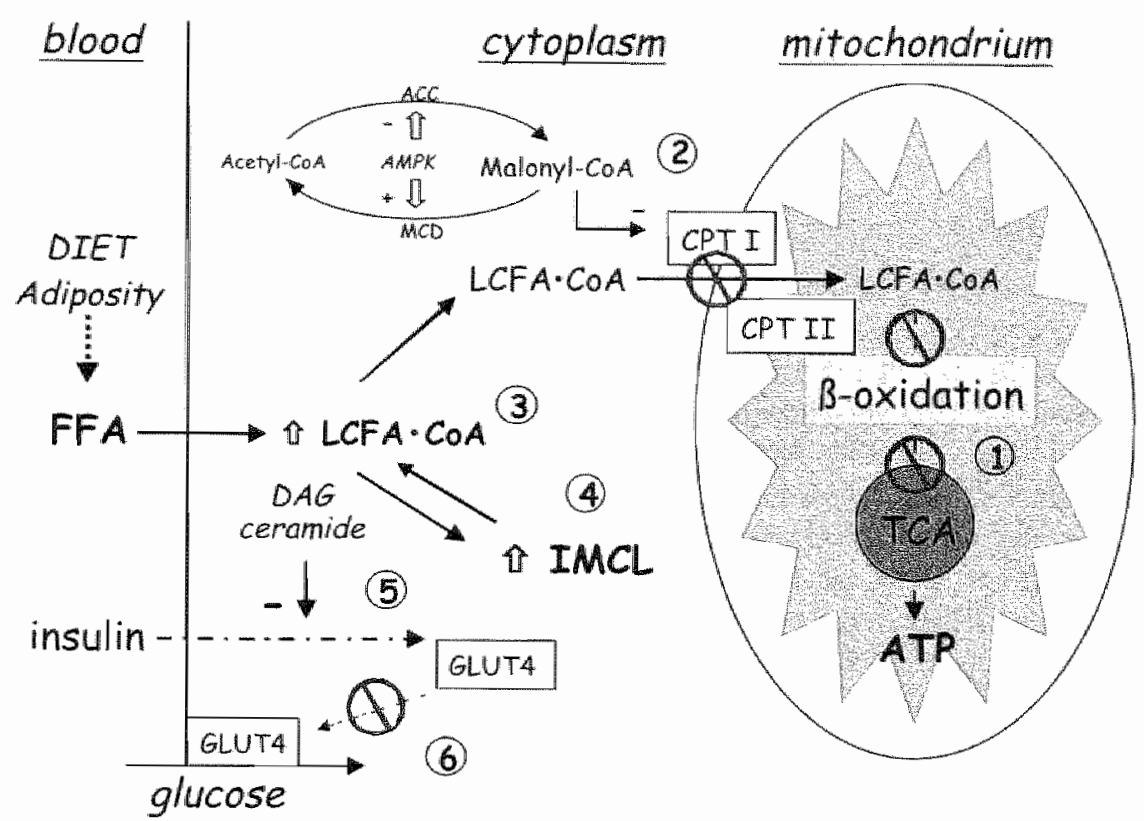

Figure 10.3 Proposed mechanism explaining the role of a disturbed fatty acid handling and/or axidation in the development of skeletal muscle insulin resistance: $A$ diminished FA oxidation through a decreased (fatty acid) oxidative enzyme capacity (0), or through dysregulation of malonyl-CoA, which inhibits CPT-1 (O) ), results in accumulation of LCFACOA within the cytosol (3) and, subsequently, an increased IMCL content (9); An increased level of LCFA-COA or other FA metabolites as DAG and ceramide, can interfere with insulin signaling and GLUT 4 translocation (5), resulting in a diminished insulin stimulated glucose uptake (i.e. insulin resistance)(6)

paired functional capacity of skeletal muscle mitochondria |76|. Another important site setting the level of skeletal muscle FA oxidation is the transport of FA into the mitochondrion by CPT-1 and 2 (see Figure 10.3). A decreased activity of CPT-1 was found in muscle of diabetic subjects [75]. CPT-1 is inhibited by high levels of malonyl-CoA, which level in turn is set by acetylCoA carboxylase (ACC-2; see Figure 10.3). Recently, it was shown, that an increased malonyl-CoA concentration (during hyperglycemia and hyperinsulinemia) inhibits the activity of $\mathrm{CP} \mathbb{P}-1$, and reduces (long-chain) $\mathrm{FA}$ oxidation [77]. It was proposed that dysregulation of the malonyl-CoA regulatory mechanism, leading to increases in the concentration of malonylCoA and LCFA-COA, plays a key role in the pathogenesis of insullin resistance in muscle [78].

In summary, lipid accumulation within skeletal muscle is merely a marker of insulin resistance with other lipid metabolites as LCFA-COA, DAG and ceramide playing a causative role. Lipids can accumulate as a result of a defect in fatty acid oxidation, increased FFA flux to muscle, or due to an imbalance 
beween FFA uptake, esterification, triglyceride lipolysis and FA oxidation. There is increasing evidence that an impaired FA oxidation, due to a reduced oxidative capacity or to dysregulation by malonyl-CoA, is most likely the primary defect causing lipid accumulation.

\section{Lifestyle changes and disturbances in fatty acid metabolism}

We hypothesized that a combined diet and physical activity intervention, known to improve glucose tolerance, would improve this disturbed capacity to oxidize FA. Most important finding was that subjects in the intervention group, in parallel with an improved glucose tolerance, maintained, or even slightly improved, their capacily to oxidize fatty acids, while in the control group fatty acid oxidation was decreased (chapter 7). Furthermore, the expression of several genes and proteins involved in (skeletal muscle) lipid metabolism was altered after 1 year of intervention. ACC-2 $\mathrm{mRNA}$ had decreased in the intervention group, while CPT-2 mRNA and HAD protein content tended to increased (chapter 8 ). These results suggest that an increase in the capacity to oxidize FA, through alterations in the expression or content of several key enzymes, may be one of the factors underlying the beneficial effects of a combined diet and physical activity intervention on glucose tolerance. These beneficial effects on the FA metabolism can, most likely, be ascribed to the inclusion of physical activity in the program. Exercise training is a potent stimulator of lipid oxidation, which is most likely related to alterations in skeletal muscle fatty acid metabolism [34,79]. Moreover, it was shown that even a low-intensity training sessions for only a few hours weekly increased fat oxidation [80,81], a regimen more comparable to our lifestyle-intervention program. Furthermore, exercise (training) increases the expression of genes which encode for key enzymes in lipid metabolism [82].

An interesting observation is the decrease found in $\mathrm{ACC}-2$ (chapter 8 ). This is in line with earlier work showing that a low-intensity endurance training program decreased ACC-2 mRNA expression in parallel with and improved fat oxidation [81]. ACC-2 plays an important role in the control of fatty acid oxidation, it catalyses the formation of malonyl-CoA, an intermediate that inhibits the activity of CPT-1. CPT-1 is responsible for the transport of fatty acyl-CoA into mitochondria. It is tempting to speculate that the observed change in ACC-2 expression after 1 year of a lifestyle-intervention underlie the corresponding changes in insulin resistance and glucose tolerance.

Changes in dietary and physical activity habits resulted after 1 year in an. maintained or even improved capacity to oxidize FA (chapter 7 and 8). Several other studies have shown that interventions manipulating (muscle) FA metabolism improve insulin sensitivity. Weight-loss in morbidly obese subjects resulted in a reduction in intramuscular LCFA-CoA and a enhanced insulin sensitivity [83]. In rats, diet-induced insulin resistance was readily ameliorated by a low-fat meal, fasting or single bout of exercise, which was closely related to a decrease in LCFA-CoA [84]. Finally, thiazolidinediones (TZD), a new class of anti-diabetic drugs, have shown to improve insulin sensitivity in parallel with 
changes in fatty acid metabolism and, at least in rats, a decreased LCFA-COA content in muscle [85-87].

\section{Concluding remarks and suggestions for future research}

In the second part of this thesis it was shown that disturbances in the capacity to oxidize fatty acids are already present in the prediabetic condition of IGT, suggesting a primary role for a disturbed FA oxidation in the etiology of diabetes mellitus. Furthermore, it was shown that IMCL accumulation was associated with glucose tolerance in a population with (mild) hyperglycemia. Changes in dietary and physical activity habits resulted in an mintained or slightly increased FA oxidation during exercise, and altered the expression of key enzymes involved in skelletal muscle lipid metabolism. This increased capacity to oxidize fatty acids could be an important factor underlying the improvement in glucose tolerance seen after 1 and 2 year of a lifestyleintervention program.

Not withstanding the considerable amount of work performed in the field of skeletal muscle metabolism and insulin resistance, several issues are still unsolved. Interesting topics that should be addressed in future research include the following:

1. Although the strong association between muscle lipid accumulation and insulin resistance, the exact mechanism behind this association is still unclear. Several mechanisms are postulated, especially the interaction between lipid metabolites and insulin signaling is an exciting field. However the majority of the work is performed in vitro or in animals, there is a strong need for in vion human studies.

2. The handling of lipids within the, insulin-resistant, muscle (i.e. FFA uptake, esterification, triglyceride lipolysis and FA oxidation) plays a crucial role determining accumulation of lipids. More insight in this complex regulatory process is important for clarifying the etiology of insulin resistance.

3. Interventions manipulating skeletal muscle FA metabolism in parallel with changes in insulin resistance (physical exercise, TZDs) not only provide more insight in the mechanisms underlying the development of insulin resistance, but also indicate which intervention strategy should be applied to reduce the incidence of type 2 diabetes mellitus. 


\section{References}

1 King H. Aubert RE, Herman WH. Global burden of diabetes, 1995-2025: prevalence, numerical estimates, and projections. Diabetes Care 1998; 21: 1414-31.

2 Zimmet P. Globalization, coca-colonization and the chronic disease epidemic: can the Doomsday scenario be averted? I Intern Med 2000; 247:301-10.

3 Zimmet P, Alberti KG, Shaw J. Global and societal implications of the diabetes epidemic. Nature 2001; 414: 782-7.

4 Hu FB, Manson JE, Stampfer MJ et al. Diet, Lifestyle, and the risk of type 2 diabetes mellitus in women. N Engl / Med 2001; 345: 790-7.

5 Alberti KG. The clinical implications of impaired glucose tolerance. Diabef Med 1996: 13: $927-37$.

6 Mooy IM, Grootenhuis $P A$, de Vries $H$ et al. Prevalence and determinants of glucose intolerance in a Dutch caucasian population. The Hoorn Study. Diabetes Care 1995; 18: $1270-3$

7 Ricardi $G$, Vaccaro $O$, Rivellese A et al. Reproducibility of the new diagnostic criteria for impaired glucose tollerance. An I Epidemiol 1985; 121:422.9.

8 Ko GT, Chan JC, Woo J et al. The reproducibility and usefulness of the oral glucose tolerance test in screening for diabetes and other cardiovascular risk factors. Am Chin Biodem 1998; 35: 62-7.

9 Saad MF, Knowler WC, Pettitt DI, Nelson RG, Bennett PH. Transient impaired glucose tolerance in Pima Indians: is it important? BMJ 1988; 297: 1438-41.

10 Motala AA, Omar MA, Gouws E. Transient impaired glucose tolerance in South African Indians does not carry a risk for progression to NIDDM. Diabetes Care 1997; 20: $1101-7$.

11 Bourn DM, Willians SM, Mann JI. Distinguishing between persistent and transient impaired glucose tolerance using a prediction model. Diobet Med 1992; 9: 744-8.

12 Qiao Q, Keinanen-Kiukanniemi S, Rajala U, Uusimaki A, Kivela SL. Risk for diabetes and persistent impaired glucose tolerance anong middle-aged Finns. Diabetes Res Clin Pract 1996; 33: 191-8.

13 Nagi DK, Knowler WC, Charles MA et at. Early and late insulin response as prediclors of NDDDM in Pima Indians with impaired glucose tolerance. Diabetologia $1995 ; 38: 187-92$.

14. Edelstein SL, Knowler WC, Bain RP et al. Predictors of progression from impaired glucose tolerance to NIDDM: an analysis of six prospective studies. Diaberes 1997 ; 46: $701-10$.

15 Tuomilehto J, Lindstrom J, Eriksson JG ef al. Prevention of type 2 diabetes mellitus by changes in lifestyle among subjects with impaired glucose tolerance. $N$ Engl I Med 2001; 344: $1343-50$.

16 Knowler WC, Barrett-Connon E, Fowler SE ef al. Reduction in the incidence of type 2 diabetes with lifestyle intervention or metformin. N Engl / Med 2002; 346: 393-403.

17 Saad MF, Knowler MC, Pettit Df ef al. The natural history of impaired glucose tolerance in the Pima Indians. N Engl J Med 1988; 319: 1500m6.

18 Eriksson J. Lindstrom J, Valle $T$ et al Prevention of type II diabetes in subjects with impaired glucose tolerance: the Diabetes Prevention Study (DPS) in Finland. Study design and 1 -year interim report on the feasibility of the lifestyle intervention programme. Dirbofologia 1999; 42: 793-801. 
19 Visscher TL, Kromhout D, Seidell JC. Long-term and recent time trends in the prevalence of obesity among Dutch men and women. Imt J Obes Relat Metab Disord 2002; 26: 1218-24.

20 Schuit AJ, Feskens EJ, Seidell IC. [Physical activity in relation to sociodemographic variables and health status of adult men and women in Amsterdam, Doetinchen and Maastricht]. Ned Tildschr Geneeskd 1999; 143: 1559-64.

21 Jones DA, Ainsworth BE, Croft IB ef al. Moderate leisure-time physical activity: who is meeting the public health recommendations? A national cross-sectional study. Arch Fan Med 1998; 7: 285-9.

22 The Diabetes Prevention Program (DPP): description of lifestyle intervention. Diaberes Care $2002 ; 25: 2165-71$.

23 McAuley KA, Williams SM, Mann Il ef al. Intensive lifestyle changes are necessary to improve insulin sensitivity: a randomized controlled trial. Diabetes Core 2002; 25 : $445-52$.

24 Dunn $\mathrm{AL}_{\text {, }}$ Marcus $\mathrm{BH}$, Kampert JB et al. Comparison of lifestyle and structured interventions to increase physical activity and cardiorespiratory fitmess: a randomized trial. JAMA 1999;281:327-34.

25 Andersen RE, Wadden TA, Bartlett Sf et al. Effects of lifestyle activity us structured aerobic exercise in obese women: a randomized trial. JAMA 1999; 281:335-40.

26 Ross $R$, Dagnone D, Jones PJ et al. Reduction in obesity and related comorbid conditions after diet-induced weight loss or exercise-induced weight loss in men. A randomized, controlled trial. Am Intern Med 2000; 133: 92-103.

27 Ayyad $C$, Andersen $T$. Long-term efficacy of dietary treatment of obesity: a systematic review of studies published between 1931 and 1999 . Obes Rov 2000; 1: $113-9$.

28 Miller WC. How effective are traditional dietary and exercise interventions for weight loss? Med Sci Sports Exerc 1999; 31: 1129-34.

29 Goldstein DJ. Beneficial health effects of modest weight loss. In / Obes Relat Metab Disord 1992; 16: 397-415.

30 Van Gaal LF, Wauters MA, De Leew IH. The beneficial effects of modest weight Ioss on cardiovascular risk factors. Int J Obes Relat Metab Disord 1997; 21 Suppl 1: S5 9.

31 Bosello $O$, Amellini $F$, Zamboni $M$, Fitchet $M$. The benefits of nodest weight loss in type II diabetes. Int / Obes Relat Metab Disord 1997:21 Suppl I: S10-3.

32 Pan XR, Li GW, Hu YH of a. Effects of diet and exercise in preventing NIDDM in people with impared ghucose tolerance. The Da Qing IGT and Diabetes Study. Diabetes Care 1997; 20: $537-44$.

33 Borghouts LB, Keizer HA. Exercise and insulin sensitivity: a rewiew. Int I Sports Med $2000 ; 21: 1-12$

34 Jeukendrup A.E, Saris WH, Wagenmakers AJ. Fat metabolism during exercise: a review-part Il: regulation of metabolism and the effects of training. Int/ Sports Med $1998 ; 19: 293-302$.

35 Vessby $B$, Unsitupa $M$, Hermansen $K$ at al. Substituting dietary saturated for monounsaturated tat impairs insulin sersitivity in healthy men and women: The KANWU Study. Diabetologia 2001; $44: 312-9$.

36 Torjesen PA, Birkeland KI, Anderssen SA th. Lifestyle changes may reverse development of the insulin resistance syndrome. The Oslo Diet and Exercise Study: a randomized trial. Diabetes Care 1997; 20:26-31.

37 Li $G$, Hu $Y, Y a n g ~ W$ of al. Effects of insulin resistance and insulin secretion on the efficacy of interventions to retand development of type 2 diabetes mellitus: the DA Qing IGT and Diabetes Study. Diabetes Res Cim Pract 2002; 58: 193-200. 
38 Chiasson JL, Josse RG, Gomis R et al. Acarbose for prevention of type 2 diabetes mellitus: the STOP-NDDM randomised trial. Lancet 2002; 359: 2072-7.

39 Buchanan TA, Xiang AH, Peters RK el al. Preservation of pancreatic beta-cell function and prevention of type 2 diabetes by pharmacological treatment of insulin resistance in high-risk hispanic women. Diabetes 2002; 51: 2796-803.

40 Haffmer S, Hotman R, Califf R el al. Targeting post-prandial hyperglycemia to prevent type 2 diabetes: Rationele and design of the NAVIGATOR trial. Diabefologin 2002; 45: A106 [Abstract].

41. Wylie G, Hungin AP, Neely II. Impaired glucose tolerance: qualitative and quantitative study of general practitioners' knowledge and perceptions. BMJ 2002; 324: 1190.

42 Randle P, Garland PB, Hales CN, Newsholme EA. The glucose fattyacid cycle: its role in insulin sensitivity and the metabolic disturbances in diabetes mellitus. The Lancet 1963; 785-789.

43 MeGarry JD. Banting lecture 2001: dysregulation of fatty acid metabolism in the etiology of type 2 diabetes. Diabetes 2002; 51:7-18.

44 Colberg SR, Simoneau JA, Thate FL, Kelley DE. Skeletal muscle utilization of free fatty acids in women with visceral obesity. / Chin lovest 1995; 95: 1846-53.

45 Kelley DE, Simoneau JA. Impaired free fatty acid utilization by skeletal muscle in non-insulin-dependent diabetes mellitus. J Chin Invest 1994; 94: 2349-56.

46 Blaak EE, Wagenmakers AJ, Glatz JF of al. Plasma FFA utilization and fatty acidbunding protein content are diminished in type 2 diabetic muscle. Am I Physiol Endocrinol Metub 2000; 279: E146-54.

47 Blaak EE, van Aggel-Leijssen DPC, Wagenmakers AJM, Saris WHM, van Baak MA. Jmpaired Oxidation of Plasma-Derived Fatty Acids in Type 2 Diabetic Subjects During Moderate-Intensity Exercise. Diabetes 2000; 49: 2102-2107.

48 Borghouts LB, Wagenmakers AI, Goyens PL, Keizer HA. Substrate utilization in non-obese type II diabetic patients at rest and during exercise. Clin Sience 2002; 103: $559-66$.

49 Blaak EE, Wolffenbuttel BH, Saris WH, Pelsers MM, Wagenmakers AT. Weight reduction and the impaired plasma-derived free fatty acid oxidation in type 2 diabetic subjects. / Clin Endocrinol Metab 2001; 86: 1638-44.

50 Turpeinen AK, Takala TO, Nutula P et al. Impaired free fatty acid uptake in skeletal muscle but not in myocardium in patients with impaired glucose tolerance: studies with PET and 14(R,S)-[18FIfluono-6 thia-heptadecanoic acid. Dinberes 1999; 48: 124550.

51 Pan DA, Lillioja $S$, Kriketos AD et ol. Skeletal muscle triglyceride levels are inversely related to insulin action. Diabetes 1997; 46:983-8.

52 Perseghin G, Scito P. De Cobelli $F_{\text {et }}$ al. Intramyocellular triglyceride content is a determinant of in vivo insulin resistance in humans: a $1 \mathrm{H}-13 \mathrm{C}$ nuclear magnetic resonance spectroscopy assessment in offspring of type 2 diabetic parents. Dinbetes $1999 ; 48: 1600-6$

53 Krssak M, Falk Petersen K, Dresner A et al. Intramyocellular lipid concentrations are correlated with insulin sensitivity in humans: a 1H NMR spectroscopy study. Diatretologia 1999; 42 : $113-6$.

54: Falholt $K$, Jensen I, Lindkaer Jensen $S$ et al. Carbohydrate and lipid metabolism of sketetal muscle in type 2 diabetic patients. Diaket Med 1988; 5; 27-31.

55 He J, Watkins S. Kelley DE. Skeletal muscle lipid content and oxidative enxyme activity in relation to muscle fiber type in type 2 diabetes and obesity. Diabetes 2001; 50: $817 \cdot 23$. 
56 Goodpaster BH, Theriault R, Watkins SC, Kelley DE Intramuscular lipid content is increased in obesity and decreased by weight-loss. Metubolsn 2000; 49: 467-472.

57 Anderwald $C$, Bernroider $E$, Krssak M at affects of insulin treatment in type 2 diabetic patients on intracellular lipid content in liver and skeletal muscle. Diobetes 2002; $51: 3025-3032$.

58 Levin K, Daa Shroeder H, Alford FP, Beck-Nielsen H. Morphometric documentation of abnormal intramyocellular fat storage and reduced glycogen in obese patients with type II diabetes. Dialketologia $2001 ; 44: 824-833$.

59 Goodpaster BH, He J, Watkins S, Kelley DE. Skeletal muscle lipid content and insulin resistance: evidence for a paradox in endurance-trained athletes. / Clin Endocrinol Metab 2001; 86: 5755-61.

60 Perseghin G, Scifo P, Danna Met al. Normal insulin sensitivity and MCL content in. overweight humans are associated with higher fasting lipid oxidation. An J Physiol Endocrinol Metab 2002; 283: E556-64.

61 Forouhi $N G$, Jenkinson $G$, Thomas EL et al. Relation of triglyceride stores in skeletal muscle cells to central obesity and insulin sensitivity in European and South Asian men. Diabelologia 1999; $42: 932-5$.

62 Prentki $M$, Corkey BE. Are the beta-cell signaling molecules malonyl-CoA and cystolic long-chain acyl-CoA implicated in multiple tissue defects of obesity and NIDDM? Diabetes 1996; 45: 273-83.

63 Thompson AL, Cooney GI. Acyl-CoA inhibition of hexokinase in rat and human skeletal muscle is a potential mechanism of lipid induced insulin resistance [In Process Citation]. Diabeles 2000; 49: 1761-5.

64 Cooney GJ, Thompson AL, Furler SM, Ye J, Kraegen EW. Muscle long-chain acyl CoA esters and insulin resistance. Ann N Y Acnd Sci 2002; 967: 196-207.

65 Schmitz-Peiffer C. Signalling aspects of insulin resistance in skeletal muscle. mechanisms induced by lipid oversupply. Cell Signal 2000; 12: 583-594.

66 Itani ST, Ruderman NB, Schmieder F, Boden G. Lipid-induced insulin resistance in human muscle is associated with changes in diacylglycerol, protein kinase $C_{\text {, and }}$ IkappaB-alpha. Diabetes 2002; 51: 2005-11.

67 Thompson AL, Cooney GJ. Acyl-CoA inhibition of hexokinase in rat and human skellat muscle is a potential mechanism of lipidminduced insulin resistance. Diabetes 2000; 49: 1761-5.

68 Amer P. Insulin resistance in type 2 diabetes: role of fatty acids. Diabotes Metab Res Rev 2002; 18 Suppl 2: S5-9.

69 Zammit VA. Insulin stimulation of hepatic triacylglycerol secretion in the insulinreplete state: implications for the etiology of peripheral insulin resistance. Ant $N$ r Acad Sci 2002; $967: 52-65$.

70 Boden G, Lebed B, Schatz M, Homko C, Lemieux S. EFrects of acute changes of plasma free fatty acids on intramyocellular fat content and insulin resistance in healthy subjects. Diobetes 2001; 50: 1612-7.

71 Brechtel K, Dahl DB, Machann J et al. Fast ellevation of the intramyocellular lipid content in the presence of circulating free fatty acids and hyperinsulinemia: a dynamic ${ }^{1}$ H-MRS study. Magn Reson Med 2001; 45: 179-83.

72 Dobbins RL, Szczepaniak LS, Bentley B et al. Prolonged inhibition of muscle carnitine palmitoyltransferase-1 promotes intramyocellular lipid accumulation and insulin resistance in rats. Diabetes 2001; 50: 123-30.

73 Mensink M, Blaak EE, van Baak MA, Wagenmakers AJ, Saris WH. Plasma free Fatty Acid uptake and oxidation are already diminished in subjects at high risk for developing type 2 diabetes. Diabetes $2001 ; 50: 2548-54$. 
74 Turpeinen AK, Takala TO, Nuutila P et al Impained free fatty acid uptake in skeletal muscle but not in myocardium in patients with impaired glucose tolerance: studies with PET and 14(R,S)-[18F]fluoro-6-thia-heptadecanoic acid. Diabetes 1999; 48: 124550 .

75 Simoneau JA, Veerkamp IH, Turcotte LP', Kelley DE. Markers of capacity to utilize fatty acids in human skeletal muscle: relation to insulin resistance and obesity and effects of weight loss. Faseb / 1999; 13: 2051-60.

76 Kelley DE, He J, Menshikowa EV, Ritow VB. Dysfunction of mitochondria in human skeletal muscle in type 2 diabetes. Diabetes $2002 ; 51: 2944-50$.

77 Rasmussen BB, Holmback UC, Volpi E et al. Malonyl coenzyme A and the regulation of functional carnitine palmitoyltransferase- 1 activity and fat oxidation in human skeletal muscle. / Clin Invest 2002; 110; 1687-93.

78 Ruderman NB, Saha AK, Vavvas D, Witters LA. Malonyl-CoA, fuel sensing, and insulin resistance. Am J Physiol 1999; 276: E1-E18.

79 Sial S, Coggan AR, Hickner RC, Klein S. Training-induced alterations in fat and carbohydrate metabolism during exercise in elderly subjects. Am / Physiol 1998; 274: E785-90.

80 Van Aggel-Leijssen DP, Saris WH, Wagenmakers Al, Senden IM, Van Baak MA. Effect of exercise training at different intensities on fat metabolism of obese men. I Appl Physiol 2002; 92 : 1300-9.

81 Schrauwen P, Van Aggel-Leijssen DP, Hul Get al. The Effect of a 3-Month LowIntensity Endurance Training Program on Fat Oxidation and Acetyl-CoA Carboxylase-2 Expression. Diabetes 2002; $51: 2220-6$.

82 Tunstall RJ, Mehan KA, Wadley GD at al. Exercise training increases lipid metabolism gene expression in human skeletal muscle. Am I Physiol Endocrino Mctob 2002; 283: E66-72.

83 Musi N, Fujii $\mathbb{N}$, Hirshman MF et al. AMP-activated protein kinase (AMPK) is activated in muscle of subjects with type 2 diabetes during exercise. Dinbetss 2001; 50: $921-7$.

84 Oakes ND, Bell KS, Furler SM et al. Diet-induced muscle insulin resistance in rats is ameliorated by acute dietary lipid withdrawal or a single bout of exercise: parallel relationship between insulin stimulation of glucose uptake and suppression of long-chain fatty acyl-CoA. Diabetes 1997; 46: 2022-8.

85 Miyazaki $Y$, Glass $L$, Triplitt $\mathcal{C}$ of al. Effect of rosiglitazone on glucose and nonesterified fatty acid metabolism in type II diabetic patients. Diabelologin 2001; 44: $2210-9$.

86 Mayerson AB, Hundal RS, Dufour Set al. The effects of rosiglitazone on insulin sensitivity, lipolysis, and hepatic and skeletal muscle triglyceride content in patients with type 2 diabetes. Diaberes; 2002; 51: 797-802.

87 Ye JM, Doyle PJ, Iglesias MA ef al. Peroxisome proliferator-activated receptor (PPAR)-alpha activation lowers muscle lipids and improves insulin sensitivity in high lat-fed rats: comparison with PPAR-gamma activation. Dinbetes 2001; 50: $411-7$. 
Summary - Samenvatting 


\section{Summary}

Prevalence of type 2 diabetes mellitus has explosively increased during the last two decades. Major contributors to the diabetes epidemic are changes in nutritional intake and physical activity patterns, accompanying ongoing globalization. Several studies now indicate that the majority of the cases of type 2 diabetes can be prevented, or at least postponed, by adopting a healthier lifestyle. This thesis describes the impact of a combined diet and physical activity intervention program on glucose tolerance in Dutch subjects at risk for developing type 2 diabetes mellitus.

In chapter 2 the design of the intervention study was outlined and the results of the preliminary screening have been presented ( $n=2820$ subjects). Abnormal glucose homeostasis was detected in 826 subjects (30.4\%): 226 type 2 Diabetes (8.3\%), 215 Impaired Fasting Glucose (IFG, 7.9\%) and 385 Impaired Glucose Tolerance (IGT, 14.2\%). Both increasing age and BMI were positively related to the prevalence of IGT and diabetes. These data reflect the world-wide increase in prevalence of type 2 diabetes and glucose intolerance. Moreover, the high prevalence of disturbances in glucose homeostasis underscores the importance of early interventions in those at risk for developing diabetes.

The diagnosis of JGT is classically made with an oral glucose tolerance test (OGTT), however reproducibility of this test is low. Up to $60 \%$ of the subjects diagnosed with IGT return to normal glucose tolerance when re-tested within a few weeks (so-called transient IGT). Subjects with IGT at both tests (persistent IGT) have the highest risk of developing diabetes, and would benefit most from a diabetes prevention program. Overall adiposity and the degree of hyperglycemia and hyperinsulinemia are recognized factors predicting persistent IGT. In chapter 3 it was shown that an increased subscapular skinfold distinguishes between those with transient IGT and persistent IGT, suggesting that centrally located subcutaneous adipose tissue is an important determinant of insulin resistance and glucose intolerance.

After a second OGTT, 114 subjects with glucose intolerance and inotherwise good health were eligible for participation in the intervention study (SLIM). Subjects were randomly assigned to the intervention group $(n=55)$ or control group $(\mathrm{n}=59)$. Intervention subjects received regular dietary advice, aimed at reducing (saturated) fat intake, increasing carbohydrate and fibre intake and moderate weight-loss. Furthermore, intervention subjects were advised to increase their level of (daily) physical activity and were stimulated to participate in supervised exercise sessions. After 1 year glucose tolerance improved in the intervention group (2-hour glucose: $-0.8 \pm 0.3 \mathrm{mmol} / 1$ ) compared to a slight deterioration in the control group $(+0.2 \pm 0.3 \mathrm{mmol} / \mathrm{l})$ (chapter 4). Body weight loss and increased physical fitness $\left(\mathrm{VO}_{2} \mathrm{max}\right.$ ) were the most important determinants of an improved glucose tolerance and increased insulin sensitivity. After two years of intervention the 2-hour plasma glucose concentration was still decreased in the intervention group (from $8.7 \mathrm{mmol} / 1$ at baseline to $8.0 \mathrm{mmol} / \mathrm{L}$ after 2 years), while it was further increased in the 
control group (from $8.6 \mathrm{mmol} / 1$ at baseline to $9.4 \mathrm{mmol} / 1$ after 2 years) (chapter 5). Since the 2-hour glucose concentration is the most important risk-factor for progression to type 2 diabetes mellitus, the improved 2 -hour glucose in the intervention group reflects a considerable risk reduction. Furthermore, the results after 1 and 2 year of intervention clearly showed that a lifestyle intervention program according to general recommendations improves glucose tolerance and reduces hyperinsulinemia, also in a less obese and more active population (i.e. the Dutch population). Finally, subjects in the intervention group adherent to both the diet and exercise intervention showed the largest reduction in 2 -hour glucose levels (chapter 5 ), confirming that the combination of both dietary changes and increased physical activity is important when reducing the risk of developing diabetes.

A second important aim of the work presented in this thesis, was to investigate the role of disturbances in (skeletal muscle) fatty acid metabolism in the development of insulin resistance and glucose intolerance. Several studies have shown that in subjects with type 2 diabetes the capacity of the muscle to oxidize fatty acids is diminished, and this could adversely affect insulin sensitivity. In chapter 6 substrate utilization and oxidation was measured by means of indirect calorimetry and stable isotopes in subjects with IGT, diabetes and weight-matched controls. It was concluded that male subjects with the prediabetic condition of IGT had the same defects in fatty acid utilization as subjects with type 2 diabetes mellitus. At rest and during moderately intensive exercise plasma free fatty acid oxidation was impaired in IGT and diabetes compared to obese controls. Moreover, after one year of the combined diet and exercise intervention program, total FA and plasma FFA oxidation were slightly improved in the intervention group and decreased in the control group, with the change being significantly different between groups (chapter 7). These results suggest that disturbances in (plasma free) FA oxidation could play an important role in the development of insulin resistance and glucose intolerance. Additionally, maintenance (or a slight improvement) of the capacity to oxidize faty acids could be an important factor underlying the beneficial effect of a lifestyle-intervention program on glucose tolerance.

Several mechanisms are proposed to explain the decreased fatty acid oxidation in (pre)diabetic muscle. An over-all reduction of ( 3 etam) oxidative enzyme capacity could be an important factor. Furthermore, evidence is accumulating that an increased content of malonyl-CoA and its regulator acetyl-CoA carboxylase (ACC), play a major role in the reduced fatty acid oxidation in diabetes by inhibiting carnitine palmitoyl transferase (CPT), the enzyme complex involved in mitochondrial fatty acid uptake. In line with this we observed in chapter 8 that after one year of the lifestyle-intervention program ACC-2 mRNA expression was decreased in the intervention group ($16.8 \pm 12.4 \%)$ and increased in the control group $(+51.5 \pm 32.3 \% ; \mathrm{P}<0.05$ between groups). This nicely parallels the observed changes in FA oxidation observed in chapter 7: a slight increase in the intervention group, and a decrease in the control group. Beside changes in ACC-2 mRNA several other genes (CPT-2 and UCP-2) and proteins (HAD) were altered after one year intervention, reflecting an improved capacity to oxidize fatty acids. 
A central role in the association between disturbances in FA metabolism and insulin resistance is played by lipid accumulation within the myocyte (intramyocellular lipid, IMCL). IMCL is found to be increased in diabetes, and is closely related to the degree of insulin resistance. However, IMCL is believed to be merely a marker of insulin resistance, with other lipid metabolikes playing a more causative role (e.g. long chain fatty acyl-CoA, diacylglycerol and ceramide). In chapter 9 IMCL content was measured in the m. vastus lateralis in a group of men with a history of glucose intolerance. A close relation was observed between increased IMCL content and an elevated 2hour glucose concentration in subjects with IGT and diabetes at the time of the test $(r=0.74, \mathrm{P}<0.01)$, but not in those subjects returned to normal glucose tolerance $(r=0.07, P=0.90)$. The latter group was characterized by a higher aerobic capacity $\left(\mathrm{VO}_{2} \mathrm{max}\right)$, which actually was increased during the last year, compared to the IGT and diabetes group. Factors, such as (lipid) oxidative capacity are suggested to modulate the association between IMCL and glucose tolerance or insulin sensitivity, and could easily underlie the observed difference between the glucose tolerant and the glucose intolerant group.

In conclusion, the work presented in this thesis revealed that:

- A lifestyle-intervention program according to general recommendations can induce beneficial changes in body composition, dietary habits and aerobic capacity in subjects at risk for type 2 diabetes.

- These (lifestyle) changes significantly improved glucose tolerance and insulin sensitivity, thereby reducing the risk of progression to diabetes.

- Adherence to both the dietary and exercise intervention was associated with the largest improvement in glucose tolerance.

- An impaired (plasma free) fatty acid oxidation could play a prominent role in the development of insulin resistance and glucose intolerance. Moreover a maintained, or slightly increased capacity to oxidize fatty acids in skeletal muscle after $\mathbb{1}$ year of this lifestyle-intervention program was suggested to be an important factor underlying the improved glucose tolerance. 


\section{Samenvatting}

(zie einde samenvatting woor verklarende woordentijst)

Gedurende de laatste twee decennia is de prevalentie van type 2 diabetes mellitus explosief gestegen. De belangrijkste factoren die hieraan hebben bijgedragen zijn (ongunstige) veranderingen in het voedingspatroon en afname van de hoeveelheid lichaamsbeweging. Beide kunnen deells worden toegeschreven aan de voortschrijdende globalisering.

Verscheidene onderzoeken hebben aangetoond dat de meeste (nieuwe) gevallen van type 2 diabetes voorkómen, of ten minste uitgesteld kunnen worden, door het aannemen van een gezondere levensstijl. Dit proefschrift beschrijft het effect van een gecombineerd voedings- en bewegingsprogramma op de glucose-tolerantie in een Nederlandse populatie met een verhoogd risico op het ontwikkelen van type 2 diabetes.

In hoofdstuk 2 werd de opzet van de studie beschreven, alsmede de resultaten van de voorafgaande screening $(n=2820)$. Een verstoring in de glucose homeostase werd gevonden bij 826 personen (30.4\%): 226 type 2 diabetes $(8.3 \%), 215$ verstoorde nuchtere glucose (IFG, $7.9 \%$ ) en 385 verstoorde glucose tolerantie (IGT, 14.2\%). Zowel leeftijd als body mass index (BMI) waren positief gerelateerd aan de prevalentie van diabetes en IGT. De gevonden resultaten weerspiegelen duidelijk de wereldwijde toename van het aantal gevallen van diabetes en glucose-intolerantie. Bovendien benadrukt de hoge prevalentie van verstoringen in de glucose homeostase het belang van vroegtijdige interventies bij diegenen met een verhoogd risico op het ontwikkelen van diabetes.

De diagnose IGT wordt gesteld met behulp van een orale glucose tolerantie test (OGTT). De reproduceerbaarheid van deze test is echter laag, ongeveer de helft van de personen met IGT blijkt normaal glucose-tolerant te zijn wanneer een tweede test binnen een par weken na de eerste wordt uitgevoerd (zogenaamde transiente IGT). Diegene met IGT bij beide testen (persisterende IGT) lopen het grootste risico om diabetes te ontwikkelen, en zouden dan ook het meeste profijt hebben van een diabetes preventieprogramma. Obesitas (vetzucht) en de mate van hyperglycemie en hyperinsulinemie zijn bekende factoren die persisterende IGT kunnen voorspellen. In hoofdstuk 3, werd aangetoond dat ook een dikkere subscapulaire huidplooi diegenen met persisterende IGT kan onderscheiden van diegene met transiente IGT. Dit suggereert dat centraal gelokaliseerd subcutaan vetweefsel een belangrijk factor is bij insuline-resistentie en glucoseintolerantie.

Na een tweede OGTT bleek dat 114 glucose intolerante maar verder gezonde personen geschikt waren voor deelname aan het interventie onderzoek (SLIM). Proefpersonen werden 'at random' verdeeld over de interventie $(n=55)$ en controle groep $(n=59)$. De interventie groep kreeg regelmatig dieetbegeleiding, waarbij gestreefd werd naar een reductie van de (verzadigd) 
vetinname, een toename van de koolhydrat-en vezelinname en enige kilo's gewichtsverlies. Verder werd in de interventie groep gestreefd naur meer (dagelijkse) lichaamsbeweging, en werd deelname aan bewegingslessen gestimuleerd.

Na een jaar was de glucose tolerantie in de interventie groep duidelijk verbeterd (2-uur glucose: $-0.8 \pm 0.3 \mathrm{mmol} / 1$ ), vergeleken met een geringe stijging in de controle groep ( $+0.2 \pm 0.3 \mathrm{mmol} / 1)$ (hoofdstuk 4). Gewichtsverlies en een verbeterde aẻrobe capaciteit waren de belangrijkste determinanten van de verbeterde glucose-tolerantie en insuline-gevoeligheid.

Na twee jaar interventie was de 2-uur plasma glucose concentratie nog steeds verlaagd in de interwentie groep (van $8.7 \mathrm{mmol} / \mathrm{l}$ aan het begin naar $8.0 \mathrm{mmol} / \mathrm{l}$ na 2 jaar), terwijl deze in de controle groep verder was gestegen (van 8.6 mmol/1 aan het begin naar 9.4 mmol na 2 jaar) (hoofdstuk 5). Omdat de 2-uur glucose concentratie de belangrijkste risico factor is voor de progressie naar type 2 diabetes mellitus, houdt deze verlaagde 2 -uur glucose een aanzienlijke risico reductie in. Tevens laten de resultaten na 1 en 2 jaar zien dat een lifestyleinterventie programma gebaseerd op algemene aanbevelingen voor voeding en beweging de glucose tolerantie verbetert en de mate van hyperinsulinemie reduceert, ook in een populatie met relatief weinig obesitas en veel fysieke activiteit (de Nederlandse populatie).

Tot slot, personen in de interventiegroep die zowel trouw an de voedings- als aan de bewegingsinterventie meededen verbeterden het meest in hun 2 -uur glucose (hoofdstuk 5), hetgeen het belang van de combinatie van dieet veranderingen en meer lichaamsbeweging voor de reductie van het risico op diabetes onderstreept.

Een tweede bellangrijke doelstelling van het onderzoek beschreven in dit proefschrift was het bestuderen van de rol van verstoringen in de vetstofwisseling (in de skeletspier) bij het ontstaan van insuline-resistentie en glucose-intolerantie.

Verscheidene onderzoeken hebben laten zien dat bij mensen met type 2 diabetes de capaciteit van de spier om vetten te oxideren is verminderd, wat negatieve effecten kan hebben op de insuline-gevoeligheid. In hoofdstuk 6 is het substraatgebruik gemeten met behulp van indirecte calorimetrie en stabiele isotopen bij personen met IGT. type 2 diabetes en obese controle personen. Uit de resultaten bleek dat bij personen met IGT dezelfde verstoring in het gebruik en de oxidatie van vetzuren aanwezig is als bij type 2 diabeten. Zowel in rust als tijdens matige lichamelijke inspanning was de oxidatie van plasma vrije vetzuren verlaggd in IGT en diabetes, vergeleken met obese controlles. Bovendien bleken na een jaar van het gecombineerde voedings- en bewegingsprogramma de totale vetzuur oxidatie en de plasma vrije vetzumroxidatie licht te zijn verbeterd in de interventie groep, terwijl deze verder achteruit gegaan waren in de controle groep (hoofdstuk 7).

Deze resultaten suggereren dat verstoringen van de (plasma vrije) vetzuur oxidatic een belangrijke rol kummen spelen bij het ontstaan van insulineresistentie en glucose-intolerantie. Bovendien lijkt het behoud, of zelfs een lichte verbetering van de capaciteit om vetten te oxideren een belangrijke factor die 
het gunstige effect van een lifestyle-interventie programma op de glucose tolerantie kan verklaren.

Verschillende mechanismen zouden de verstoorde vetzuur oxidatie in de (pre)diabetische spier kunnen verklaren. Een overall reductie van de capaciteit om vetten te kunnen oxideren kan een belangrijke factor zijn. Voorts komt er steeds meer bewijs dat een toegenomen hoeveelheid van malonyl-CoA en zijn regulator acetyl-CoA carboxylase (ACC) een belangrije rol spelen bij de verlaagde vetoxidatie. Malonyl-CoA remt carnitine palmitoyl transferase (CPT), het enzym complex betrokken bij de mitochondriele vetzuur opname. In overeenstemming met deze hypothese werd in hoofdstuk 8 , na een jaar van het lifestyle-interventie programma, in de spier een afname van de ACC-2 mRNA expressie gevonden in de interventie groep $(-16.8 \pm 12.4 \%)$, terwijl de expressie in de controle groep juist was toegenomen ( $+51.5+32.3 \%$; P-waarde $<0.05$ tussen de groepen). Deze bevinding past goed bij de veranderingen in de vetzuuroxidatie gevonden in hoofdstuk 7 : een geringe toename in de interventie groep en een afname in de controle groep. Naast de veranderingen in ACC-2 mRNA werden ook veranderingen in andere genen (uncoupling protein 2, UCP-2) en eiwitten (hydroxyacyl-CoA dehydrogenase, HAD) gevonden ma een jaar interventie, die alle een beter capaciteit van de skeletspier om vetzuren te oxideren weerspiegelen.

Een centrale rol in de associatie tussen verstoringen in het vetzuurmetabolisme en het ontstaan van insuline-resistentie is weggelegd voor de accumulatie van lipiden in de spiercel (intramyocellulaire lipiden, IMCL). De hoeveelheid IMCL is verhoogd in diabeten, and is sterk gerelateerd aan de mate van insuline-resistentie. Echter, IMCL is warschijnlijk meer een marker van insuline-resistentie, terwijl bepaalde metabolieten van lipiden, zoals long chain fatty acyl-CoA, diacylglycerol en ceramide een causale rol spelen in de relatie met insuline-resistentie.

In hoofdstuk 9 werd de hoeveelheid IMCL gemeten in de m. watus lateratis van een groep mannen met een verstoorde glucose tolerantie. Er was een sterke relatie tussen een verhoogde hoeveelheid IMCL en een verhoogde 2-uur glucose concentratie bij personen met IGT en diabetes $(1=0.74, \mathrm{P}<0.01)$, maar niet bij diegene die transient glucose intolerant bleken te zijn $(r=0.07, P=0.90)$. Deze latste groep werd gekarakteriseerd door een hogere aërobe capaciteit, welke gedurende het afgelopen jaar zelfs was toegenomen, in vergelijking met de IGT - en diabetes groep. Factoren zoals de (vet)oxidatieve capaciteit van de spier zouden mogelik de associatie tussen IMCL en insuline sensitiviteit kunnen beinvloeden, en daardoor de gevonden verschillen tussen de glucose tolerante en glucose intolerante groep verklaren.

De volgende conclusies kunnen worden getrokken uit de onderzoeken die in dit proefschrift zijn beschreven

- Een lifestyle-interventie programma gebaseerd op algemene aanbevelingen voor voeding en lichaamsbeweging leidt tot gunstig veranderingen in het gewicht, het voedingspatroon en het aeroob vermogen van mensen met een verhoogd risico op type 2 diabetes. 
- Deze veranderingen gaan gepaard met een verbeterde glucose tolerantie en insuline gevoeligheid, en verlagen daarmee het risico op progressie naar diabetes.

- Personen die zowel goed aan het voedings- als bewegingsprogramma meededen boekten de grootste verbetering in glucose tolerantie.

- Een verlaagde (plasma vrije) vetzuur oxidatie kan een belangrijke rol spelen bij het ontstaan van insuline resistentie en glucose intolerantie. Een behoud, of lichte toename van de capaciteit om vetzuren te oxideren in de skeletspier na een jaar van het lifestyle-interventie programma is mogelijk een belangrijke factor die het gunstige effect op de glucose tolerantie verklaart.

\section{verklarende woordenlijst}

prevalentie

type 2 diabetes.

$1 G T$

IFG

$B M I$

insuline-resistentie

hyperglycemie
myperinsulinemie
subscapulair
subcutaan (wet)
aerobe capaciteit
substraatgebruik
oxidatie
plasma vrij vetzuur
mitochondriele

MRNA

\section{het aantal gevallen (van een zickte)}

iouderdoms"-suikerziekte, meest voorkomende varm van diabetes $(90 \%)$. gekenmerkt door te hoge bloedsuiker, begint op latere leeftijd ( 40 jaar) verstoorde glucose tolerantie of glucose-intolerant; gekenmerkt door normale nuchtere bloedsuiker, maar een te hoge bloedsuiker na een maaltijd; wordt beschouwd als een voorstadium van diabetes, $\$ 50 \%$ krijgt binnen 10 jaar diabetes

licht verhoogde nuchtere bloedsuiker, normale glucose tolerantie Body mass index (= gewicht $(\mathrm{kg}) /$ lengte $\left.(\mathrm{m})^{2}\right) ;<25$ is normaal; $25-30$ overgewicht; > 30 obesitas (vetzucht)

verminderde gevoeligheid woor de werking wan het hormoon insuline, dat mormaal gesproken zorgt voor o.a. de opname van glucose uit het biloed in de weefsels; centraal kenmerk wan IGT en diabetes

(te) hoge bloedsuikersplegel (passend bij insuline resistentie)

(te) hoge insulinespiegel in het bloed (passend bij insuline-resistentie) onder het schouderblad

onderthutds (vet), i.t.t. wiscerad (rondom de organen)

uithoudingswermogen, goede mat voor iemands getraindheid

thet gebruik (meestal de verbranding) van koolhydraat en wet

verbranding

vetzuuli 'vrij' voorkomend in het bloed

wan het mitochondrion, dat deel wan de cel waar o.a. de werbranding plaatsvindt

(genetische) code voor de productie van enzymen en eiwitten; hoe hoger de expressie, des te meer enzym/eiwit er kan worden gemaakt 
Abbreviations 


\begin{tabular}{|c|c|}
\hline (H)-MRS & (proton) magnetic resonance spectroscopy \\
\hline $\mathrm{ACC}$ & acetyl -CoA carboxylase \\
\hline ADP & adenosine diphosphate \\
\hline AMP & adenosine monophosphate \\
\hline AMPK & AMP-activated protein kinase \\
\hline ANCOVA & analysis of covariance \\
\hline ANOVA & analysis of variance \\
\hline ATP & adenosine triphosphate \\
\hline BMI & body mass index \\
\hline $\mathbb{B W}$ & body weight \\
\hline $\mathrm{cm}$ & centimeter \\
\hline $\mathrm{CO}_{2}$ & carbon dioxide \\
\hline COA & co-enzyme A \\
\hline $\mathrm{CPT}(\mathrm{CAT})$ & carnitine palmitoyl (acyl) transferase \\
\hline CS & citrate synthase \\
\hline DAG & diacyl glycerol \\
\hline DM & diabetes mellitus \\
\hline DPP & diabetes prevention program (US) \\
\hline DPS & diabetes prevention study (Finland) \\
\hline EDTA & ethyleen-diamine-tetra-acetate \\
\hline EMCL & extramyocellular lipid \\
\hline En\% & energy percent \\
\hline FA & fatty acid \\
\hline FABP & fatty acid binding protein \\
\hline FAT/CD36 & fatty acid transporter / CD36 \\
\hline FATP & fatty acid transport protein \\
\hline FFA (NEFA) & (plasma) free fatty acid (non-esterified fatty acid) \\
\hline FFM & fat free mass \\
\hline FM & fat mass \\
\hline $\mathrm{g}$ & gram \\
\hline GC & gas chromatography \\
\hline GLUT 4 & gllucose transporter 4 \\
\hline h & hour \\
\hline 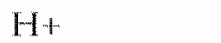 & hydrogen ion \\
\hline HAD & hydroxyacyl-CoA dehydrogenase \\
\hline $\mathrm{HbA}_{\mathrm{ic}}$ & glycated hemoglobin \\
\hline HDL & high density lipoprotein \\
\hline HK & hexokinase \\
\hline HOMA & homeostasis model assessment \\
\hline HPLC & high pressure liquid chromatography \\
\hline HSL & hormone sensitive lipase \\
\hline IFG & impaired fasting glucose \\
\hline IGT & impaired glucose tolerance \\
\hline$I M C L$. & intramyocellular lipid \\
\hline IRMS & isotope ratio mass spectrometry \\
\hline
\end{tabular}




\begin{tabular}{|c|c|}
\hline $\mathrm{kg}$ & kilogram \\
\hline $\mathrm{kj}$ & kilojoule \\
\hline LCFA & long chain fatty acy] \\
\hline LCFA-COA & long chain fatty acyl co-enzyme $A$ \\
\hline LDL & low density lipoprotein \\
\hline LPL & lipoprotein lipase \\
\hline $\mathrm{m}$ & meter \\
\hline $\mathrm{MCD}$ & malonyl-CoA dehydrogenase \\
\hline $\min$ & minute \\
\hline M] & megajoule \\
\hline $\mathrm{mm}$ & millimeter \\
\hline $\mathrm{mRNA}$ & messenger ribonucleic acid \\
\hline MUFA & mono unsaturated fatty acid \\
\hline $\mathrm{n}$ & number \\
\hline NGI & normal glucose tolerance \\
\hline ns & not significant \\
\hline $\mathrm{O}_{2}$ & oxygen \\
\hline OGIT & oral glucose tolerance test \\
\hline OR & odds ratio \\
\hline$P$ & probability value \\
\hline$P C R$ & polymerase chain reaction \\
\hline PPAR $\alpha$ & peroxisome proliferator-activated receptor- $\alpha$ \\
\hline PUFA & poly unsaturated fatty acid \\
\hline $\mathrm{Ra}$ & rate of appereance \\
\hline $\mathrm{Rd}$ & rate of disappereance \\
\hline RER & respiratory exchange ratio \\
\hline $\mathrm{RQ}$ & respiratory quotient \\
\hline RT-PCR & reverse transcription $\mathrm{PCR}$ \\
\hline SAFA & saturated fatty acid \\
\hline SD & standard deviation \\
\hline sem & standard error of the men \\
\hline SKF & skinfold thickness \\
\hline TCA & tricarboxylic acid \\
\hline $\mathrm{TG}(\mathrm{TAG})$ & triglycerides (triacylglycerols) \\
\hline UCP & uncoupling protein \\
\hline $\mathrm{VCO}_{2}$ & $\mathrm{CO}_{2}$ production \\
\hline VLCD & very low calorie diet \\
\hline VILDL & very low density lipoprotein \\
\hline $\mathrm{VO}_{2}$ & $\mathrm{O}_{2}$ uplake \\
\hline $\mathrm{VO}_{2} \max$ & maximal oxygen uptake \\
\hline$W^{-}$ & power \\
\hline WHO & world health organization \\
\hline WHR & waist to hip ratio \\
\hline Wmax & maximal power output \\
\hline
\end{tabular}


Nawoord 
Bewegen, meer bewegen, een centraal thema van dit proefschrift, maar zeker ook 'A Way of Life". Met de paplepel werd het er ingegoten; de vraag was thuis dan ook niet of er bewogen moest worden, maar waar, en hoe vaak en wanneer. De interesse voor het onderwerp van dit proefschrift is duidelijk daar gelegd. En tja, Pa en Ma...., de conclusie dat (meer) bewegen gezond is, dat wisten jullie zonder al dat onderzoek ook wel. Moest ik daar nu 4 jaar over doen!! Al staan ouders natuurlijk aan de basis van alles, en kun je ze overal voor bedanken, bij het opzetten van het bewegingsprogramma voor het interventie-onderzoek kon ik handig gebruik maken van jullie ervaring als 'trainer' op het gebied van 'Meer bewegen voor ouderen' en seniorensport.

\section{'Lopen moet ik, Lopen zal ik..'}

Bewegen is vooral lopen, en dan het liefst lang lopen. Niet alleen goed voor lijf en leden, maar zeker stimulerend voor de geest. Mijn gedachten gaan regelmatig terug naar de zomer van 1998. Niet op mijn plek als dokter in het ziekenhuis, kreeg ik de vraag of $i k$ niet wou reageren op een AIO-plaats bij Ellen Blaak. Een goede keus, bij een goede 'baas'. Ellen, dank voor deze mogelijkheid, en dank voor de vrijheid die je me gaf om me te ontwikkelen in de wetenschap. Ook dank aan Wim Saris, als eerste promotor de grote lijn bewakend, maar zeker ook met oog voor detail. Verder dank aan Tjerk de Bruin en Edith Feskens als begeleiders op wat meer afstand; jullie specifieke deskundigheid heb ik gewaardeerd.

Woorden van dank ook voor het werk van de leescommissie: Harm Kuipers, Hans Keizer, Peter de Leeuw, Rob Heine en Jaako Tuomilehto. A special word of thank for Jaako and his co-workers from the Finnish Diabetes Prevention Study. I very much appreciated the cooperation within the EDIPS project, I learned a lot from the meetings in Helsinki and at Sardinia. Kiitos!

Hard gelopen is er ook, zeker door het fantastische 'SLIM-team', met als kern Jos, Marja en Tanja. Jos, ofwel dokter Mabuse, nooit te beroerd voor een opbeurend woord in de (te) vroege ochtend; Marja, de blonde reus, almaar voortdravend en soms wat doordravend; en Tanja, de Tolk, elke proefpersoon in het lokale dialect te woord staand. Gezien het werk dat jullie hebben verzet zouden jullie eigenlijk ook op de kaft moeten staan.....

Het SLIM-team was en is groter: lise, betrokken bij de beginfase, en onmisbare schakel voor "de dames van de screening; Ingrid, een degelijke vervangster; en de stagaires Judith, Gijs en Judith, die onder het mom van 'leermoment' vele OGTT's hebben afgenomen. Daarnaast wist Gijs nog een grote groep proefpersonen door de scan te halen, en daarmee een belangrijke bijdrage te leveren aan hoofdstuk 9. En niet te vergeten mijn collegAlO's Eefje en Margriet, samenwerkend bij respectievelijk de start en het verwolg van SLIM. Succes op weg naar het eigen proefschrift. Tot slot, misschien wel de SLIMste van het team, en volgens mij in zijn slaap nog pijnzend over het diabetes probleem: Rob van Dam ( $d r$ Rob), vervanger namens het RIVM, en aangenaam gezelschap tijdens congressen. 
Bijzonder enthousiast waren (en zijn) de diverse trainers van UMSport, die naast studenten nu ook ineens aan 'die oudjes' les moesten geven. Dat jullie het goed deden blijkt wel uit de foto's, video's, afscheidskadootjes en verkleedpartijen die jullie ten deel vielen. Dank, Birgitte, Beate, Frans, Vincent, Ruud, Sofie, en vele anderen.

\section{Lopen moet ik, Lopen zal ik}

Lopen zonder enige doel...

Altijd in beweging, figururlijk en vaak ook letterlijk, regelmatig doelloos: de bonte verzameling van collega's bij $\mathrm{HB}$ en $\mathrm{BW}$, met als bruisende kern de Orgie . Alhoewel, in beweging? Begint ook daar de bewegingsarmoede toe te slaan? Was de Orgie in het begin nog goed voor de minimaal drie afmattende trainingen per week; dit veranderde geleidelijk meer en meer in de organisatorische kant van sportevenementen (HBTourpool). Nu echter gaan de verhalen aan de koffieautomaat vaker over inspanningen van anderen en over heroïsche prestaties van vroeger. Troost, Joost en P-ke (de Orgie ${ }^{(i)}$ ), Reinout, Matthijs, Lars, Jogchum, Erwin en Luc. Dank, 't was leuk, en we lopen vast wel weer eens massaal warm voor een of andere rare tocht, wedstrijd of prestatie. Ook prettig 'werken' was/is het met Chris, Michiel, Tanja, Eva, Eefje, Cyriel, Marieke, Annemarie (21/11 !), Guy, Ronnie, Gert, Joris, Berber, Gijs, Gabby, Marleen, Ronald, Ton, Claudia, Joan, Esther, Edgar, Wouter, Dean,..

Alhoewel lopers individualisten zijn, had en heb ik over hulp niet te klagen: Jos, nomaals, dank voor de vele honderden bepalingen. Joan en Wendy dank voor het labwerk. Verder, het SIRC: Annemie, Frank, Anita en Ton, voor de isotopen bepalingen, Eline en Vera voor de MRS-metingen, Loek voor de technische ondersteuning en Gert en Esther (Mw. Moonen) voor de blotjes. Hubert Vidal, Emanuelle and Paulette, thank you for teaching and helping me with the PCR's during my short stay at your lab in Lyon. Merci a vous.

Geen onderzoek zonder vrijwilligers, geen studie zonder proefpersonen. Zonder hen zou er geen anlyse verricht en geen letter geschreven zijn. Waardering, soms zelfs bewondering voor de manier waarop ze bereid waren hun levenstijl in meer of mindere mate aan te passen. Wij hadden makkelijk praten met BMI's van < 23 en de drive om veel te bewegen. Maar naast significante resultaten leverde al die inspanningen veel meer op. I hoop dat het niet voor niets is geweest.

\section{Lopen noet ik, Lopen zal ik,}

Lopen zonder enig doel,

Min lopen is geen woortbewegen, mijn lopen is gevoel.

Flarden van een 'geloofsbelijdenis', de essentie van het lange afstandlopen verwoord door vriend, loopmaat en ex-collega Lars, maar zeker ook beleden door ex-marktonderzoeker, ex-bondscoach, (ex-)journalist, maar bovenal vriend Gerrino. Lopen als een metafoor voor het leven? Met jullie als steuntje in de rug lukt het deze dag wel (en de andere dagen natuurlijk ook). 
Het zit er bijna op. Niet alleen na een lange duurloop is het prettig om weer thuis te komen. Kris, geen geslijm en gezeur hier. Promoveren is ook maar gewoon een baan, daarnaast is er voldoende vrije tijd en vrijheid, en die is voor ons zeker zo belangrijk. Laten we dat houden zo.

Het boek is vol, er is genoeg geschreven, ik heb veel geleerd, van velen. Waarvoor mijn dank.

De boodschap moge duidelijk zijn:

Lopen moet ik, maar vooral, Lopen zal ik.

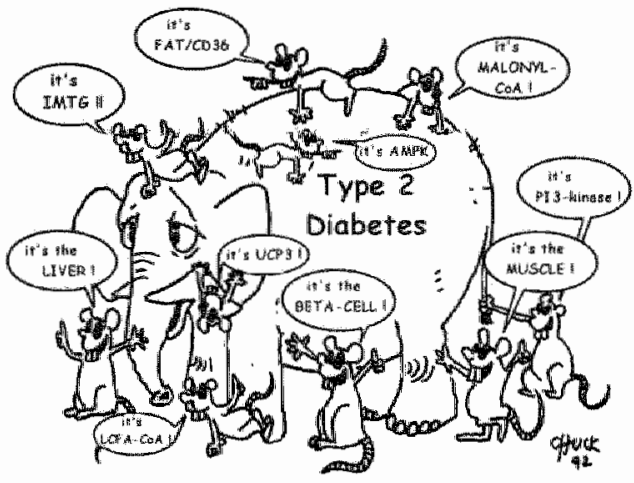




\section{Curriculum vitae}

Marco Mensink was born on September 28, 1971 in Zwolle, the Netherlands. In 1989 he completed secondary school at the 'Rijks Scholen Gemeenschap de Springborn' in Epe. The same year he started at the Maastricht University to study Health Sciences, followed in 1991 by Medicine. In 1995 he completed his study Heath Sciences, specialization Movement Sciences, with as main topic: 'Exogenous glucose oxidation during prolonged exercise in highly trained men versus untrained men. In 1998 he received his medical degree.

From 1998 till 1999 he worked as a physician at the department of Internal Medicine, "Twenteborg Hospital', Almelo.

In 1999 he started his Ph.D. research at the Department of Human Biology, Maastricht University. Title of the project, in which several other PH.D. students were participating, was: "Relevance of genetic predisposition and lifestyle factors in the pathogenesis of type 2 diabetes". Main research question was: "Can lifestyle favorably affect the natural history in subjects at high risk for type 2 diabetes?"' with special attention for the role of skeletal muscle fatty acid metabolism.

Since february 2003 he is postdoctoral fellow at the Department of Human Biology, Maastricht University. 


\section{List of publications}

full popers

Jeukendrup AE, Mensink M, Saris WH, Wagenmakers AJ. Exogenous glucose oxidation during exercise in endurancemtrained and untrained subjects. I Appl Physiol 1997; 82: 835-40.

Mensink M, Blaak EE, van Baak MA, Wagenmakers A], Saris WH. Plasna free Fatty Acid uptake and oxidation are already diminished in subjects at high risk. for developing type 2 diabetes. Diabetes $2001 ; 50: 2548-54$.

Mensink M. Corpeleijn E, Feskens EJ "Kruijshoop M, Saris WH, de Bruin TW, Blaak EE. Study on lifestyle-intervention and impared glucose tolerance Maastricht (SLIM): design and screening results. Diabetes Res Clin Pract 2003; 61: 49-58.

Mensink M, Feskens EJ, Kruijshoop M, De Bruin TW, Saris WH, Blaak EE. Subscapular skinfold thickness distinguishes between transient and pensistent impaired glucose tolerance: Study on Lifestyle-lntervention and Impaired Glucose Tolerance Maastricht (SLIM). Diabet Med 2003; 20: 552-557.

Mensink M, Feskens EI, Saris WH, De Bruin TW, Blaak EE. Study on Lifestyle Intervention and Impaired Glucose Tolerance Maastricht (SLIM): preliminary results after one year. Int I Obes Relat Metab Disond 2003:27:377-84.

Mensink M, Blaak EE, Vidal H, De Bruin TW, Glatz JF, Saris WH. Lifestyle changes and lipid metabolism gene expression and protein content in skeletal muscle of subjects with impaired glucose tolerance. Diabtologin 2003 ; in press.

submitted manuscripts

Mensink M, Blaak EE, Corpelein E, Saris WH, De Bruin TW, Feskens EJ. Lifestyle intervention according to general recommendations imroves glucose tolerance in Dutch subjects. submitted.

Mensink M, Blaak EE, Wagenmakers AJ, Saris WH. Lifestyle-intervention prevents a further impaiment in fatty acid oxidation in subjects with impaired glucose tolerance. subwitted. 
Mensink M, Goossens GH, Kooi ME, Saris WH, Blaak EE. Increased IMCL content in the $\mathrm{m}$. vastus lateralis is associated with glucose intolerance in subjects with IGT and diabetes: a $1 \mathrm{H}$-MRS-study. submitted.

Mensink $M$, Schrauwen $P$, Hesselink MK, Moonen-Kornips E, Schaart $G$, Saris WH, Blaak EE. Increased uncoupling protein 3 content after one year of a lifestyle-intervention in glucose intolerant subjects. submitted.

popular publications

Mensink M, Blaak EE. Leefstijl van invloed op voorkomen type 2 diabetes mellitus. Voeding Nu 2002; 11:21-23. 